\title{
Rethinking Facadism The Contemporary New Zealand Villa
}

\section{Hayley Wright}

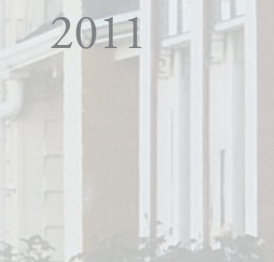





\section{Hayley Wright}

\section{A 120-point thesis submitted in partial fulfillment of the requirements for the degree of}

\section{Masters of Architecture (Professional)}

at the

Faculty of Architecture

of

Victoria University of Wellington

2011 



\section{Abstract}

New Zealand, Heritage, Facadism, Restoration, John Ruskin, Victorian Villa

The New Zealand Villa is a significant cultural icon of New Zealand. Its architecture encapsulates a rich story of New Zealand's colonial heritage, but preserving this legacy requires respect and understanding in the face of societal change. Presently, villa's are being 'modernised' by owners pressured to maintain the aesthetic 'respectability' of the traditional villa, while simultaneously demanding that their private realms reflect contemporary concerns. Differing expectations and conflict in architectural values results in an irretrievable loss of the villa's cultural integrity.

As the villa becomes permanently entrenched in New Zealand's cultural heritage, an 'authentic' depiction of the architecture becomes subjected to facadism. District plans and heritage rules indirectly promote the 'authenticity' of facadism; however the term authentic is presented to the populace under false pretences resulting in spurious imitation forced upon villa's. Facadism results in a Potemkin City; replicated façades, insufficient in and lacking appreciation for, New Zealand's architectural history. This paper questions facadism in comparison to historical and contemporary methods of architectural change. It aims to rethink the notion of facadism and communicate alternative ways of approaching change that is honest and suitable to the aging dwelling and to the occupational demands of contemporary life.

A methodology for assessing the New Zealand villa will analyse the social aspects of the traditional design through a contemporary lens. An analytical study will be conducted that will review the social and architectural attributes associated with the traditional villa and how it catered for demands and rituals of the Victorian society. It will evaluate the villa's position in contemporary society and focus attention to the roof as a horizontal facade. Principles will explore how the villa's traditional roof and planning attributes can be applied to contemporary lifestyle and cater for a changing occupancy.

A design phase tests the principles through various sites and scales. The desired outcome will present a developed prototype of a 'non frontal' villa designed for the contemporary family unit. It sets out to achieve this through a series of tests exploring how the designed principles can develop a conceptual depiction of a villa. The design outcome of this thesis presents two conclusions. First a contemporary typology of the spatial language of the New Zealand villa and, second, that the villa's facade in contemporary environments has become a three dimensional object with a horizontal nature that needs to be catered for in contemporary architecture. 


\section{Table of Contents}

Abstract

Table of Contents

Introduction

1. The Restrained Facade

Indirectly Promoting Facadism

The Falsehood of Facadism

The Facade of Thorndon

2. Truth to Change

Ruskin's Theory

The Contemporary View

The Victorian Society

Hierarchy and Planning

Threshold

Context and Environment 
Traditional Roof Analysis

Model Exploration 


\section{Acknowledgments}

A great appreciation to the following people for their help and support over the course of this thesis:

My supervisor Peter Wood for his help and encouragement to think outside the square and produce a unique piece of research.

My mum for her love and support throughout university, which without I would not be where I am today.

My family, friends and class mates who have endured my stressful habits and managed to detach me from my work.

Patricia Bruner, Jeremy Salmond, Christina Mackay, Jessica Kay and Hester Borren for the generous time given and supportive comments that have contributed significantly to my thesis. 


\section{Introduction}

The New Zealand Villa encapsulates a rich story of the Victorian society and colonisation of New Zealand. Preservation of the villa in a developing city and time requires respect and understanding in the face of societal change. This research questions the aesthetic nature of facadism and its resultant impact on the architectural heritage of the villa. Facadism throughout the thesis will denote the restoration and retention of the 'authentic' street facade of New Zealand Villa's. It aims to rethink the nature of facadism through both the verticality and horizontal nature of the villa in contemporary environments. The vertical facade will refer to the front elevation and the horizontal facade will refer to the roof and view from above. When the research refers to the traditional villa, it is referring to the body of buildings designed and built during the Victorian Society period in New Zealand.

\section{Potemkin City}

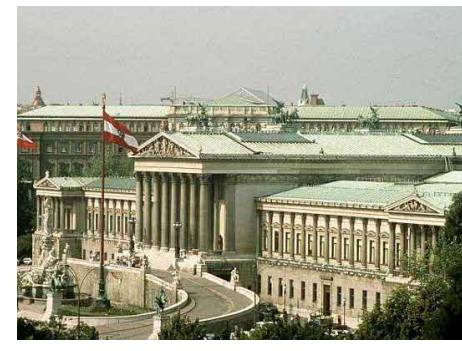

Fig 2: Vienna Ringstrasse: Boulevard and Parliament [Unknown Photographer].

1 Loo's criticism went beyond a mere opinion; he was blamed as the individual most responsible for introducing the principles of abstract, austere, orthogonal design to numerous pre world war Viennese buildings (Maciuika, 2000: 75).
To set the context of this thesis we will begin by addressing the legend of the Potemkin City. The Potemkin City is a historical myth associated with false facades erected to deceive the truth of a city. The original Potemkin village was derived in the Crimean Peninsula by the Russian Military in hope of impressing the Russian ruler, Catherine the Great. The military fabricated the appearance of a territory already developed when she passed through on inspection (Maciuika, 2000: 79). The villages' were erected of canvas and pasteboard, intended to transform a visual desert into a flowery landscape for the eyes of Her Imperial Majesty (Loos, 1987:95). While initially this was an architectural myth, architect Adolf Loos affirms that such practice was evident in Vienna in 1898. He suggests the facades of the Viennese Ringstrasse are presented as through a modern Potemkin had carried his orders there. They aim to persuade someone that Vienna had been transported into a city of aristocrats (1987: 95). In Adolf Loos's criticism of Vienna he quotes

"Should we be ashamed to be nineteenth-century men and not men who want to live in a building whose architectural style belongs to an earlier age? If we ceased to be ashamed, you would see how quickly we would acquire an architecture suited to our own times" (1987: 96). ${ }^{1}$

The connection between Vienna and the Potemkin village of Russia can further be linked to current forms of architectural practice evident in New Zealand. The Potemkin City in contemporary terms can be informally referred to as facadism. Its process strives to present a false interpretation of an architecture that has passed its time. At present this parody is accepted: a majority of New Zealand Villa owners are living behind historical facades instead of embracing the twenty-first century.

Heritage architecture is controlled by plans and policies indirectly promoting facadism. While this method aims to create an idealised image of the past, it divorces the relationship between the streetscape and the aging villa behind the façade. The pressure to maintain streetscape 'respectability' conflicts with the desire of contemporary occupants. 
Alteration becomes primarily subjected to retaining aesthetics. Contemporary needs are forced to work around the visual dominance of the villa that is no longer functional. Differing expectations of architectural values, results in an irretrievable loss of the villa's cultural integrity.

Society has developed since the nineteenth century. The domestic occupation of the New Zealand villa has moved beyond the ritualised lifestyle of Victorian culture. Families have developed different desires within the private sphere of their home. While the internal architecture is arbitrarily adapted to accommodate societal change, the external typology has become permanently entrenched as a dormant icon in contemporary environments.

Architects, designers and non-professionals have access to literature that speaks of the general history of the Victorian villa and offers a good way for people to understand the origins and style of the villa. However, the degree to which this existing information has been studied and extended upon only offers material based on the process of restoring a villa back to its traditional features. The ignorance of Council authorities and lack of awareness by villa owners is resulting in unsympathetic alterations based purely on the aesthetic connection to the past.

There are positive attributes associated with the villa in society today such as its generosity of scale and natural ability to be adapted. But there are equally as many failing the villa's ability to function coherently with the demands of changing occupants. The cold awkward living spaces and rotting architectural elements need to be developed alongside the changes in society. Attention to the streetscape facade is not enhancing the villa's ability to morph with time; it is restricting the villa from aging and developing with a nation.

\section{Thesis Structure}

\section{Methodology}

Research for design through the interpretation of accepted social, civic and architectural norms. It will analyse and integrate synthesis by design.

\section{Method}

This thesis is arranged in three sections, the first questions through research and theory the authentic nature of facadism as a method of alteration. The second establishes a theoretical language to rethink the domesticity of the Victorian villa through a social lens and develop a contemporary typology suited to present day society. The third section applies the developed framework in a design-orientated phase and presents a non-aesthetic based depiction of a contemporary villa.

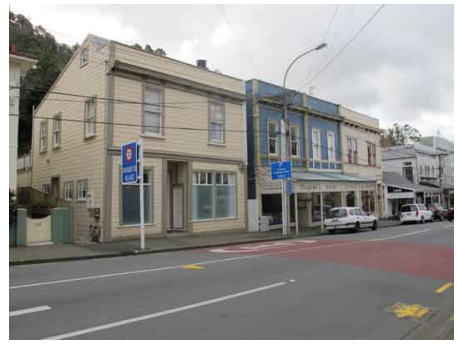

Fig 3: Tinakori Road Thorndon, Replicated Facades.

2 John Ruskin once quoted 'There is no law, no principal based on the past practice, which may not be overthrown in a moment by the arising of a new condition or the invention of a new material. Materialism is increasing with the advance of the age and necessities of the day demands' (Ruskin, The Seven Lamps of Architecture, 1890: 3). 
Section One: 'A Deceptive Facade'

The research begins by reviewing the current issues with respect to the District Plan and Heritage Guidelines in New Zealand. These documents are set out to ensure that communities work collectively to protect an 'authentic' appearance of New Zealand's architecture. Chapter 1 will address the issue of facadism with reference to the District Plans, Heritage Guidelines and theory of facadism. For the purpose of this research, the Wellington District Plan will be used as the main document, and will focus primarily on the implications of rules that indirectly promote the method of facadism. It will question the nature of facadism and its miscommunication between the past and present.

The New Zealand villa was designed for the late nineteenth century society. In order for the villa to cater for contemporary occupants it needs to be adapted through honest methods of architectural change that are true to the dwelling's position in time. Chapter 2 will assess the method of facadism against John Ruskin's Seven Lamps of Architecture, focusing primarily on his lamp of truth and lamp of memory. Ruskin's theory of architectural change is further compared to modern methods that are still using his theory in a contemporary manner. Academic Fred Scott and Sally Stone and Grahame Brooker are used as key contemporary figures. A coherent alteration cannot be achieved unless the traditional architecture and its position in today's society are understood. Understanding the development of architecture through time and accepting the need for alteration will allow alternative approaches to architectural change to be coherent with the twenty-first century.

\section{Section Two: 'A Contemporary Lens'}

The second section will implement a series of explorations in order to assess the traditional villa through a contemporary lens. It will begin by addressing the architectural and occupational history of the villa. Chapter 3 will review the domesticity of the Victorian family. The rituals and expectations of the Victorian society were controlled by the architecture of the New Zealand villa. Research will assess the rituals through the notion of hierarchy and planning, threshold, context and environment. Before the past can be interpreted into a contemporary context it is important to determine the position for the villa in present day life. Chapter 4 will assess how the villa currently functions in society. Information sourced will be guided by literature and personal interviews with New Zealand architects. It will address the positive and negative attributes of the traditional villa and assess contemporary thoughts on the process of restoring and retaining the traditional elements.

\section{Position Statement}

It becomes apparent in this study that the position of the villa in contemporary society has changed. Architectural changes are being implemented to the interior of the villa to fit occupant's needs and the exterior remains static as a visual connection to the past. The facadism referred to in Section One discusses the vertical plane of the method that conceals the modern changes to the streetscape. It becomes evident through this study that facadism is not only occurring on this plane, it is the horizontal plane of the roof that is concealing the modern changes that have already been executed in the internal plan. 
Chapter 5 further reviews the roof as a façade. It begins by exploring the traditional gable roof and reassessing how the traditional aspects can be reinterpreted to cater for contemporary roof issues. A set of principles will provide a guide to approaching the design of a gable roof on a contemporary villa plan.

The thesis further uses the same process to address the hierarchy and planning of the traditional villa through a contemporary lens. Chapter 6 provides a series of principles that review proportion, horizontal and vertical form, threshold and room roles. The principles allow for the traditional language to be understood through contemporary planning techniques. They have further been applied to the main rooms of the traditional villa to suggest options of the how contemporary spaces can use the principles to achieve different relationships depending on occupational demands of the space. The principles provide a base for which a diagrammatic plan of the contemporary villa can be placed on site in order to later be adjusted to site conditions and client function.

\section{Section Three: 'A 'Non-Frontal' Villa'}

The final section will execute the design phase. The design will aim to achieve two things; first it will test the contemporary roof and planning principles through various sites and experimentations. Secondly it will address the design as a 'non-frontal' villa giving attention to the three dimensionality of the facade and how it can be read through various scales and viewpoints. The design work proposes a series of conclusions, which will be communicated in the discussion in Chapter 8 of this work. The work brings to an end by readdressing the purpose of this thesis and its contribution to the realm of architecture. 


\section{Section One}

\section{A Deceptive Facade}

Section One will question the nature of facadism and its resultant impact on our architectural heritage. Facadism is a result of miscommunication between the past and the present. Architecture of the past was designed for inhabitation of that period. In order to alter architecture to fit with the future we need to acknowledge that occupants desire change with the movement of society. When an architectural typology becomes dormant, changes to architecture become subjected to aesthetic. This disregards the life of the building and its ability to age with the day. This section will discuss the heritage values, district plan and guidelines through the context of the New Zealand Villa as a victim of a historical imitation. Research will question the notion of authenticity and discuss facadism against alternative methods of architectural change. It will focus on concepts that allow a building to remain true to its aging state whilst equally be adapted to function for contemporary occupant needs.

The Restrained Facade| Truth to Change 


\section{The Restrained Facade}

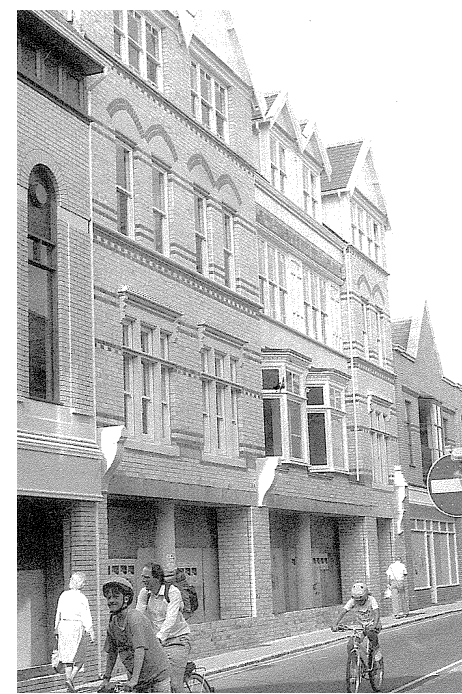

Fig 4: Joy Street, Barnstaple, North Devon. A rebuilt facade stands in front of a new retail development [Photograph: Jonathan Richards].
Facadism as a concept raises many implications for this built environment and its inhabitants. As a method it aims to create an attractive and successful urban environment through the reproduction of external aesthetics. Its process lacks consideration for the building behind the façade and this creates a division between the interior occupancy and the exterior appearance.

As an expert on the topic of facadism, Jonathan Richards believes that facadism relates to the philosophy and practice of preserving historic facades or creating replicas. He states that 'There are other manifestations of facadism such as the internal guttering and redesign of free standing buildings or buildings with more than one principal elevation leaving only the outer shell of the building' (Richards, 1994: 7). The practice is evident in the progression of heritage architecture in New Zealand. At present facadism is being indirectly promoted. The rules do not directly use the word facadism. It is the terminology and the implied use of the word 'authentic' linked to the street facade that is ultimately resulting in facadism. This is restraining the legacy of New Zealand villa from functioning coherently with contemporary needs. Facadism throughout this thesis will denote the retention and restoration of the street facade alone of the New Zealand villa.

Indirectly Promoting Facadism

New Zealand heritage is determined through its Maori origins, European colonisation and the physical and visual character of space, architecture and diverse culture. Protecting this heritage and acknowledging the past provides the population with an enhanced sense of place, belonging and pride in the heritage values of a country (Wellington City Council, Wellington Heritage Policy, 2010).

New Zealand District Plans control the development of the land. Each district has their own rules and each suburb has specific character guidelines. The guidelines primary aim is to protect New Zealand's architectural heritage. Regulations contradict this objective through indirectly encouraging the method of facadism as a positive approach to change. The rules promote that the architecture maintains an 'authentic' façade, 'authentic' exterior appearance and 'authentic' streetscape aesthetic typical of the traditional villa typology. This is diminishing the 'respectability' of the villa from developing with society. It is beyond the scope of this paper to assess the full District Plans around New Zealand. For the purpose of this research, the Wellington District Plan will be used as the main document. It will provide specific insight on the implications of rules which appear to in some way promote facadism.

A passage in the document states 'Authenticity is a major determinant of significance in heritage buildings, maintaining or enhancing authenticity by restoration is encouraged (Wellington City Council, District Plan, 2009: 21: 5).

Chapter 1 - The Restrained Facade 
Facadism becomes a result of statements such as: 'The facade is sometimes the only item in term of heritage value that is retained as it is often the most visible element from the streetscape' (2009: 21:6). This statement appears to be suggesting that there is a connection between visual aesthetic and authenticity. Again, 'When the façade only is to be retained, every effort should be made to ensure that the new building respects the design, scale and materials of the retained façade'. And further 'Alterations to street elevations should be kept to a minimum and, if possible, not altered at all. The preferred elevation to be altered, if necessary, is a rear or secondary elevation, those less likely to be seen by the public' (2009: 21:5).

It is clear in such statements that facadism is being indirectly promoted to the nation through the concept of restoring and retaining the external aesthetic of the facade alone of heritage buildings. This disregards the correct way the method restoration was intended to be used. The theory of restoration was derived by French theorist, Eugene Viollet-le-Duc. He wrote 'An architect entrusted with the restoration of a building must capture the authenticity of the entire dwelling. He should clearly know the form and style, structure and anatomy in order to master every detail' (Viollet-leDuc \& Hearn, 1990: 278). As a method in New Zealand, facadism clearly exploits Violet-le-Duc's theory by restoring only the external facades of the architecture and streetscape aesthetic. Facadism applied to domestic architecture is untrue, disrespectful and deceiving to the eye. This is not restoration, nor authentic.

\section{The Falsehood of Facadism}

Architecture becomes known through a characterised typology. The distinct attributes that distinguish the villa's placement in New Zealand are associated with the external aesthetic of the roof angle, verandah and bay window. These features are becoming out of date and tacked on to the architecture in order to respect and provide an 'authentic' connection to the past. The true history of architecture lies not only in the aesthetics of the façade, but in the history of the entire dwelling, and the history of the occupants who have lived there. The promotion of replicated aesthetic is the outlining issues linked to facadism

The division of the interior and outer shell is an approach that is commonly performed on villa's in New Zealand, the result of this risks becoming a Potemkin City; replicated façades, insufficient and lacking appreciation for New Zealand's architectural history. While the Potemkin city was a Russian myth, its concept remarkably links to the issue of facadism in New Zealand. 'Whether one tries to erect out of brick and poured cement the stone palaces, where feudal lords reside' (Loos, 1987: 96) or reinterpret the façade of the nineteenth century Victorian Villa in New Zealand, the same principal applies. Richards states that facadism is a method that leads to little or no relationship between the façade and the rest of the building; a divorce between exterior and interior (Richards, 1994:11). This is precisely shown earlier in the references to the district plan. Facadism is a form of protection of the street character of a place; however, this results in the loss of historical information contained in the fabric behind facades (1994:13). The effects of facadism can further be explained through the suburb of Thorndon in Wellington.
3 Viollet-le-Duc returned ruined structures to full order through a detailed knowledge of history and imagination. He believed "To restore a building, is not to preserve it or rebuild it; it is to reinstate a sense of completeness that could have never existed at any given time" (Viollet-le-Duc \& Hearn, 1990: 269). 


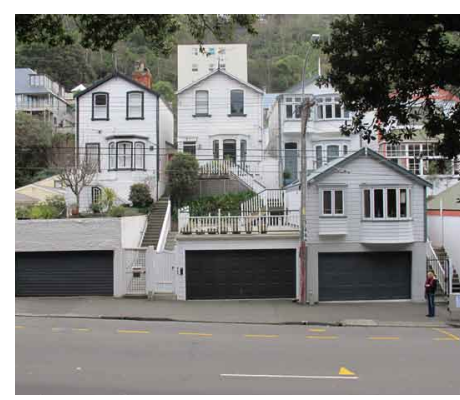

Fig 5: Tinakori Road, Thorndon. Victorian villa facades retain the traditional aesthetic.

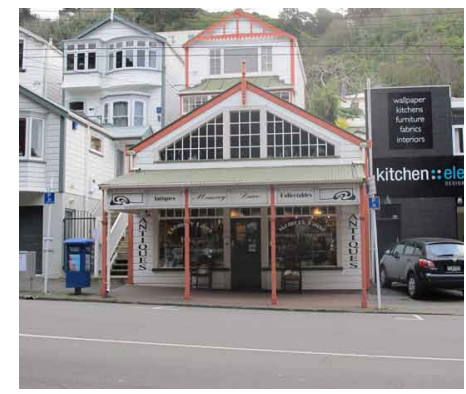

Fig 6: Tinakori Road, Thorndon, Victorian typology remains replicated in new facades.
Thorndon was the first developed community in Wellington and is one of many villa suburbs in New Zealand affected by facadism. European settlers built most of the Thorndon villa's in the mid nineteenth century. These villa's were once overcrowded working slums in a smoke filled inner city suburb (Dalley \& Labrum, 2000: 213). The villa's today front an idealised image of a middle class dwelling and streetscape, deceitful to the traditional working-class dwelling that first inhabited the sites. Their 'authentic' portrayal in today's society is a misleading representation of how they traditionally appeared and were inhabited.

Thorndon is strictly bound by District Plan rules and Heritage Guidelines that heavily restrict change and adaptation to heritage buildings. This is due to the land in Thorndon being highly valuable in both social and economic aspects. The pressure to maintain the status of Thorndon is restraining its architecture. Maintaining the appearance of traditional facades and streetscape 'respectability' restricts the dwelling from aging with the twenty-first century.

The Wellington City Council classes the majority of Thorndon as a 'Special Character Area'. The suburb's town centre is the only vicinity listed as a heritage zone in the District Plan. Heritage zones are more restricted to change than character areas, yet both are primarily concerned with exterior and streetscape image. Both sets of regulations are enforced to insure that new buildings and alterations protect the suburb's architectural context. The character guidelines provide an analysis of the Thorndon area. It presents the general appearance and respectability of the heritage, townscape, building form and detail. Further outlining objectives and guidelines as to how changes to the architecture should be treated. Both documents are concerned primarily with the external appearance. An example of this can be seen through two quotes in the guidelines:

1. "Whilst none of the buildings individually have architectural merit, collectively they form a section of townscape with unique qualities" (Wellington City Council, Thorndon Character Area and Design Guides, 2006: 4).

2. "The character of the suburb can be achieved through the visual intricacy of the street edges, consistency of building scale, narrow frontages, verandah, door detail and roof" (2006: 5).

There are current debates about making the entire character area of Thorndon into a heritage zone of the District Plan. A consequence of this will see facadism occurring as a more prominent method of change; this is currently evident in the town centre of Thorndon. The District Plan rules promote the 'authenticity' of restoring the external facade. The method of facadism does not work for the villa as the interior is still allowed to become modernised for contemporary living. It defeats the purpose of what this facadism is 'aiming' to achieve. The exterior becomes divorced from the interior and results in a false imitation of a historic streetscape. The effort to make the entire area of Thorndon a Heritage Zone will bring with it the short and long term implications evident in the superficial fronts seen in the town centre.

Chapter 1 - The Restrained Facade 
The study is not against keeping the historical integrity of the villa alive, it is merely arguing that the villa has aged. While the Thorndon area has great heritage value, it is also a contemporary living area. Property owners want to take advantage of modern building technologies when adapting and modifying their properties (Wellington City Council, 2011:1). The lifestyles of occupants have developed significantly as independent desires have changed. Retention of the exterior walls of the villa and having the freedom to modernise and demolish the interior is contradictory and inauthentic to the integrity of our heritage. While Council regulations have good intentions, their approach needs to be coherent with society today.

\section{Chapter Summary}

This chapter ends questioning the concept of 'truth'. It is hard to decipher what is real and what is an imitation of the past and this is often a debatable topic. The preservation of street character is false; a dishonest and misleading deception of our past. Architectural change needs to be true to the aging dwelling, whilst function for a changing city and time. The traditional villa's were designed for the nineteenth century Victorian society and therefore not longer meet the needs of modern day living. Aiming to create nostalgia through the reproduction of past aesthetics is untrue to the architecture of the villa. Truth is seen through the acceptance of time and the willingness to correspond with change. Research will further review alternative methods of approaching architectural change that allows the New Zealand Villa to authentically age with time and adapt to a contemporary demands. 


\section{Truth to Change}

Architectural change is implemented in order to allow for adaptation to a new situation and architectural condition. Holding on to the facade and aesthetic of the past while changing the internal plan restricts the dwelling from aging as a whole. Architectural typologies need to take into account that the occupant's needs are constantly developing. It is not only the aesthetics of a building that determine a typology, it is acknowledging and developing the spatial and occupational attributes that allows changes to remain true to the architecture. The notion of truth in architecture can be connected back to John Ruskin's historical connotation of architectural change. His theory is still being applied in contemporary situations, however new approaches have developed throughout the twentieth century. This chapter will review John Ruskin's theory of alteration and compare it to contemporary theories of change practiced by Fred Scott, Grahame Brooker and Sally Stone. Understanding the positive theory of change will generate an understanding as to how true and honest changes to architecture can in practice be coherent with the twenty first century.

\section{Ruskin's Theory}

John Ruskin's primary architectural theory is presented in his 'Seven Lamps of Architecture. His lamps provide an impressive account of the degree architecture should achieve sacrifice, truth, power, beauty, life, memory and obedience in order to be successful. Ruskin believed the purpose of today should be expressed in a new building, or part of, not in drastic restoration. 'Restoration is the dressing of a corpse, which denied its character of age' (Wheeler, 1992: 19). The right of the home belongs to the first builder of the house and should always remain respected as occupants change and attempt to reform the architecture. He insists that 'restoration is a lie; we should never summon upon the dead' (Scott, 2008:44). This negative response to restoration makes it apparent that his theory would equally discard facadism. Richards believes both the Lamp of Truth and Lamp of Memory are Ruskin's way of presenting his rules and unconditional rejection of facadism. He states, Truth regards facadism as a dishonest and distasteful concept (Richards, 1994:30). Reviewing his opposing opinion and both his lamp of truth and memory will provide an alternative way of understanding how architectural change can be approached.

In his Lamp of Truth, Ruskin denotes that truth is essential for the wellbeing of architecture and keeping the past honest into the future 'there are two duties respecting architecture; the first to render the architecture of the day, historical; and the second, to preserve, as the most precious of inheritances that of our past ages - it is in becoming memorial and monumental that a true perfection is attained by civil and domestic buildings' (Wheeler, 1992:10). Truth would be gained through the honesty of a building. His theory is suggesting that we should review architecture in its present state and acknowledge that architecture will change relative to time. 
Ruskin quotes 'We may be not be able to command good, beautiful or inventive architecture but we can command an honest architecture' (Ruskin, The Seven Lamps of Architecture, 1890: 35). Being true to an architectural change is essential for heritage architecture to develop and keep up with the demands of the future.

At present a nostalgic connection to the past is subjected to a reproduced typology. Honest architecture of the villa can be seen through its ability to adapt to a new situation and new occupational condition. Changes should respect the part of the heritage dwelling that is still functional, but remodel, add or remove those elements that are no longer coherent with the occupational demands. A memory of the past can authentically be achieved without mimicking historical facades. Ruskin's Lamp of Memory best helps to understand this. Memory outlines the importance of celebrating a new reading of architecture to function for a changing occupant. In the Lamp of Memory Ruskin quotes 'The greatest glory of a building is not in its stones but in its age and sympathy in which the walls have been washed by passing waves of humanity' (1890: 339). It is through the change of occupants that we begin to see the individualism of architecture. Dwellings adapt to the function required by the changing dwellers. Suppressing the past with modern imitations restricts the architecture from celebrating its age. Ruskin suggests that change can become a part of a new reading. Seeing the ages pass through the walls will allow a patina to permanently be read through the age of space, even when changes need to function for a new situation. This can be achieved as much through the exterior as the interior.

Ruskin's views would align well in this thesis if it is visualised through the context of the villa in contemporary society. In regard to methods of change, it is apparent Ruskin encouraged preservation. He encourages architecture to develop with time while concurrently supports the idea that we should rid elements that have decayed and are no longer appropriate in the dwelling. Ruskin quotes 'There is no law, no principal based on the past practice, which may not be overthrown in a moment by the arising of a new condition' (1890:3). He believes we should stop trying to deal with restraints and requirements and instead try to determine some constant, general law of right (1890:3). By this statement it appears he is suggesting we should not be subjected to a series of restrictions and guidelines. This is precisely the position the New Zealand villa is in today with the requirements forced upon by the District Plans and Heritage Guidelines approach to 'authenticity'. Rules and restrictions lead to an untrue outcome as seen with the process of facadism and the New Zealand villa.

The flexibility of the villa typology has the ability to adapt to a new living situation. This is being disregarded through methods such as facadism, concerned primarily with an external aesthetic. The key to Ruskin's theory is to preserve what still functions and alter what no longer works for current society. That is, culturally sensitive adaptation is required. 
John Ruskin's theory of approaching alteration was conducted during the nineteenth century; however interpretations of it still remain evident in practitioners' and academic theories throughout the twentieth century.

Fred Scott's thesis 'On Altering Architecture' and Sally and Grahame Brooker key book 'Re-readings' refer to an essay by Rodolfo Machado, 'Old Buildings as Palimpsest $s$ ' which summarises the ideals of architectural change. Machado assesses alteration on a theoretical level, referring to the concept as a formal intervention on an existing form. He states: 'Remodelled architecture can be regarded as palimpsest. If an original building is considered as the first discourse then remodelling can be conceived as rewriting' (Machado, 1976: 46). If the function of a building is altered, then a buildings story begins again; a new plot and interpretation is composed. In the process of remodelling, the past takes on a greater significance because it itself is the material to be altered and reshaped. "The past provides the already written, the marked canvas on which remodelling will find its own place' (1976: 49).

Sally and Grahame Brooker further developed Macahdo's theory of remodelling. Even though a building can evolve and change, a building can retain a remembrance of the former function and value. It has a memory of the previous purpose engrained

4 The Brooker's state that remodelling for a new function is not a new concept, it has been done throughout history for example they refer to the baths of Diocletian in Rome that were converted into a church by $\mathrm{Mi}-$ chelangelo. It still maintains traces of its original function through its architectural design (Brooker \& Stone, Re-readings 2004: 9). within its very structure (Brooker \& Stone, Re-readings, 2004: 9). They too disagree with the concept of facadism 'Damaging is the remodelling of a building in a way that is to be a copy or a pastiche of the existing ...... retaining just the façade of a building and constructing behind it in an unsympathetic structure'(2004: 9). In line with this, Fred Scott suggests we should be combining the new with the past. 'Alteration is about the art of response as it is an art of individual genius. It sets out to make an agreement between new and existing' (Scott, 2008: XV). Restricting change, the New Zealand Villa is currently experiencing results in implications such as facadism.

It is expected that most villa's have been adapted prior to today. It is the villa's present condition which needs to be considered in the next reading of the architecture. The Brooker's believe that through an in-depth understanding of an existing situation we can create a coherent and comfortable alteration that respects the original building (2004: 14). 'The memory of the building can be written on its walls, either exposed or deeply suppressed. A building may have been reused a number of times - making up the history of her site. The initial design of the building and the continuous uses has influenced the way further adaptations are done' (2004: 21). Scott further supports this. He believes that architecture operates like ideology; it is clearly conceived in the beginning by the authors and more diffusely received by the public or inhabitants. The New Zealand villa was shaped by the Victorian society and the Victorian Society shaped the villa as we know it today bearing its historical significance. Whilst the internal plan has begun to change to accommodate this, the exterior has become dormant in order to generate a nostalgic connection to the past. The past remains in the past. It will never be regained. A contemporary reading should be celebrated through the change of the architecture both internally and externally, not suppressed behind a reproduced facade. 
Scott touches on this topic asking what is authentic 'houses that are made good in their current condition? or restored to their original when they were first occupied' (Scott, 2008: 33) A home needs to be comfortable for the occupants of its time. Scott believes we should be stripping back the architecture and developing an intervention or alteration that understands the cultural, physical and spatial attributes of the building (2008: 113). He believes we can reinterpret the traditional function through a contemporary lens. Understanding the inhabitation of the traditional building and the spatial arrangement of its first inhabitants can be reinterpreted into a language suited to contemporary occupation. This process outlined by Scott explains that we need to understand the entirety of a dwelling from its original through to today in order to execute a coherent alteration. The successful marriage of old and new, of past and future is dependent upon a thorough knowledge or anticipation of what is expected (Brooker \& Stone, Rereadings, 2004: 21).

On top of this process Sally and Grahame Brooker further believe an alteration to suit today's lifestyle, needs to consider the environment and the way the architecture needs to be designed. Environmental issues can influence the alteration of a dwelling. Issues could arise through sunlight, obstructed views and heightened buildings within the surroundings. Therefore when altering we need to cater for such contemporary issues. For instance, light to control space and form, surface to control the direct relationship between human contact, openings to facilities movement, merging to bind areas together and planes to distinguish a permanent or temporary relationship between spaces (2004: 147-148).

\section{Chapter Summary}

As suggested by Ruskin, Scott and the Brooker's, before a coherent alteration can be achieved we need to understand the villa from its traditional occupation through to the demands of today. The following sections will implement a series of studies which will assess the traditional typology of the villa through a contemporary lens. 


\section{Section Two}

\section{A Contemporary lens}

Section Two will work through a series of stages and aim to achieve an understanding of the traditional villa from its origins through to its placement in society today. Historical importance exists not only in the façade and streetscape of the New Zealand villa, but significantly in the social and domestic attributes associated with the traditional design. The villa shaped the Victorian family and in turn the Victorian family shaped the architecture of the villa. To design for the future we need to understand the past. This section will review how the domesticity of the Victorians was controlled through the design of the traditional villa. This approach will depict the social attributes associated with the traditional villa through hierarchy, planning, threshold and environment. It will review the villa's position in current society and depict the positive and negative attributes of the traditional design in contemporary environments. A set of principles will offer a method for reading the traditional through a contemporary lens; to provide logic to how an alteration can integrate the past.

Genuine Depiction of the Past | Position in Time | Contemporary Roof | Contemporary Plan 


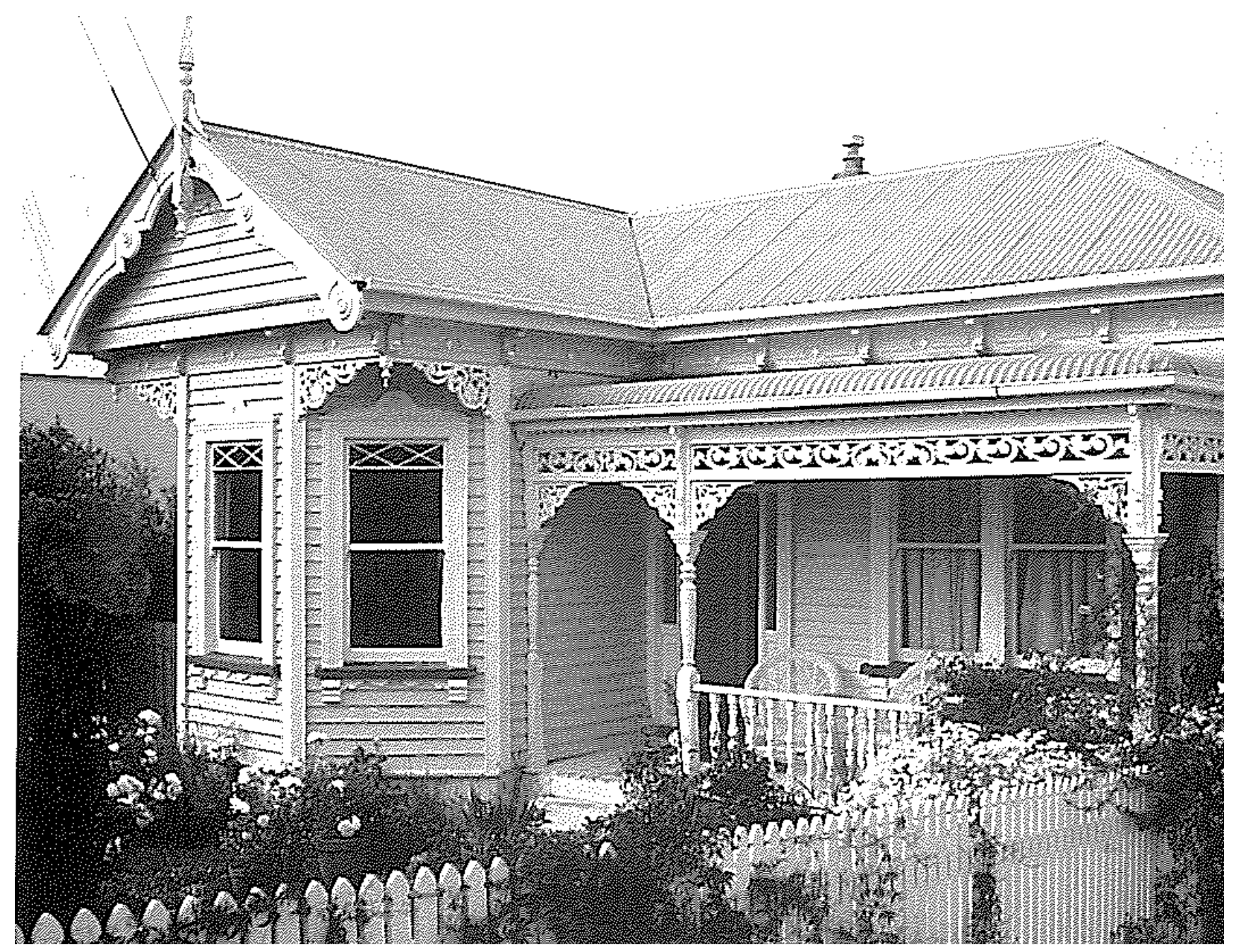

Fig 7: Tradtional Victorian Villa, Ohinerau Street, Remuera [Photograph: William Toomath].

16 Section Two - A Contemporary Lens 


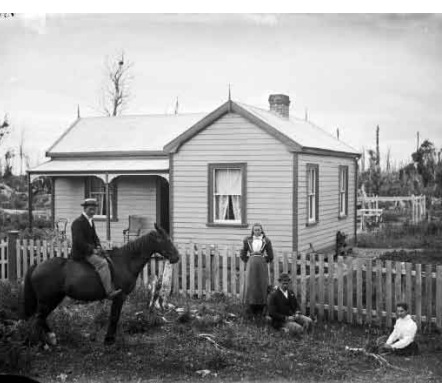

Fig 8: Family outside of a Victorian Colonial House, 1895 [Photograph: James McAllister].

\section{Genuine Depiction of the Past}

The perceived typology of Victorian Villa's activates a nostalgic connection to New Zealand's architectural history. At present the villa's link to heritage is through an aesthetic reproduction of an idealised past. While this is true to the architectural style, it is not true to what the mature architecture wants to be. Domesticity has changed with societal change. The traditional design is no longer suitable for modern day ideals. It is outside the scope of this thesis to reflect on the history and meaning of domesticity. It is however important to clarify what is meant by Victorian domesticity and how this influenced the architectural design of the New Zealand villa.

Domesticity is the aura of home life. It developed as a response to the separation of home, work and the distinction between genders. Author Gwendolyn Wright affirms that ideals of domesticity came from abroad (relative to the US) and were significantly linked to John Ruskin. Ruskin emphasised that 'each dwelling should reveal something about the personal character and class or condition of the occupant' (Wright, 1980: 12). This chapter will assess the hierarchy and planning of the villa through movement patterns, public and private spaces and the specific roles attached to each of the traditional rooms. It will review threshold in terms of doors, windows and verandah and further address the context and environment of the villa and how it was influenced by the Victorian society. Understanding the original meaning of the villa's design will allow sympathetic changes to be made that respond to changing needs of the occupants.

\section{The Victorian Society}

Following the year 1840 and with the growing European colonisation of New Zealand, Victorian society became a dominant culture in New Zealand. Their endeavour to build a new life was focused on finding a home and developing a family. The skills and knowledge of the European settlers allowed international styles to be introduced and adapted to New Zealand. Architecture combined Gothic and Italian design with the local materials and craftsmanship unique to New Zealand; the villa was a result of this. By 1850 the typical houses being built in New Zealand showed little nostalgia for the traditional British homes. The Victorians' attention became fixed on the present and the promise of the future, with little desire to dwell on the past they had escaped (Toomath, 1996: 51).

The Victorian middle class dominated society during the nineteenth century. Their structured lifestyle was associated with good manners, a strong work ethic, good posture and good fortune. Correspondingly their house was robust, exuberant and well built of fine materials that were ingeniously worked by machine (Salmond, 1986: 89). The villa was a generic form of architecture that was formulated through a kitset of parts. Each part was mass produced by steam powered machines which began to arrive here in New Zealand during the late 1850s (Salmond, 1986:90). It accommodated the Victorian rules and rituals linked to home life, work life and the distinction between genders. 
Gender separation was one of the most significant qualities of the Victorian family. Males and females had particular lifestyle roles which were independently adapted to New Zealand. This division was reinforced by the daily roles of men and women. The man would leave the home in the morning to work and return in the evening to rest, eat and sleep. During the day it was the woman's home and during the evening it was the mans. Women were traditionally responsible for the domestic order of the house and could not enjoy the relaxing haven of the home in the way other house hold members did (Cieraad, 1999: 144). They were required to stay at home to nurture, care and maintain their family. The home became the domestic sphere for the wife and children during the day, allowing the relationship between mother and child to grow (Heyden \& Baydar, 2005: 8). Housekeeping was demanding as everything needed to be immaculate and ordered. A home that did not maintain high standards comparable with the other houses in the suburb was regarded as disruptive and threatening to the family's reputation. The design did not cater for storage space therefore belongings were often placed directly on the walls as decorative elements. Interiors were heavily decorated; clutter was considered as a gesture of wealth and success.

The architecture of the New Zealand villa expresses the routine-focused lifestyle of the Victorians, a lifestyle that is no longer evident in the contemporary family structure.

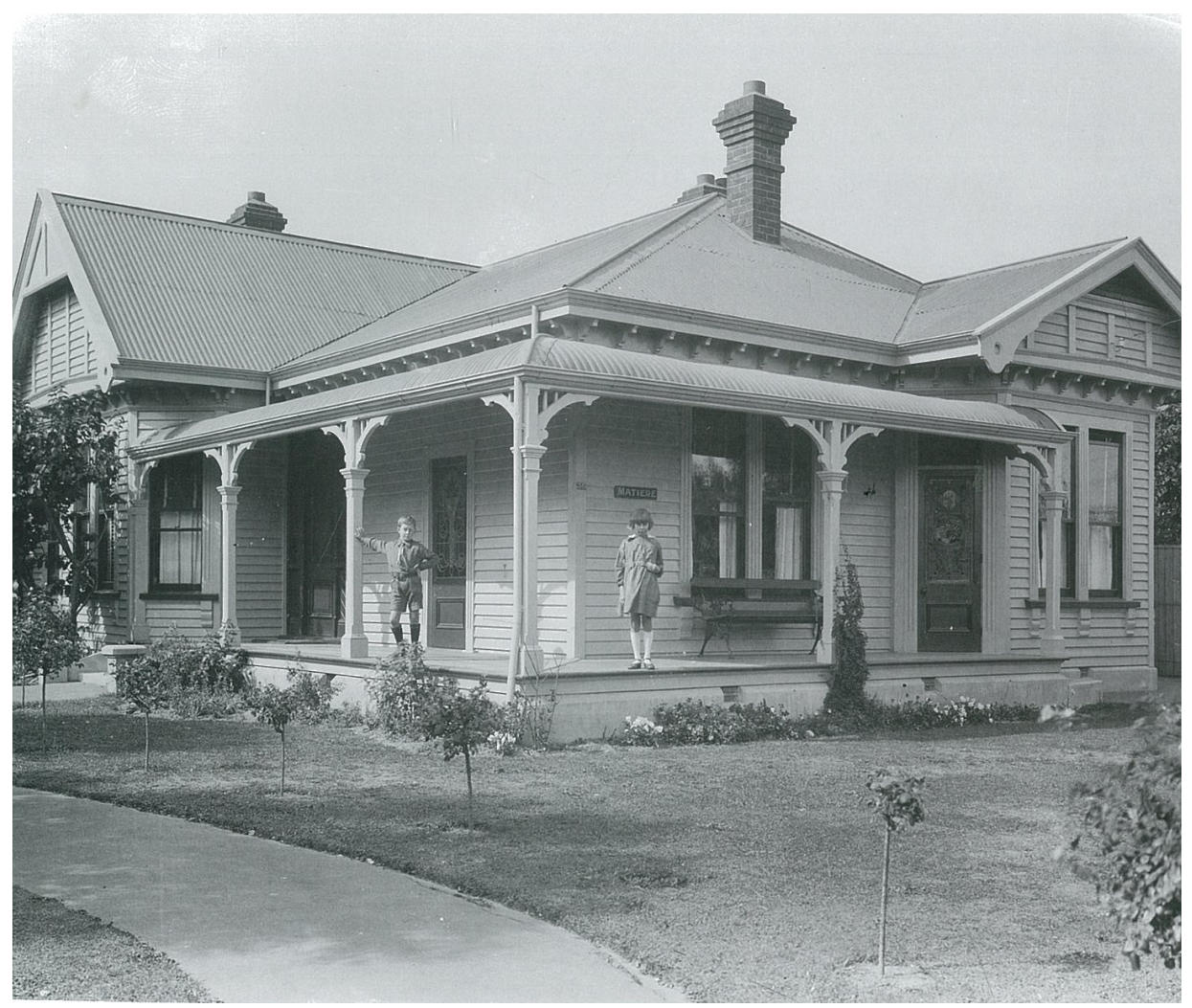

Fig 9: Matiere, Christchurch, 1910. Return Bay Villa, presenting the prominence of the verandah [Photograph: S Head Collection, Alexandra Turnbull Library]. 


\section{Plan and Form}

The architectural plan of the villa was inherited from the Neo Classical practices and represented the idea of sequential progression through a hierarchy of modulated spaces (Wagner, 88). The basic square plan was symmetrical with four main rooms. This further developed a long central hall with rooms attached off it. The front rooms were the prestigious rooms of the home facing the street edge and the back rooms were the functional operational zones. The symmetry of the square plan was often broken through the front façade of the house by projecting one room slightly forward. This was to increase room size and escape plainness by making the house asymmetrical (Toomath, 1996: 8). Families often opted to maintain symmetry and added a double bay window on the opposing side. Variations were further made to accommodate different city and climatic conditions. In Wellington, some of the two story houses took on the double bay style. The house was almost cut down the centre and one half placed on top of the other, yet still maintained the characteristics of the villa typology (Salmond, 1986:169).

The formal layout of the plan expressed the gender roles within the home. A woman's house-keeping role was expressed by her daily routine in the house. She would control and maintain the entire dwelling using the back rooms as the base for performing cleaning duties and the front for entertaining and comforting her husband in the evenings. A woman's responsibilities were catered for through the simplicity of the design; a commonality between villa's during the period of 1840-1910.

The simplicity of the plan is further reflected in the simple physical form. It was a timber skeleton propped up on piles and covered with corrugated iron roof. Openings were filled with factory-made standard windows and doors and edges decorated inside and outside with mouldings brackets and form work (Salmond, 1986: 112).
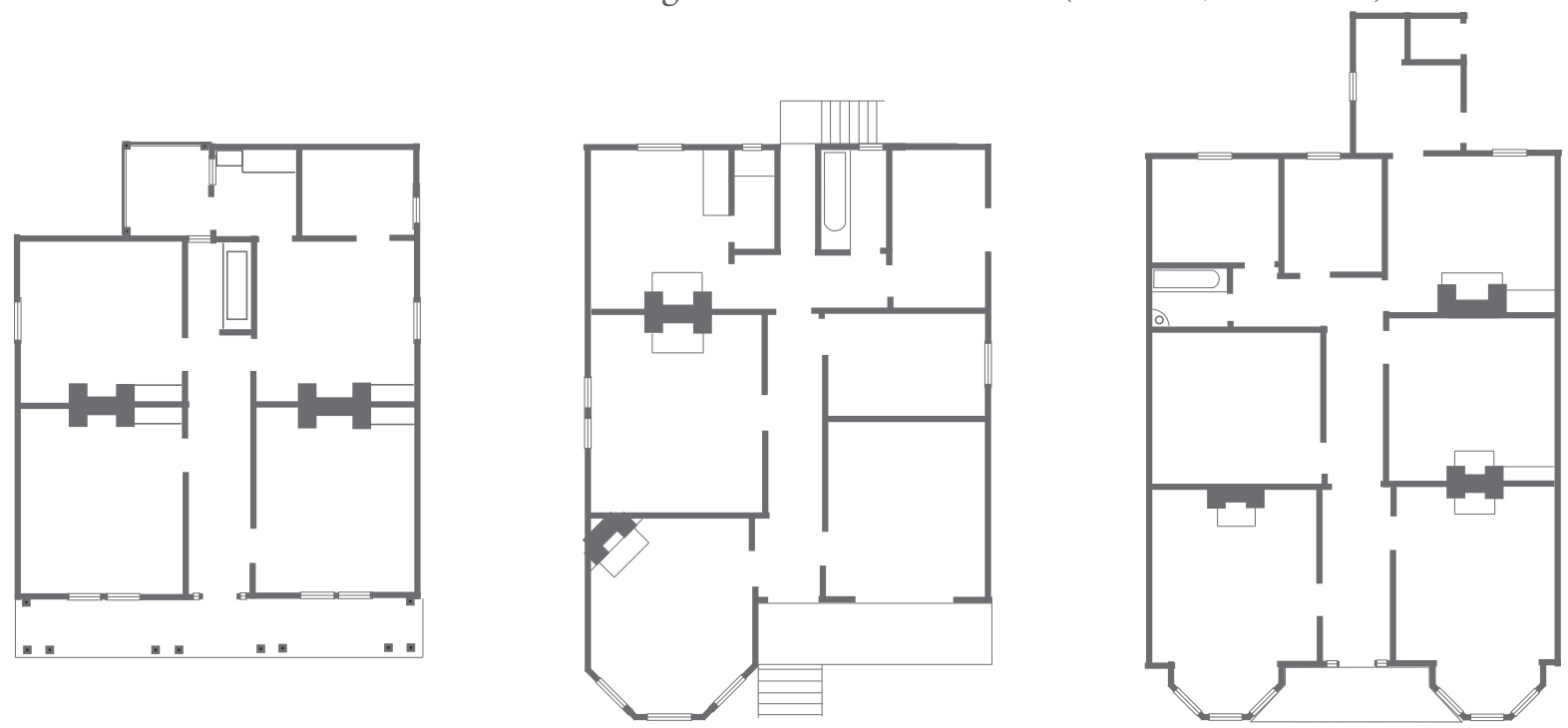

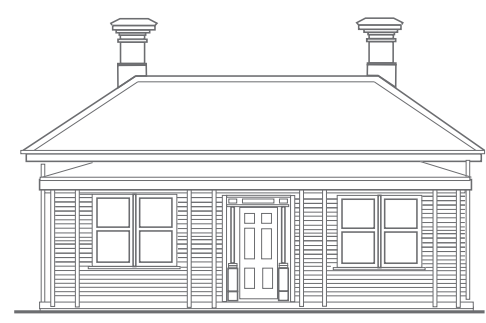

Basic Plan
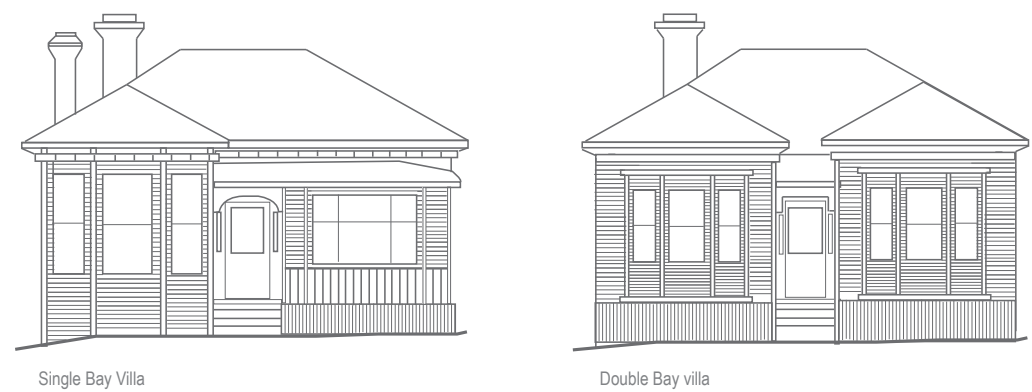

Fig 10: Traditional Villa Elevations: The diagrams expresses the low scale humbleness of the dwellings. The diagrams present the 3 main variations between the front façade. The Single Bay Villa became the most common and prominent type of villa around New Zealand. 
Each family member or social group entering the villa, generated their own pattern of movement and circulation which had an effect on the way the house was used. The dynamics of the space always happened in a process of three actions: the beginning zones, the mediation zone, and the destination.

The first movement is associated with entering and leaving the dwelling, or being within the household and mediating to another room. This would be evident through a guest or family member moving to the bathroom.

The second movement is the mediation space. The hall way was always the second space the family members and guests would pass through before reaching their desired space. Due to this the hallway became a valued attribute of the villa design.

The third zone is associated with destination; the parlour, kitchen, bedroom or bathroom. There was always a reason for going from one space to another due to the specific uses assigned to each room. You would only occupy a space for a specific activity. The parlour for entertaining, the kitchen for cooking, the dining room for eating and the bedroom for sleeping. An example of this can be expressed through the process of a guest arriving. When guest are invited to the home the journey began at the front gate through to the front door. The guests mediate through the front of the hall and then into the parlour to be hosted.

\section{Public and Private}

The public and private customs associated with the Victorian family were significant determinants of the architectural composition of the villa. Aside from the traditional metaphor that men went to work and women cleaned, more needs to be acknowledged architecturally about this relationship. To the public eye the Victorian family displayed a wealthy appearance and kept their domestic rituals behind the walls of the villa. The movement through the architectural plan from front to back required the streetscape to be the most prominent public view of the home and the back of the house to act as the hidden services area. Due to this spatial movement the front was always made a priority to keeping up a well maintained appearance.

The movement through the dwelling was signified through the function of the rooms and the status attached to spaces within the villa. Di Stewart believed that for the middle class Victorian woman the graduation through the public rooms at the front to the private of the back reflected the complexity of her roles within the home and in social life (Stewart, 1992: 49). The functional division was a symbolic matter, reinforcing divisions between sexes within a home and strengthening the division between work and leisure (Wright, 1980: 34). The public and private movement was further emphasised through the room roles.
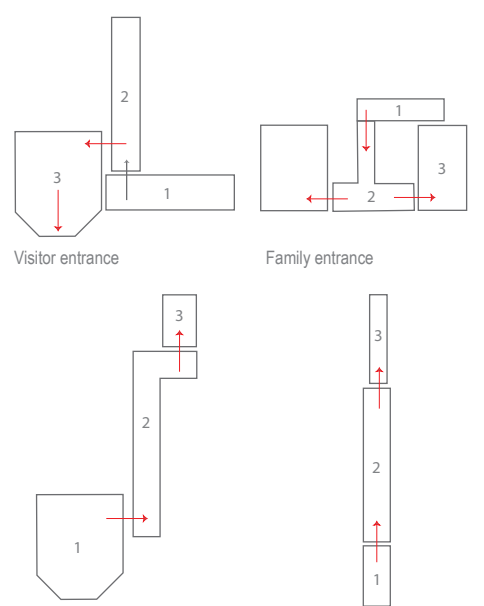

Visitors to bathroom

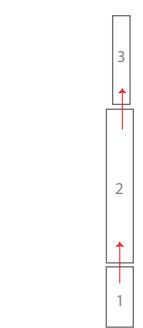

Front to back door
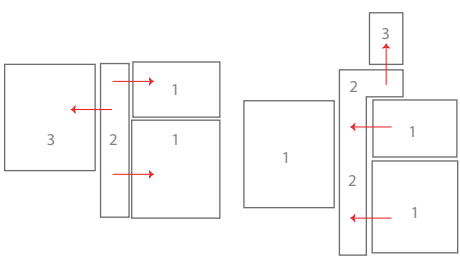

Internal movement Family to bathroom

Fig 11: Traditional Movement Patterns.
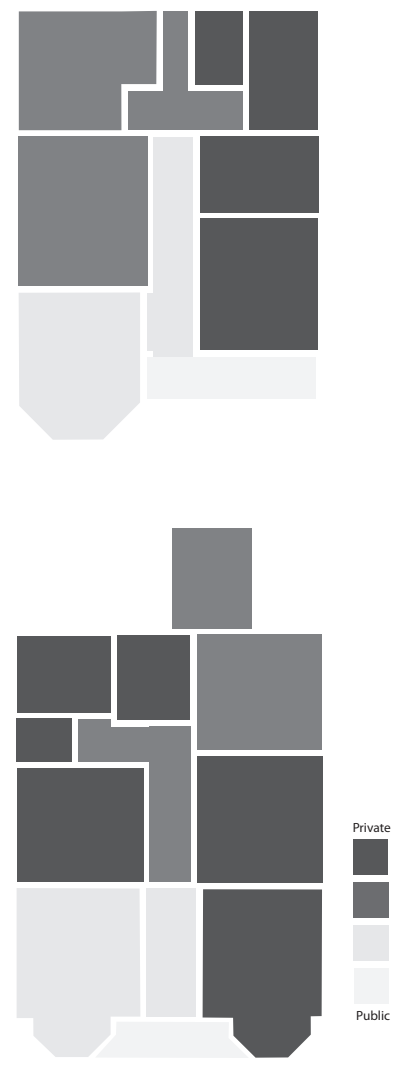

Fig 12: Hierarchy of Public to Private. 


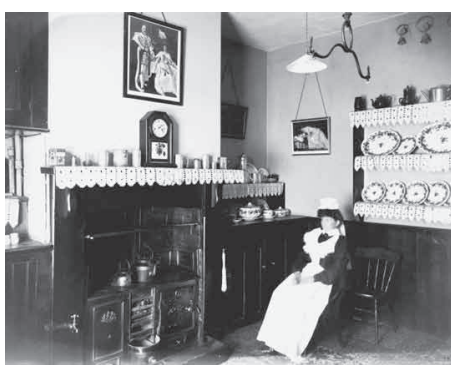

Fig 13: Typical Victorian Kitchen 1905 [Photograph: Steffano Webb].
Room roles had a generic configuration across most villa designs. Life was most lived at the back of the dwelling where necessary daily activities needed to be performed. The spatial connection of the plan was determined by a hierarchy of spaces varying in size and importance as them moved further back in the plan. Each room had a specific role, determined through their routine lifestyle as opposed to their design attributes. The following analysis will present a brief description of how each room was occupied by the Victorian society.

\section{Kitchen}

Although the kitchen was placed at the back of the house it was the room that was occupied the most. Author Miriam Macgregor states life was lived in the kitchen; it was the place where family affairs and decision were made. Acquaintances were entertained in the parlour, but friends in the kitchen' (Macgregor, 1976: 13). Kitchens were used for preparation and cooking. There was a separate scullery where dishes were washed. As with the rest of the home there was lack of storage therefore the plates and cutlery were often on display.

\section{Bathroom}

The bathroom was uncommon in the first villa's, having an outhouse situated in the far corner of the back garden. Bathrooms were included inside the dwelling during the 1890s. It was a small utilitarian room containing nothing more than a basin and a bath (Stewart, 1992: 68). It was placed at the back of the dwelling in the private service area of the home. The bathroom was and still is the most private space of a domestic home. A room that both the family and visitors occupy. It was a functional space that lacked internal decoration and aesthetic value.

\section{Parlour}

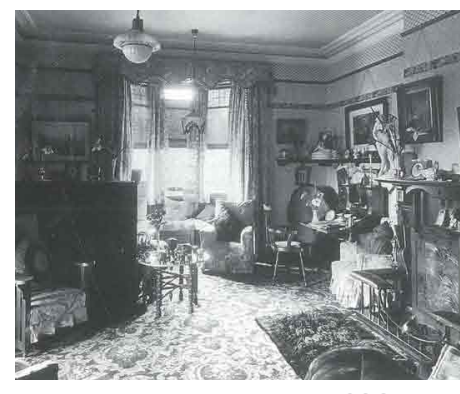

The parlour was the grandest room in the villa. It was the room that required the most attention both in cleaning and decoration. The room highlighted the social and public part of the house, and would often be the furthest some guests would make it into the villa. The parlour, also referred to as the drawing room, is a shortening for the word withdrawing room. Its main function was a space where the family could withdraw from the rest of the household for greater privacy (Bryson, 2010: 135). Women took more delight in this space as it symbolised a place where they could relax when not doing the housekeeping. Petersen believed that most men did not like their parlour as they preferred to relax in an easy chair, rather than sit up straight on elegant chairs. For women they were still laced up in corsets and therefore sitting up straight and maintaining an appearance was easier on the back than slouching (Petersen, 2001: 103). The parlour would always face the street to accommodate the public eye. Often this attribute would be a disadvantage as the space would be placed on the south end of the dwelling without sun. 


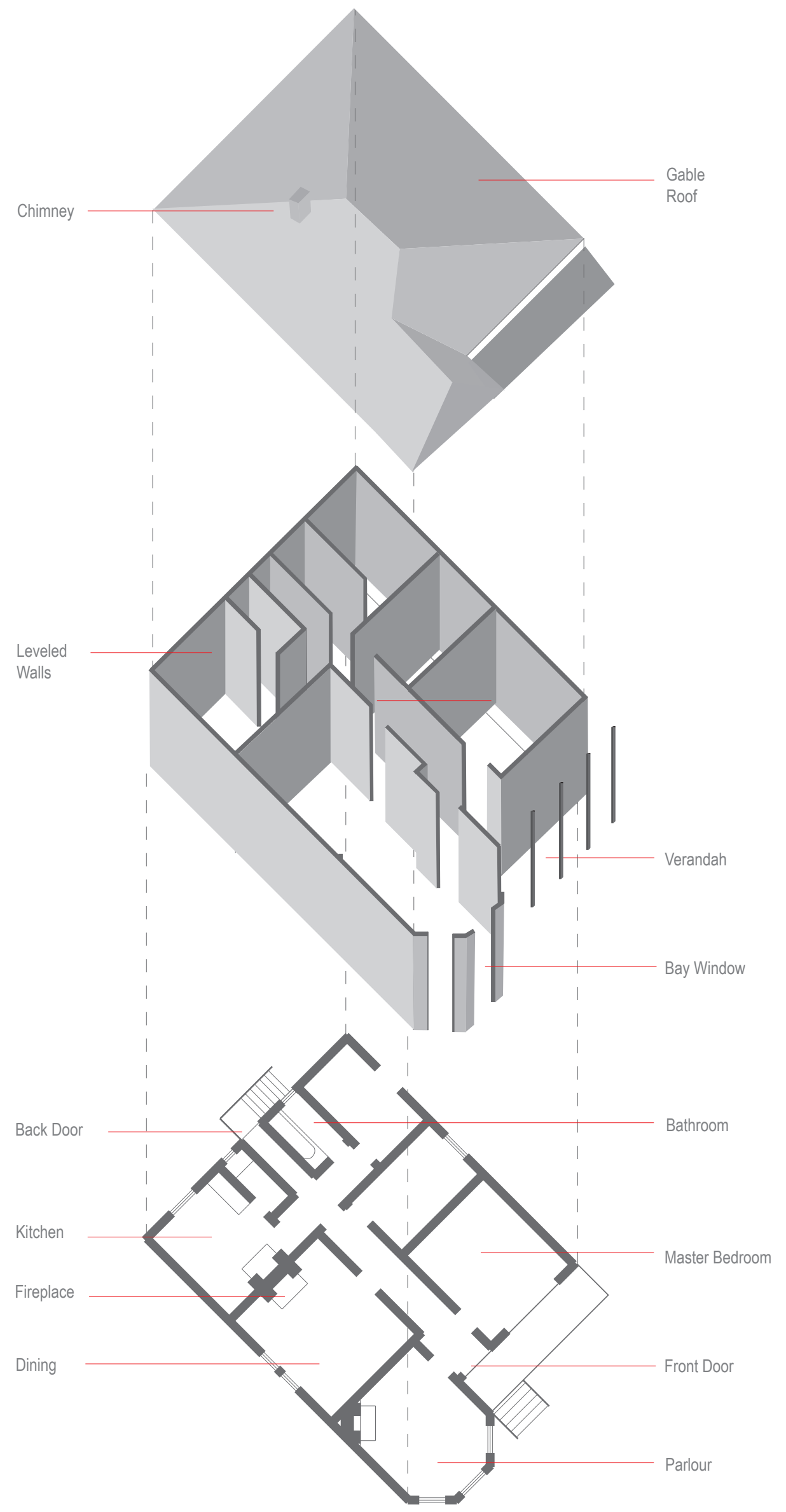

Fig 15: Axonometric diagram, presents how the villa was traditionally divided into room roles. The best rooms at the front and the operational rooms at the back. 


\section{Dining Room}

The majority of family socialising happened in the dining room, were the family would eat, talk and read books together. It has been recognised that by the 1890 s the dining room has been adopted in the middle class homes as one of the best rooms (Salmond, 1986: 169). Its placement in the dwelling was often in the centre of the plan of the hallway, therefore it would receive limited sunlight and required a fireplace to keep the space heated for the family.

\section{Bedroom}

The master bedroom is positioned at the front of the house; opposite side to the parlour. It was the husband and wife's room. The children's rooms would be located in the smaller rooms behind. The spatiality of the bedrooms was very generous allowing for personal activities to be preformed within. Bill Bryson notes, 'The bedroom is a strange place. There is no other place in the house were we spend more time doing less and doing it mostly quietly and unconsciously, than here. And yet it is in the bedroom that many of our lives most profound and persistent unhappiness are played out'(Bryson, 2010: 320). The bedroom as a private space held the secrets of the Victorians that were never seen by the public.

Fireplace

The open fireplace was the only source of heat in the traditional villa's; therefore they were placed in most of the rooms. The number of fire places used in the dwelling would be dependent on the climatic conditions of the city. Brick chimneys were internal back to back through walls to retain maximum heat while the rest of the house froze due to poor insulation (Toomath, 1996:127). Although there were many in the villa it was the fireplace in the parlour that provided the majority of warmth

Fig 16: Drawing of a nineteenth century brick fire place [Drawing: Jeremy Salmond]. when the family was home and bonding through reading, card games, and talking.

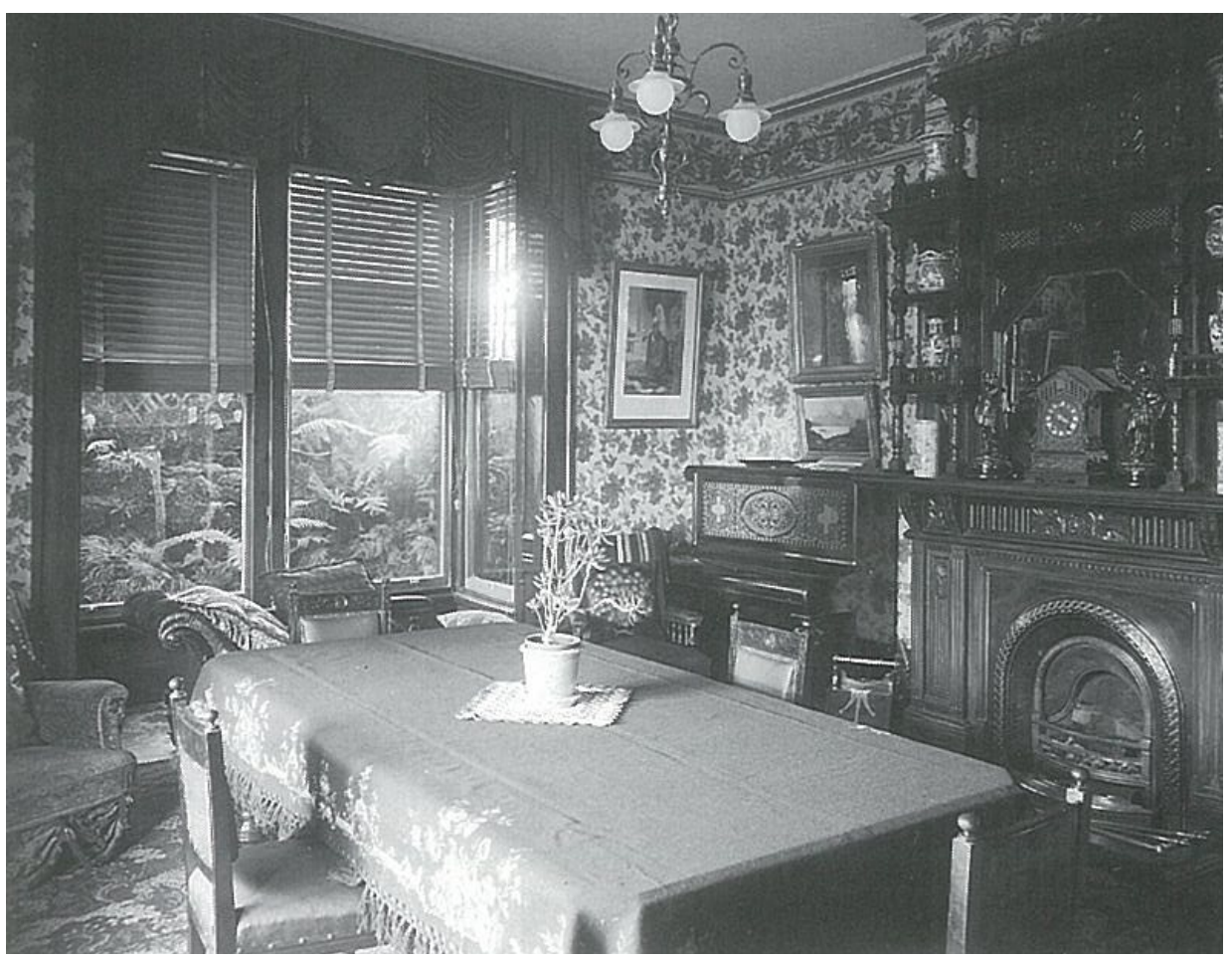

Fig 17: Typical Victorian Dining Room with cluttered belongings on display [Photograph: Steffano Webb].

Chapter 3 - Genuine Depiction of the Past 23 
The front door of a villa played an important role of the entire dwelling. It represents the boundary between the domestic space of the citizen and the town's authority (Cieraad, 1999: 3). The door was centrally located in the villa facade and in line with the front gate and path. This made the entire movement into the property a sequential progression. The front door marks the threshold between the public and the private space signifying the passing between two spatial atmospheres. Entering and leaving can be interpreted as rituals of passage, which evoke not only a progressive spatial transition but also a change of status (1999: 58).

The back door was the secondary door, were the family, close friends and service deliveries would enter. The front door held the status of protection and identification. It was the marginal zone which controlled the identification of visitors (1999: 55). The door would always obtain a peephole, which allowed the resident to see without being seen and to identify a visitor before opening the door. When a visitor would approach the door they often would step back to allow for the resident to see them fully (1999: 56).

\section{Hallway}

The hallway was one of the most lived and occupied spaces of the villa. It was a transition zone from front to back and a threshold between the social and domestic realm of the villa. Its prominence is highlighted through its alignment with the front door, front gate and front path. The hall's central position allowed for easy dynamic movement. Its generous space between $1.5-1.8 \mathrm{~m}$ wide allowed for inhabitation, decoration and ornamentation. While the hall held a high status in the house, it was the darkest space as the small windows in the adjoining rooms failed to extend light into the hallway.

Within the hall there was a secondary threshold. The corridor would become smaller halfway down the hall to mark the transition between the public and private space of the home. This would be signified by an arch, a change in ornamentation, a door or a curtain pulled across. Guests did not enter past this space unless they needed to use the bathroom. Privacy was further controlled through this method.

For the visitor the hall provided information about the number of people living in the home. This would be evident through the number of shoes or objects (Cieraad, 1999: 57). Halls would be heavily decorated to impress visitors and often obtain large mirrors so both the family and the visitors could ensure they were well presented when answering the door or leaving the house.

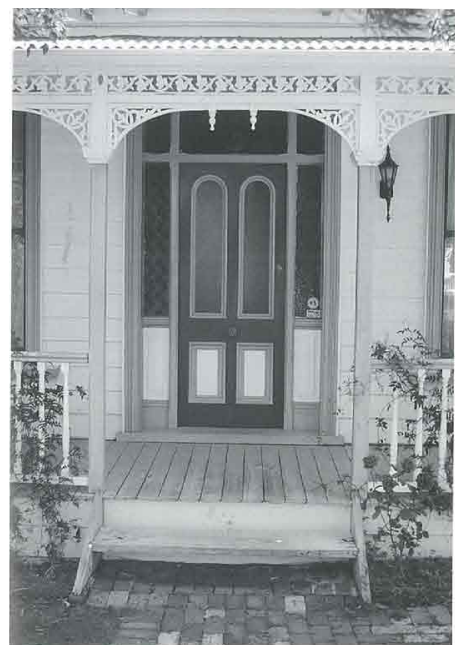

Fig 18: Nineteenth century front door. Symmetrical with an ornamental verandah [Photograph: William Toomath].

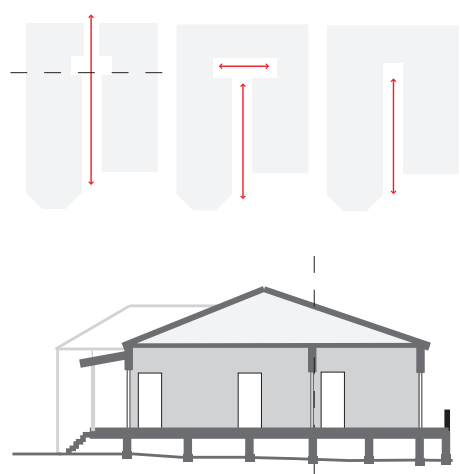

Fig 19: Hallway diagram, expresses multiple option and longitudinal nature of the space.

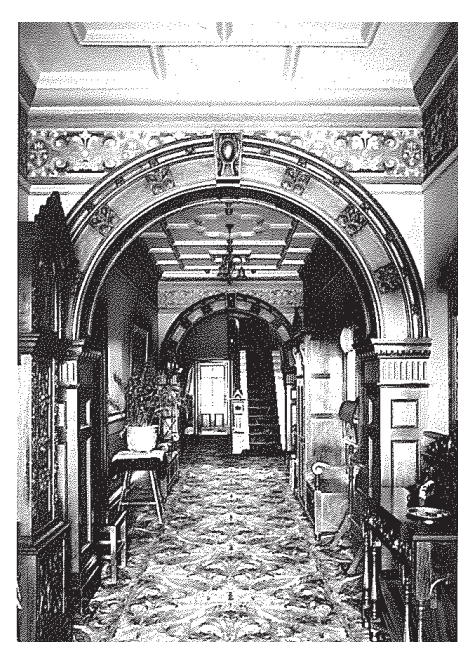

Fig 20: Typical nineteenth century decorated hallway leading to the back of the dwelling [Photograph: Steffano Webb]. 


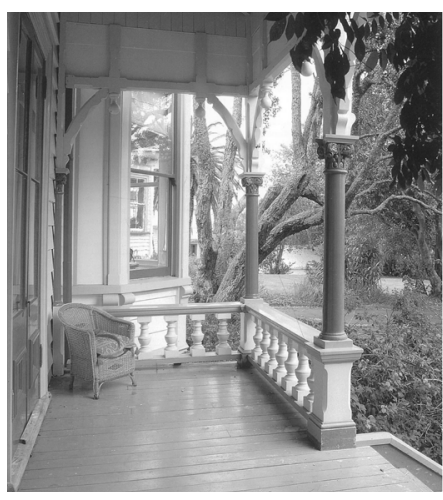

Fig 21: Verandah detail and ornamentation [Photograph: Norman Zammit].

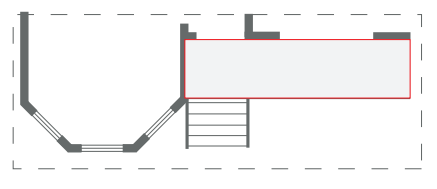

Private

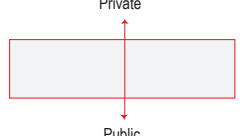

Fig 22: Traditional verandah was the threshold between the inside and out of the front of the dwelling.

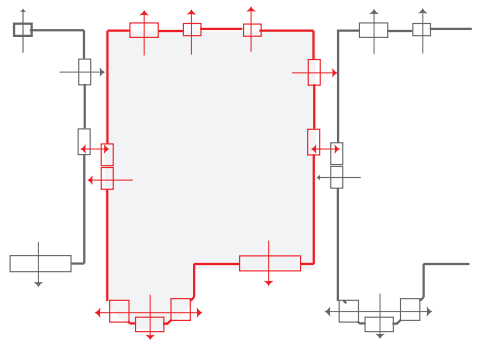

Fig 23:Traditional window relationship between neighbouring villas.

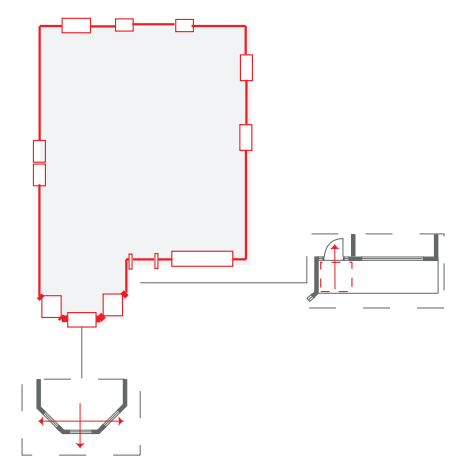

Fig 24: Bay window configuration.
The verandah's role in the domesticity of the Victorian society was to function as a threshold between public and private space. It wasn't until the 1880s that the verandah became an extension to the roof and was introduced into the house. There were a number of different variations, some were symmetrical to the façade whilst others, asymmetrical. The verandah was developed in colonial architecture as a sheltered space on one or more sides of a house for relaxing and entertaining (Stewart, 1992: 49). Families would use the verandah as a transitional space, allowing them to be outside without having to be completely delved into the public realm. The verandah functioned in some climates better than other and sometimes had to be closed over due to issues of wind and bad weather. Traditionally it was treated as a promenade than an outside room however later became a space for tea parties and entertaining (Jenkins, 1953: 51). Verandahs were also a major element of the decorative schema.

\section{Windows}

The wall space dominated the window space of the traditional villa, 30\% of the perimeter was window and the remainder was wall. The front windows were the only windows used as a viewing mechanism. The other smaller windows served merely as a device for ventilation. Victorian middle class were obsessed with proper ventilation and therefore double hung sash windows were seen as an efficient advance in the battle against diseases (Stewart, 1992: 40). Due to the minimal role windows played in the villa, there was no consideration for the alignment of windows with neighbouring housing often resulting in an overlap of side windows allowing vision through one house to the other or out to a blank wall. This would have caused an invasion of privacy.

Although windows were small they were often covered with curtains. This limited the amount of vision from the outside and reinforced the level of privacy that was demanded. Consequently this limited the light they received from the small windows.

\section{Bay Window}

The bay window was the most glorified element of the villa. It was factory produced during the 1880s and had their own little roofs added to create an early simple form of the bay villa (Stewart, 1992: 32). John Ruskin believed the bay window evoked the revered domestic virtues or protection, security, trust and traditional family bonds (Wright, 1980: 13). The design used 45 degree windows to create 3 viewing planes. This allowed vision up, down and perpendicular to the street.

There was often no window between the wall of the bay window and the verandah. When a guest would approach entrance to the home they would often encounter a 90 degree dark corner which would be utilised as a waiting zone until entrance was accepted. Often there would be 2 small windows either side of the front doors, however this would be for decoration purpose over security and often the glass would be patterned to disable vision. Once a visitor entered into the parlour, the guest generally would travel towards the bay window and find themselves on the opposing side of the dwelling signifying their importance and welcoming into the home.

Chapter 3 - Genuine Depiction of the Past 25 


\section{Suburb and streets}

The villa's were built in the expanding suburbs of New Zealand as a rapid response to the increasing numbers of immigrants. The rules and rituals of the Victorian society influenced the way the mass produced villa's were positioned and united on the street. This was acknowledged in the Evening Post during November 1940 'The individualism that allows every building in its street to have its own dissenting style was even more acute in New Zealand than overseas, giving New Zealand towns an amazing contrast of dignity and ostentation of style, restraint and ornament' (Evening Post, 1940: 7). The alignment with the street was a custom for the Victorians. This provided street presence, status and an overall sense of togetherness. Bay Villa's united down the street edge is a strong reason for heritage rules promoting the restoration of streetscape appearance.

\section{Orientation}

The front of the villa always faced the street edge regardless of its orientation to the sun. The sun, the wind, water and a view were the main factors of site in the early dwellings prior to the villa. As soon as streets were developed and the villa became a prominent design for the Victorian society the dwellings formed and an alignment and turned their faces to the street (Salmond, 1986: 61). A villa community presented a series of dwellings recognised through repetition of the front facade and roof.

\section{Garden}

The garden traditionally played an important role in the villa. Gardens were important as they were utilised to grow food and provide for the family. Vegetable gardens were common in all villa's and were the woman's responsibility. The garden for the woman was often an escape from the internal chores that they were required to maintain. During the showers of August they worked in their gardens, digging, hoeing, planting and sowing the vegetables to feed the family in future months (Macgregor, 1976: 57).

The garden whilst providing for the family was a further element of status. It was the division between home and the community. The front always had to present a well groomed garden and the back was often untidy. Communication from the front garden was often through a visual distance. The Victorians were not anti social, there were often special annual events where everyone would meet and converse in the community; this would be a special occasion, national celebration or local event. The Victorians would primarily provide their own entertainment within the privacy of their own home.

\section{Chapter Summary}

This chapter has allowed us to understand how the traditional villa shaped the Victorian society and the Victorian society shaped the villa. The rituals and expectations of the Victorians influenced the way the architecture was lived and this has become a historical typology. The following chapter will review the position of the villa in contemporary society and how it has developed with time.

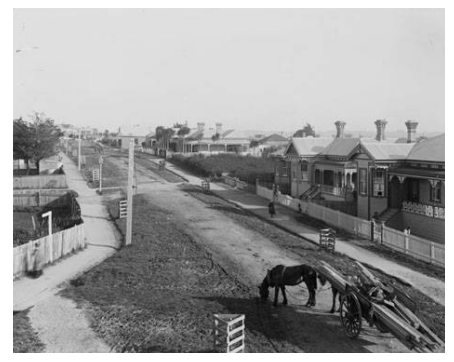

Fig 25: Devonport 1903, single story villas. Streets did not have cars and used horse and carriage [Photograph: Auckland War Memorial Museum].

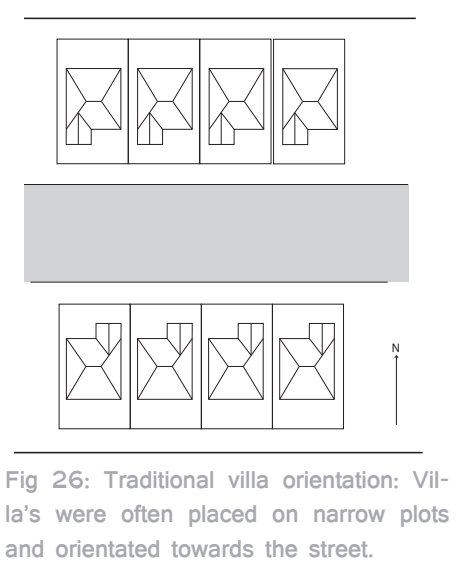

and orientated towards the street.

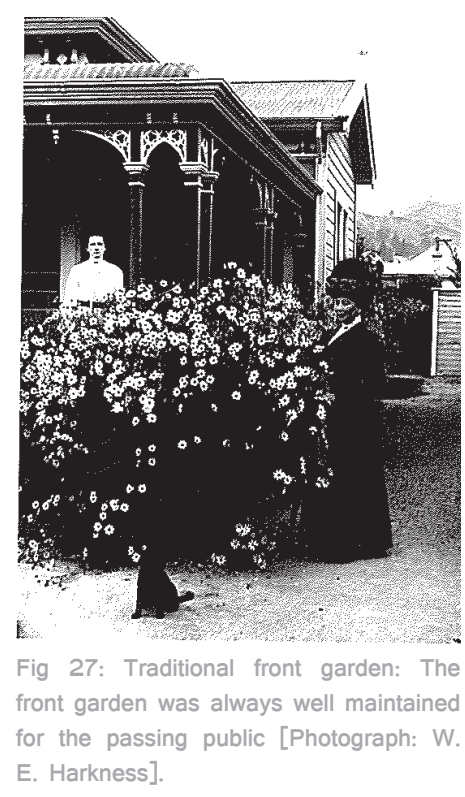




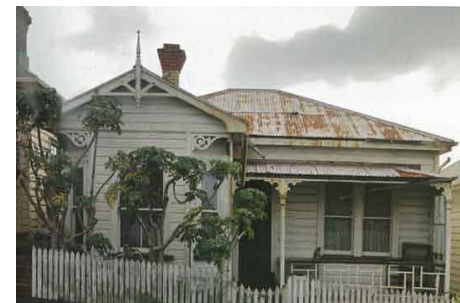

Fig 28: Neglected villa [Photograph: Patrick Reynolds].

\section{Position in Time}

Style Development

Attitudes towards the New Zealand villa have altered significantly since the nineteenth century. It is important that we honour the legacy of the villa however it is imperative that we recognise that the conventional concept is no longer suitable for contemporary society. Heritage architecture needs to function for changing family units and individual client demands.

The villa established a variation of typologies during the late nineteenth century. Architectural change to the villa began to occur with the development of society and the rise of new architectural movements in New Zealand. During this transitional period the villa was neglected. People were concerned with architectural innovation as opposed to the cold and simple dwelling the villa offered. The shrinkage of the timber linings meant that villas became drafty and this drove the need for interior re-lining. Interest in the adaptation and restoration of the villa became prominent in the 1970's (Stewart, 1992: 7). People opted to restore the villa, fix its rotting elements or adapt the villa to function for the changing family unit. The enforcement of District Plans in 1991 brought with it implications. Occupants became pressured by council rules to maintain the traditional appearance of the villa while simultaneously adapt the architecture for contemporary use. Internal changes kept developing with societal change; however the exterior aesthetics became restricted to change. From these adaptations it is clear that the villa has a natural ability to change. This quality should be celebrated through the remodelling of the dwelling to function for a new occupant structure. Change can be implemented that adapts the Victorians codes of living to function for contemporary living requirements. Approaching change without a clear understanding of the traditional dwelling and its position in the present time can result in a loss of the villa's cultural integrity; as outlined by the process of facadism. Douglas Lloyd Jenkins believes 'The villa needs to be viewed as a blank canvas. A series of inert interconnected boxes that, those that live in them can use or alter in any way they like' (Jenkins, The New Zealand Villa, 2011). This chapter will assess the villa's position in contemporary society. It will question the positive and negative attributes of the traditional villa and its position in today's society. Information is sourced from literature and personal interviews with a range of New Zealand based architects.

\section{Contemporary Opinions}

Interviews were conducted with five New Zealand architects in order to attain a general understanding of how architects see the villa in contemporary society (See Appendix 1.)

There are many views and opinions towards the position, value and use of the villa in our lifestyle today: those who unquestionably fight to save the villa, and those who believe we should demolish them and build contemporary dwellings. Finding a median between both is the ideal position required, in order to respect the past but function for today.

Chapter 4 - Position in Time 27 
Positive

The word villa suggests romance through its connotation with Italianate precedents and the relationship between the translations of stone to timber (Marshall, 2011). It provides a unique connection to our settler history and the villa's role in establishing our population in Auckland, Wellington and Christchurch (Lawson, 2011). The architectural composition of the villa as a detached house was the most common dwelling type in the settler society of New Zealand. The separate house with a garden was the quintessential 'kiwi dream' and still remains an essential requirement in the changing social values and practices (Wagner, 86). The verandah is noted as still being one element that functions extremely well today. The verandah provides a spatial generosity through its connection to the street (Walker M. , 2011). Its threshold provides a gesture to the public.

The spatial quality that has remained popular in the villa today are the generosity of space. Although often on a small piece of land the internal spaces were large, offering a satisfactory level of comfort. The $3 \mathrm{~m}$ ceiling heights reinforced this through expanding the volume of the space. The spatial qualities is further valued for its ability to provide roof inhabitation; this aspect was never implemented by the Victorian society. The natural flexibility of its plan to alter and change without a large amount of labour or removal of defining elements of the traditional dwelling is a defining quality of the villa in today's society.

There are mixed opinions on the ornamentation of the villa. While it creates picturesque external aesthetics, it is believed to function at its best when it is or was traditional. It cannot be imitated with modern materials, as patina is lost and the authenticity of the elements becomes false. However, the internal decoration was regarded as a basic human need. Jenkins states 'The villa can take any decorative scheme you throw at it. (Jenkins, The New Zealand Villa, 2011). However some would argue against this with the idea that the villa was a specific genre. The villa's ability to accommodate different occupant groups remains a valued attribute in contemporary society.

\section{Negative}

Aside from the positive attributes of the villa, there are many negative issues which surround this housing typology. These are commonly concerned with the aging dwelling and its structure.

Villa's are cold due to lack of insulation, they rot due to untreated timber and require constant maintenance and material up keep from their original construction which has aged. The villa's orientation to the street often resulted in the sun penetrating through the house into the service spaces that required it the least such as the kitchen and bathroom. This was one of the biggest flaws of the villa. The lack of consideration for sun or daylight entering into the building was the cause for most of the ongoing problems; others consist of the lack of fireproofing or soundproofing (Cook, 2011). The traditional plumbing and wiring systems are no longer satisfactory. These attributes come with the nature of the villa and also need to be fixed. It is a necessity not a quality of the past that can be brought into the future. This needs to be controlled as the villa is a significant energy absorber. 
Spatially the villa is a cellular unit designed through a hierarchy of spaces. Due to the formality of different rooms, it often makes contemporary living uncomfortable and awkward to live in. It becomes a common theme in the interviews that the better part of villa's today are the aspects that are modified, the additions and alterations. Open plan and indoor-outdoor living are the qualities that make these houses work for society today.

The contemporary view of the context and environment relates back to the issue of orientation to the street. They are often regarded as being inappropriately sited due to the obsession with the street front. Marshall Cook believes the idea was you only had one facade to the street that you decorated, the rest of the dwelling was plain and simple. To revisit the villa, consideration needs to be given to the plot size and the shape is very important. Cooks thinks the nice thing about it, is that all of our inner city is set up on tight sub-divisions and is ideal for development. Not for restoration (Cook, 2011).

While the positive and negative attributes seemed to follow similar opinions, the question of retention and restoration of the villa was sparse. On one hand it is regarded as being absolutely essential and on the opposing view we have architects who believe we should disregard everything. Gary Lawson believes it is a 'case by case if you have got a street of 6 or 7 villa's and there is one that is in the balance. Then in most cases you should retain and restore that one to keep the theme within the street. In most but not all, restoration and preservation should be seriously considered but in others not at all'. Douglas Lloyd Jenkins supports this, 'it should be one of respect, it doesn't automatically require 'authenticity' - it does however require careful thought and consideration. It's not necessary to restrict what gets done to villa's' (Jenkins, The New Zealand Villa, 2011). And Malcolm Walker 'I think they should be acknowledged but I don't think they should be hallowed' (Walker M. , 2011). It comes down to the issue of respect, respect should be given to the dwelling it its aging state and context.

The contemporary opinions of the villa provide a base for which we can assess what elements of the villa are still valued today. The following part will further review the current position of villa's and how they have been altered to fit with societal rules and contemporary demands.

\section{Current Position}

The way we currently approach change is largely restricted to the internal plan and back of the dwelling. The issue with facadism is that while the interior of the house is being modernised, the exterior is being suppressed; generating a split typology. Although it presents itself as a villa, it is an imitation of a past that is no longer relevant. Jeremy Hanson, Patrick Reynold's and Jeremy Salmond's book 'Villa from Heritage to Contemporary' provides an impressive account on the development of the villa into contemporary life and the various new functions the villa has adopted. Their book explains that villa's began to evolve stylistically over time with changes in architectural fashion (Hanson, Salmond, \& Reynolds, 2010: 26). 
In terms of facadism, their book explains that for every villa that's lovingly restored there are dozens of other unsympathetically, albeit lovingly, altered at best or butchered almost beyond recognition at worst (2010:114). This is what we want to avoid with implementing changes to villa's. While we don't want a reproduced false facade, we also don't want an alteration that speaks an opposing language to the villa. Architectural change should be implemented that presents the traditional language through a contemporary lens. An alteration should correspond to the past in a contemporary manner.

The villa has moved beyond its traditional function for the conventional family, they have taken on new lives as offices and shops (2010: 133). The adaptability and flexibility of the villa has allowed the villa to cater for various generations and different lifestyle demands. ${ }^{5}$

At present the changes made to the interior do not follow a contemporary typology, they are arbitrarily done to cater for the occupants demands. Such changes are being implemented as they are concealed within the external shell of the villa. While the changes have been successful as shown in fig 29 -35, the changes fail to speak the same language as the traditional typology. This thesis aims to re-position the traditional qualities of the design through a contemporary lens. It will generate a set of principles to understand how change to the internal and the exterior can be implemented. Changes should be celebrated as opposed to being suppressed by the external shell of the villa.

\section{Chapter Summary}

It becomes evident in this chapter that the gap in this research is the manner in which the plan of villa continued to develop with time and the exterior halted. The position of the villa in contemporary society has changed. Architectural changes are being implemented to the interior of the villa to fit occupant's needs. Although at present the changes are arbitrarily done, they still recognise that change needs to be conducted. Before we take into consideration the positive and negative attributes as outlined by the architects and determine a contemporary typology for remodelling that speaks the same language of the traditional villa, attention needs to be given to the dormant exterior. The facadism referred to in section one only discusses the vertical nature of the method; the aesthetic of the front facade creating an idealised image of a time that has passed. The front facade, while deceptive, is not the element hiding the modern changes. It becomes apparent that the roof is acting as a horizontal element of the facade. The roof is the element that is concealing the changes made to the plan from above. The following chapter will explore how the roof would appear today if it had continued to develop in parallel with the plan when the roof and exterior stopped developing. It will determine possible paths the roof could have followed if they had continued to develop with the plan and the change of time.
5 'To get the best of villa's in today's world we need to adapt them to the needs of our generation.... Limitations of their programme make them still useful today as their simply built structure makes them extremely adaptable (Hanson, Salmond, \& Reynolds, 2010: 9). 

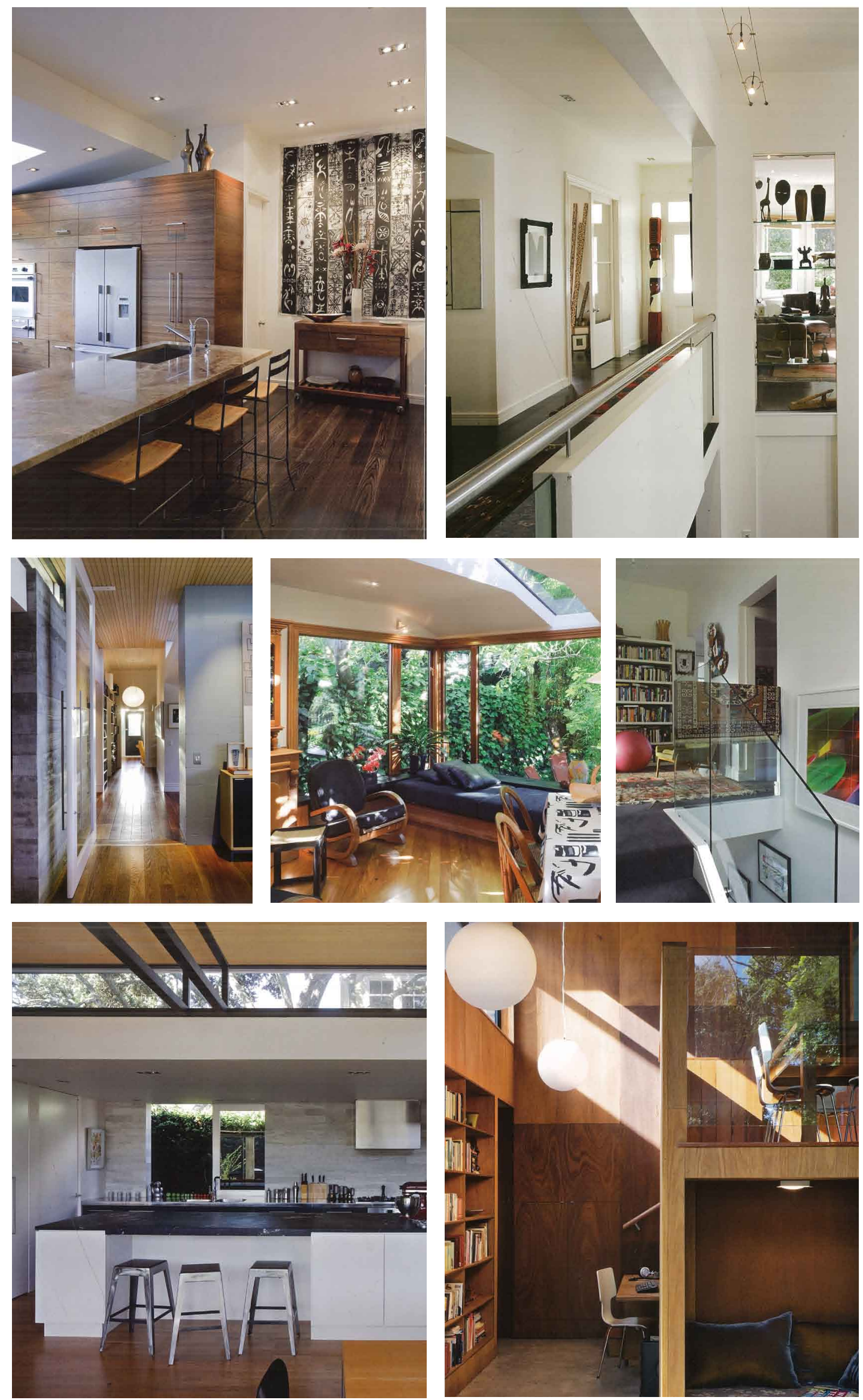

Fig 29 - 35 (From top to bottom, left to right): A series of images taken from Salmond, Hanson and Reynolds book present a number of altered villas and their contemporary function for a contemporary family. While the alterations look to be successful, all appear to be arbitrary and not implemented in accordance with the traditional typology of the villa. [All Photographs: Patrick Reynolds] 


\section{Contemporary Roof}

As determined by the findings of the previous chapter, the internal plan of the villa has continued to evolve while the exterior has become dormant as a way of preserving the past. The vertical plane of the front facade aims to achieve a nostalgic connection through its aesthetic and the horizontal nature of the roof facade suppresses the changes made to the internal plan while maintaining the traditional form of the gable roof. This chapter will further assess the development of the roof from its traditional purpose to its function today. It will review the traditional gable roof and assess how the roof could have developed to function in contemporary environments for contemporary issues.

During the period of 1840 - 1910 the villa style was emerging in New Zealand. Architect Jeremy Salmond calculated more than 6000 variations of the villa were possible, each traced through the roof form. The form of the main roof was instrumental in shaping the final form of the villa. The plan would be the primary element of change and the gable roof would be the secondary element, which would map onto the internal plan. Exterior elements such as the verandah and bay window would further influence the roof form and cater for the streetscape appearance.

As society developed into different classes, so did the villa. The basic square villa was constructed for the early working class; a square footprint with a gable roof. The single bay villa was further developed to cater for the middle class. This introduced a hallway which cut down the space of the rooms and this meant the parlour would project out to cater for size change, making the dwelling asymmetrical. The extension to the plan meant the roof had to embody a secondary element to follow. The double bay villa, which also catered for the middle class, was developed to restore symmetry that the single bay had lost. The fourth variation was the corner or return bay; this was for the middle to upper-class. It developed from the smaller versions to accommodate the larger families. It had an enlarged plan with rooms ranged equally on either side. In this the roof introduced parallel gables and central roof gutters (Salmond, 1986: 169).

This issue with the plan to roof pattern arose when the internal plan continued to develop with society and the roof and exterior elements stopped. The roof needs attention in order to develop our understanding of how the roof form and exterior elements could have been adapted simultaneously with the changes made to the plan for changing occupants. 

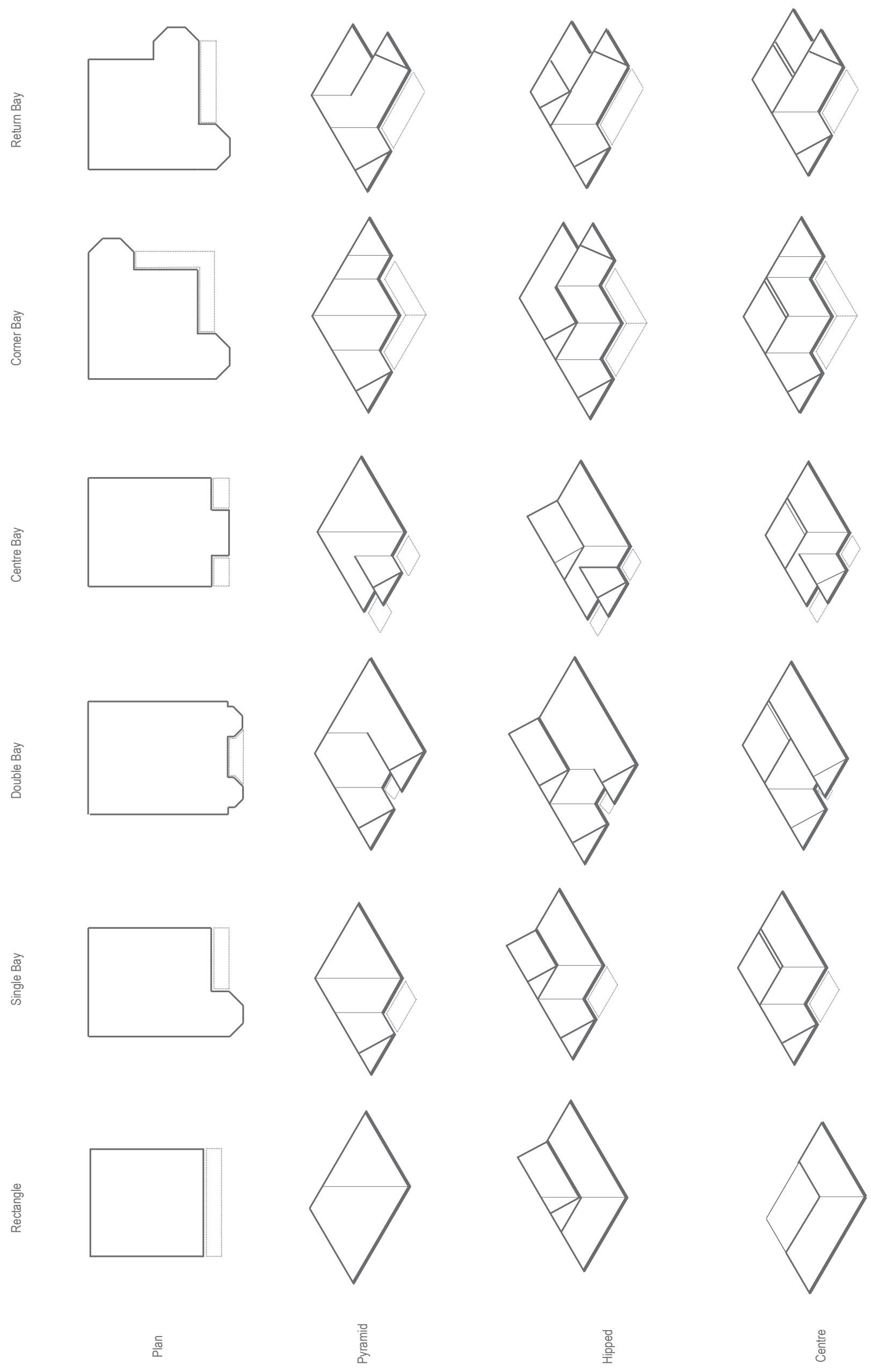

氜

Fig 36: Reinterpreted diagrams from Salmond's book. This emphasises the plan to roof relationship (Salmond 1986: 168 - 173) 
The roof form that will be considered in this research will be the gable roof as it was the most visual form used in the traditional villa. Before the roof can be accessed through contemporary issues it needs to be analysed in its basic form in a generic manner. The roof will be reviewed through the square villa, single bay and double bay villa.

\section{Shape and Form}

The basic roof was composed of four planes each set at a low pitch, meeting at a central apex. Changes to the internal planning, such as the introduction of the hallway and extension to rooms meant that the roof needed secondary planes to function for the change in shape and scale. Tertiary elements such as the verandah were further added.
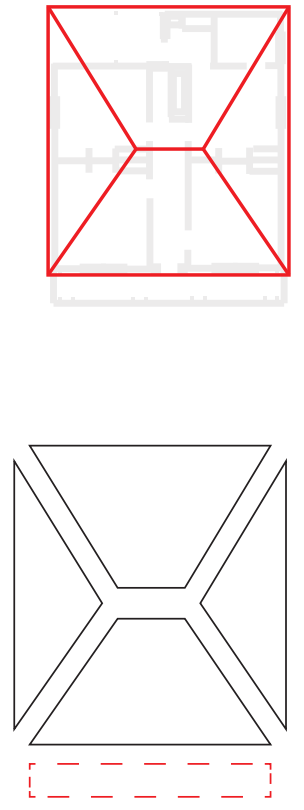
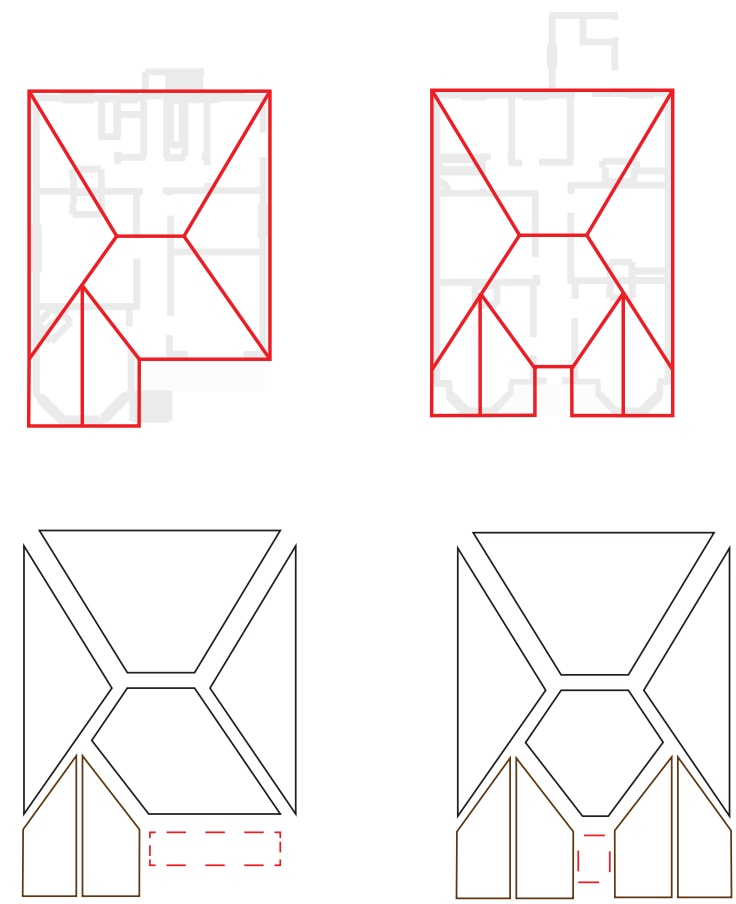

\section{Streetscape}

The gable roof was a repeated element which created a distinct pattern both in elevation and in plan. The front elevation was the most important element during the nineteenth century as it was seen from the street. However, the gable roof remains common today through its repetition from above.

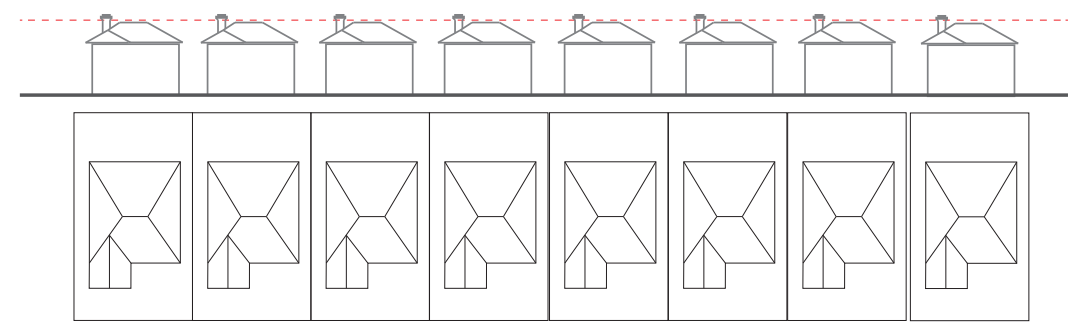


The gable on the basic villa was symmetrical in both directions, the movement to single made the entire dwelling asymmetrical and the double bay brought symmetry back to one axis. While symmetry throughout the house would have been preferred, priority was given to the front facade as it was the public face of the house development.
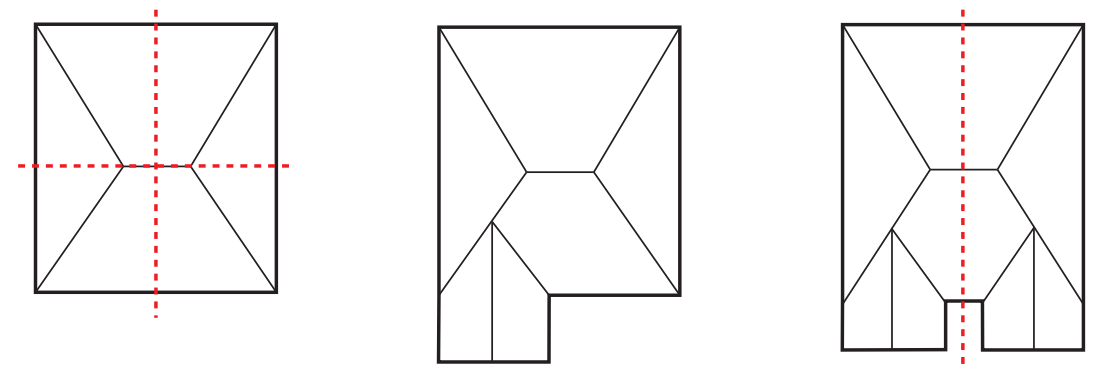

\section{Construction}

The construction was very simple, the main structural members in the roof were the rafters which met at the ridge board and were held together by a collar tie at mid-span. The rafters sat on top of the walls and originally stopped short at the outer face of the wall without an overhang (Salmond, 1986: 119). In later versions it appears the rafters would span to the edge of an eave. Hips catered for angles and valleys were introduced as the roof changed with the developed plan.
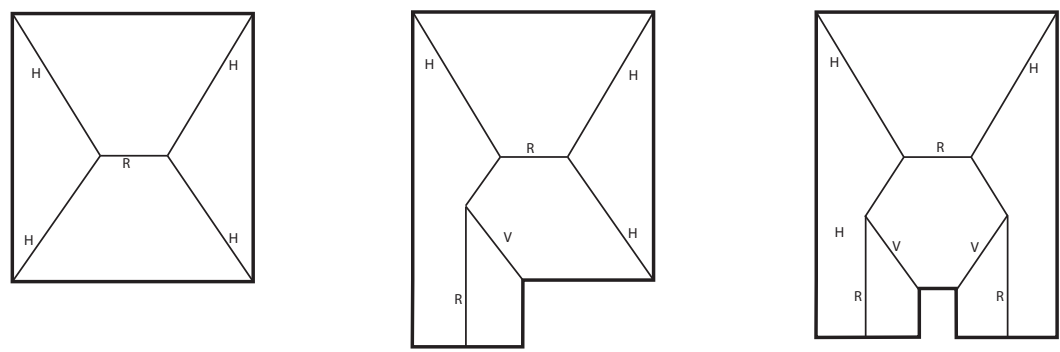

\section{Chimney}

As discussed earlier, fire places were essential in the traditional villa's as they were the main source of heating; multiple fireplaces resulted in multiple chimneys visible from the street. The chimney was always visible from the street and often highly decorative.
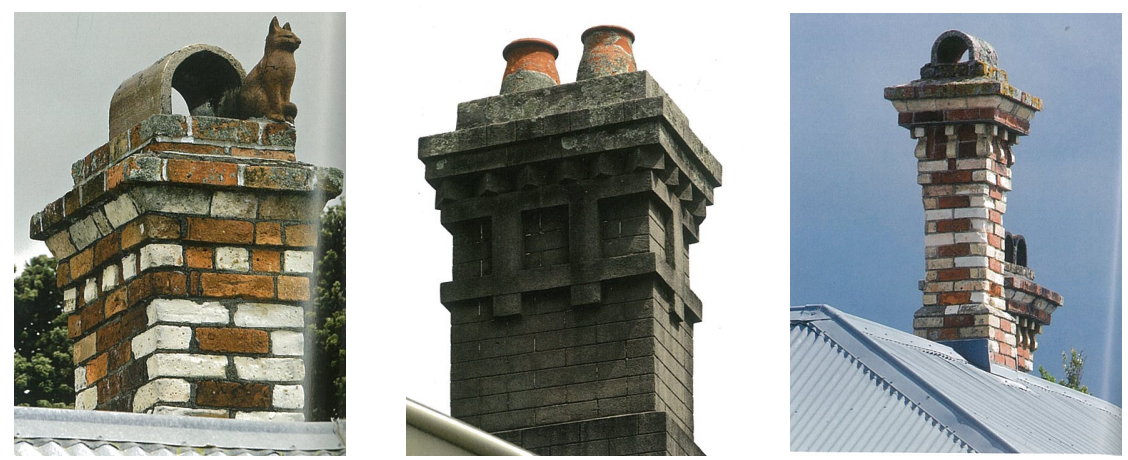
Through understanding the traditional gable we further need to understand the contemporary issues at which this gable roof would have faced if it had continued to develop with society. Society has grown rapidly with technology, fluctuating family units and contemporary lifestyle requirements. The view from above is now becoming important. The roof has become a horizontal facade, through the technology of Google Earth and aerial views, elevated views which invert scales and shrink a cityscape (Boldrick, 2007: 11). The view from above is no longer denoted through maps with sharp lines and colours, but through satellites producing an image of a location determined through roads, gardens and roof-scapes (2007: 12). The roof plays a much more widened role than it traditionally did in the nineteenth century. Once a simple shelter from the wind and rain, the roof now has to cater for the following contemporary issues:

\section{Views}

An increase in height of neighbouring buildings generates a range of view angles and positions, due to this privacy is needed to control inward views beyond the street level. Technological innovation has further influenced methods of viewing a house. Aerial maps and programmes such as Google Earth offer a view of the villa primarily through the roof.

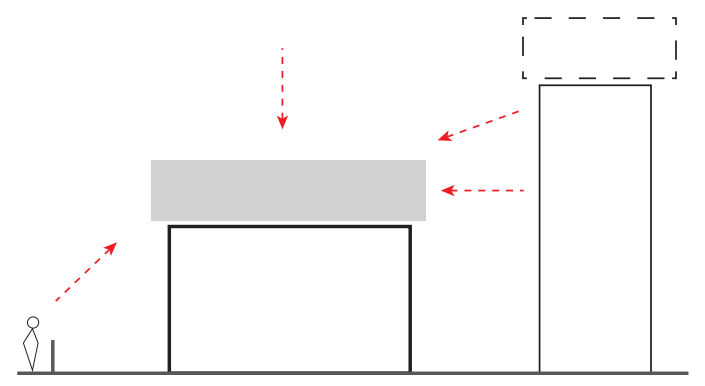

\section{Light}

More emphasis is placed on light entering a contemporary dwelling. With urban infill and an increase in building height it is often practical to bring light in from above as oppose to at the side. This can also control privacy.

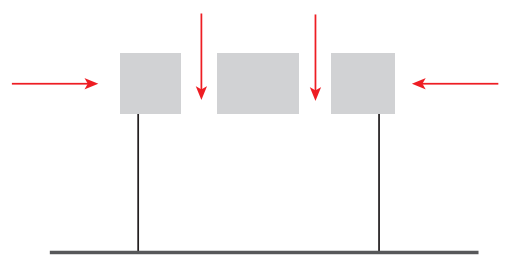

\section{Occupation}

Living within the roof space has become common in many sloped roof dwellings. Outdoor activity on the roof has also increased. The roof should be flexible to cater for both requests.
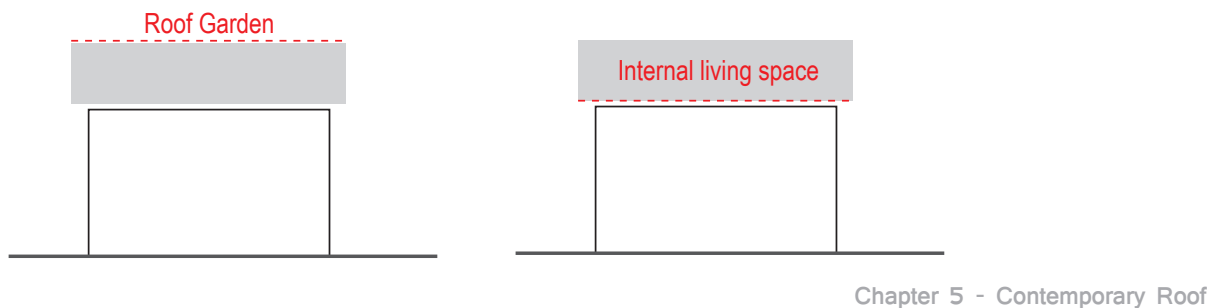
Longer spans are often needed to cater for additional outdoor shelter such as car ports and shelter for outdoor living. It is essential to have a sufficient ridge span to cater for the longitudinal length of the house.
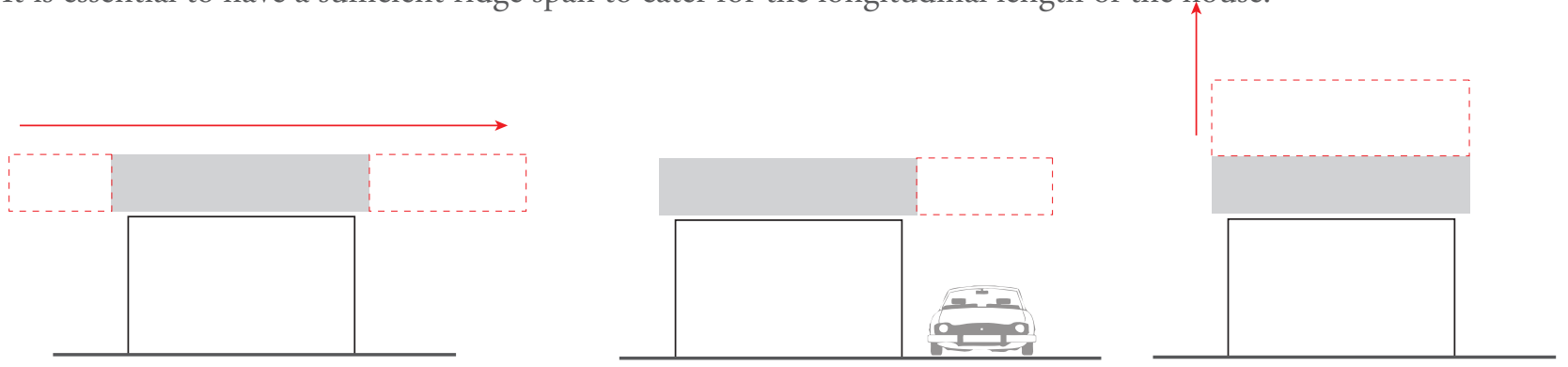

Fig 45

\section{Technology}

The innovation of technology has allowed architecture to cater for client comforts through the efficiently of the products. For example, air-conditioning units can be placed within a roof space or storage area and solar tubes cut into the roof bring light into dark spaces. While the roof no longer has to cater for chimneys, it has to accommodate techonlogical systems.

\section{Material}

Roof materials will continue to develop with time. There are now many alterative options for roofing materials which can influence the way the roof shelters a dwelling. As well as offering different aesthetic styles, development in material use can effect internal energy levels, and structural detailing. Materials need to be carefully researched as they can provide more to a building today than they originally could in the nineteenth century.

\section{Structure}

Roof structure is continually developing with technology however it is still common to follow the traditional practice of roof building for modest residential housing. It can also add rigour and aesthetic value to a roof.

\section{Form and shape}

In comparison to the gable roof the form and shape of a roof today can be virtually anything it desires. The gable roof still maintains its traditional form however can be challenged to cater for contemporary issues. 
The following experiment was done to test how the elements of the traditional gable roof could be reinterpreted to cater for contemporary issues. This process will begin with a series of conceptual models that use the elements in alternative ways to achieve the above issues.
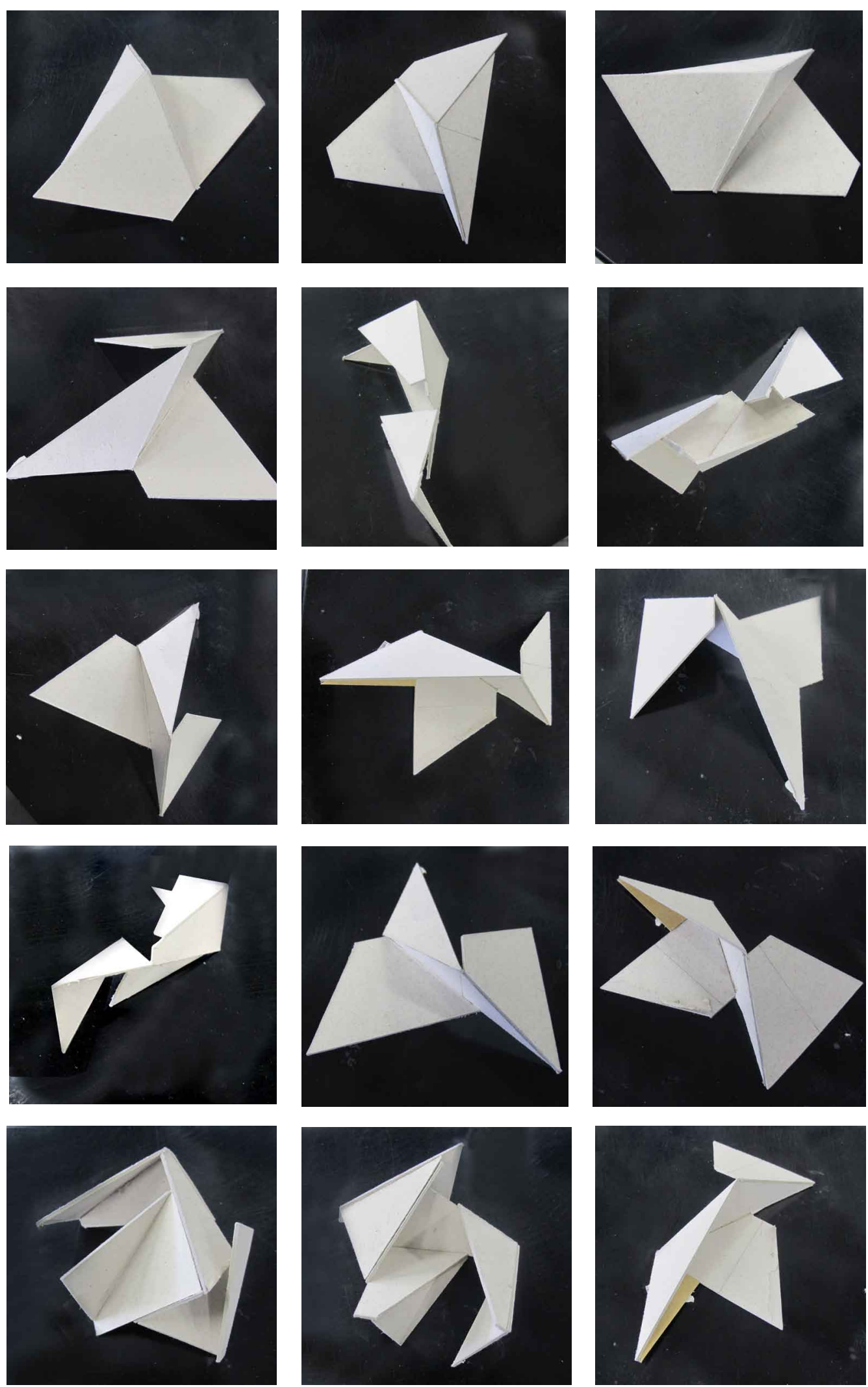

Fig 46: Abstract cardboard models for roof exploration. 
The concepts drawn from the abstract model experiment and the roof analysis were further explored through diagrams to understand how the gable roof elements need to be approached to address the contemporary issues. From this it becomes apparent that there are recurring common elements that need to be considered in contemporary roofs today. Five principles have been formed which incorporate contemporary issues with the traditional aesthetic and construction of the villa:

\section{Horizontality}

A horizontal plan is required in order to allow habitation on top of a roof.

Horizontal plane

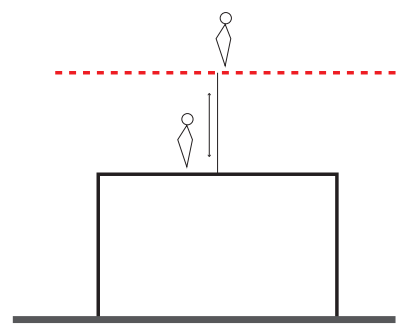

Hierarchy of horizontal planes

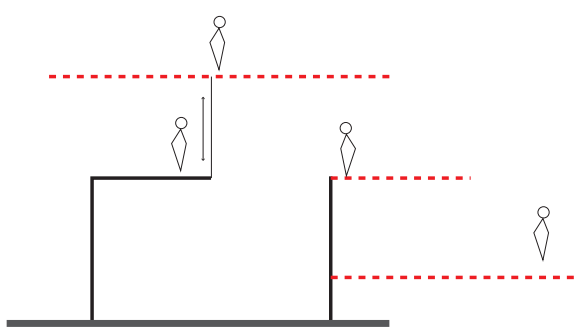

\section{Verticality}

Space within the roof is required to achieve internal inhabitation. This height will further control any unwanted external views from neighbouring buildings.

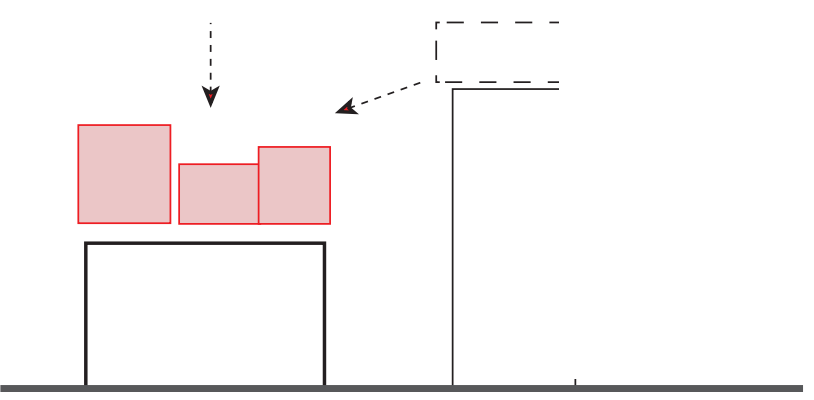

Pitch

A higher pitch will further cater for roof inhabitation and control views.

High pitch

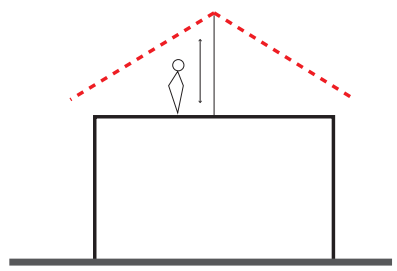

Angle

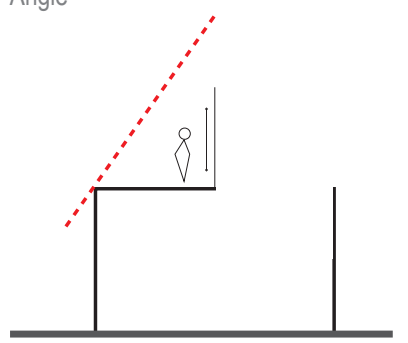

Displaced pitch and horizontals

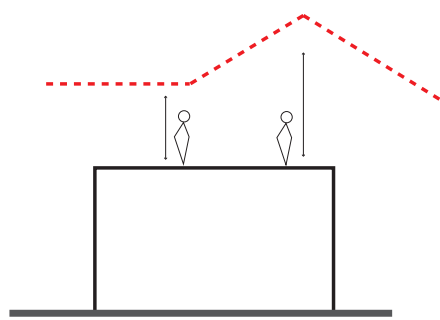




\section{Threshold}

Roof windows and openings placed within the roof planes will cater for view and light control
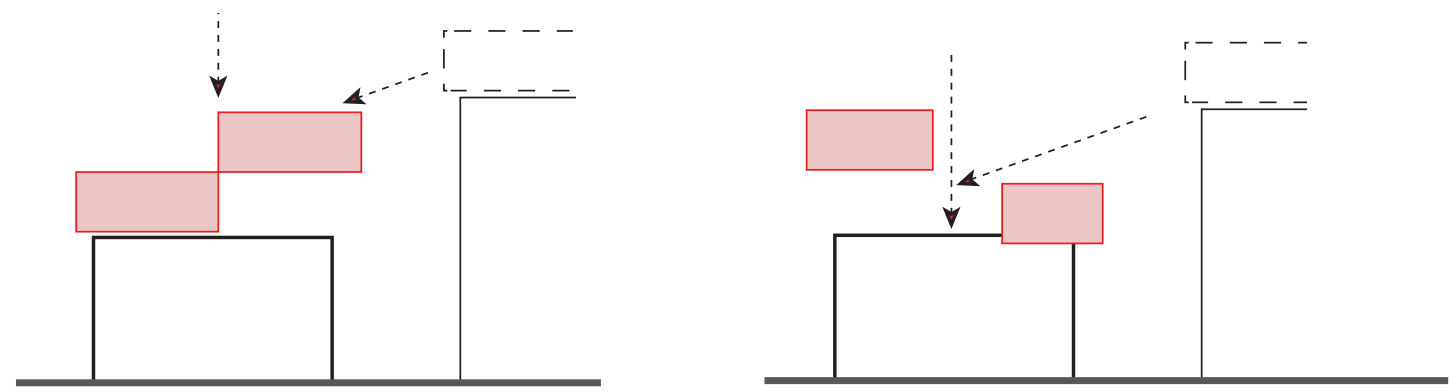

\section{Ridge}

A lengthened ridge will cater for the longitudinal qualities of the plan as well as additional elements such as carports and overhangs.
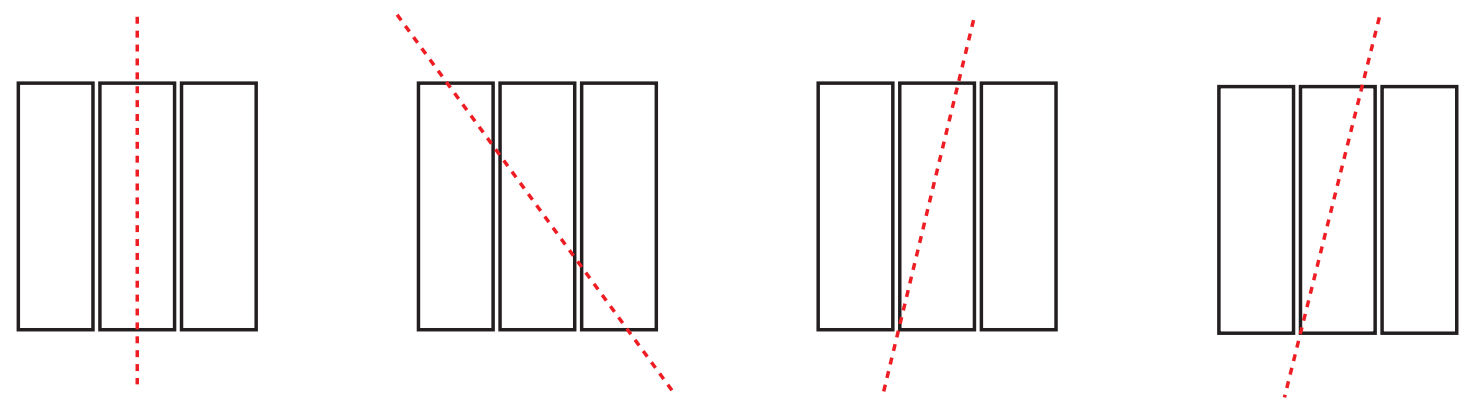

\section{Chapter Summary}

A roof today plays much more of an important role in the dwelling, as a horizontal facade to the ever encroaching outside world. As its importance grows, the roof needs to develop with society as the traditional villa plan has presented. This chapter has analysed the traditional aesthetics and construction of the roof.

The following chapter will now analyse the hierarchy of planning and external elements of the traditional villa through a contemporary lens. This will take into consideration the positive and negative attributes discussed in the earlier findings and attempt to present a contemporary set of principles that will allow remodelling to avoid being arbitrary and attempt to speak the same language as the traditional villa. Once a similar set of principles have been formulated in respect to the plan, a design can begin to implement both the roof and plan findings. 


\section{Contemporary Plan}

\section{Contemporary Planning Principles}

The hierarchy and planning of the traditional villa was based on a set of design strategies that functioned for the structured lifestyle of the Victorian society as analysed in Chapter 3. The primary planning principles and the secondary roof structure were identical in most villa's during the nineteenth century. The issue with facadism is that it focuses solely on the aesthetics. The structure and form of villa was not designed with aesthetics in mind. Aesthetics and individualism were achieved through further elements such as decoration and ornamentation. With the contemporary understanding of the roof already reviewed in the previous chapter, this chapter will focus on the spatial qualities of the traditional villa and how they can be reinterpreted into a contemporary lifestyle.

This chapter will refer back to the traditional analysis of the villa presented in Chapter 3. It will review the hierarchy and planning of the villa to develop a set of principles that explore how the traditional language of proportion, movement, public and private, horizontal and vertical form, room roles and threshold can be implemented through a contemporary lens. For the purpose of this experiment it will apply the principles to main living spaces associated with the Victorian villa and present alternative ways of using the spaces for a contemporary society. The principles will allow flexibility for different living situations, sites and clients. They will take into account the positive and negative findings sourced in Chapter 4.

\section{Proportion}

Traditionally proportion was a key element of the New Zealand Villa. The villa worked in a series of three transverse spaces across the width of the site. A central hallway to mediate the family and visitors in and around the house and rooms down either side. Proportion should still be respected today. A contemporary depiction of the villa should aim to determine a fixed transverse dimension on site and aim to work within three zones.
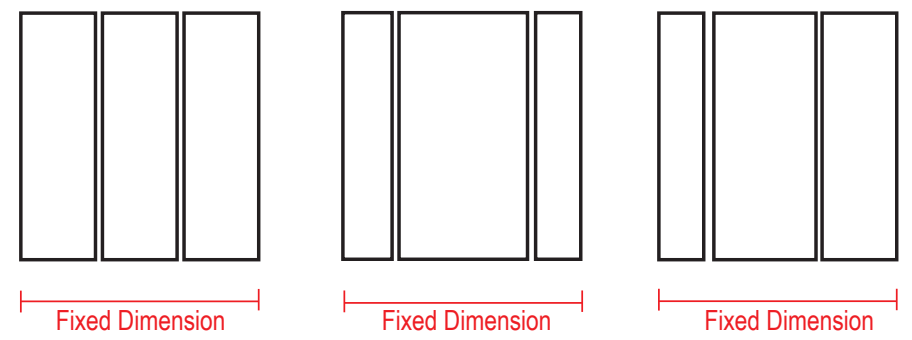

\section{Movement}

The key movement patterns of the traditional villa followed the series of three zones; the central zone being the hallway. This model allows for the same language of movement to be implemented without restraining the secondary movement to one space. The hallway as the mediation zone would today be equivalent to the living areas; kitchen, lounge, dining with the outer zones accommodating the private spaces. Refer back to Chapter 3 , movement patterns.

$\begin{array}{lll}\text { 1 Begin } & 2 \text { Mediate } & 3 \text { Destination } \\ \text { Entrance } & \text { Lounge } & \text { Bathroom } \\ \text { Outdoor } & \text { Hallway } & \text { Bedroom } \\ \text { Garden } & \text { Kitchen } & \text { Laundry } \\ \text { Garage } & \text { Dining } & \text { Office }\end{array}$

Top to Bottom: Fig $52-53$

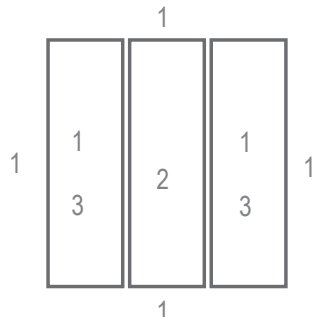

Plan

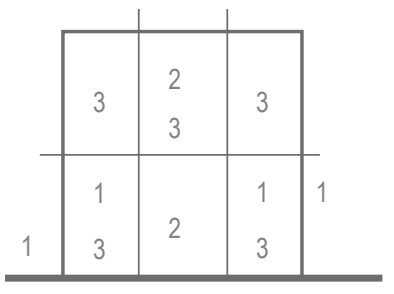

Elevation 


\section{Public and Private}

The public and private realm of a contemporary domestic dwelling is less formal than the traditional villa. Public spaces are associated with the living spaces therefore would be placed within the central mediation zone. The operational and private spaces would be placed to the outer zones with emphasis on vertical privacy within the dwelling. The three transverse zones allow the traditional language to be used whilst allowing the three zones to function for a contemporary unit.

$\begin{array}{lll}\text { A-Public } & \text { B - Operational } & \text { C - Private } \\ \text { Lounge } & \text { Hall way } & \text { Bathroom } \\ \text { Kitchen } & \text { Kitchen } & \text { Bedroom } \\ \text { Entrance } & \text { Office } & \text { Laundry } \\ \text { Exit } & \text { Kitchen } & \text { Office } \\ \text { Garden } & \text { Laundry } & \\ \text { Dining } & \text { Garage } & \\ \text { Outdoor } & & \end{array}$
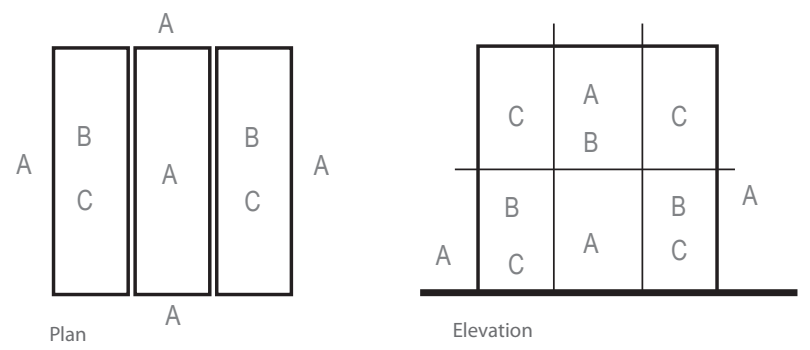

\section{Horizontal Form}

The traditional villa was allowed to adapt through a longitudinal extension of the front and back rooms. If we use this principal through both longitudinal and transverse paths we can generate new relationships which link internal spaces. This allows the transverse proportions to remain fixed and the front and back spaces flexibly to adapt to accommodate contemporary functions within a house.

Deduct externally

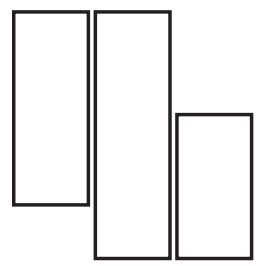

Deduct internally

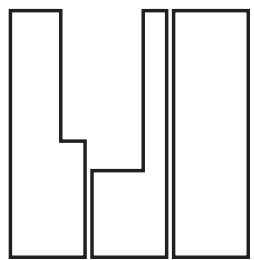

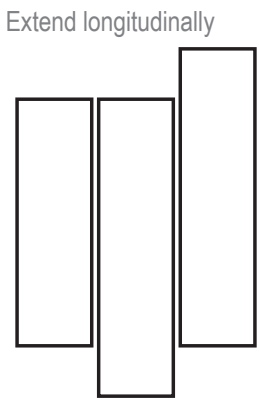

Merge

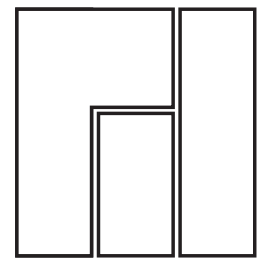

\section{Vertical form}

Traditional planning was restricted to merge the top into the bottom. Each level functioned on equal height systems. Vertical merging is an option which could further enhance the height and spatiality within the villa, forming new relationships both above and below the ground.

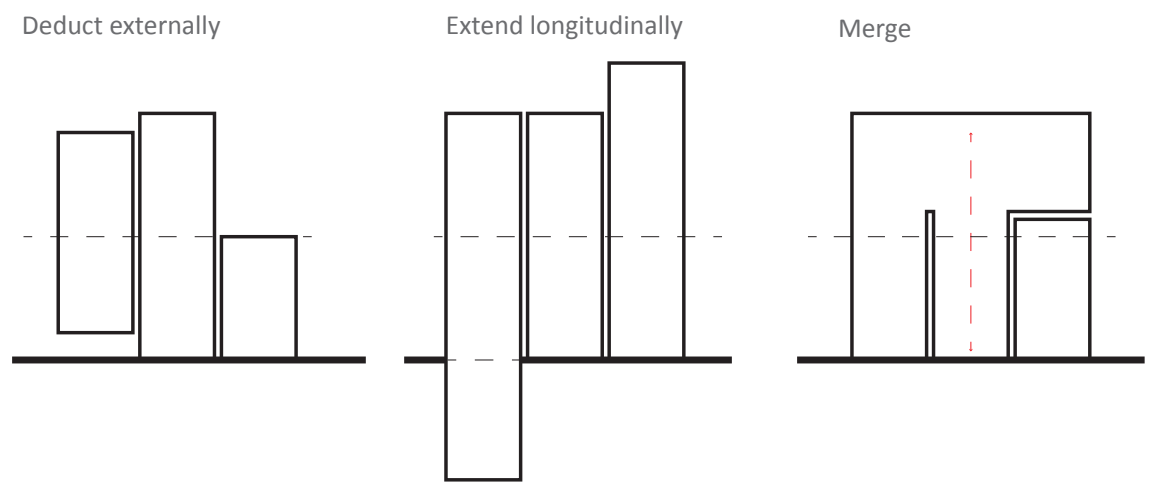




\section{Room Roles}

The traditional villa was separated into specific room roles. The room roles can now be looked at as spatial roles, allowing communication and movement between spaces.

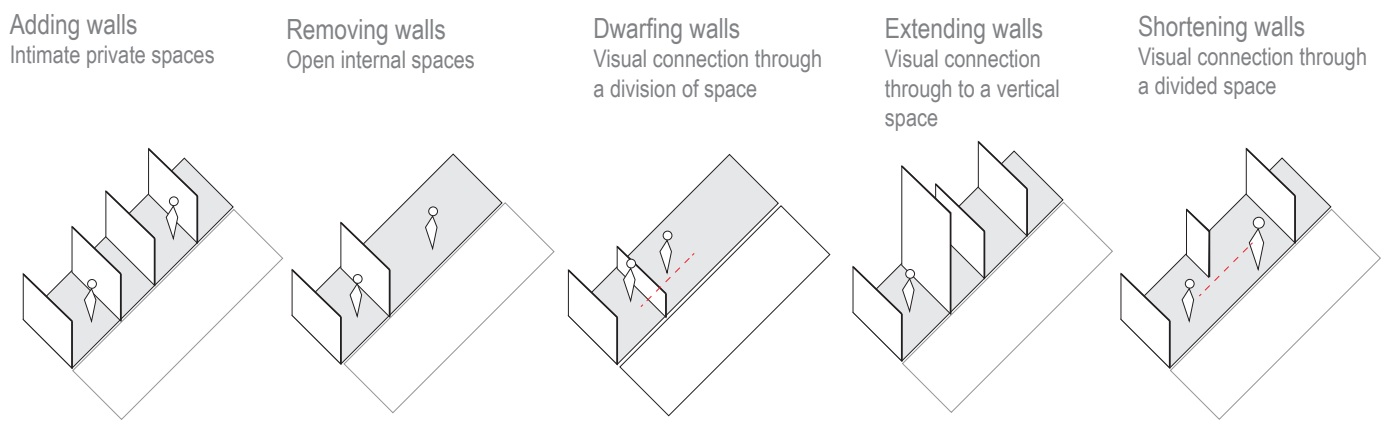

\section{Floor Placement}

Floor displacement of the traditional villa was primarily used to control the entrance in and out of the villa. This concept can be further extended within the internal plan of the dwelling to control the spatial planning of the contemporary family unit.
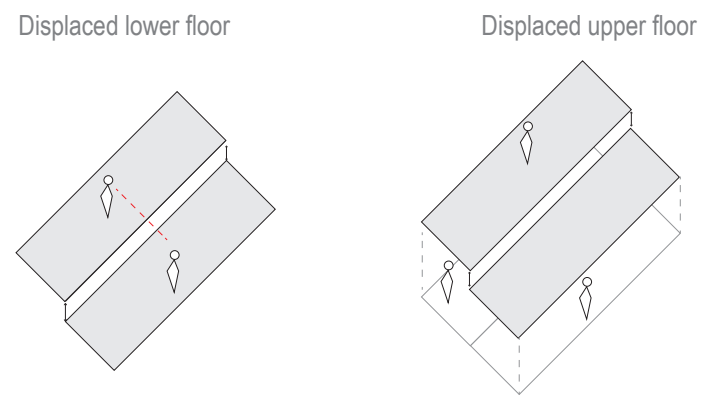

\section{Threshold}

The traditional thresholds were associated with room roles, entrance, exits, circulation and movement. Thresholds still hold a similar manner however can be used to control space both horizontally and vertically. They do not have to be subjected to access and departure points.
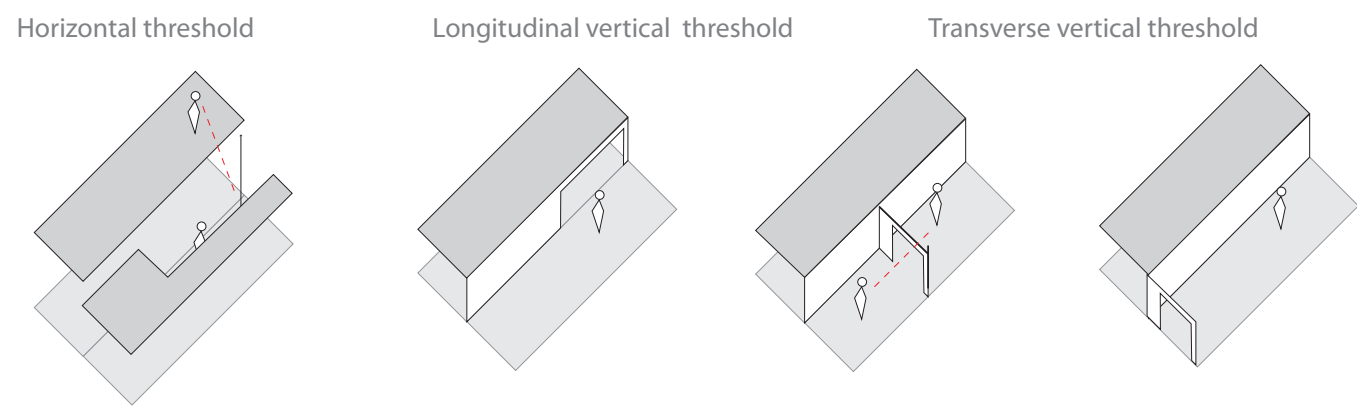
Kitchen

The kitchen in contemporary society has become a focal point of the house were the majority of activity happens. The kitchen is used by all members of the home therefore needs to be easily accessible. Fig 60

Placement

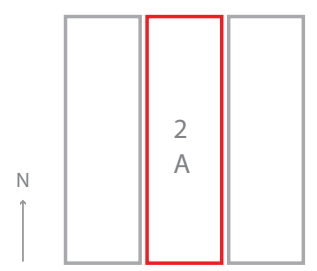

Plan

Horizontal form

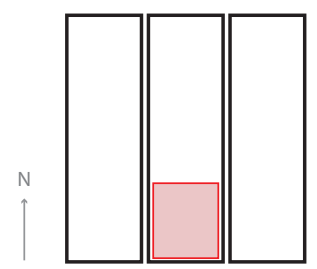

Kitchen centrally placed on the south would allow other living spaces to benefit more from the sun.

Vertical form

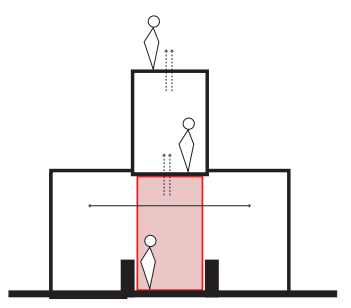

Private space placed above kitchen to benefit from heat rise. Kitchen made focal point, public living spaces either side for communication

Floor placement

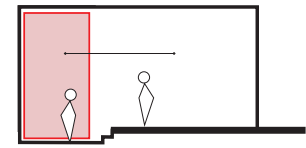

Lowering the floor level allows communication between two spaces and increases the ceiling height of the space.

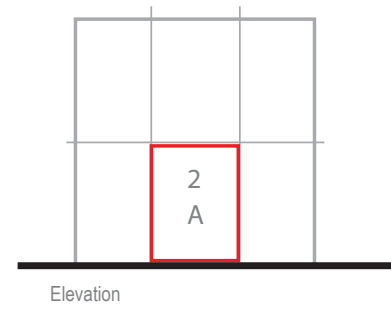

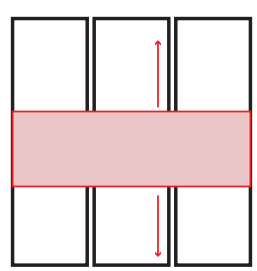

Kitchen passing through the three transverse sections to be a focal point in the house.

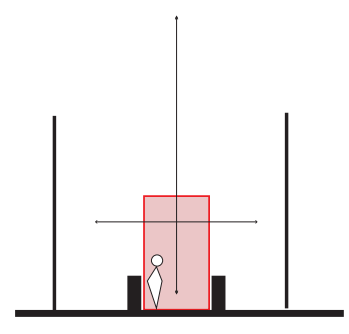

Double height space allows the kitchen to appear as a focal point in the house and have a wider presence in the dwelling. would allow the space

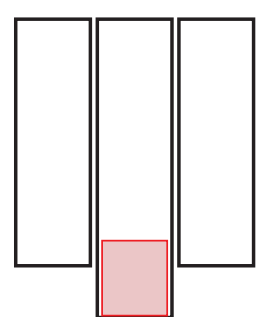

Extending the kitchen beyond the private spaces allows it's presence to be noticed and provides exterior connections.

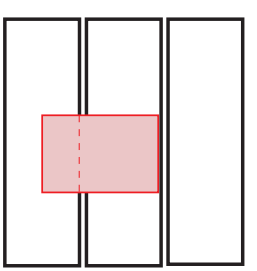

Extending the kitchen into the private realm allows for preparation zones to be introduced.

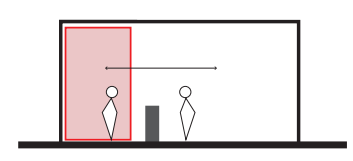

Kitchen and living space creates spatial roles oppose to room roles. Division created through dwarfed wall or kitchen furniture.

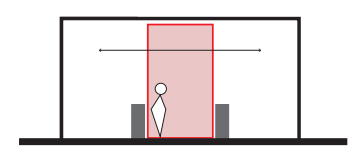

Kitchen centrally placed allows the kitchen to provide communication either side.
Threshold

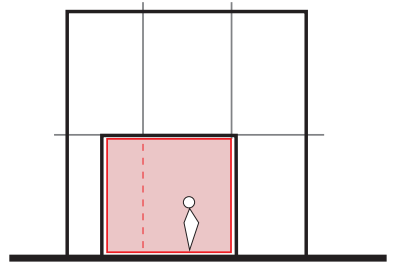

Extending the kitchen into the private realm of the home will allow for the kitchen to have private space for preparation and public for presentation.

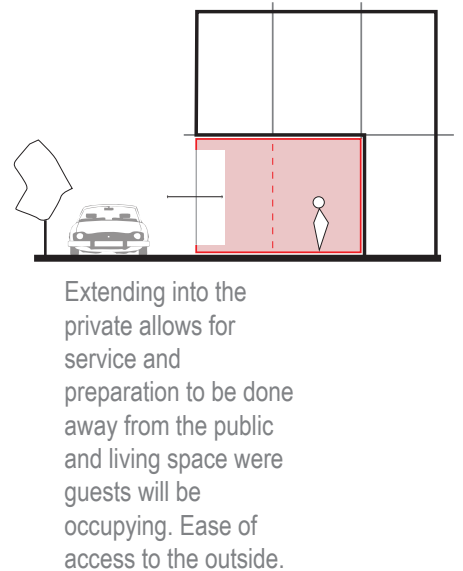




\section{Living Room}

The contemporary living room is the most social space of the domestic home. It is often the most occupied space and the zone that all visitors occupy. Connection to outside living and sun is desired along with a connection to other rooms both horizontally and vertically. The living zone needs to cater for the relaxation of every member of a contemporary family. Fig 61

Placement

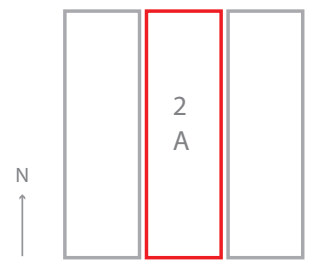

Plan

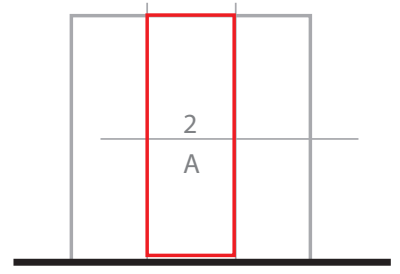

Elevation

Horizontal form

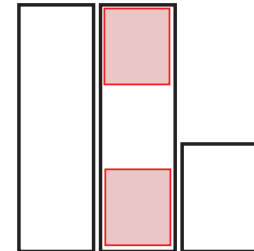

Split living allows both public and private spaces to be created.

Vertical form / floor displacement

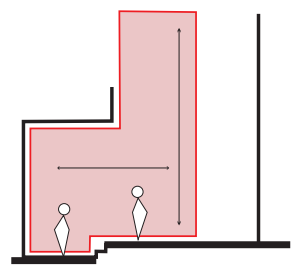

Having both an intimate and open plan element allows for two functions to happen within one zone. This further creates a vertical link within the dwelling.

Threshold

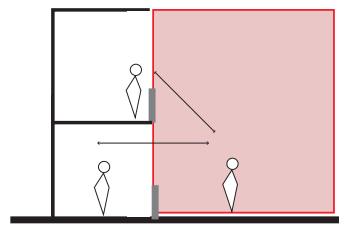

Double height space will emphasis the height of the traditional and allow the living space to function on more than one level of the home. Internal thresholds will allow connection through different spaces

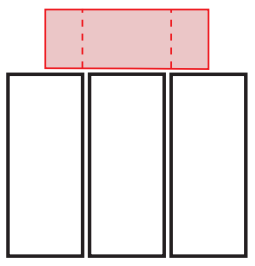

Extending the living space into the private realm will allow for intimate spaces to be created. This could

provide evening spaces with technology.

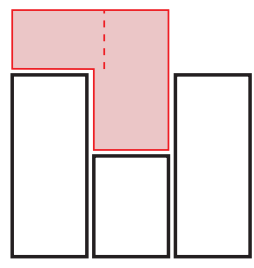

This form creates a dead end space, that responds to the parlour. This would often be the furthest guest made into the traditonal villa.

Wall form

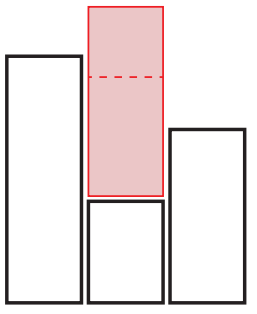

Extending the living room past the private zones allows for the space to open from all sides whilst creating a closed isolated space.

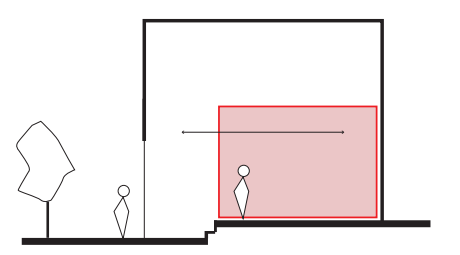

Displacing the floor above the front door gives the internal space power over the entrance space.

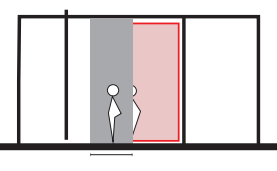

Shortening the transverse width of walls allows the space to function as one with a division for separate functions.

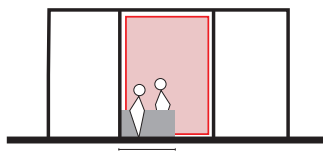

Dwarfing and shortening allows a subtle division between spaces. Having both visual and physical connection.

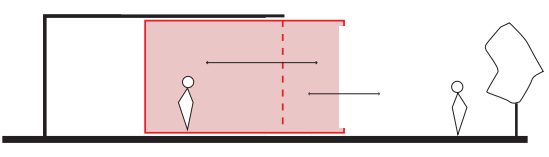

Extending the living space beyond the private realm allow for it to be removed from the dwelling whist still attached. External thresholds to the back of the home allow the threshold to be greater if the back of the home is turned away from the public eye. 


\section{Bathroom}

The traditional bathrooms were suppressed to the back of the home; the space with the least attention. The notion of the bathroom today can be challenged through introducing multiple bathrooms to cater for individual needs and privacy. Fig 62

Placement

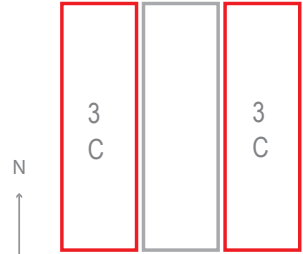

Plan

Horizontal form

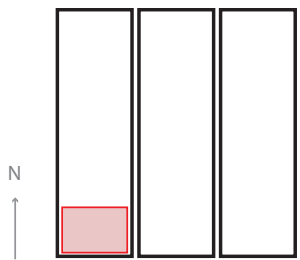

Having the bathroom placed in the south end of the home allows for other spaces to benefit from the sun.

Vertical form / floor displacement

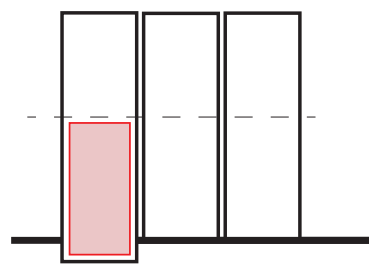

Sinking the bathroom into the ground could allow more emphasis to be placed on the bathing activities within the bathroom.
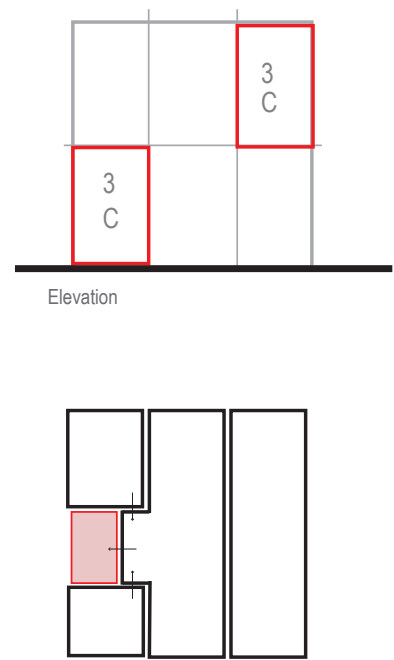

Deducting internally and merging functions would allow the living zone to provide access to the bathroom while providing a semi public mediation space.

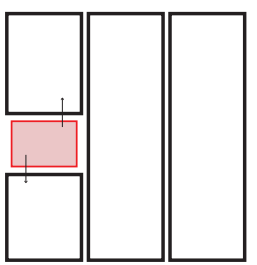

Shared bathroom. This could provide a link between rooms when the bathroom does not need to be directly linked to the living zone.

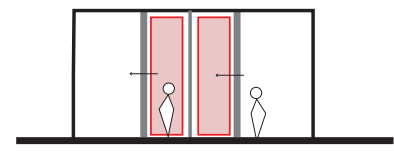

Added walls can be used within the bathroom space to creates intimate spaces and caters for two occupants

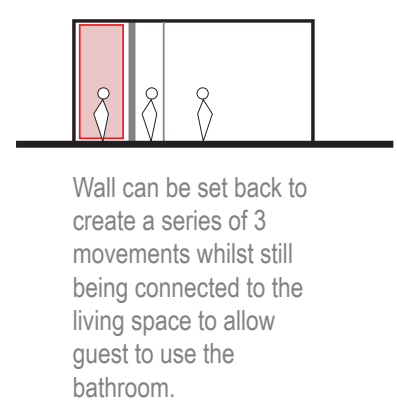

Threshold
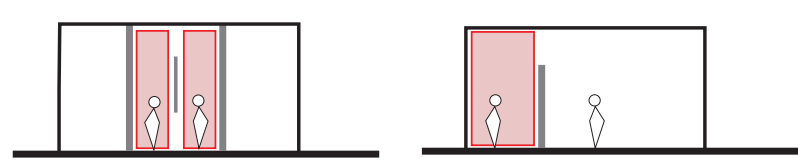

Internal thresholds used within the bathroom can divide the space whilst make it one zone. Internal thresholds opened up into the wider zones of the dwelling allows one vertical movement pattern in the space but divides the spaces into two. The bathroom become recognised as a independent zone in the house.

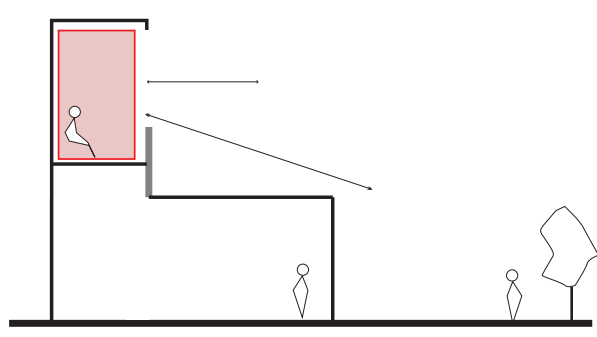

Double height space will link the height of the traditional villa and allow the living space to function on more than one level of the home. 


\section{Bedroom}

The bedroom still functions the same today as it did in the traditional villa. Today a bedroom is used for more than a sleeping function. The desire for a bedroom to have sun is a quality that should be considered. Fig 63

Placement

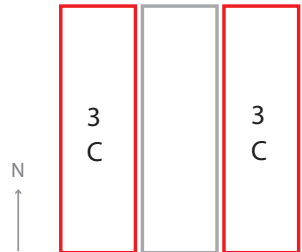

Plan

Horizontal form

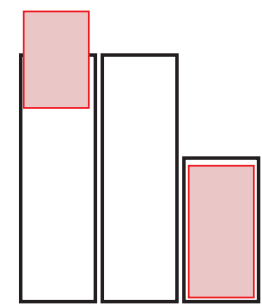

The bedrooms would function best on the north end of the plan to utilise the sun. Options of subtracting the room back allows it to get sun put not dominate the north edge.

Vertical form

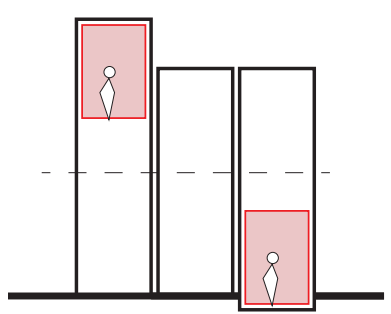

Extending vertically will allow more height in the space. Extending below will create a isolation space.

Wall form

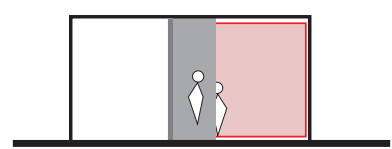

Shortening the transverse walls allows spaces in the room to be divided whilst still connected.
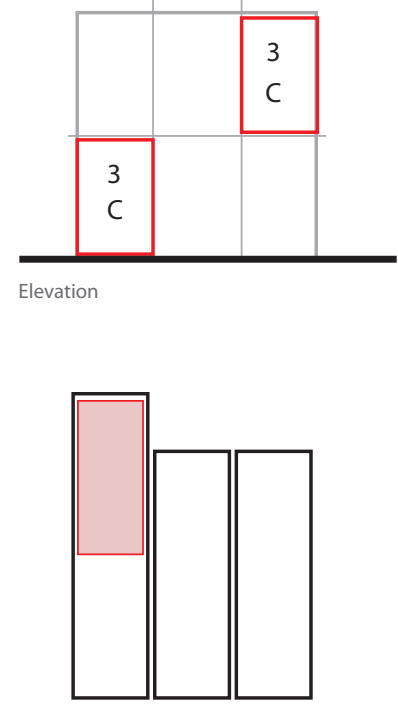

Extending the bedroom past the body of the home allows for

isolation within the

room to be created

whilst providing

connection to the rest

of the home.

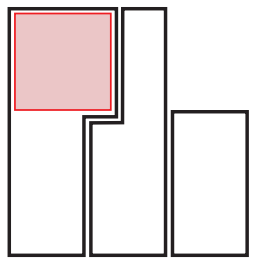

Merging the bedroom into the public realm will provide a

connection to the living

spaces whilst still

being confined by partitions.

Floor displacement

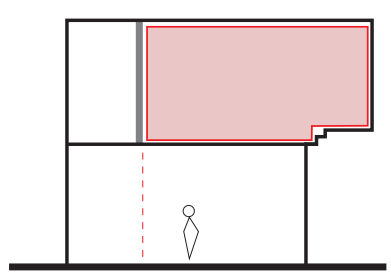

Having a part of the

bedroom displaced vertically

allows the space to have

multiple zones.

Threshold

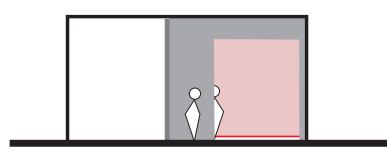

A threshold within the

space allows for two

zones to be created. A

threshold frames the

movement between

spaces whereas a

shortened wall opens up

the roof line. 


\section{Dining Room}

Today there is more emphasis on the dining space having access to the outside and sun. Allowing visual and physical contact between the kitchen and the dining space increases communication. Fig 64

\section{Placement}

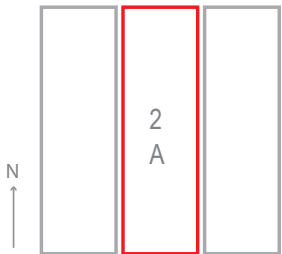

Plan

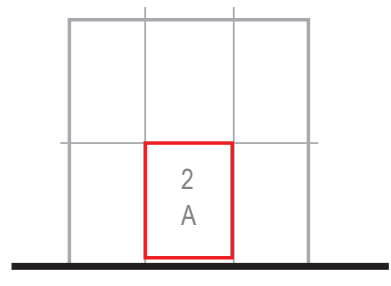

Elevation

Horizontal form

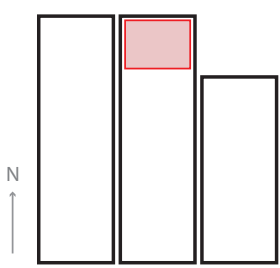

Dining room placed in north of the dwelling creates an option for sun and outdoor connection.

Vertical form / floor displacement

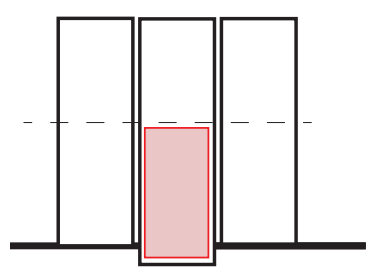

Sinking the dining space below ground level will provide a shift in scale, allowing the space to function as a separate zone.

Wall form

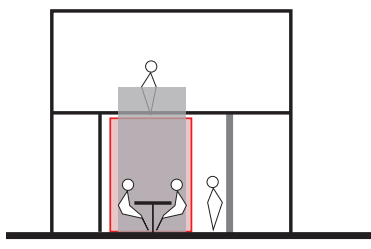

Creating a vertical link allows the dining space to be observed from other spaces in the home increasing the communication

between spaces.

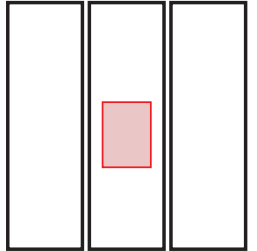

Dining in the centre of the home provides a barrier between other rooms and a central communal space.
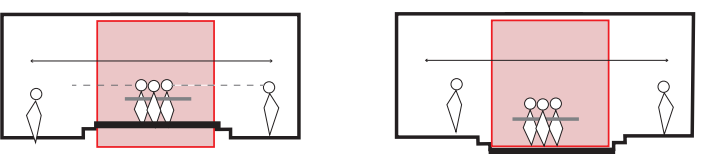

When you sink the floor it makes the zone appear more sacred as everyone looks down into it. Raising the floor above ground level allows the people sitting to have the same eye level as the residents standing in other zones.

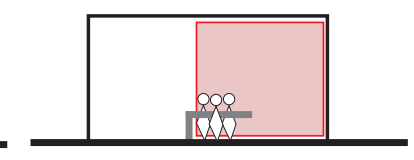

Opportunity for the wall to divide space and function for dining activities.
Threshold

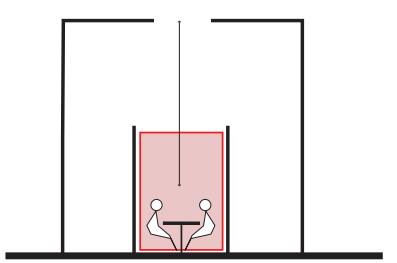

Providing a threshold directly above the space allows for direct sun to enter the dining area and opens up the dwelling space. 


\section{Verandah}

The verandah today would be equivalent to the deck or balcony. This would often be placed on the north end of the dwelling to provide sun and access to outdoor spaces. Fig 65

Placement
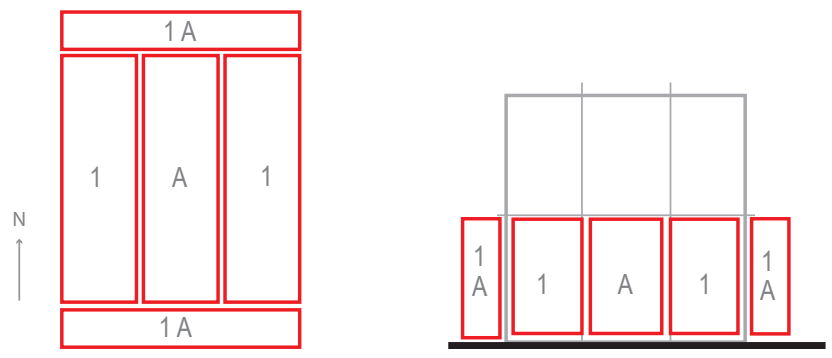

Horizontal form

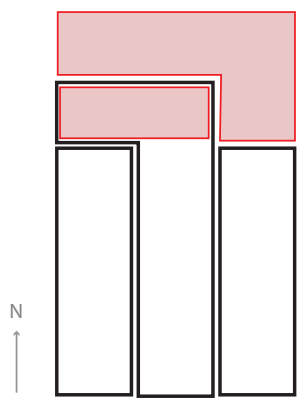

Creating an indoor and outdoor verandah on the northern face of the building allows for the sun to penetrate though and internal space whilst allows

occupation within the outside zone. This could be in the public or private end of the building depending on orientation.

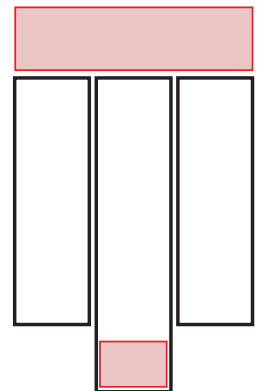

An indoor verandah can cater for security issues allowing entrance into the space to be internal with the ability to view out. This would work well on the southern end of the building

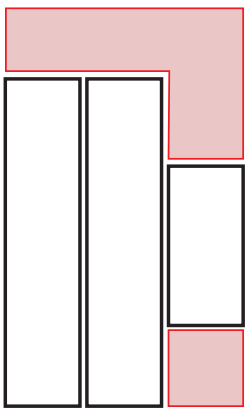

Deducting from the building and wrapping verandah space around the dwelling allows a area to open into the central living zone. The outdoor can be

occupied and the

internal can view out

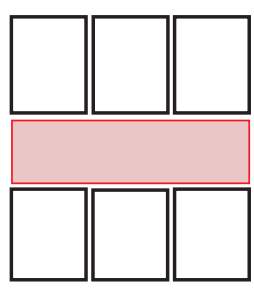

The verandah as a central space in the dwelling. This could function in a situation were a division between two spaces is required for client needs.

Threshold

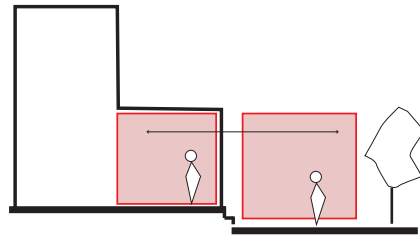

This creates an opportunity to have a internal verandah mixed with an external outdoor space. The internal space is risen above the exterior to create a visual and physical division.

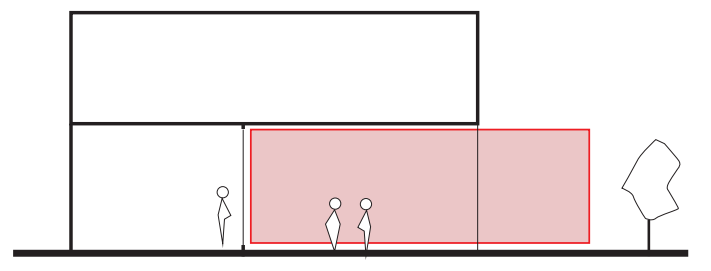

Having the verandah placed down the

side of the dwelling could have a

relationship with the internal spaces. 
Traditionally the hallway was the mediation zone. Equivalent to this today would be the living zones of the home. The hallway can still play a role in a contemporary home through connecting the living to the private spaces. There is no longer a need for it to be as formal as the traditional villa. Informal hallways can be created through an open plan design. Fig 66

Placement

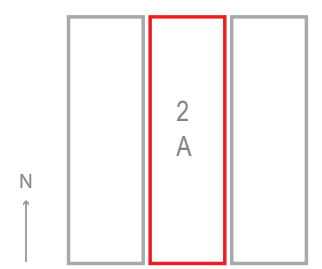

Horizontal form

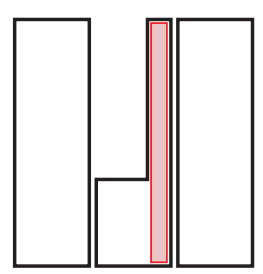

Vertical form / floor displacement

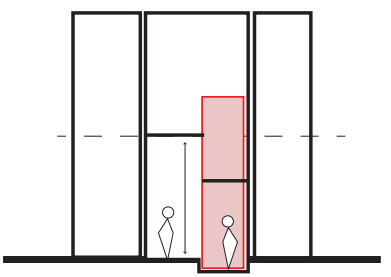

A level change will allow the perceived entrance and hall way of the dwelling to become more intimate whist still

function in the public

realm as vertical living.
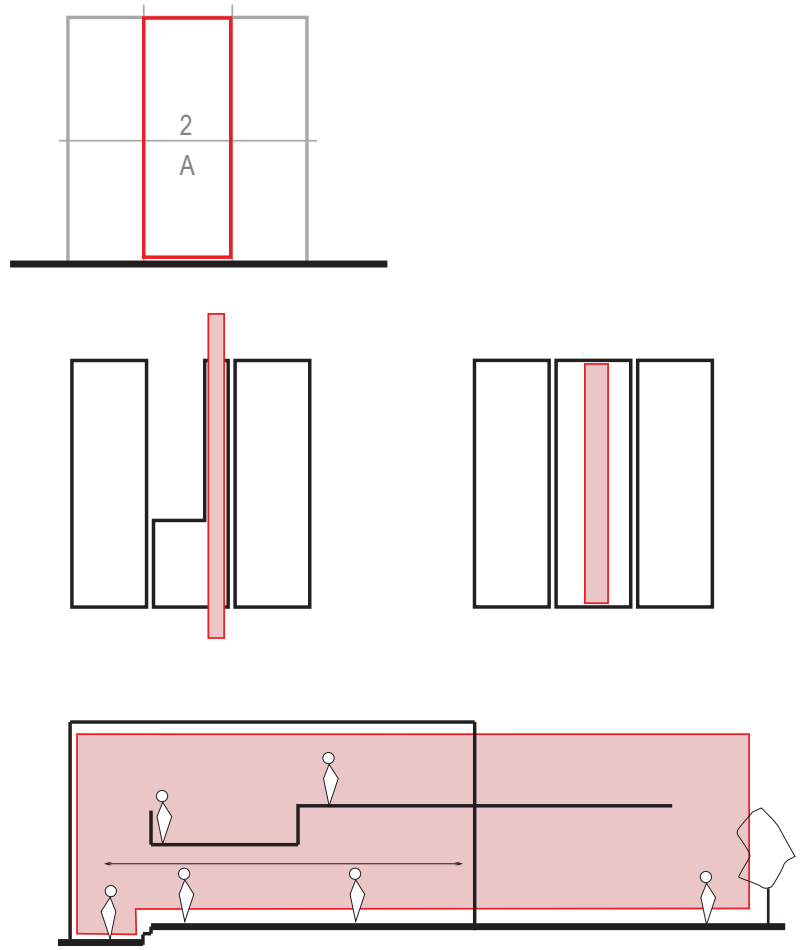

Using a vertical hierarchy within the hall way zone will allow the circulation to function through different floor planes. This creates a notion of the hallway whilst avoiding the boundary.

Wall form
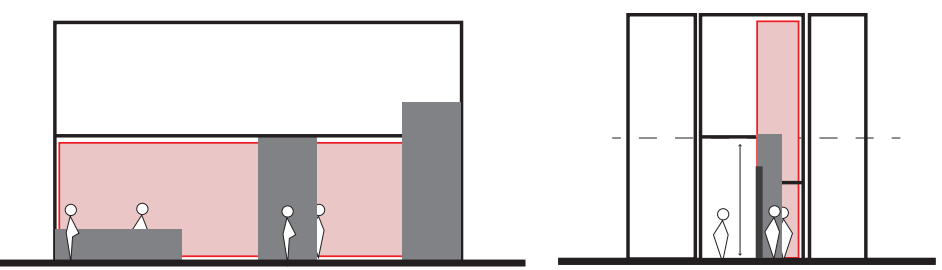

Walls can frame a space without confining it. The use of dwarfed walls mixed with height changes allow for vision and views to be changed whilst passing though a space.

Thresholds

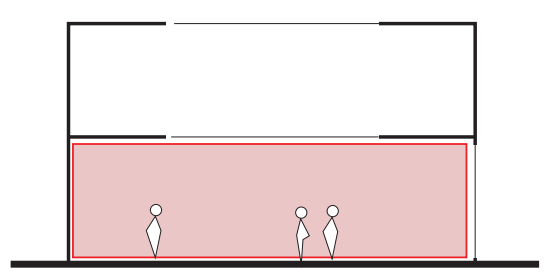

The use of thresholds beside and above the hallway can give power to the space allowing natural light to filter in and again frame the passage. This method opposes the use of walls to frame the space. 


\section{Bay window}

The bay window was a prominent feature of the villa. It provided both an indoor and outdoor connection as well as security through its large angled windows. The notion of the bay window would still function well for a contemporary dwelling as a light mechanism that could still embody the formal extension out. Fig 67

Placement

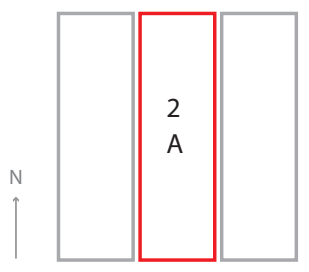

Horizontal form

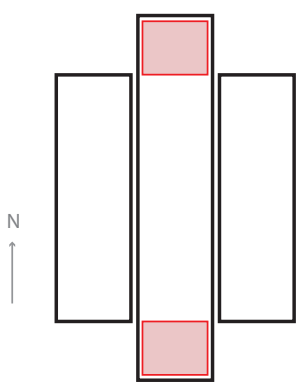

Extending beyond the building to provide different functions in the south and north end of the dwelling.

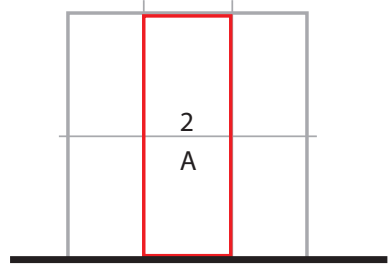

Vertical form/floor displacement

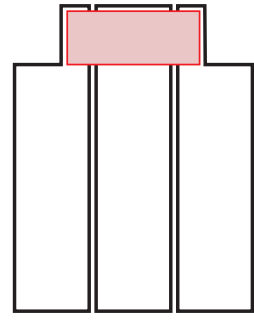

Extend beyond the public space of the home into the private realm. Intimacy and communal opportunities can be created within one zone.

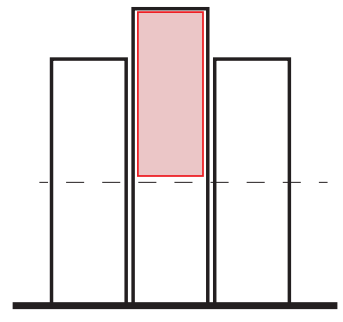

The bay window can be challenged through a vertical shift to provided a higher view.

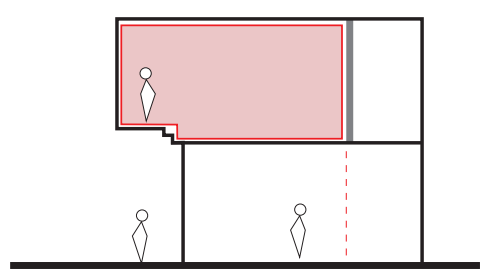

Displacement allows views from above. This allows the same notion of the Bay window to be created through a new method.

Fire place

The fire place is no longer a necessity of the home; however, it is still often valued as an important quality of the home. The use of multiple fire places can still be an option in contemporary home. Fig 68

Fireplace

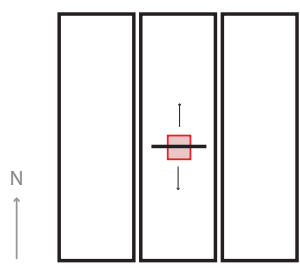

Having the fireplace central to plan can become the hearth of the home

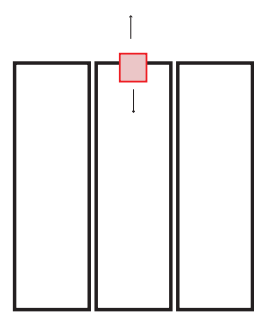

One fire place to function for two spaces, one internal and the other external.

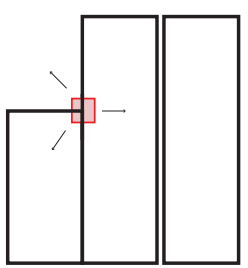

One fireplace to function for 3 spaces, two internals and one external.

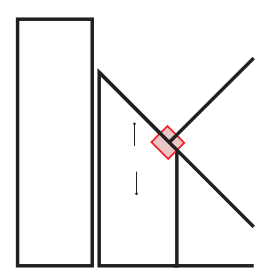

The placement of the fire place can influence the shape of the floor plates and rooms

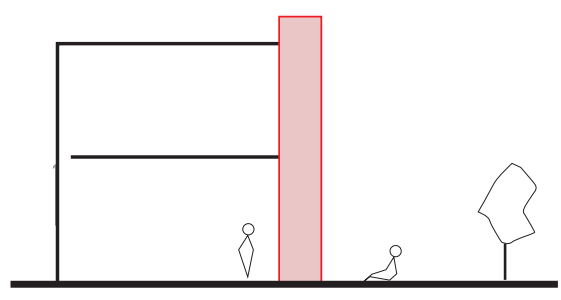

Making the fireplace a prominent feature in the home can provide opportunities for aesthetics and functional value. 


\section{Garden}

Contemporary gardens appear to embody the majority of the surrounding site; gardens no longer need to maintain the hierarchy that was present in the traditional villa. A contemporary garden has a role in the horizontal facade as it is viewed from above. Fig 69

Garden
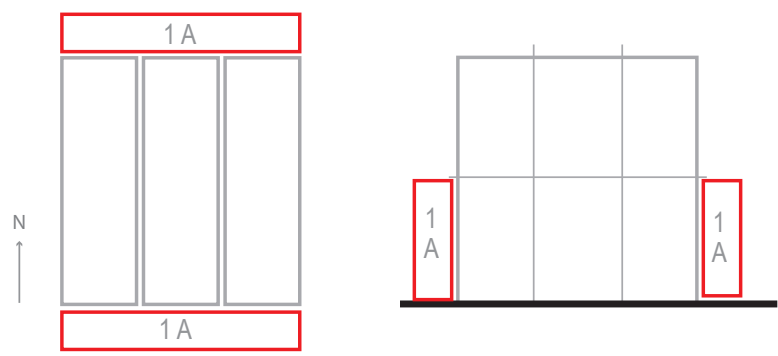

The garden will be best poisiton close to the home around the exterior perimeter. It will have many possibilites depending on site.

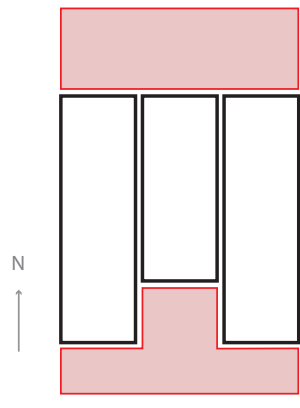

The building could deduct to accommodate the garden space moving into the dwelling to create an entrance point.

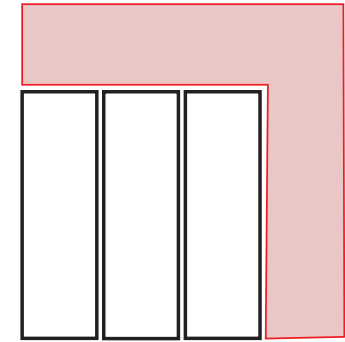

Having the garden wrap around the north edge and the side of the dwelling allows for movement around the dwelling to be creaed.

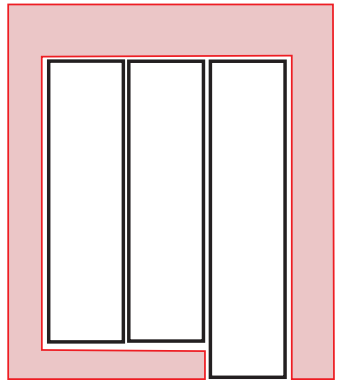

The garden has the ability to wrap around the entire dwelling. This allows the building to function the more than just the front and back

\section{Chapter Summary}

The principles presented in this chapter and the translations of traditional rooms of the villa into contemporary spaces helps to visualise the connection between the past and the present. Contemporary architecture can still display elements of the past whilst functioning for a new occupation. The following will put the principles to practice. It will test the principles through the design of a contemporary villa testing both traditional as well as contemporary planning techniques. 


\section{Section Three}

\section{A 'non frontal' villa}

Section Three: 'A non frontal villa' will develop the design phase. Chapter 8 will test the roof and planning principals on three different sites in the Wellington Central area. It will develop three 1:200 conceptual designs suited to each site and further go no to develop the Oak Avenue site. The development will experiment through various scale and forms. Chapter 8 will present a contemporary villa based on the spatial and occupational attributes associated with the traditional villa. The design will act as a prototype to present how the social aspects linked to the traditional villa can be read through a contemporary language.

The Principle Test | The Contemporary Villa 


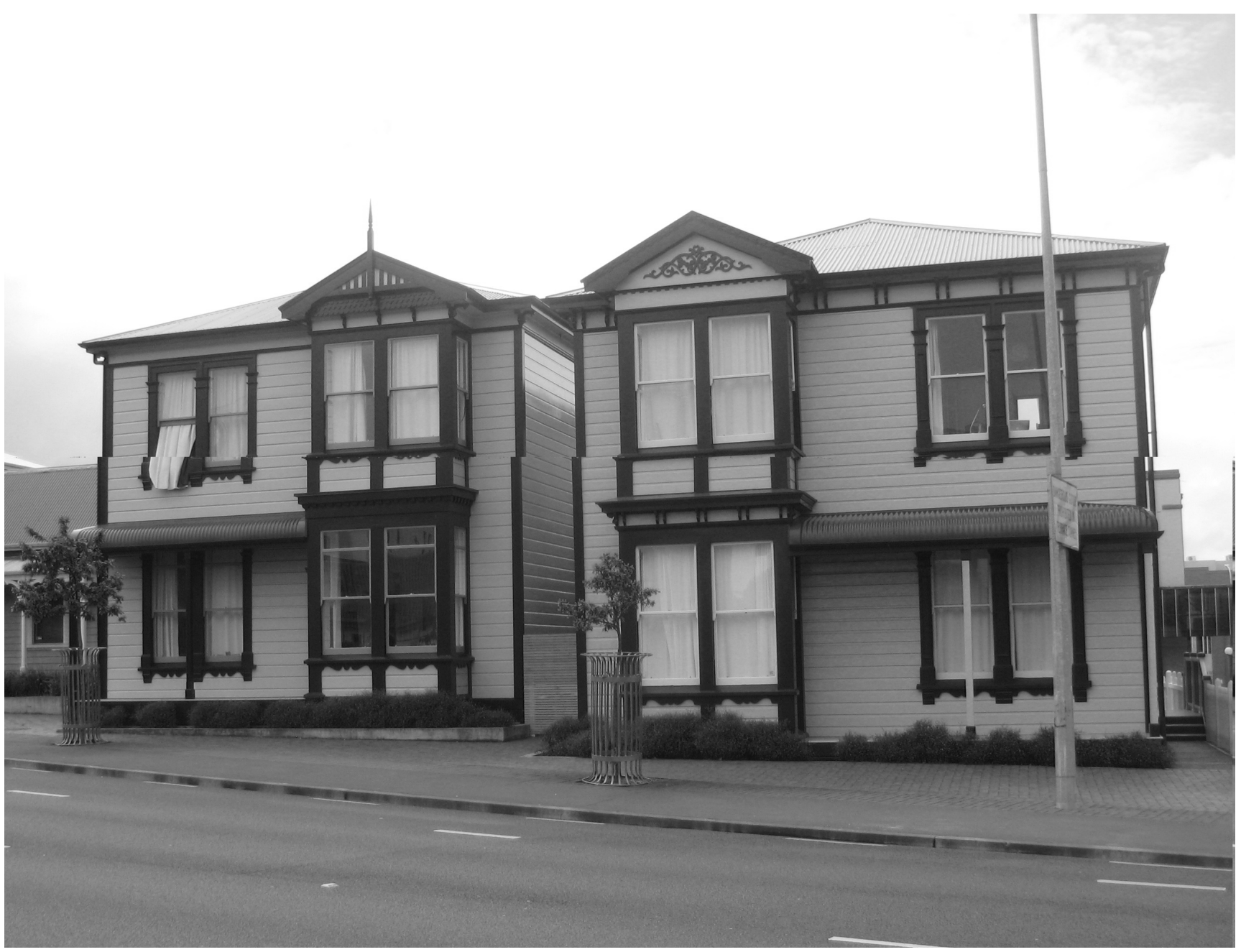

Fig 70: Arthur Street, Wellington. Relocated and Restored villas of the Tonks Road, Wellington Inner City Bypass project.

56 Section Three - A 'Non Frontal' Villa 


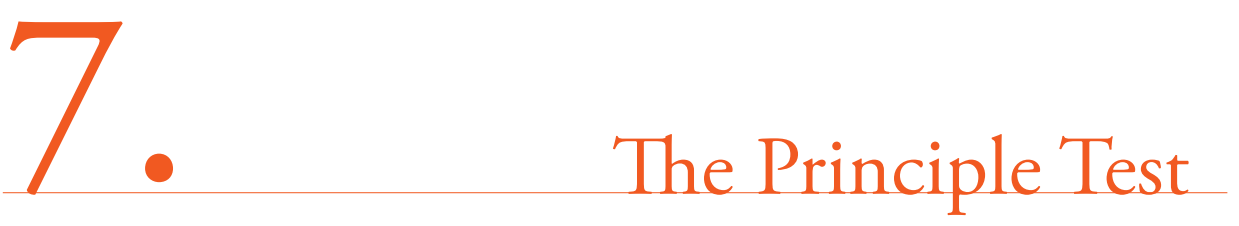

Iteration one will aim to test the roof and planning principles on 3 different sites within the Wellington Central area. The aim of this experiment is to present a conceptual plan of the most suitable position for the generic spaces of the traditional villa, integrated with the roof principles generated in Chapter 5 and Chapter 6. The 3 sites are a part of the Tonk's Road relocation and restoration project. The conceptual designs will relate to the site's proportion, sun and orientation to the street.

\section{Tonk's Road}

In 2005 seventeen historic buildings were relocated as part of the New Zealand Transport Agency's Wellington Inner City Bypass Project. These buildings occupied the original Tonk's Avenue and were relocated $30 \mathrm{~m}$ north east of their position to new sites in order to make way for new Inner City Bypass. The villa's were either restored from their neglected condition or demolished and rebuilt as exact replicas of the original. Through facadism an exterior depiction of the villa was achieved; the interiors of these buildings remain empty for new occupants to renovate freely;

6 The villa's have become vacant, vandalised and looted for the past 2 years and are slowing being sold and occupied. this has resulted in an idealised development, out of place and unrealistic. For the scope of this thesis this project will not be discussed in further depth. As a site generator, it offers a perfect opportunity for the restored and rebuilt villa's to have been re-developed to fit their new context and the contemporary lifestyle. The design phase will aim to test what could have been implemented on the new sites instead of reproduced villa shells.

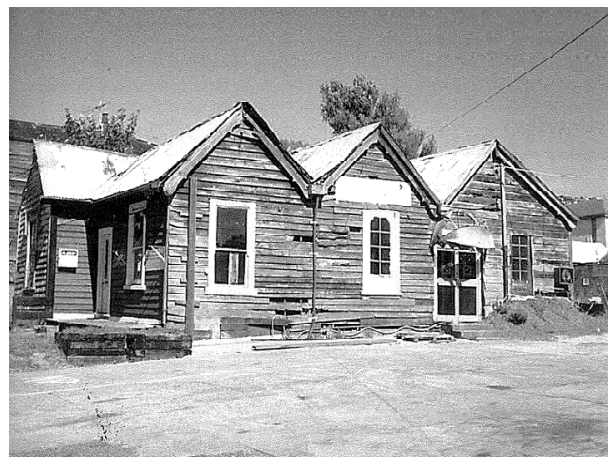

Fig 71: No. 270 Tonks Road villa in neglected state prior to relocation [Photograph: Gary Tonk's].

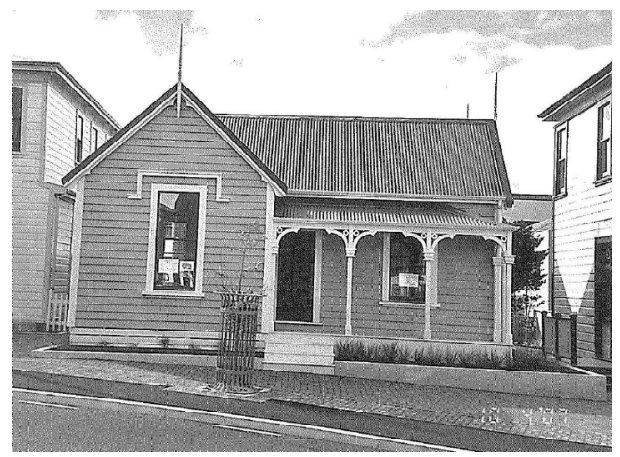

Fig 72: No. 270 Reconstruction and Relocated to become No. 17 Kensington Street [Photograph: Gary Tonks]. 
Site one:

268 Cuba Street is a long narrow site. The New Tonk's Road occupies the south edge of the site with a panel beaters and large car park on the north edge. The front of the site is placed in line with pedestrian movement down Cuba Street providing an opportunity for enhanced connection with the street.

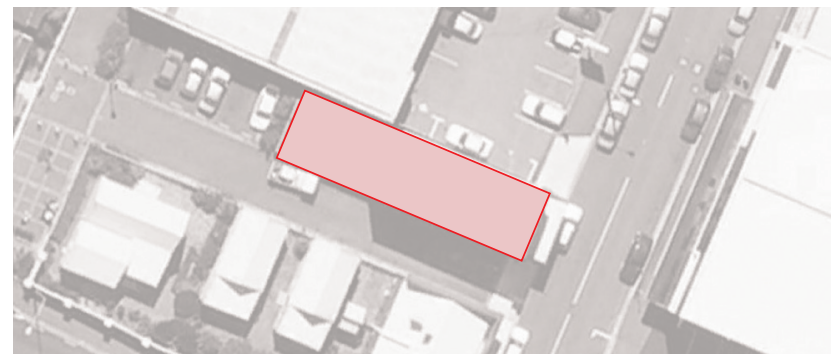

Fig 73: Aerial View, 268 Cuba Street [Google Earth]

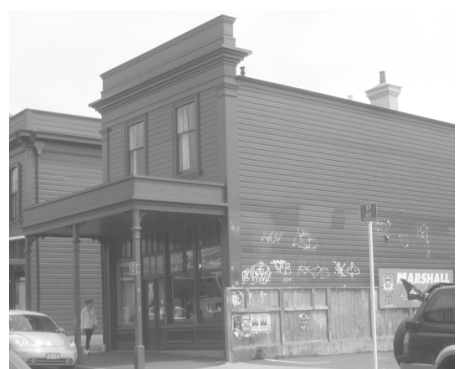

Fig 74: Existing restored villa.

Site two:

Oak Avenue is the largest of the three sites. The main axis is orientated towards the west and east edge, and parallel to the main pedestrian route. The house has three main facades visible to the public; the west facade facilitating as the most private.

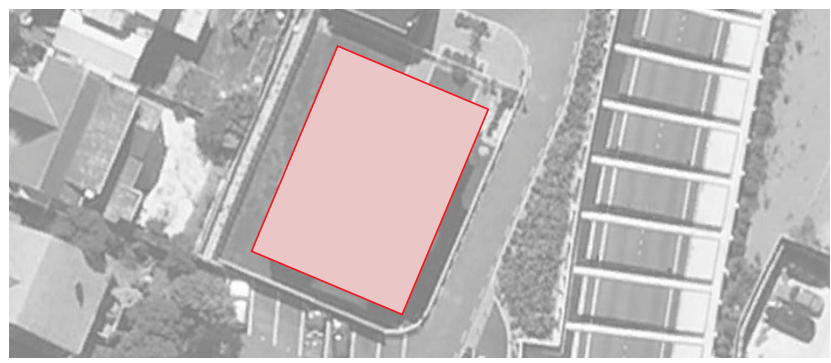

Fig 75: Aerial View, Oak Avenue [Google Earth].

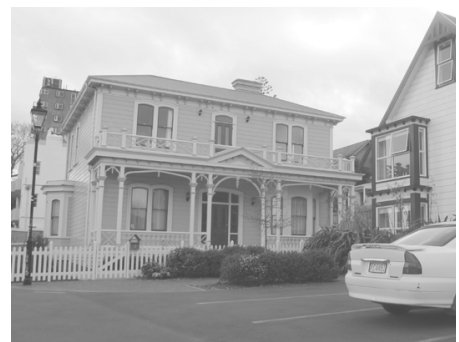

Fig 76: Existing restored villa.

Site three

12 Arthur Street faces out on to both the bypass edge and the inner edge of the New Tonk's road. The south end is parallel with the bypass providing design opportunities on the north end of the dwelling.

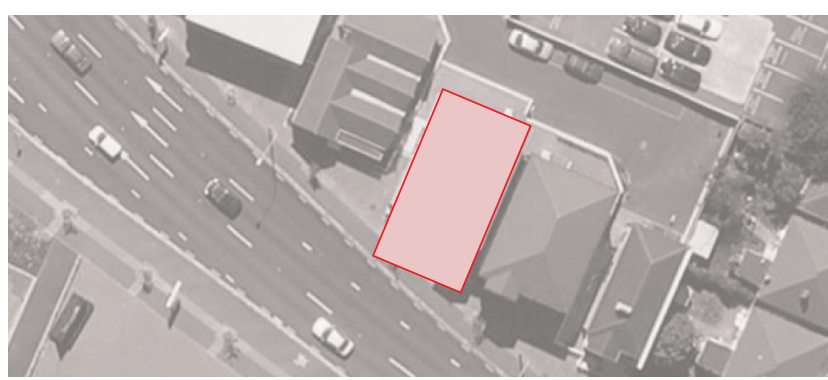

Fig 77: Aerial View, 12 Arthur Street [Google Earth].

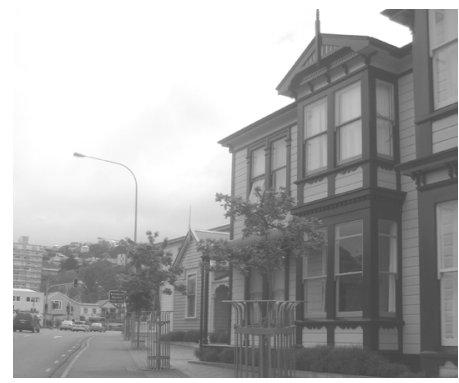

Fig 78: Existing restored villa.

The implementation of the contemporary principles begins with reviewing the site in plan to determine the orientation to north and the most suitable fixed proportion for the width of the site. The degree at which each plan of the sites has been developed will present a conceptual option as to how the conventional rooms of the traditional villa - the kitchen/ living/ dining/ bedroom/bathroom/hallway and garden could be placed on site. Spatial diagrams have initially been done as an experiment to determine the best position for the generic spaces of the villa relative to site dimensions, proportions, sun, roads and neighbouring buildings.

A conceptual plan has further been designed for each site to implement the spatial diagrams and the design principles proposed in Chapter 5 and 6 . The conceptual roof in the designs aims to test the roof principles manipulating the shapes that would have originally created a gable roof on site to fit best for site. The roof aims to encapsulate the three dimensionality of the site and aims to cater for the immediate site conditions. It tests thresholds and angles for view and light control and gives attention to the horizontal view from above. Physical models were made alongside the plans to address scale, orientation and the roof at a conceptual level. 


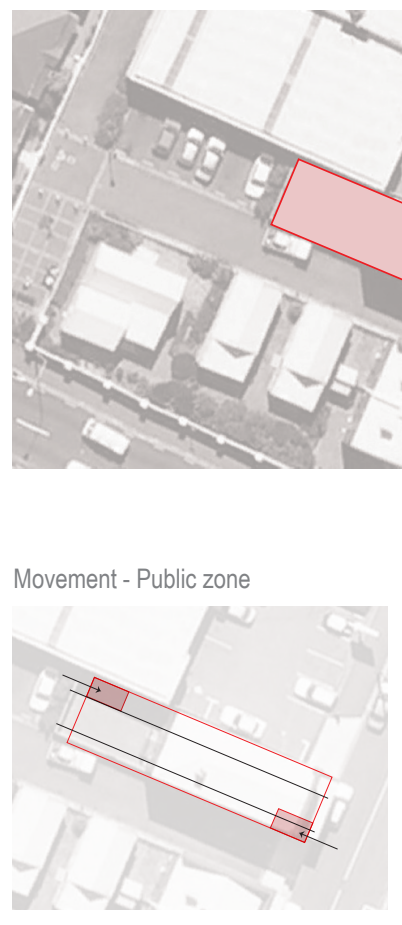

Entrance

Movement - Operational

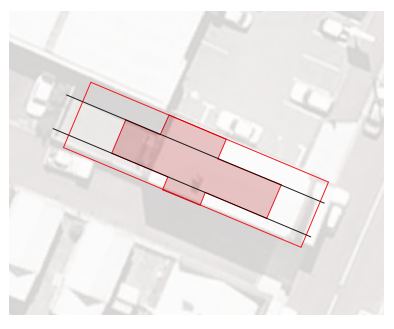

Living

\section{Movement/ Private}

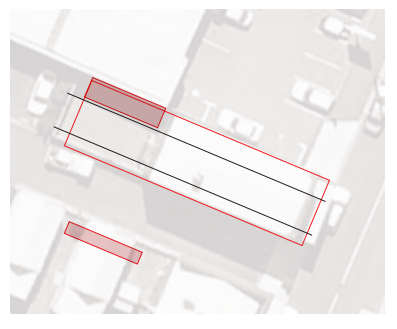

Bathroom

Roof Patterns

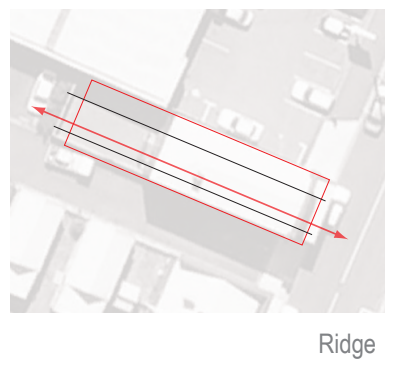

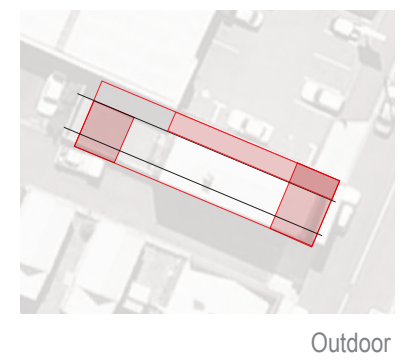

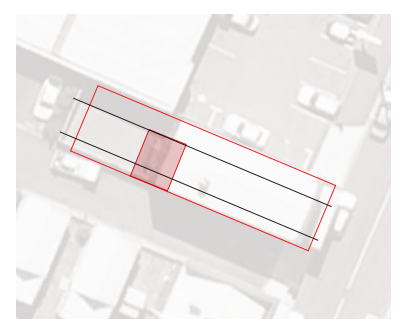

Kitchen

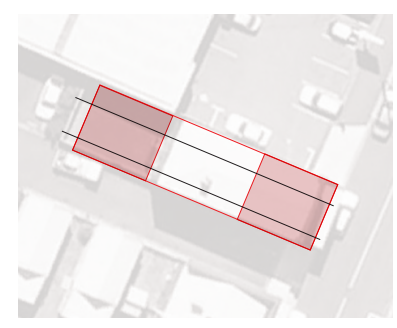

Bedroom

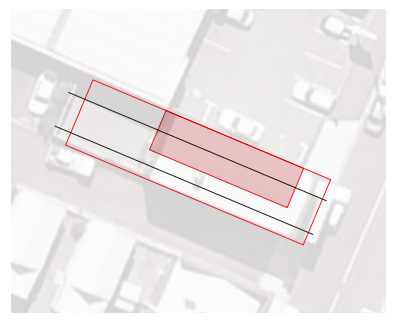

Threshold
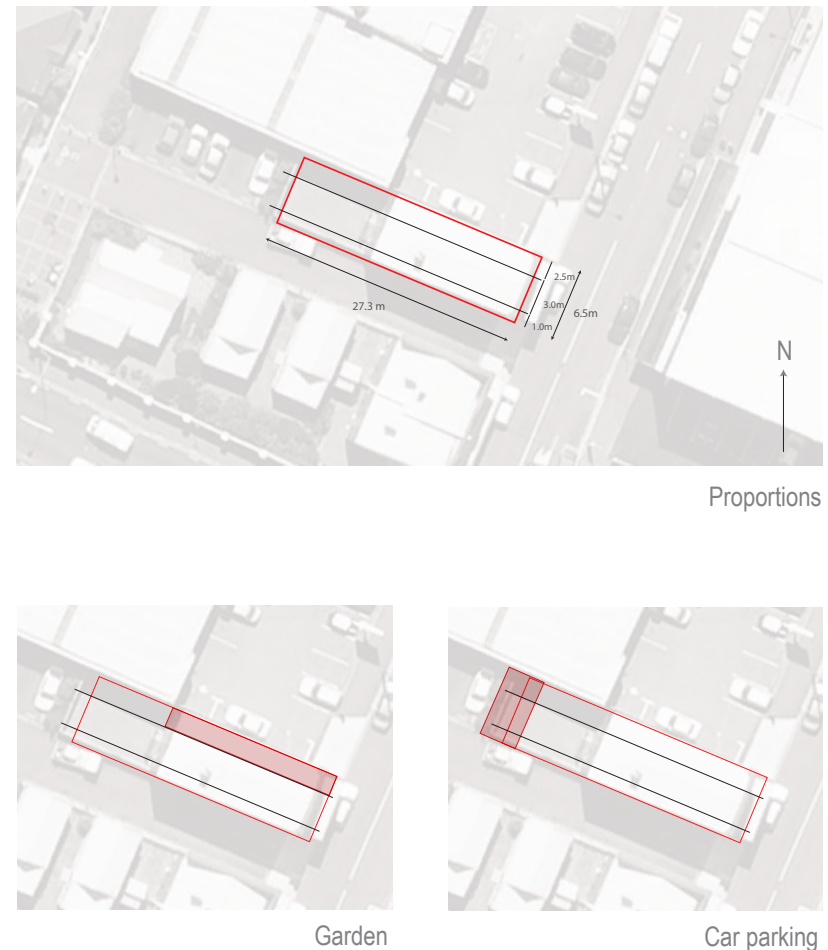

Car parking

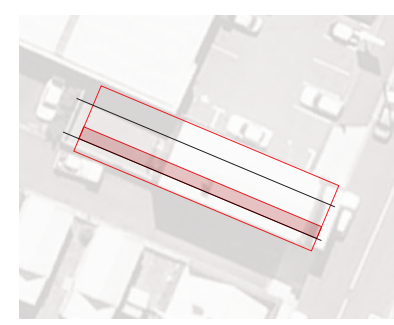

Hallway

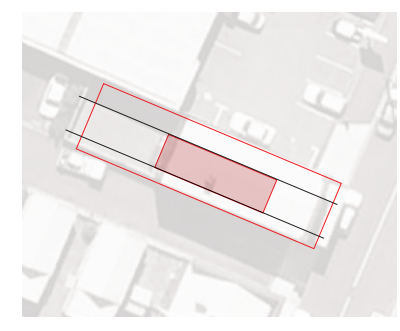

Dining

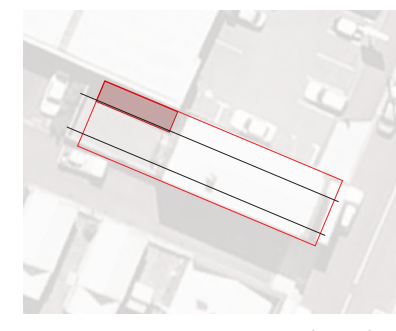

Laundry

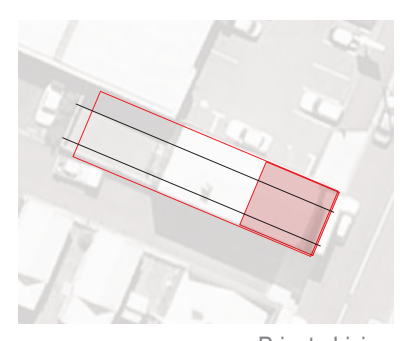

Private Living

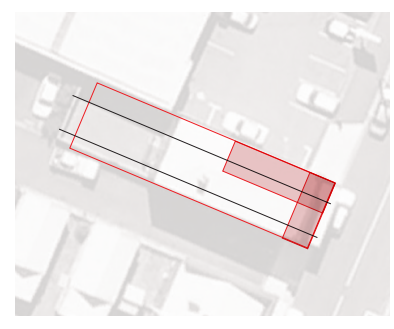

Horizontal

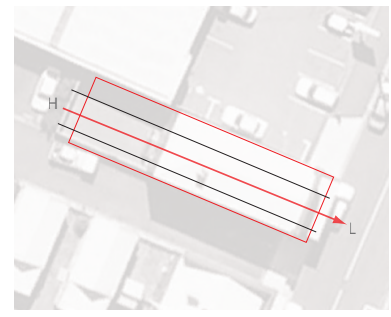

Verticality + Pitch

Fig 79: Room placement diagram: Each of the traditional villa spaces were placed within the site boundary according to the principals and most suitable position on the narrow site. 
Conceptual Plan 1:200

Due to the length of the plan the bottom floor accommodates the majority of living and operational spaces and the second floor is dedicated to the sleeping and bathing zones depending on client requests.
There is an opportunity to have and upstairs external verandah to communicate with atmosphere on Cuba Street

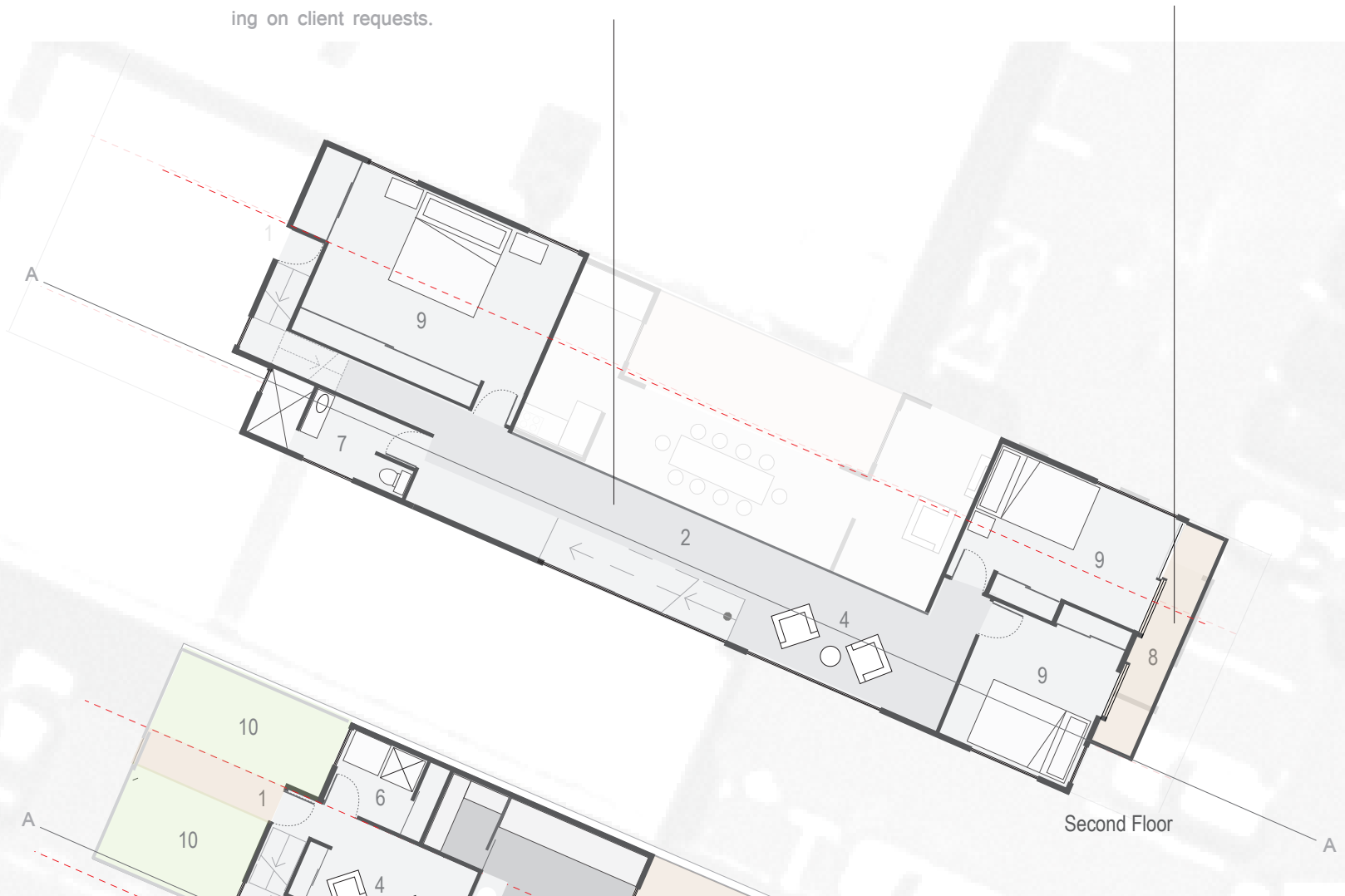

1. Entrance

2. Hallway

3. Dining

4. Living

5. Kitchen

6. Laundry

7. Bathroom

8. Outdoor Area

9. Bedroom

10. Garden

This main stairwell is be used as a visual element on the south facade, as well as a privacy control device through width of the dwelling.
The open hallway allows transition through the open living, dining, kitchen and further into the closed living retreat zone.
The main entrance is placed on the east facade to allow immediate connection to the busy pedestrian traffic of Cuba Street 
Conceptual Section 1:200

Fig 81

A secondary stairwell is placed at the back of the dwelling to allow the residents ease of access around the dwelling. The second story allows part of the dining and kitchen zone to be viewed from the upper level, emphasising the volume of the spaces.
The outdoor, dining and kitchen is elevated from the ground level as the North edge faces onto a car park. Elevating it allows for these central spaces to be vertically removed from the flow of pedestrians and maximise the availability of light entering.

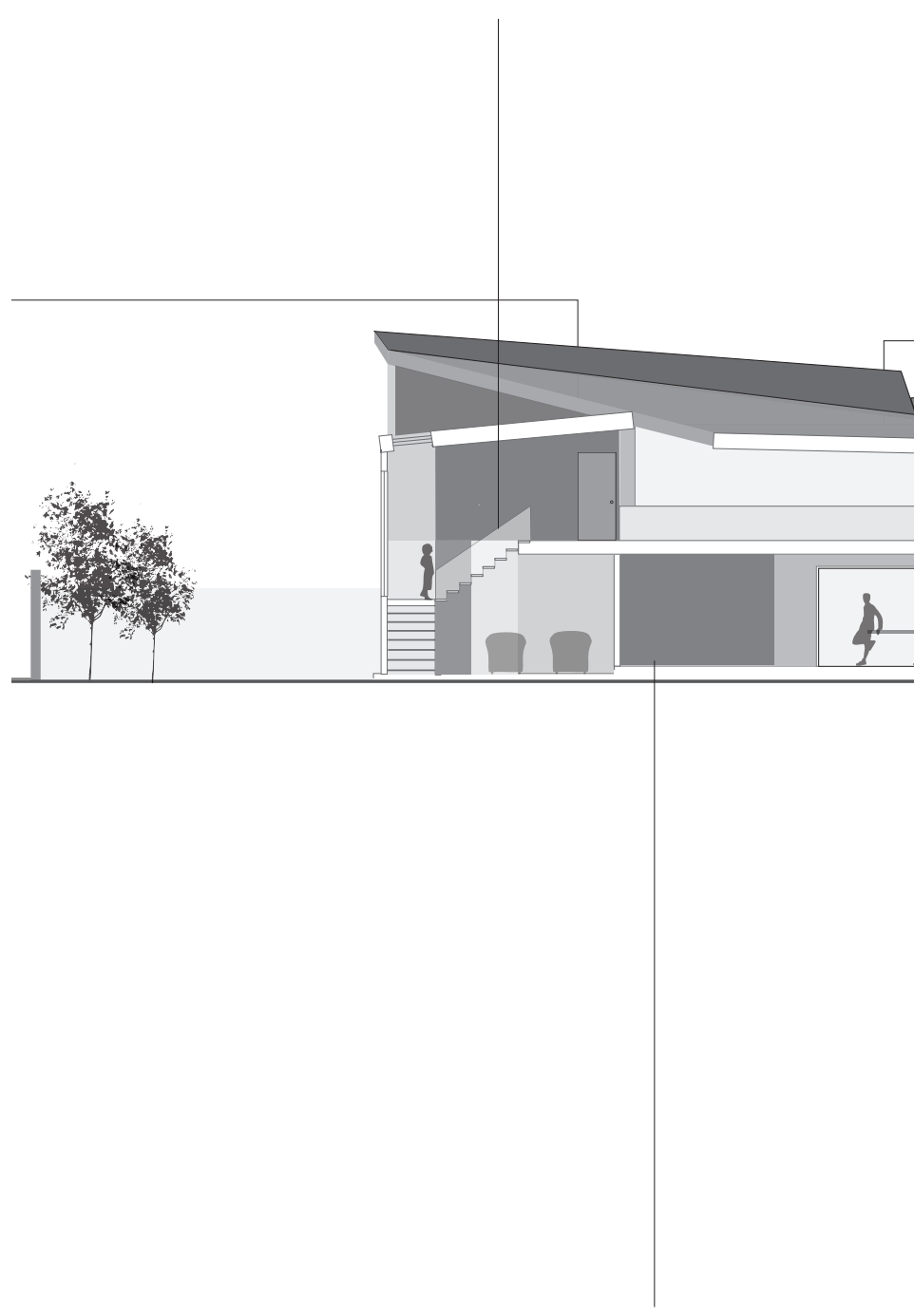

There is a displacement between the entrance and the dining space and further dining space down to the retreat zone. This principle allows the spaces to still function as one but achieves a sense of separation through a change in level.
The change of level emphasises the longitudinal axis of the hallway without confining the hallway to one segregated room as it functioned in the traditional villa. 
The north-west edge of the roof has a high pitch which wraps itself down and around the hall way space. This minimizes the amount of external vision into the dwelling; maximizing privacy and provides internal roof inhabitation. The roof further wraps over the front of the plan and provides a threshold over the kitchen, dining and living double height space. This maximizes the daylight entering in and controls the views from the higher buildings wrapping around the perimeter of the site.
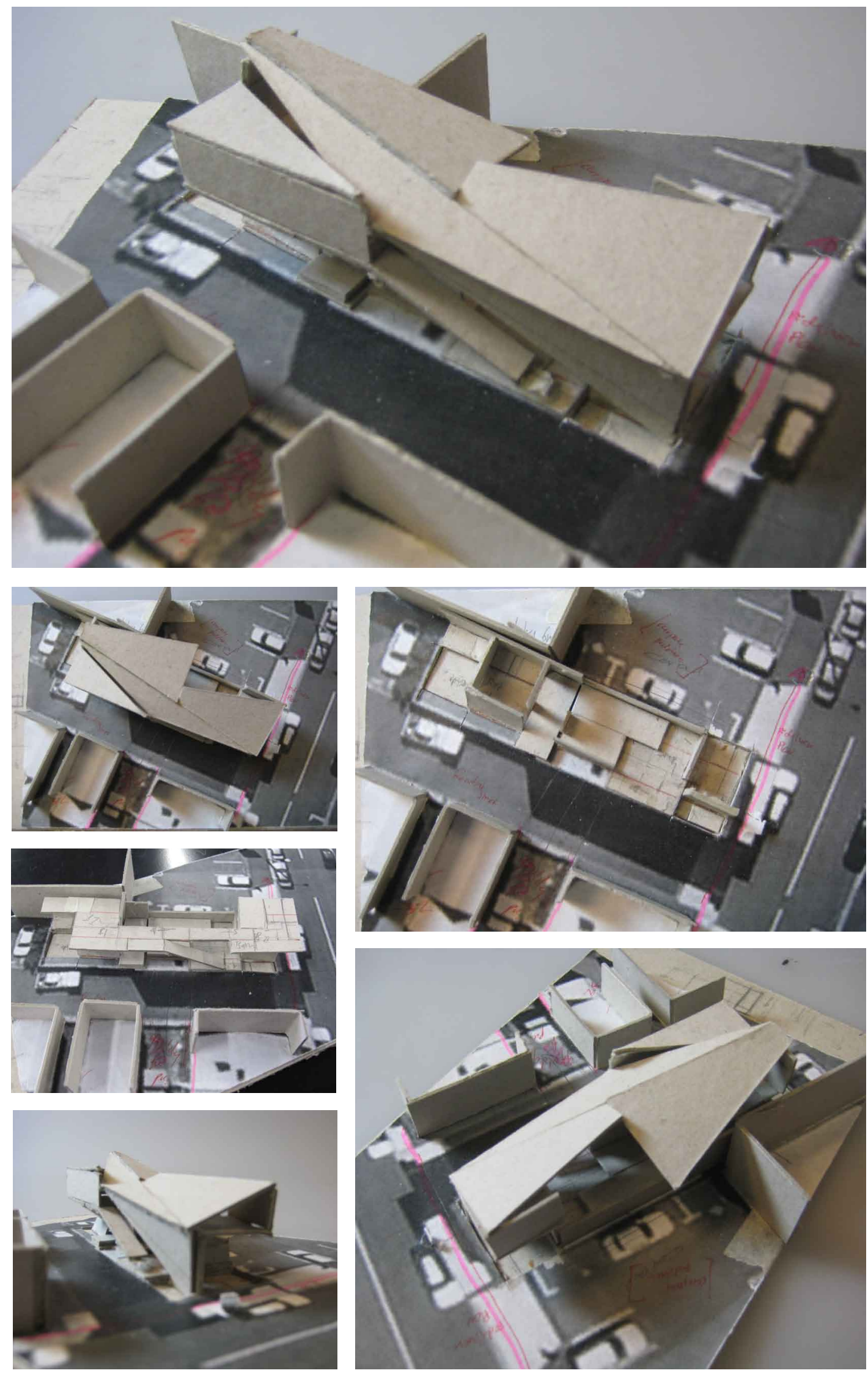

Fig 82: Conceptual cardboard models 1:200. 

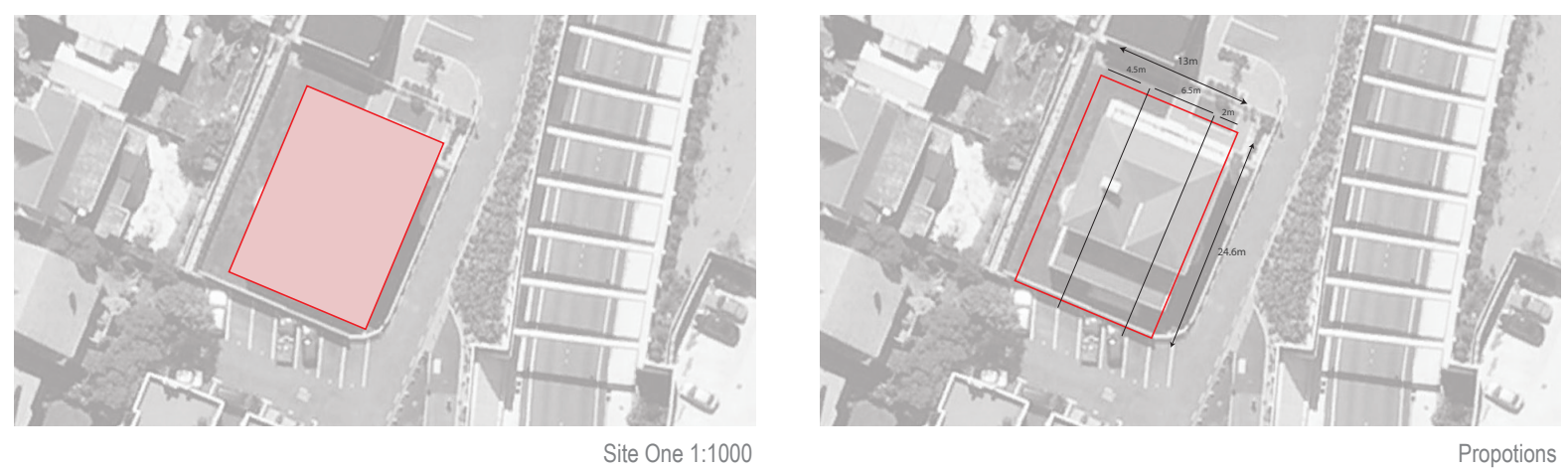

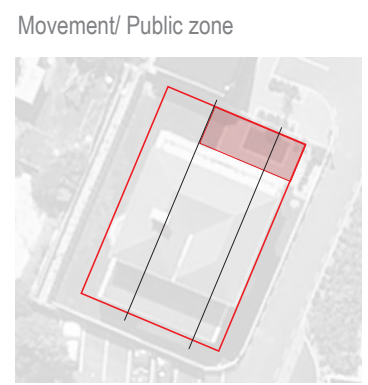

Entrance

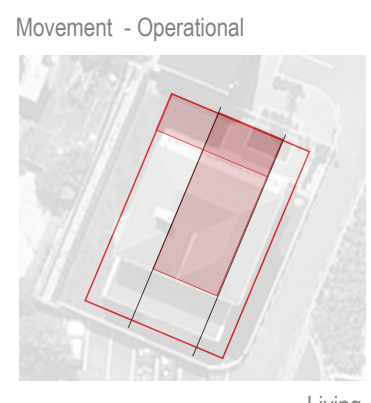

Living

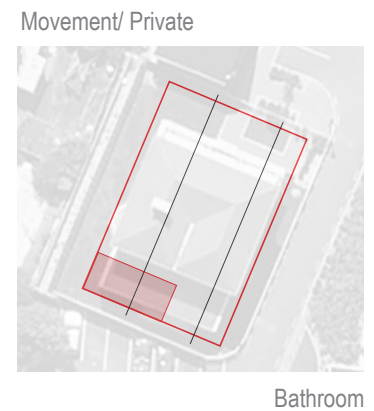

Roof patterns

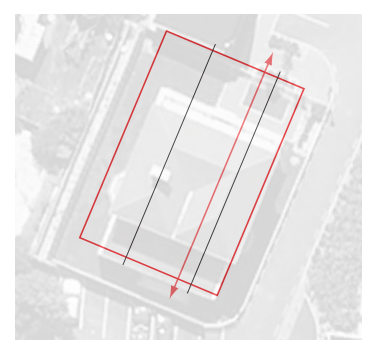

Ridge

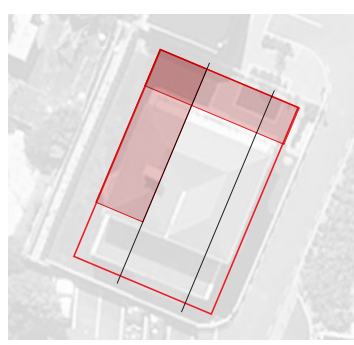

Outdoor
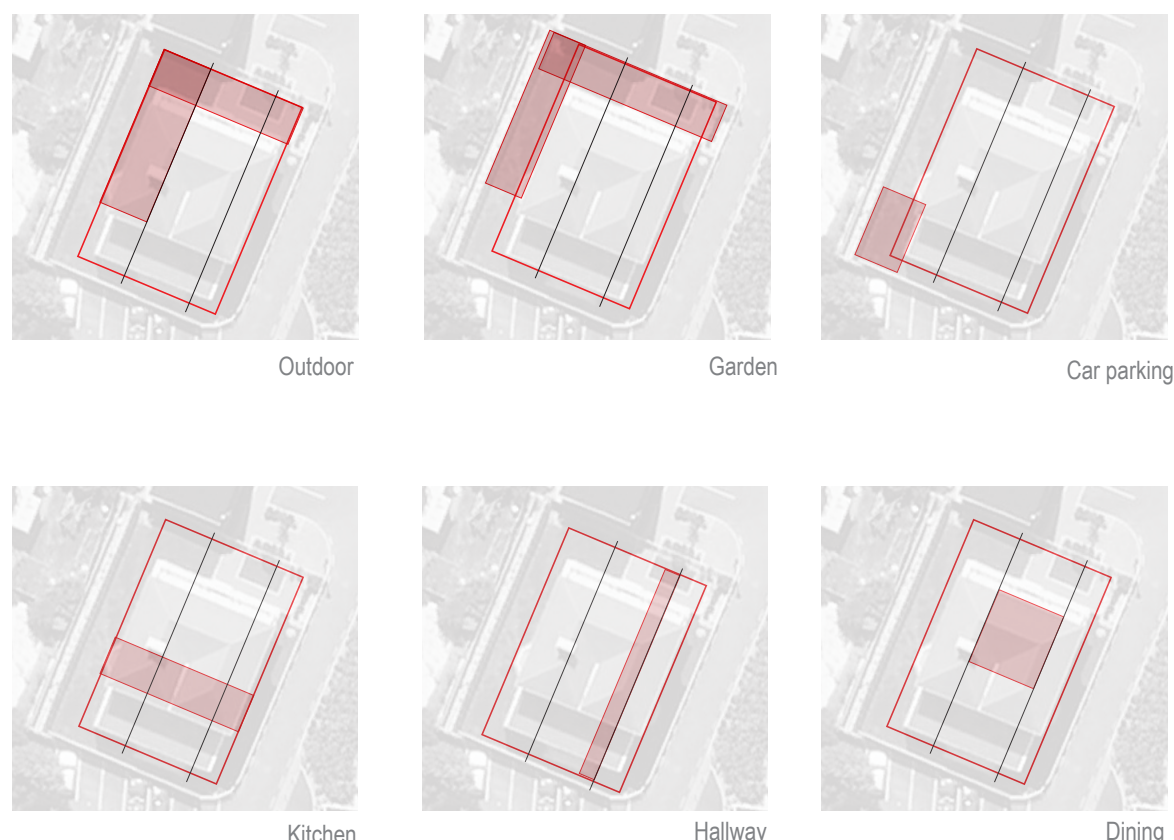

Car parking

Garden
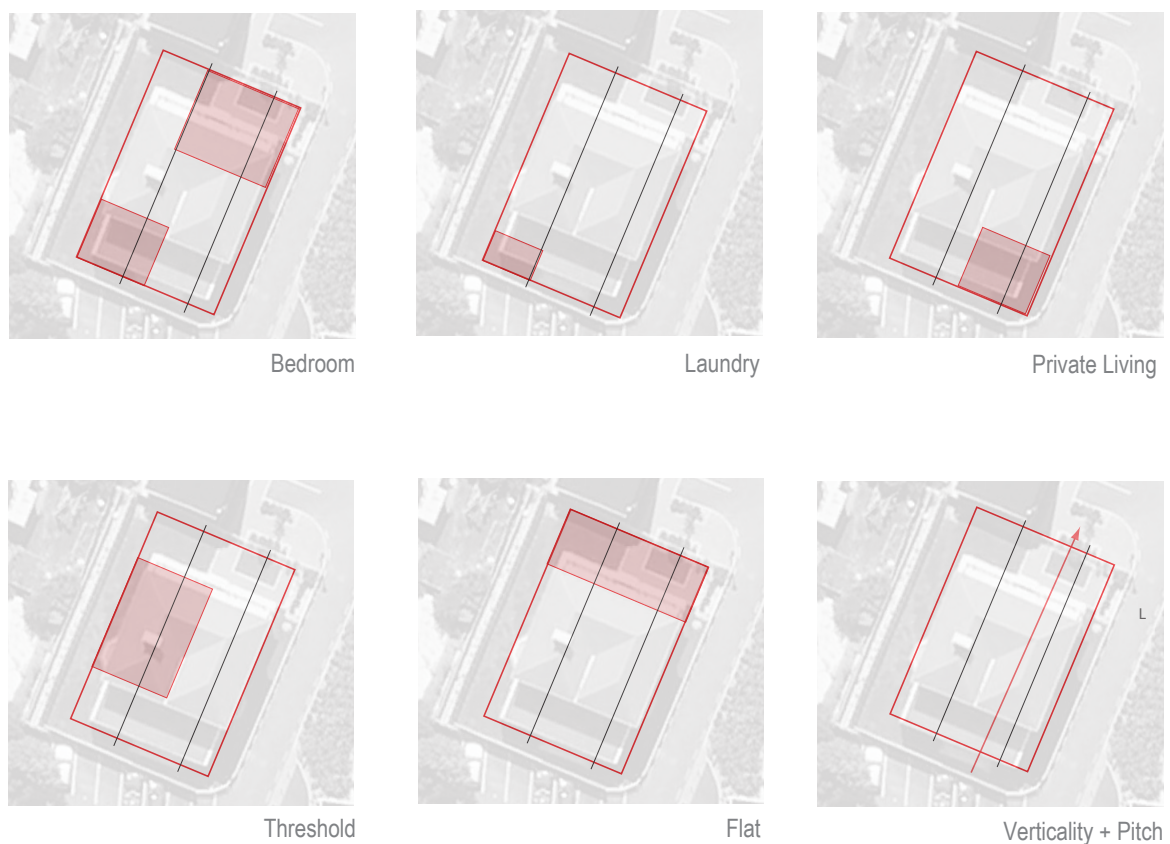

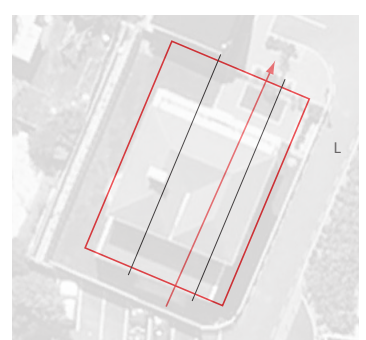

Verticality + Pitch

Fig 83: Room placement diagram: Each of the traditional villa rooms were placed within the site boundary according to the principals and most suitable position for each space in relation to the three public facades. 
Conceptual Plan 1:200

Fig 84

The upper floor has primarily been developed

to cater for the bedrooms and bathroom zones

of the house.
There is a secondary zone through the kitchen that further leads into the laundry and out to the vegetable garden.
Entrance is suggested along the north facade in line with the main entrance of Oak $\mathrm{Av}$ enue.

1. Entrance

2. Hallway

3. Dining

4. Living

5. Kitchen

6. Laundry

7. Bathroom

8. Outdoor area

9. Bedroom

10. Garden

The outdoor area engages with the living and dining zone allowing direct indoor/ outdoor access.
The stair well occupies the east elevation of the house and provides a visual link through the home. The vision and privacy is controlled by the roof planes. 
Conceptual Section 1:200

Fig 85

Upper floor living looks out over the double height zone above the open living and dining through a horizontal and vertical connection.
A secondary stair is placed at the back of the dwelling for ease of access around the operational end of the dwelling.

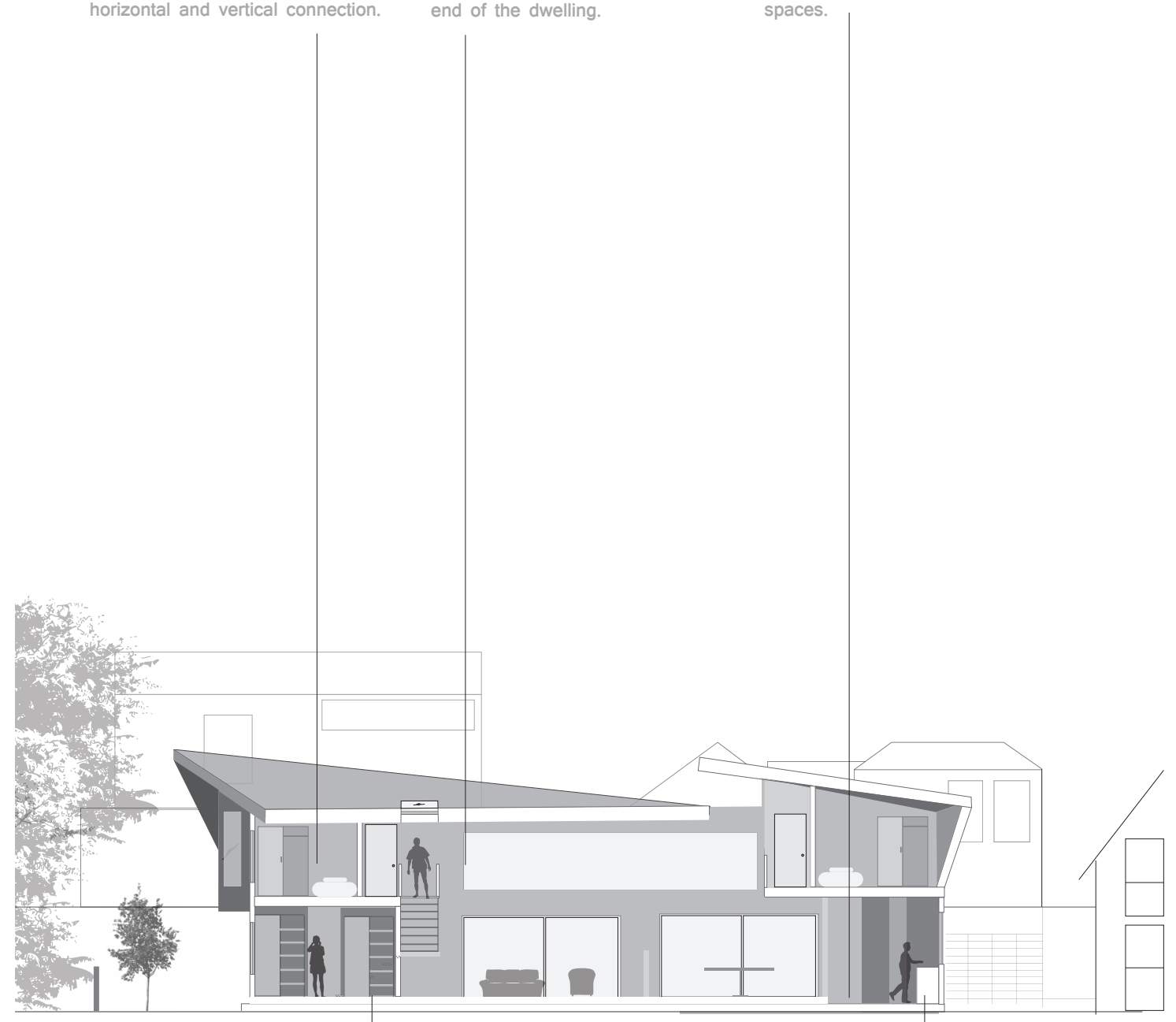

An open hallway links the main living zones together whilst allows them to function as separate spaces.

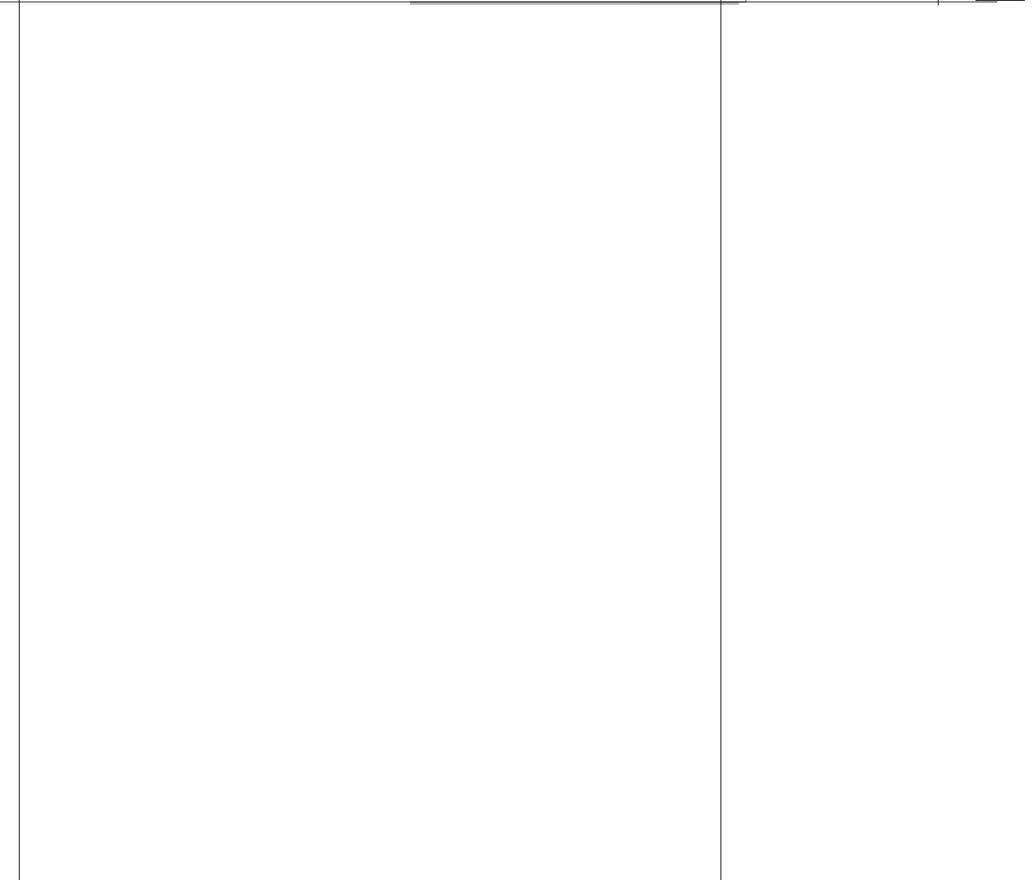

The destination of the hallway is the

The kitchen is level with the entrance zone however cannot be entered until access lower that the other living areas linkto the dwelling is gained. 
Models 1:200

The roof enfolds around the south west corner of the villa creating a high pitch that turns and wraps down around the hallway of the villa reaching to the entrance point of the west facade. It further turns back on its self and moves up to canopy over the North facade. This provides a threshold in between the two roof planes and lengthened ridge line to span the entire dwelling The concept allows the central living zone to maximise the sunlight and control the views from neighbouring building and the heighten city line across the western edge.
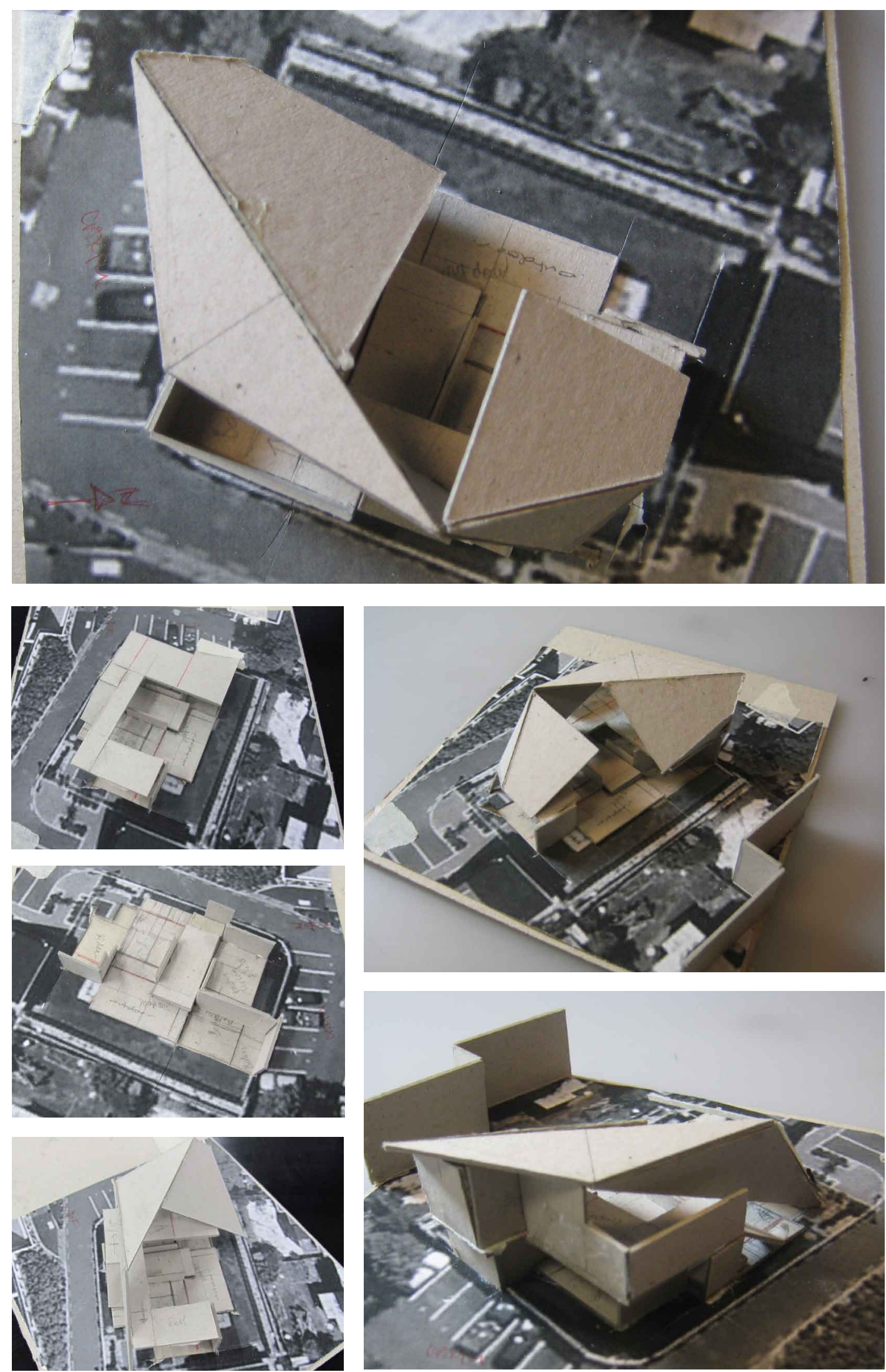

Fig 86: Conceptual cardboard models 1:200. 


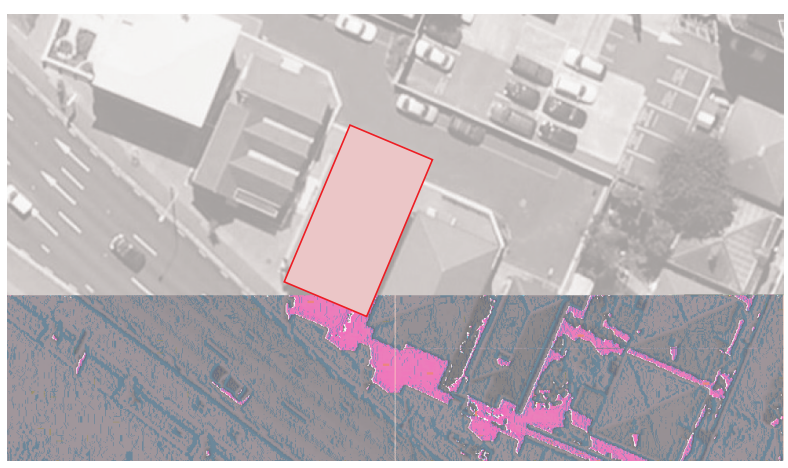

Site One 1:1000

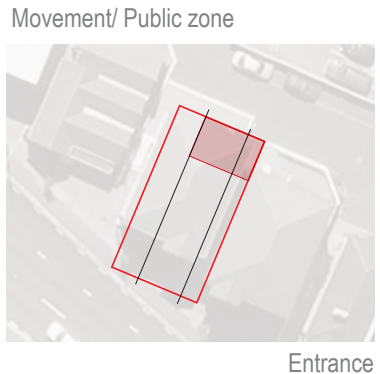

Movement - Operational

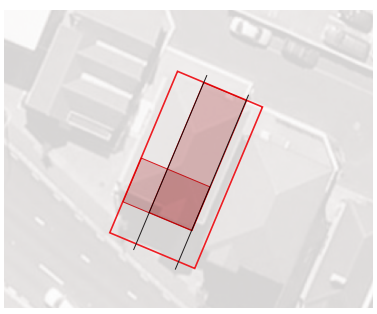

Living

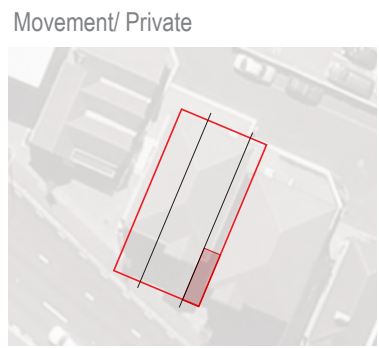

Bathroom

Roof Patterns

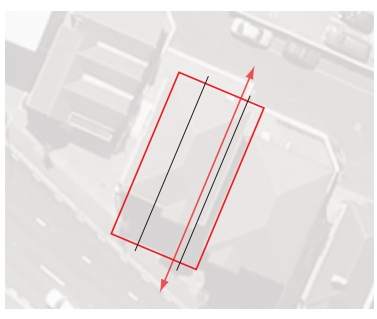

Ridge
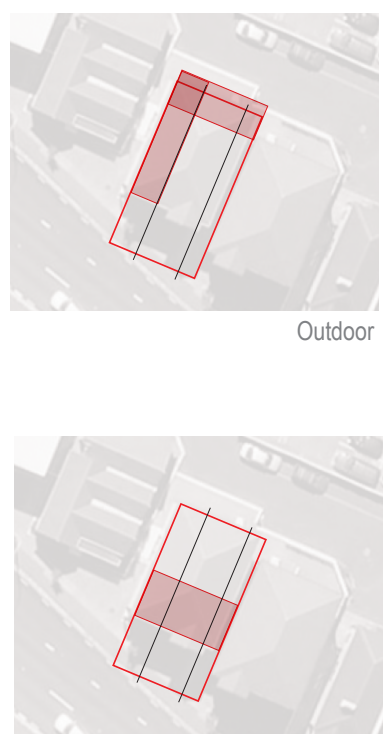

Kitchen

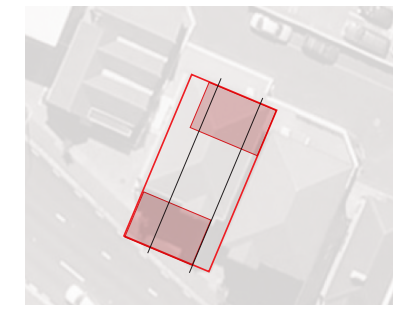

Bedroom

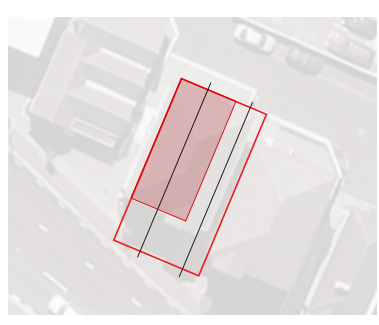

Threshold
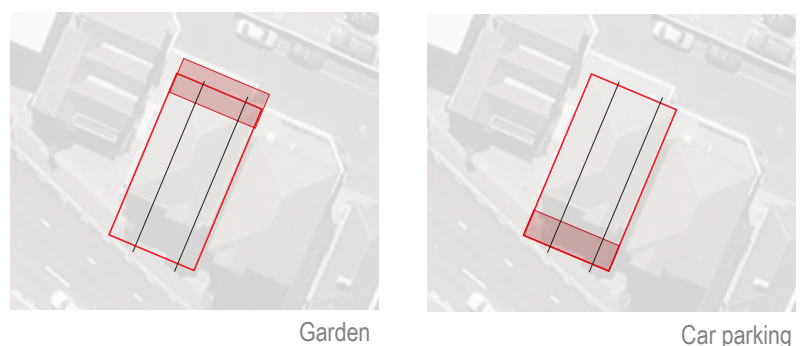

Car parking

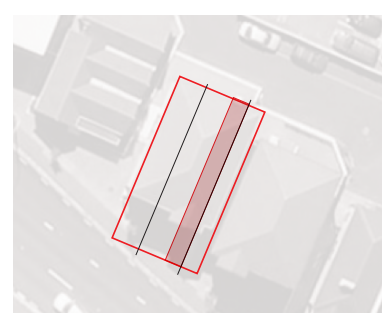

Hallway

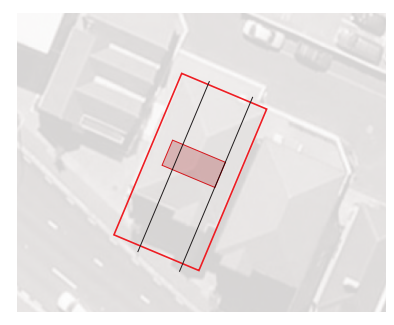

Dining

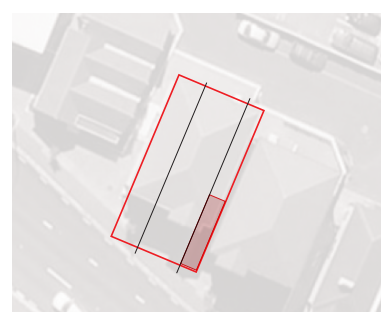

Laundry

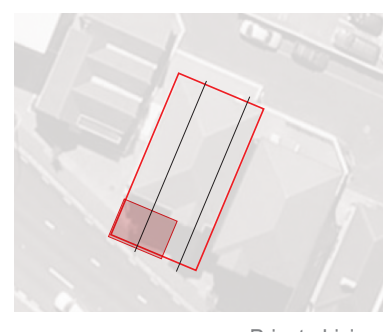

Private Living

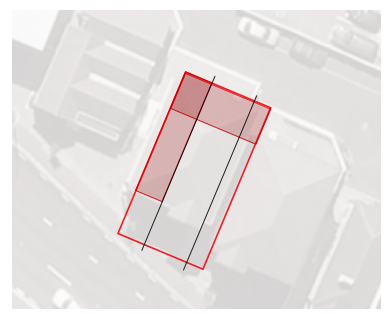

Flat

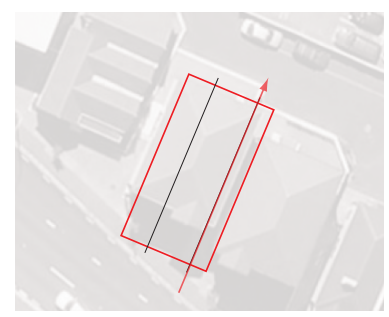

Verticality + Pitch

Fig 87 Room placement diagrams: Each of the traditional villa spaces were placed within the site boundary according to the principals and most suitable position for the space and the relationship to the Bypass and new Tonk's Road. 
Conceptual Plan 1:200

The upper floor would accommodate the bedroom and bathing and spaces as well as a secondary smaller living zone.
Secondary threshold allowing connec-

tion from the end of the upper hallway to the entrance zone.

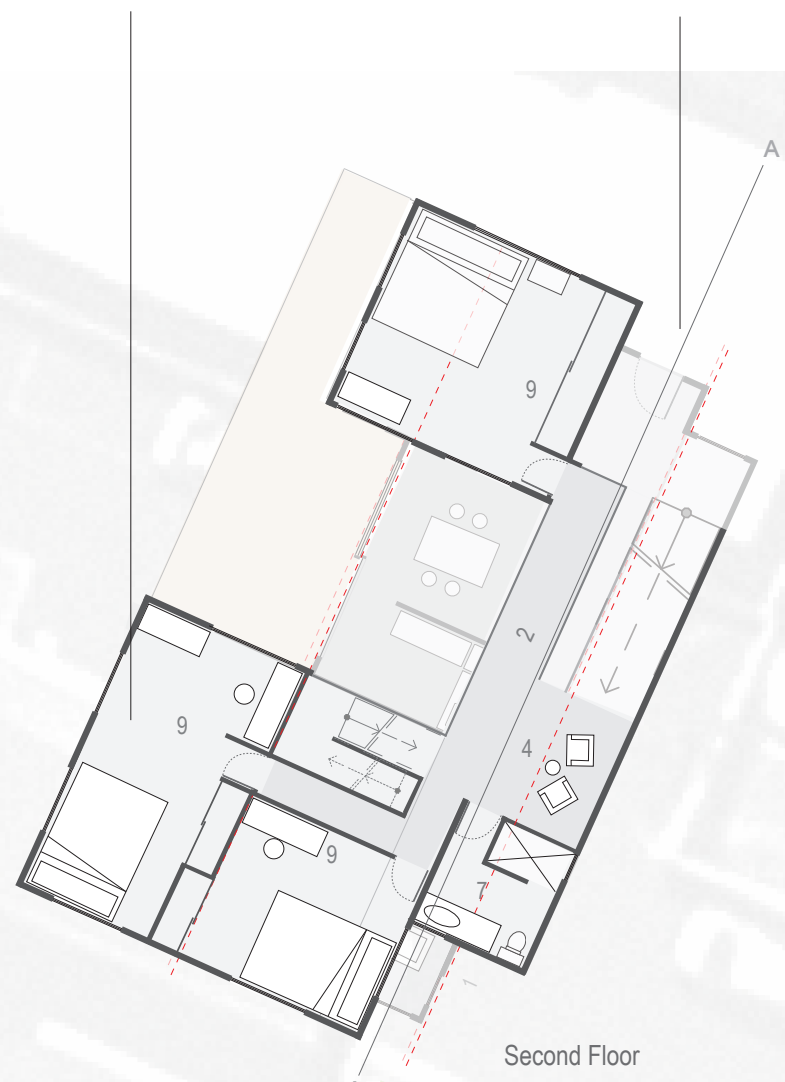

1. Entrance

2. Hallway

3. Dining

4. Living

5. Kitchen

6. Laundry

7. Bathroom

8. Outdoor area

9. Bedroom

10. Garden

The outdoor space is linked to the edge of the open living zone, dining zone, kitchen and bedroom space. This creates a sun orientated space that is encased by essential living zones.
The open living space is on the same level as the entrance creating an internal verandah connection and communication with the front community passing by. 
The Wellington Bypass occupies the south side of the dwelling creating an annoyance, therefore would require buffer space to control, the concept has suggested vegetation.
The hallway extends vertically to accommodate the upper floor rooms. This allows vision over a dwarfed barrier into the downstairs communal living spaces.

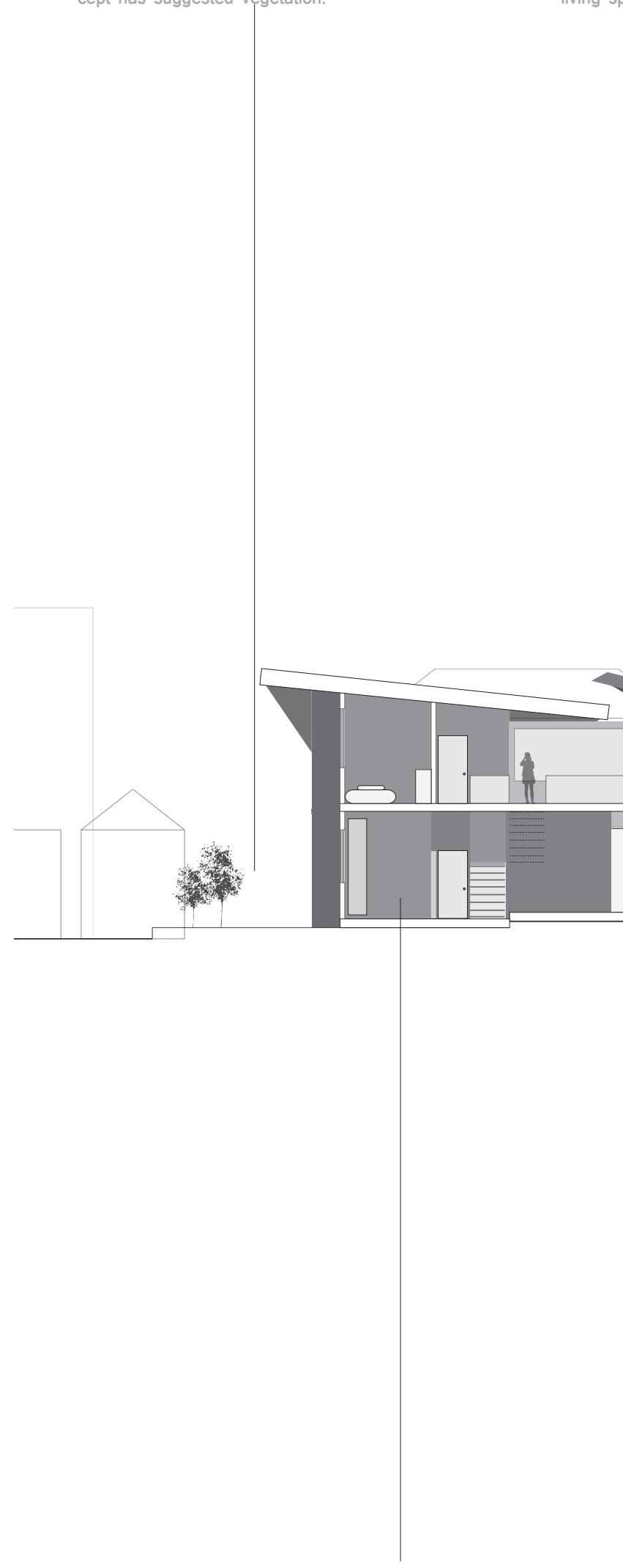

The end of the hallway retreats to the closed living space used for evening entertainment and links through to a space set aside from bedroom living. This would be displaced to differentiate the spatial roles of the home.

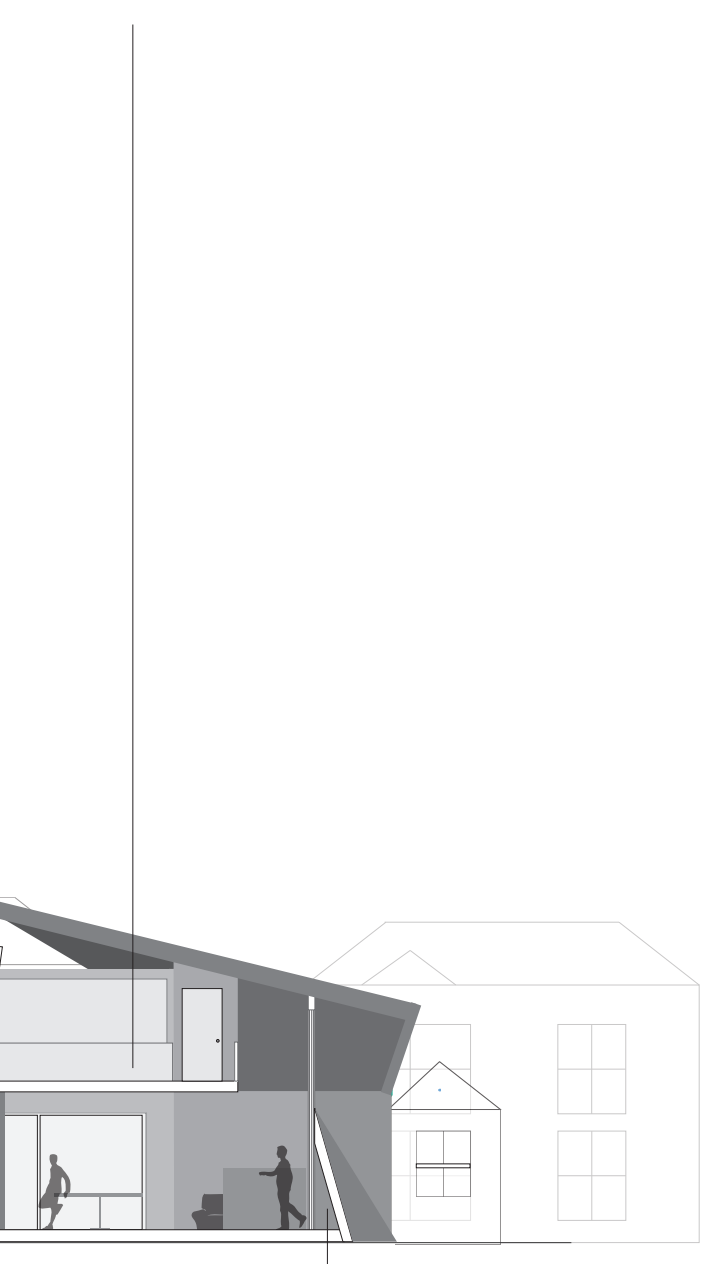


Models 1:200

The roof works as two elements. The first generates a high pitch on the south-east corner wrapping down the eastern edge and entrance point. The second canopies over the front of the north facade and meets with the first at a central point. The space between both creates two thresholds, one above the entrance and the other through the centre of the west facade. The model informed a dominant entrance point onto the New Tonk's Road.
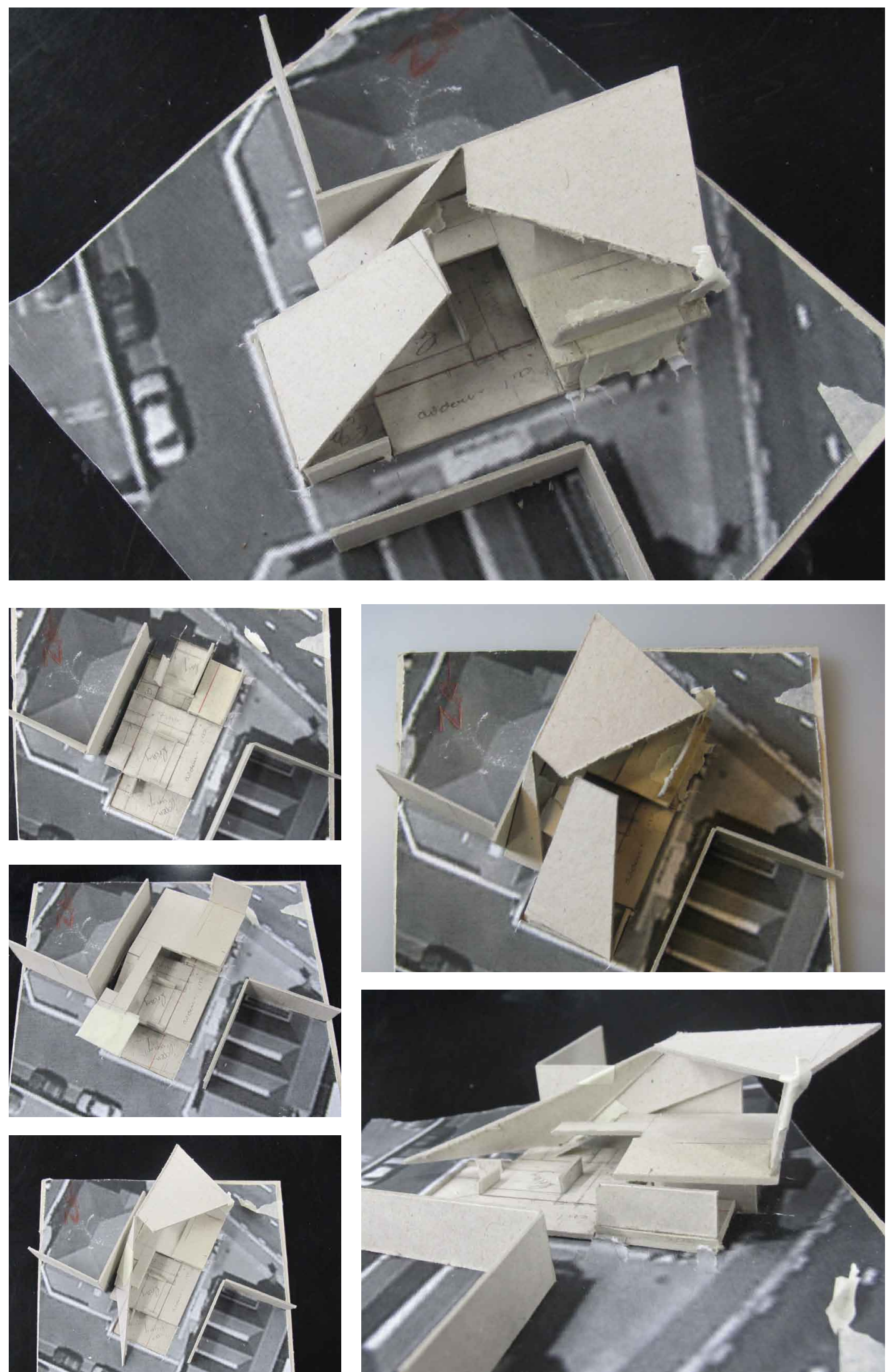

Fig 90: Conceptual Cardboard models 1:200. 
The outcome of this design development has been the comparable planning principles between the three sites and conceptual plans. Beyond these common principles, the roof offers a level of individualisation through the use of angles and openings. Oak Avenue has been chosen for further development. The following design iteration develops the building program at a 1:100 and 1:50 scale. The aim of this experiment is to refine the conceptual plan of the 1:200 scale. It will further clarify the conceptual plan and roof design in relation to spatial proportions and movement zones determined through the principles. This experiment will further review the site conditions of Oak Avenue and integrate the conceptual plan with the site. It will begin to review how the traditional materiality of the villa can begin to influence the way in which the plan spatially functions through a contemporary language. This test allows the social relationships specific to the traditional villa to be communicated prior to introducing contemporary specifics and demands of a cliental. This development has been done through physical model making and experimentations with traditional villa materials.

\section{Site Study}

Further site analysis was implemented at this level of development. An understanding of the neighbouring buildings, roads and places with further set the context of the site.

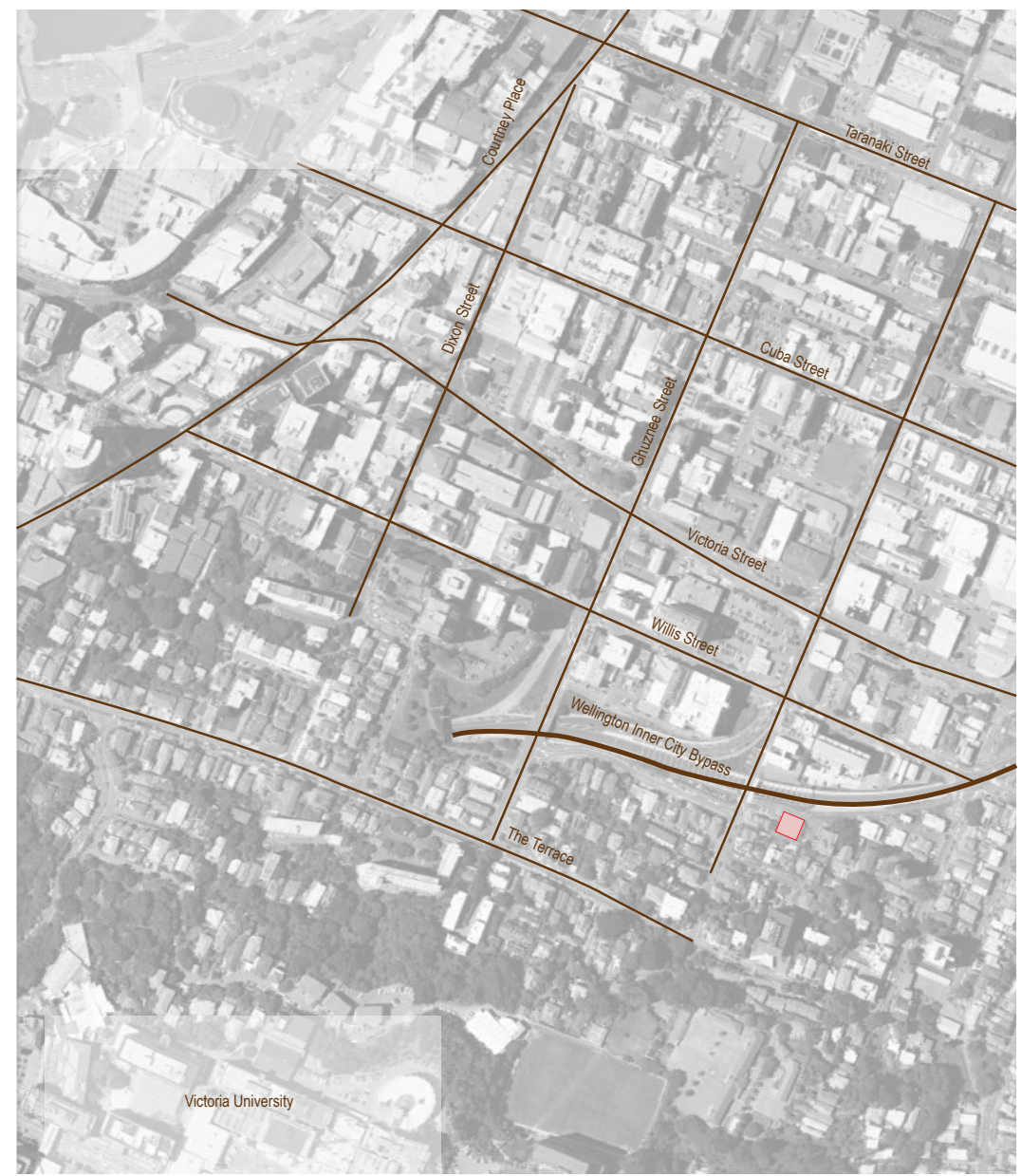

Fig 91: Wellington Central City: The site is situated in the heart of Wellington city therefore there is a high possibility of the building being viewed by the public and from above. It is positioned in line and parallel to various main roads in Wellington, and sits above the new bypass and over-bridge. 
Building Hierarchy

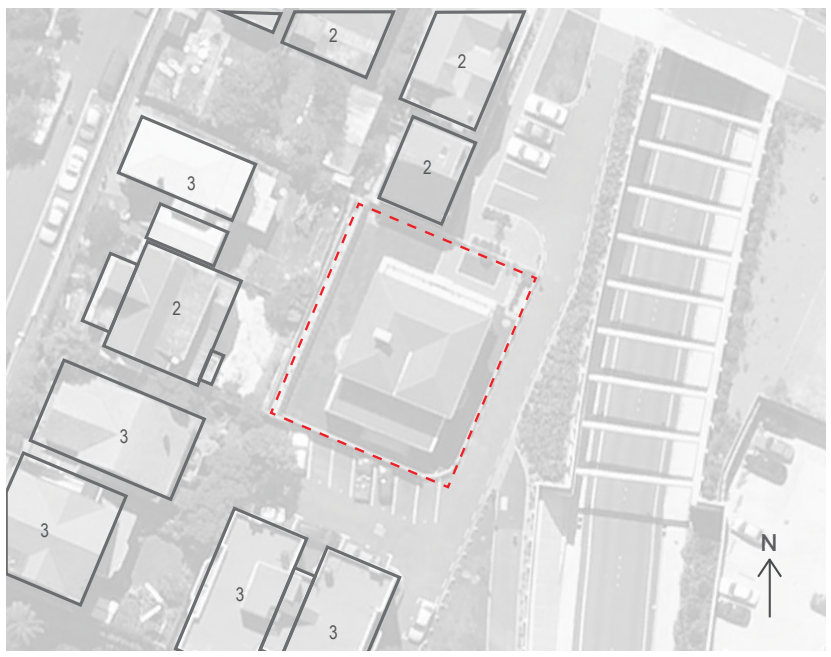

The neighbouring buildings range between two and three stories high. Retain ing this scale is necessary. The dwellings positioned to the west of the site are elevated on a hill which allows the Oak Ave site to be more generous with vertical scale.

Sun Patterns

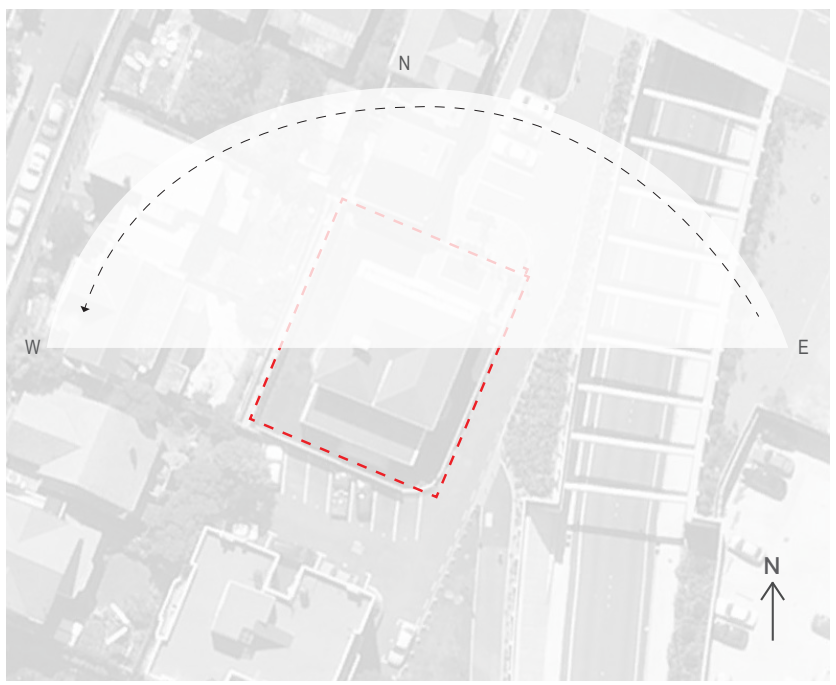

The sun wraps around the north west of the site which means priority to the main outdoor space needs to be given to this corner. The roof pitch has been placed in the south corner to cater for this in the conceptual models.

\section{Green Spaces}

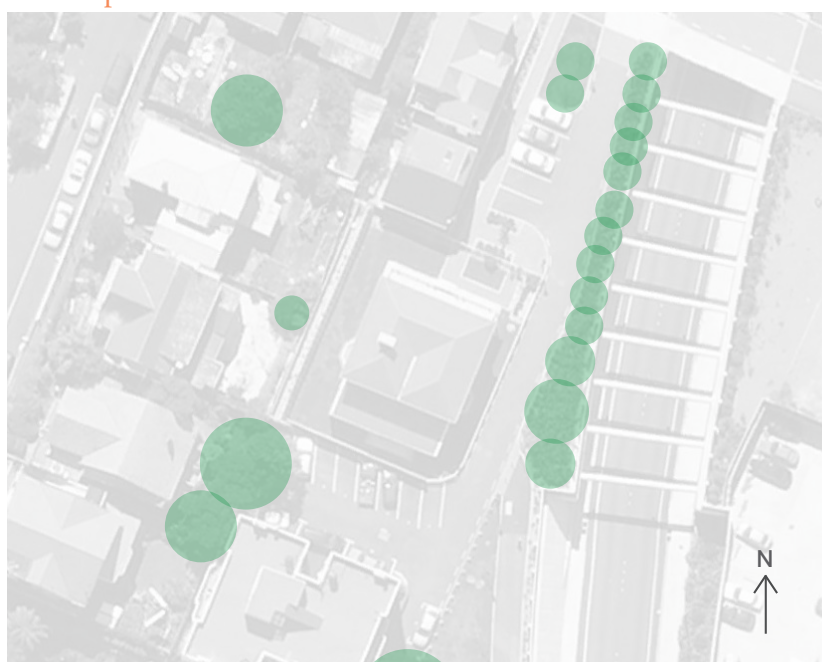

There is not much existing vegetation visible on the site, this is used to create privacy for neighbouring dwellings and a buffer between the residential housing and the Bypass edge.
Pedestrian Movement

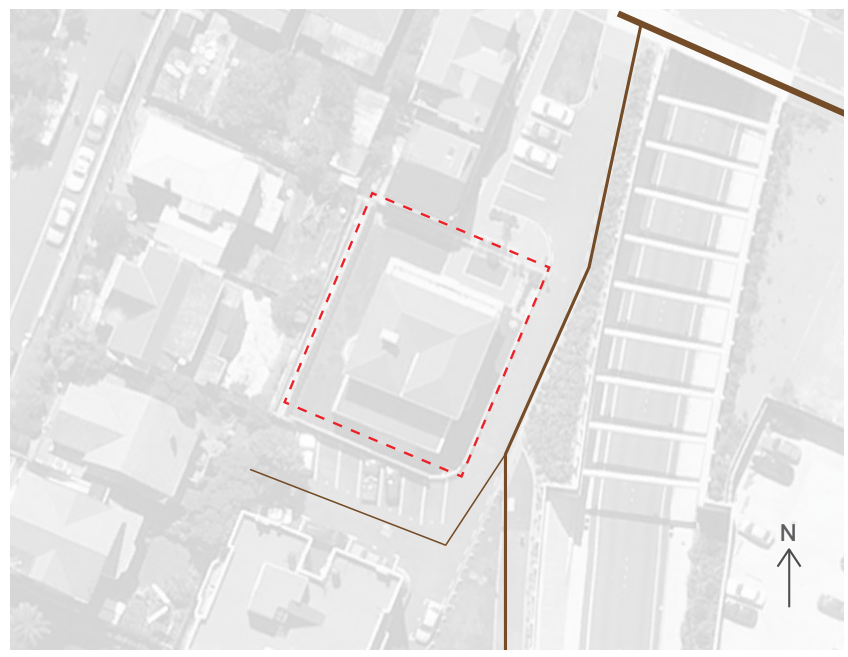

There is only one pedestrian route around the site and this occupies the east edge of the home. It leads out onto a primary pedestrian road; Vivian Street, however this road is not immediately connected with the site.

\section{Car Movement}

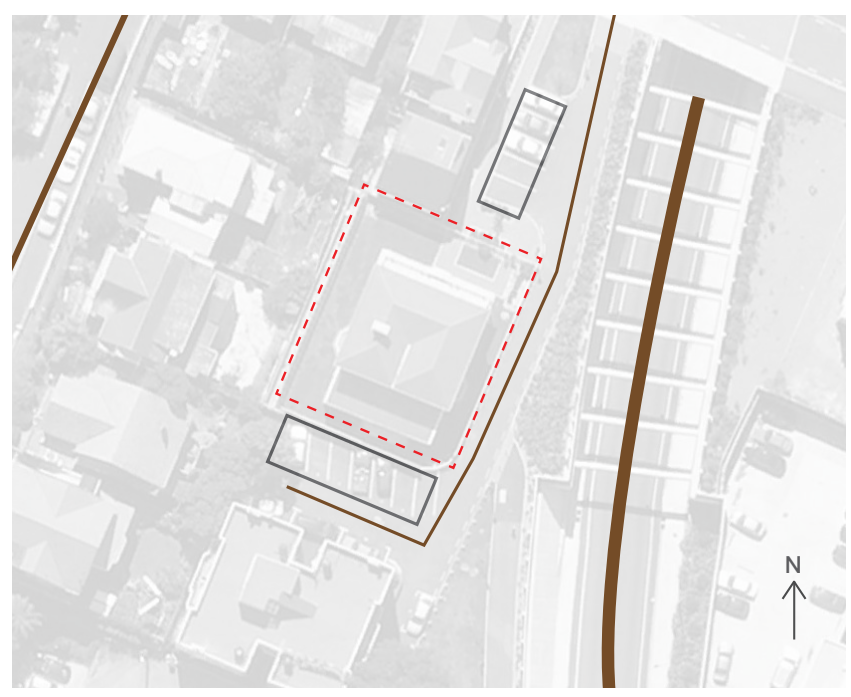

The site occupies a segment of the Bypass perimeter which is elevated $4 \mathrm{~m}$ below the site and therefore is not too much of a concern. There is a pedestrian friendly road along the east edge leading to multiple car parking options.

Site Contours

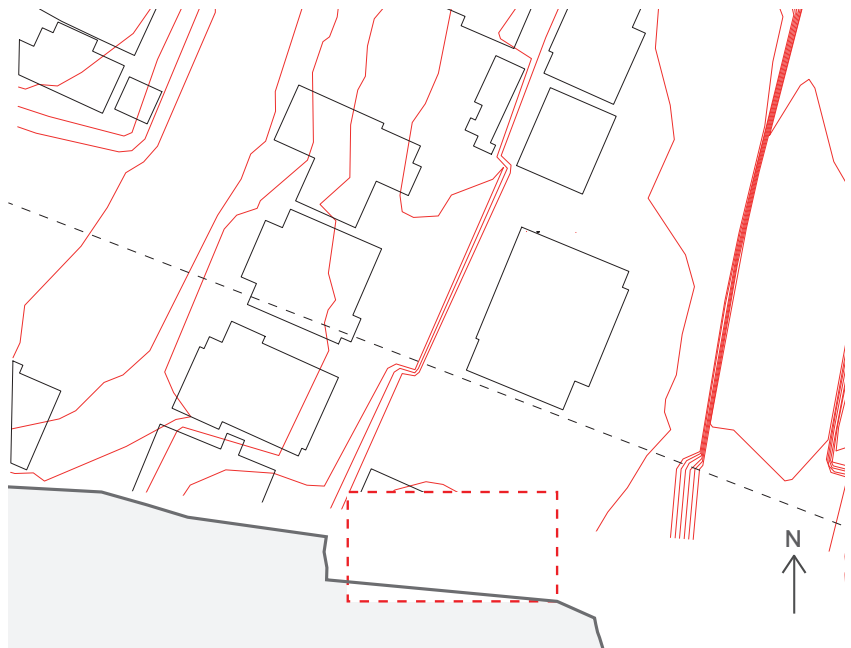

The site sits on a gentle gradient with the slope steeping behind it. This elevates the neighbouring west buildings and allows the site to have a private zone below the retaining wall. Views from the neighbouring buildings above into the building could be an issue. 
At this scale an understanding of the conceptual plan in relation to neighbouring building heights and the spatial planning has been developed through model making. The changes to the conceptual plan have mainly been the repositioning of spaces to function more efficiently with the various site conditions and internal movement of the occupants. It became evident at this scale that the living room would be more appropriate at the front of the dwelling, pushing the kitchen further back. Further changes to the plan will be applied later in the design phase with respect to specific to contemporary client demands.

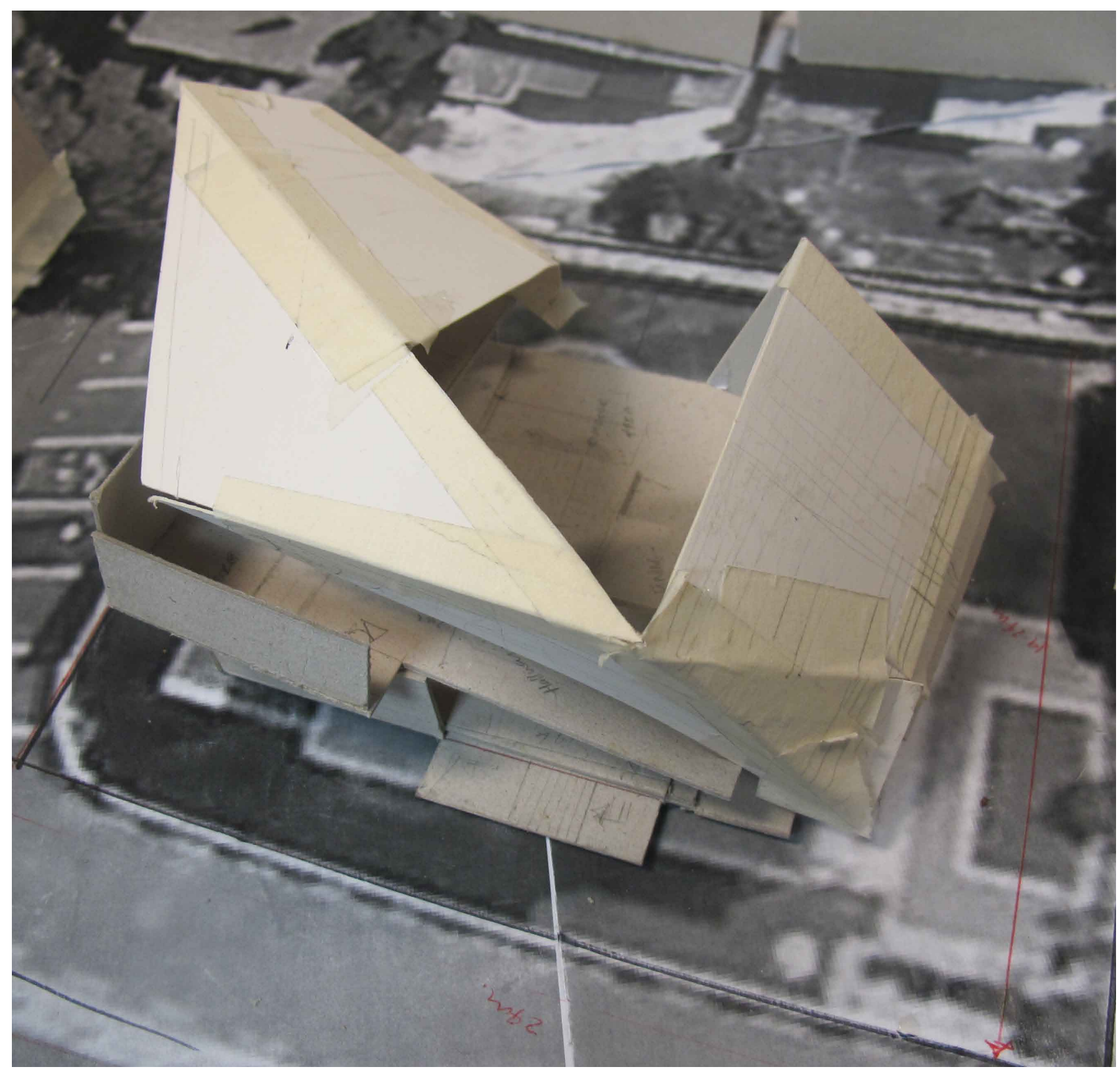

Fig 92 (Opposite page) Oak Avenue site studies.

Fig 93 (Above) Conceptual cardboard models 1:100. 
At the 1:100 scale the original roof angles appeared to be quiet dominating in comparison to the neighbouring building. The angles have been reduced to fit well in the context. The south west pitch has become further wrapped around the upper bedroom floor to create a wall/ roof function. The northern roof angle has followed the same process to wrap down around the front of the upper floor wall to create dominating front element.
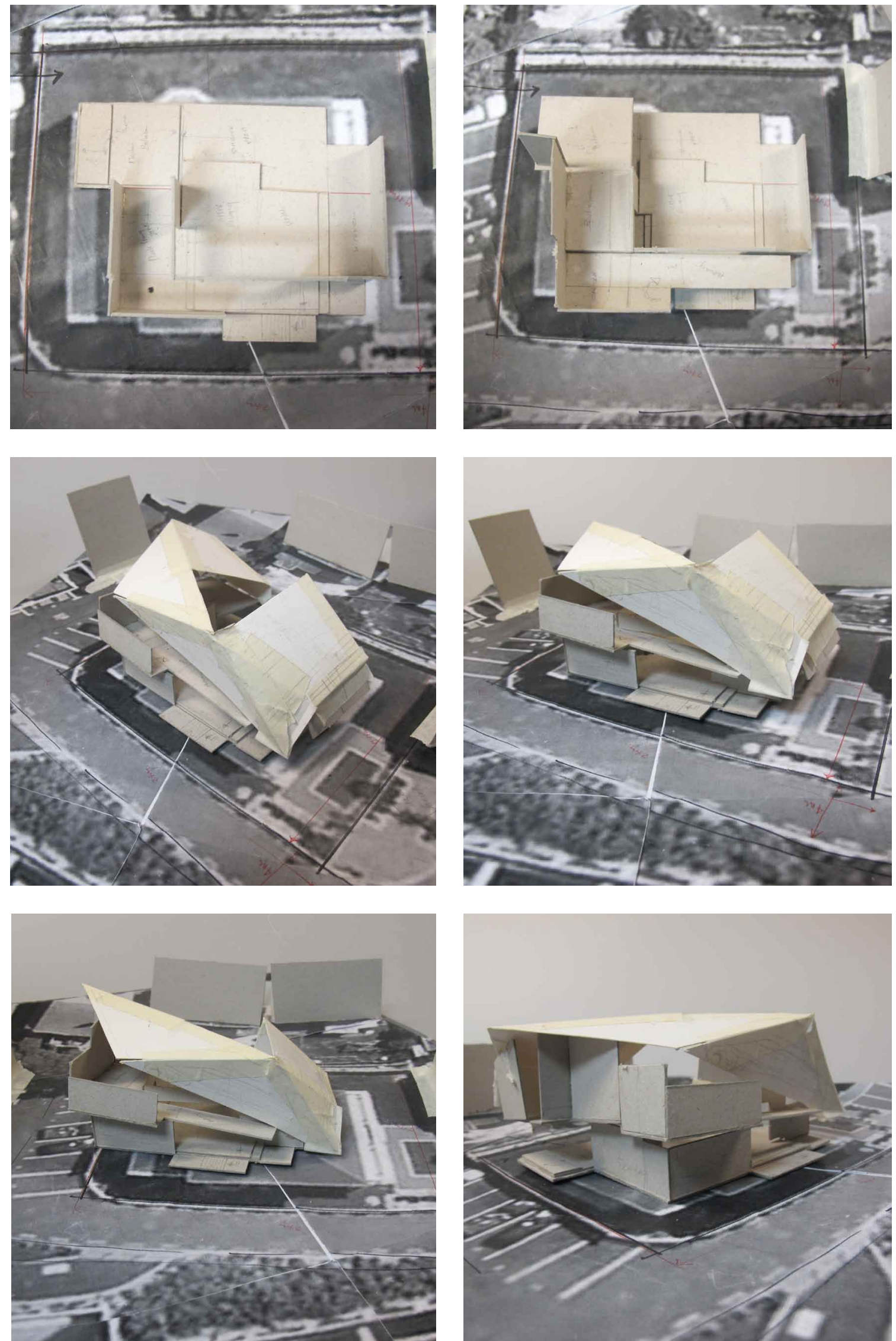

Fig 94: Conceptual cardboard models 1:100

74 Section Three - A 'Non Frontal' Villa 
The roof form appeared to be sitting as a canopy over the lower floor of the villa and therefore makes the scale of the building appear larger than it should. Further development of the model led to a drop in roof height down over the lower floor. This lowered plane allows the roof to function as an element of the exterior facade, creating a closer relationship to the site. Doing this also allows the upper floor to function as an internal inhabitation space of the roof.
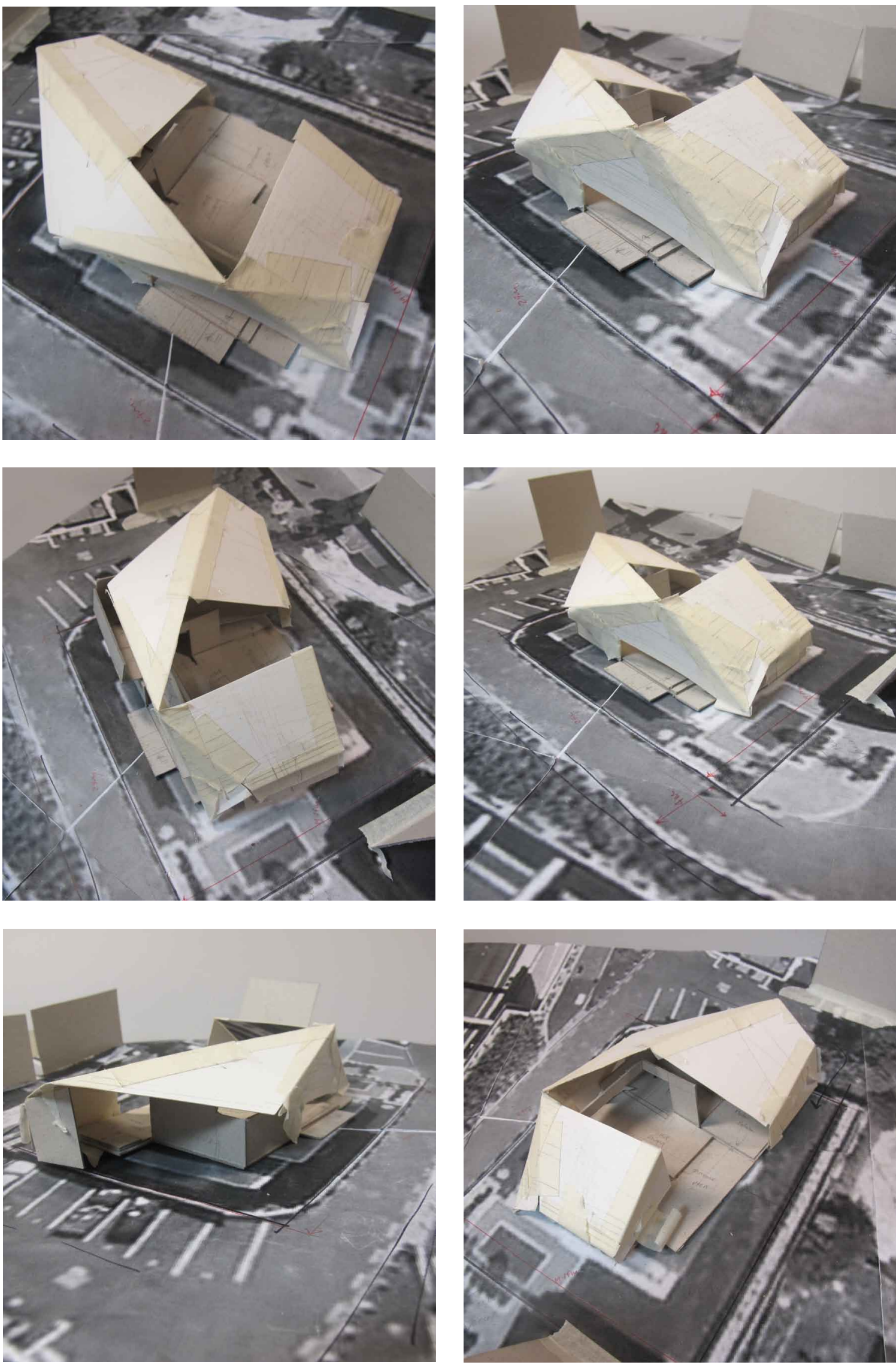

Fig 95: Conceptual cardboard models 1:100. 
Before a further design iteration was approached, a visit was made to an existing villa that was under an alteration process. Traditional materials from this house were reviewed and connections were made between the material qualities and the occupation of the traditional villa.

From the range of materials collected, a series of common qualities were found. These were perforated materials, layering of material and material change to control the use and separation of space. The materials whilst aged held a beauty that could be reinterpreted in a contemporary manner to influence the spatial and occupation attributes of a home.

The characteristics noted from the material study will be applied alongside personal ideas for how details can influence the way a space is occupied. The following model is a 1:50 scale model that explores ideas of the traditional in a contemporary language.
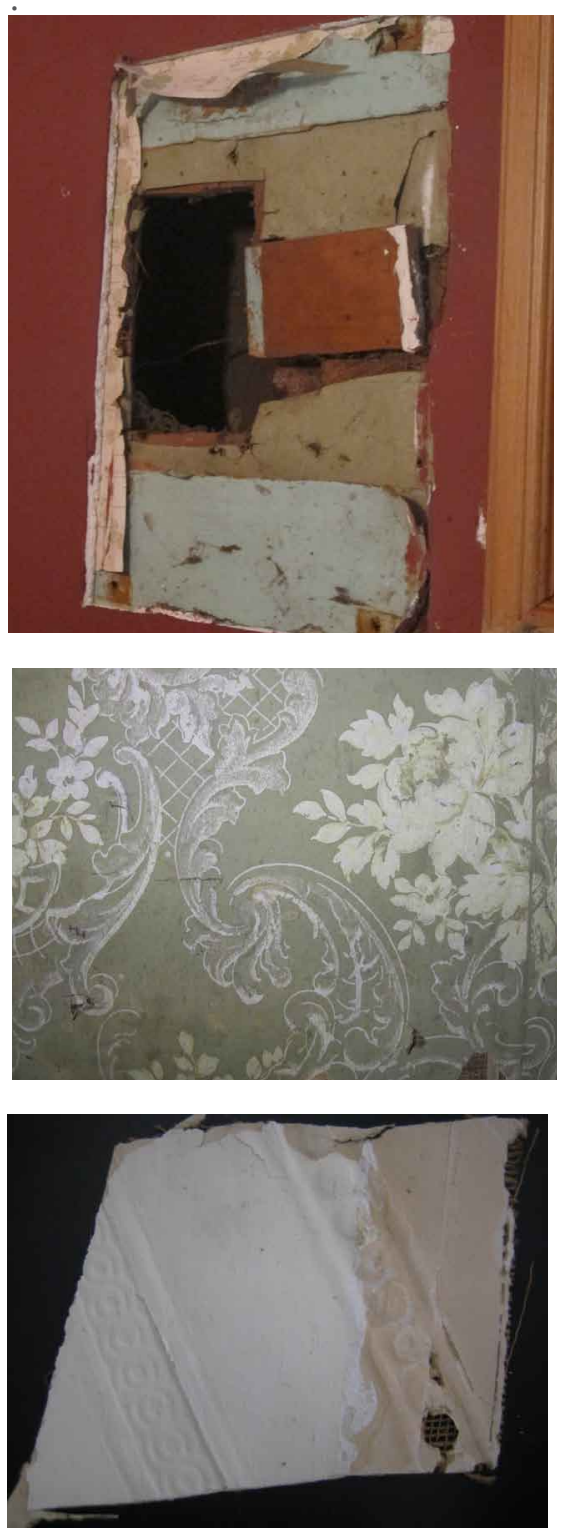
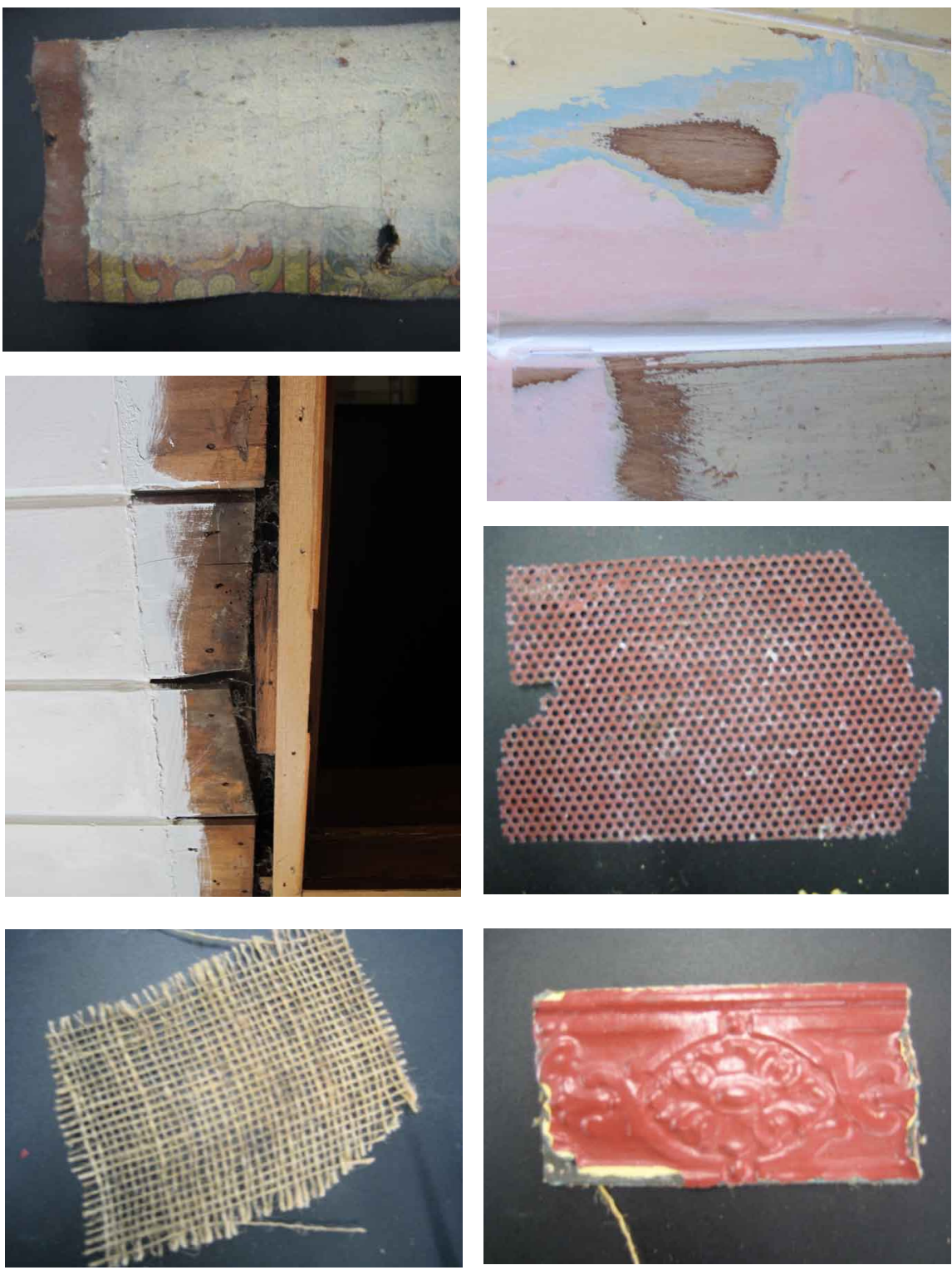

Fig 96: Material Exploration from an existing villa in Wellington, New Zealand.

Fig 97: (opposite page) Conceptual Exploration 1:50. 


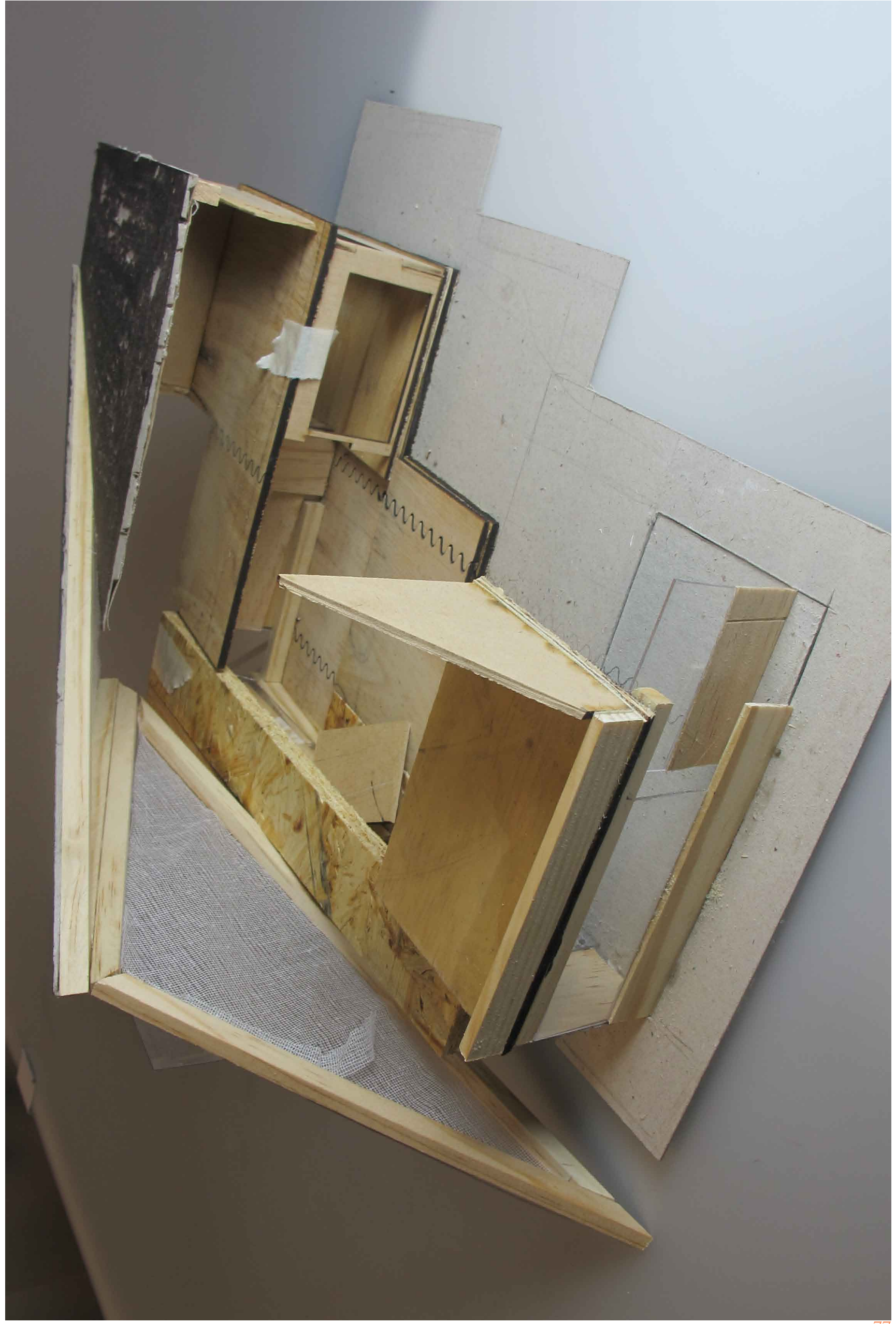



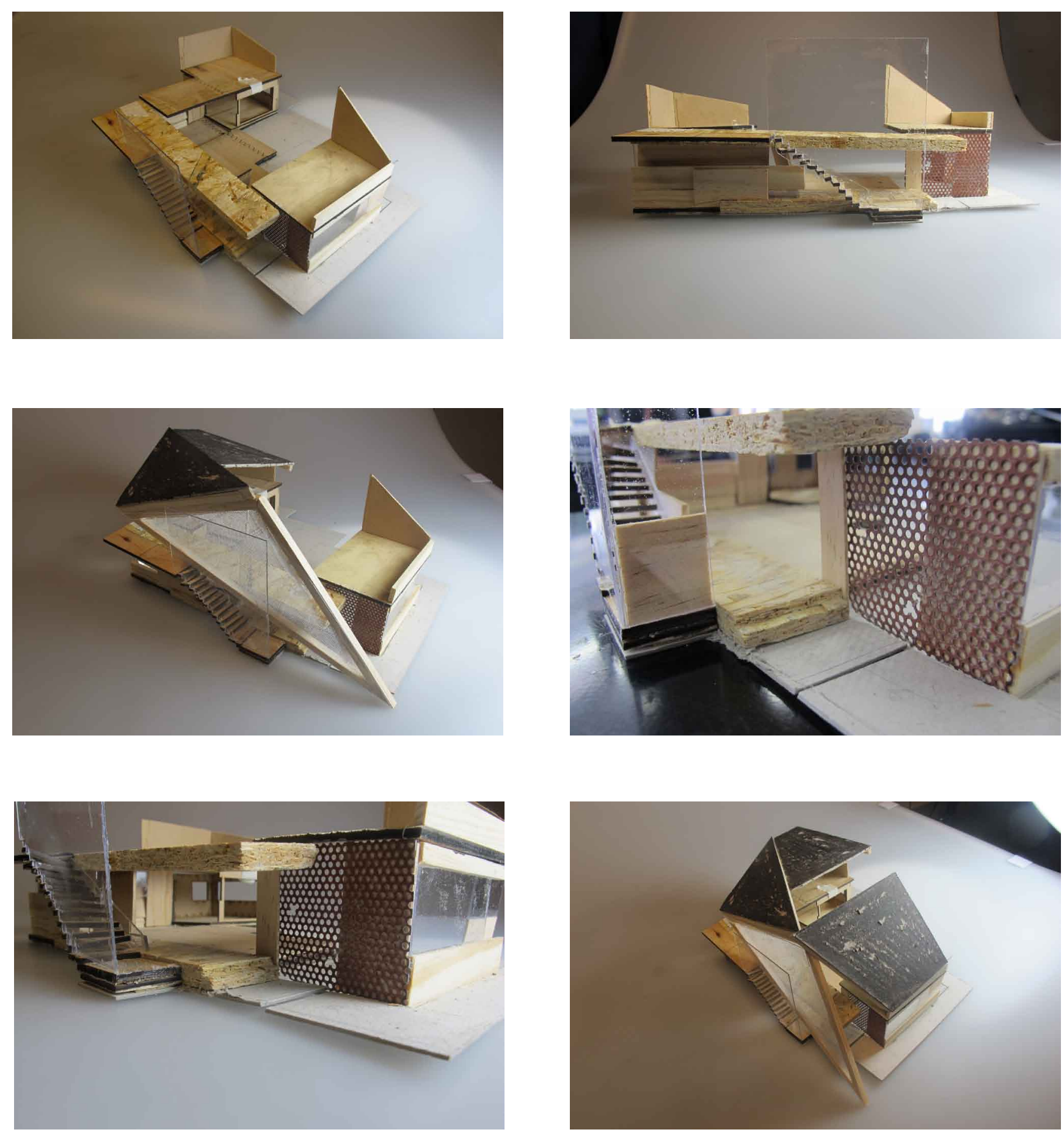

Fig 98: Conceptual Abstract Models 1:50. 
Planning

The planning principles have been controlled in the 1:50 model through the use of different materials. The material shift expresses the change from public to private zone through an evident floor joint using the ogee pattern. The ogee pattern was a traditional pattern used in the Victorian villa for both ornamental and functional reasons such as moulding and guttering shapes. It is used in the model as a way of exploring different scales. The model expresses how the distinction between spaces can be controlled. No specific materials have been determined.

Hallway

This model expresses the hallway in a larger and thicker material on both the ground and upper floor. Although the hallway is linking in with the other living zones, it allows the space to have a unique character and denotes its important connection to the past social living of the Victorians. Due to the material thickness and aesthetic it becomes a visual element from the exterior. This further emphasises its importance.

\section{Screens}

The traditional meat safe mesh has been used in this model to provide a screen between the entrance and the living zone. The screen being perforated, allows limited vision into the living zone making the visitor intrigued. This links to the traditional relationship of the visitor approaching the 90 degree angle of the verandah and waiting to be greeted into the home. The idea of screens could further be manipulated in other areas of the dwelling as a way of controlling the public to private relationships.

Layers

The idea of layering which came across as a prominent characteristic of the traditional materials could be used as a method of further controlling vision and privacy within the house. In this model layering has been used as sliding walls to allow the internal occupant to control the view and light into interior spaces. The horizontality of the sliding planes further creates a connection to the horizontality of the weatherboards traditionally used in villa's.

Roof

The notion of layers has further been reviewed in the construction of the roof. Externally it displays a solid material and further layered to the internal with material to create an aesthetic on the inner ceilings.

The roof structure was very dominant in the abstract model therefore the material choice needs to be sensitive to the site.

This chapter has allowed the roof and planning principles to be explored at various scales. A conceptual plan and form has been determined. The outcome from this set up a base for which the next stage of development which can be further be applied to a contemporary living situation. It will further develop the conceptual plan and aim to embody the qualities found through the material study and abstract representations of this chapter. 

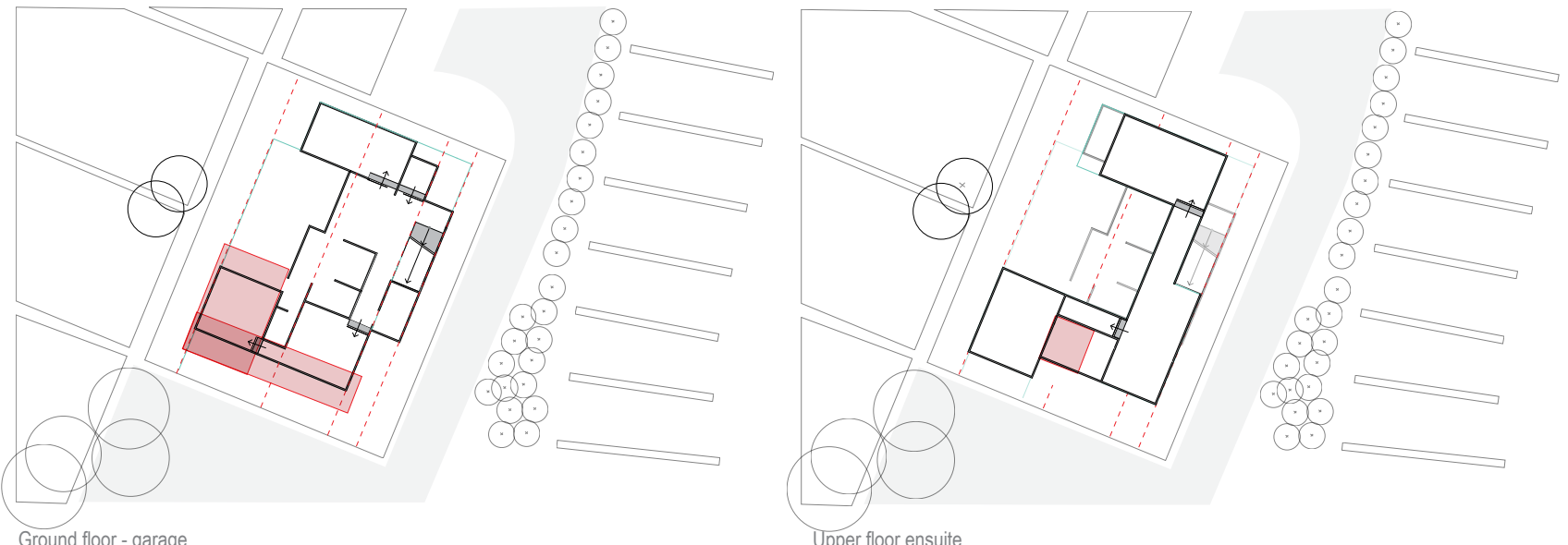

Ground floor - garage

Upper floor ensuite
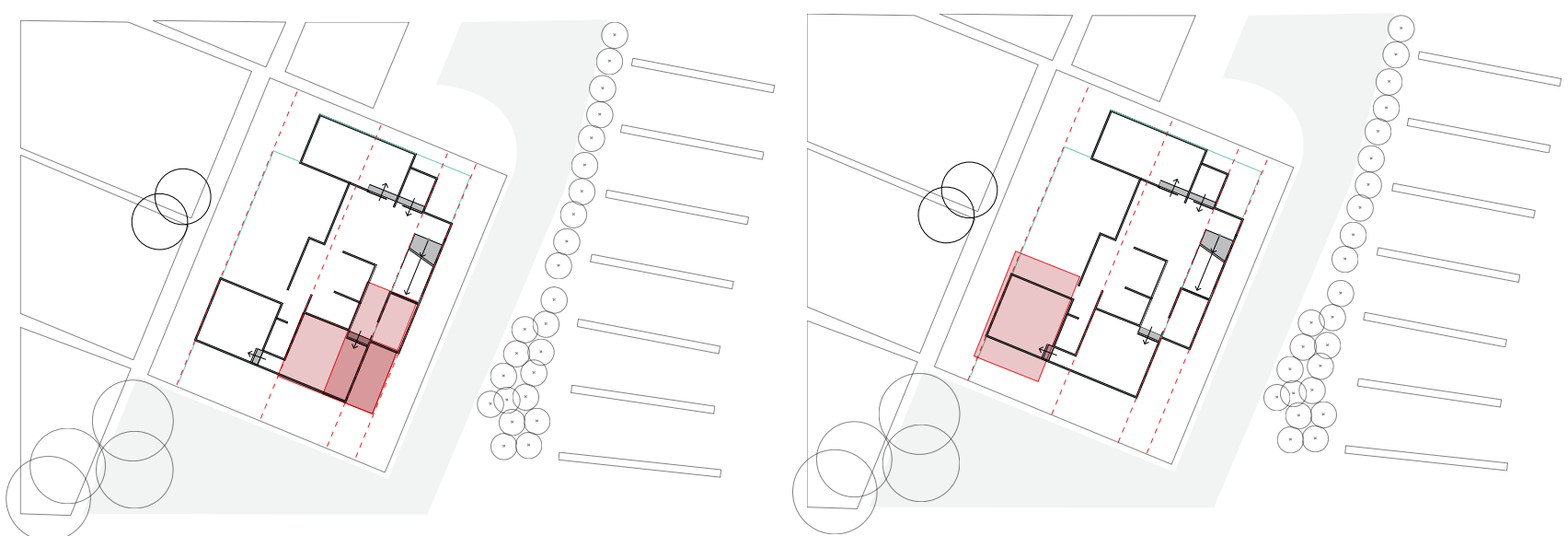

Ground floor - children space / tv room

\section{Ground floor - office}
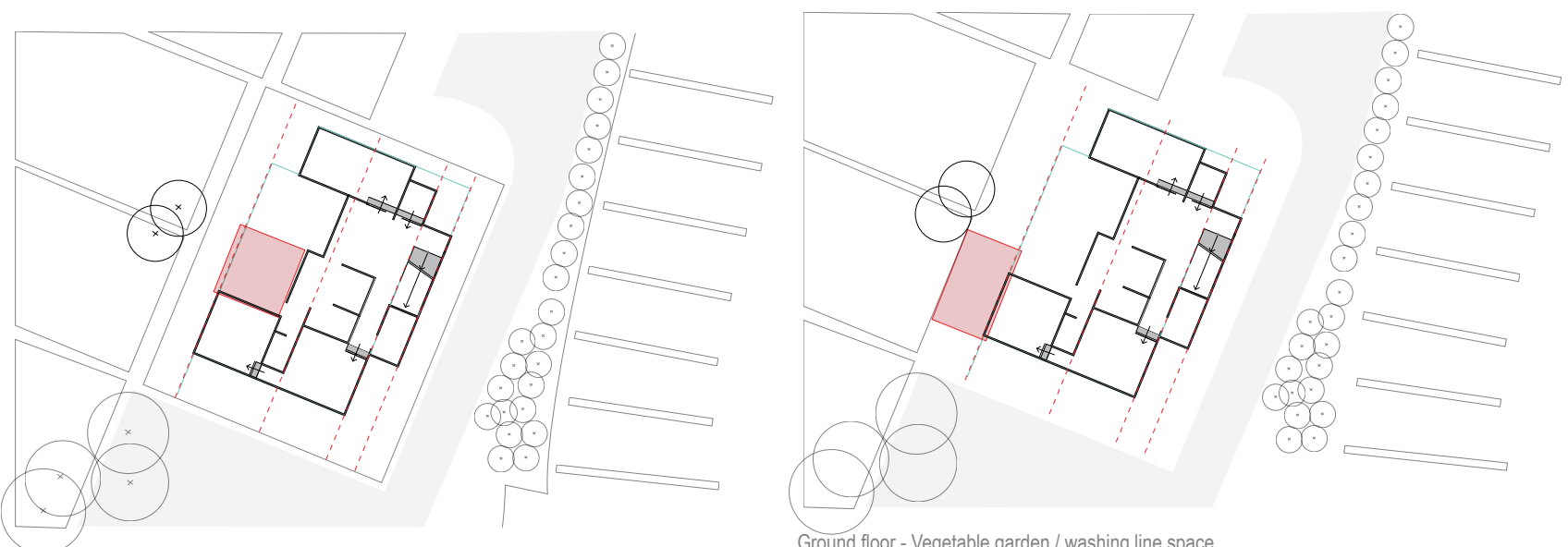

Ground floor - outdoor cooking area

Ground floor - Vegetable garden / washing line space

Fig 99: Contemporary Room Placement: The conceptual plan already designed for this site accommodated the traditional villa rooms which are still relevant today the kitchen/living/dining/bedrooms/bathrooms and outdoor space. There are now specific client requests for rooms that need to be catered for in a contemporary design these have been generalised down to the bathroom ensuite, the office, the garage + alternative parking space, and the tv room. $\mathrm{A}$ further diagrammatic experiment was done, to suggest were these contemporary spaces would best fit over the conceptual plan already design. This will allow the development of the design to further include the contemporary spaces. 


\section{The Contemporary Villa}

The preceding design iterations have allowed the roof and planning principles to develop a conceptual plan for a contemporary New Zealand Villa. In order for this conceptual model to keep developing it needs to be applied to specific modern day requirements. This experiment provides an example as to how the character of the traditional villa can be explored through a contemporary manner for a contemporary client group. The client group chosen to test the conceptual design is the contemporary family unit. For the purpose of this exercise the contemporary family has been generalised. The parameters have been distinguished from data taken from the Wellington region 2006 Stats New Zealand Census (See Appendix 2).

\section{Hierarchy and Planning}

The design outcome is primarily concerned with the occupational language of the traditional villa and its placement in a contemporary lifestyle. It has been derived through the analysis of the traditional villa and the contemporary roof and planning principles developed earlier in the research. The degree at which the aesthetics and material has been designed is to suggest how the visual and materialistic qualities can influence the way the space is occupied. For the scope of this project the ogee pattern, a common pattern used for the ornamental and functional objects of the traditional villa's has been used as the ornamental driver to test ornamentation at different scales. It has been used to explore various functions for occupational requirements of the contemporary villa internally, externally around the three dimensional facade. This is primarily to keep coherence of the scale and would develop with further analysis of ornamental studies. The degree at which materials have been developed is purely for visual representation and to express the materials shift from one spatial zone to another therefore specific material decisions will not be discussed within this final chapter.

The spatial planning of the design provides ease and comfort for the movement and living of the contemporary family. The following stage will present the spatial arrangement of the villa through plans and section and further explain how the spaces are occupied and used through perspectives. The perspectives will aim to present how the design compares to the traditional domestic lifestyle of the Victorian society but now still caters for contemporary needs.

The developed roof form is best presented through the north and east elevations. Each express the way the roof form folds around the dwelling and shows were the angles and thresholds have been implanted to control the internal living spaces. The roof pattern expresses a horizontal nature that links the roof back to the traditional weatherboards used in the villa. The horizontal lines are used to control thresholds and movement of the roof planes. The roof as a facade is further analysed through the context and environment to suggest how the immediate site context can work with the roof plane to allow the dwelling to function from an aerial scale as well as a human street scale. 
Ground Floor Plan 1:100

Fig 100

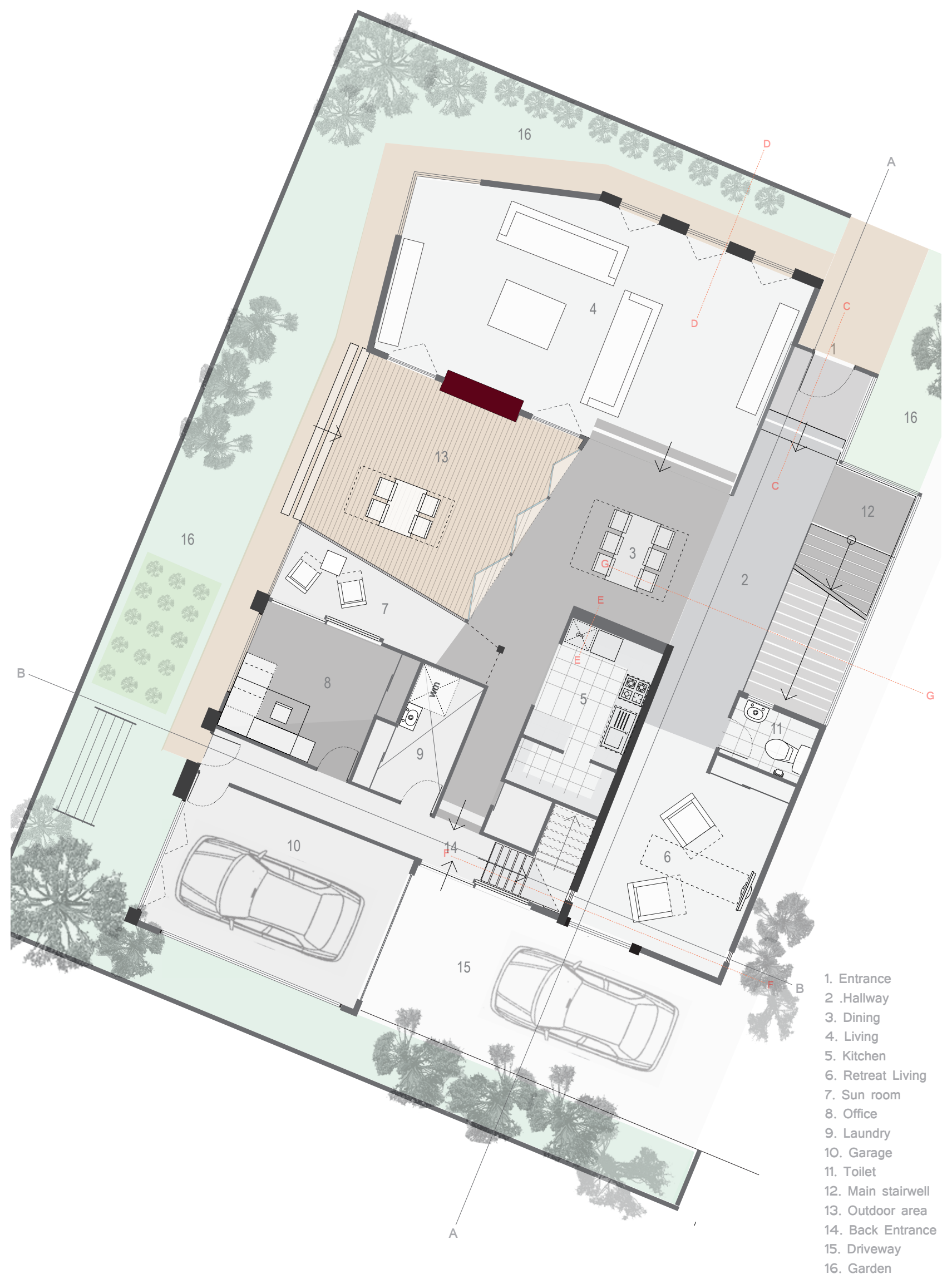


Upper Floor Plan 1:100

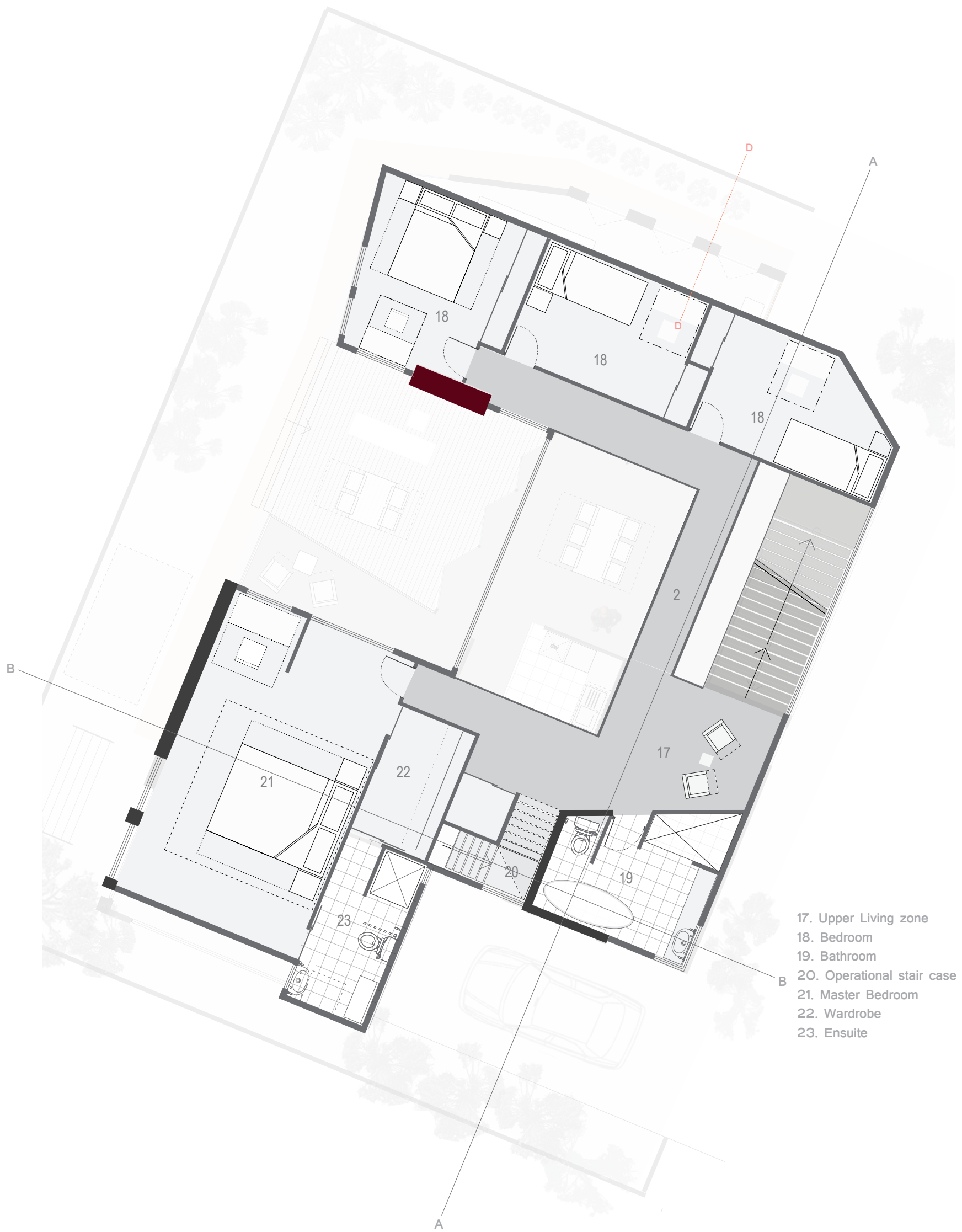




\section{Entrance}

The entrance maintains the similar language to the verandah and front floor relationship of the traditional villa. Upon entrance you are similarly at a 90 degree angle waiting to be let in. A perforated wall blurs vision into the space and creates intrigueness as to what the function of the space is for any uninvited or new guests. The entrance allows the family to have authority over guest having the living floor plate elevated above the entrance with a window to observe who is at the door. To open the front door you mediate down to this lower level where the window changes to a mirror, allowing the residents to check themselves in the mirror before letting their visitors enter or leave the house. The use of mirrors in the traditional hall way was highly required for the Victorian family to ensure they were always well presented. The entrance plane links round the dwelling to provide a connection to the back of the home and creates a threshold between the living space and front garden.

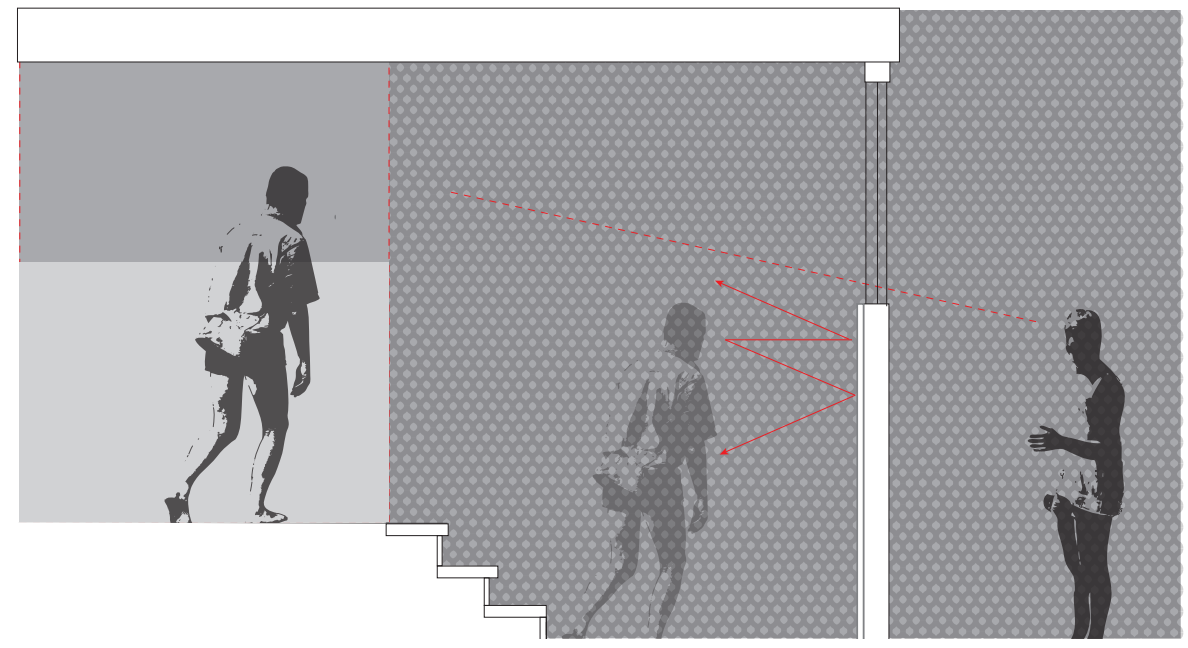

Fig 102: Section CC: The movement of the resident viewing and meditating down to answer the door to the visitor. 


\section{Parlour}

The contemporary link to the traditional parlour and bay window relationship is through the movement from the entrance point up into the hallway, dining and further around and down into the living room. It creates the notion that you have been allowed access into the main space that is only visible from the street through the three front windows (see north elevation). The displacement of the floors allow the living spaces to have separate roles whilst embodying a communal connection. The living room is situated on the north west corner of the home therefore recieves maximum sunlight.

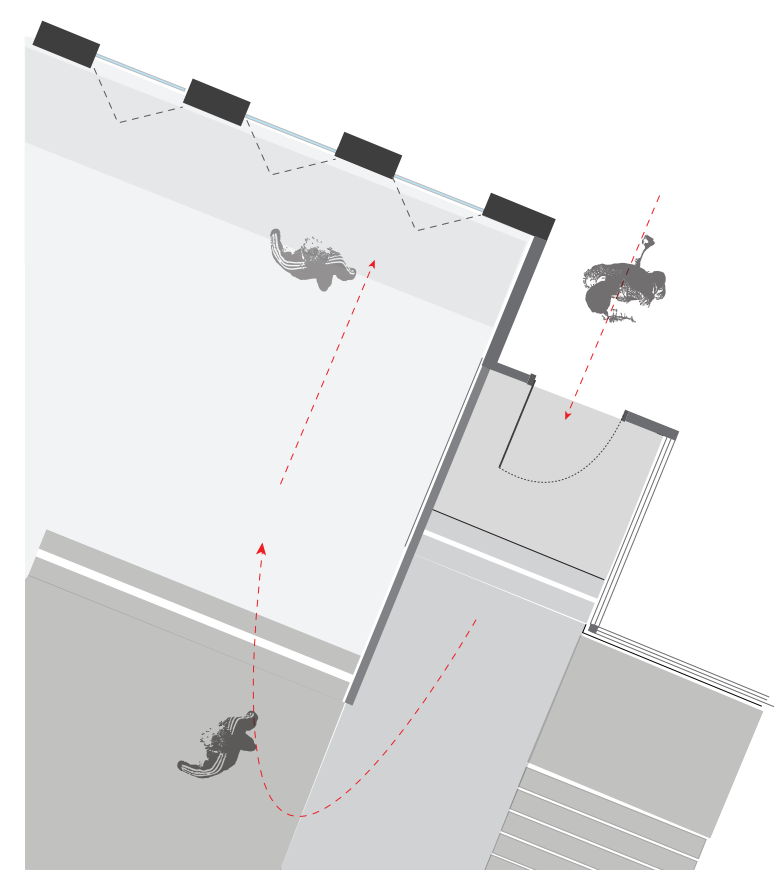

Fig 103: The movement of a resident or visitor from the entrance to the living room. 
North Elevation 1:100
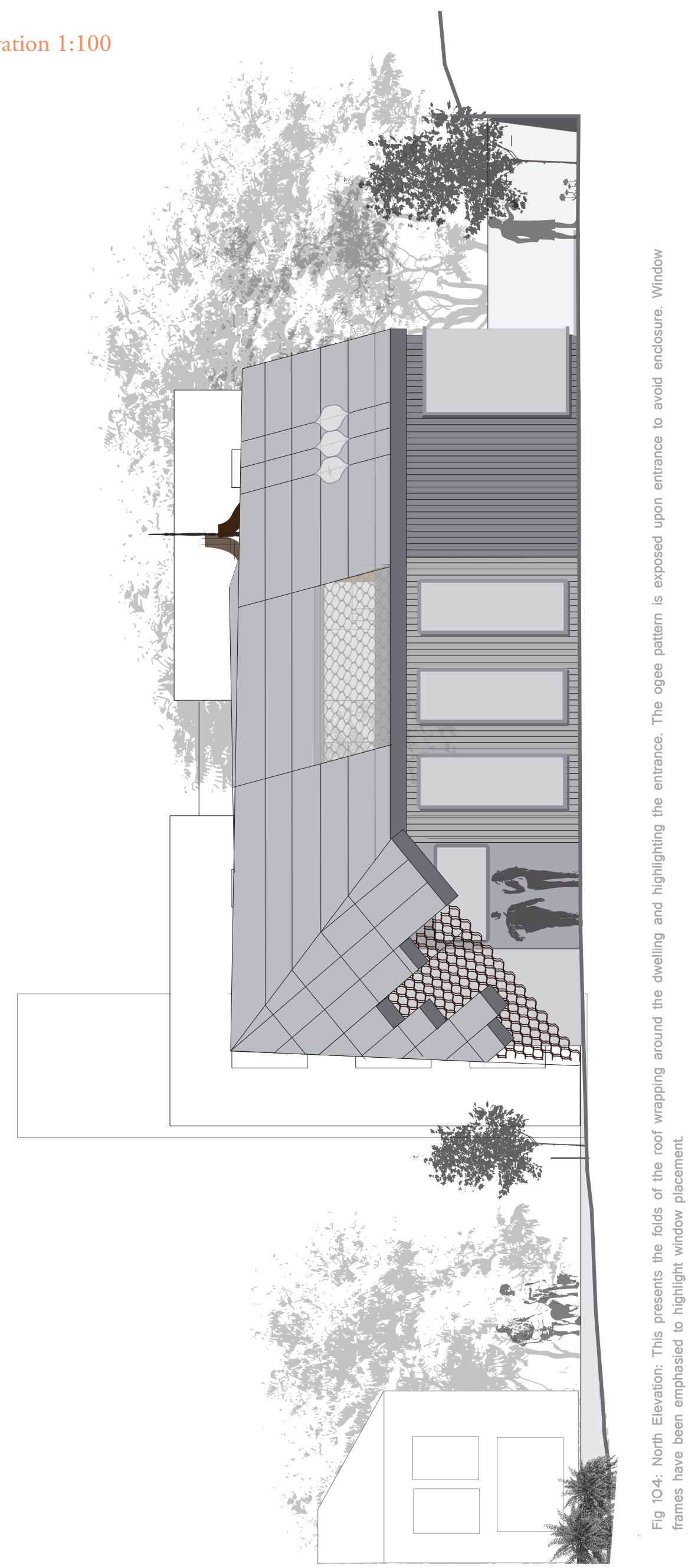


\section{Bay Window}

The connection to the bay window is reinterpreted through the northern roof angle wrapping down around the front wall creating a dominant element of protection and view of the people passing and entering the home. The three windows leading down from the roof are pushed forward in plan and angled back allowing the prominence of the windows to be evident by passing public. Within the living room zone this area becomes a space of retreat were you can sit and view the northern hillside of wellington. It meets with a vertical sun zone created by the double height space above. The framing around the three windows has been widened to allow the window to be encased in a dominant framing; signifying their importance (see north elevation).

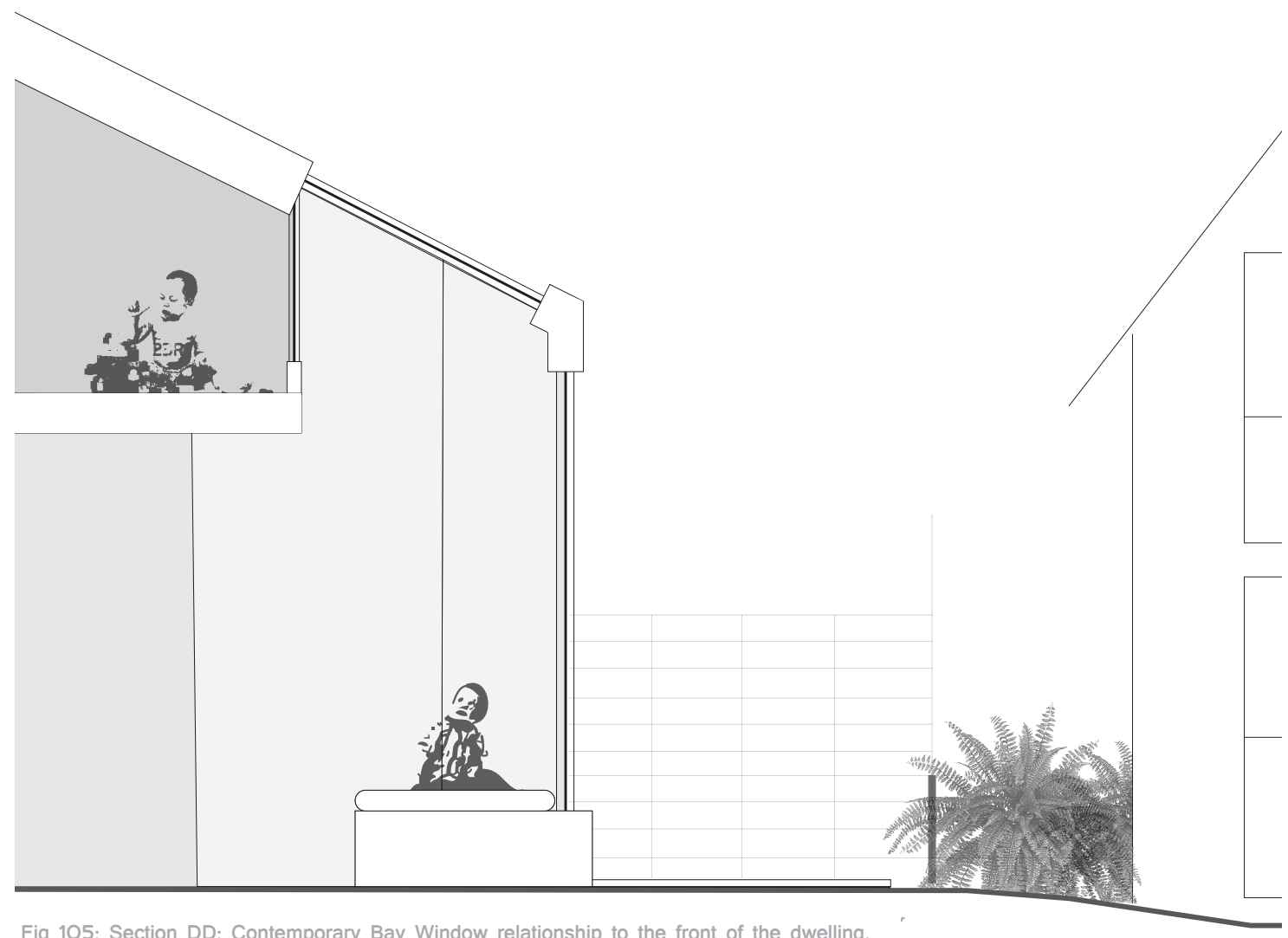

Fig 105: Section DD: Contemporary Bay Window relationship to the front of the dwelling. 
Section AA 1:100

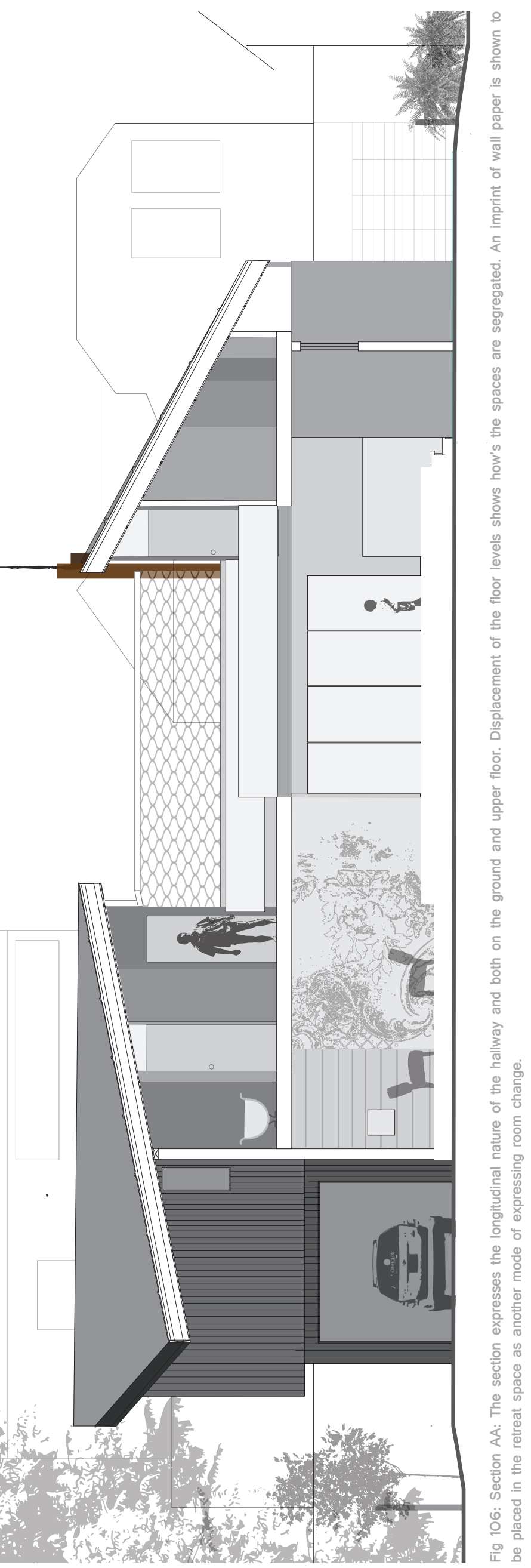




\section{Hallway}

Upon entrance into the villa the space in controlled by an open hall way which passes through the main stairwell, dining and kitchen space. The hallway creates a longitudinal connection down the house leading to a destination living retreat space. The retreat is designed to cater for technology and entertainment for children. The floor is displaced lower than kitchen and dining to segregate the space and create an element of separation (see section AA). The hallway extends vertically to the upper floor where it allows double height vision into the dining and kitchen through the use of a dwarfed barrier. Its presence becomes evident in the upper floor bathroom creating a zone within the bathroom for the toilet to be placed. It provides direct access to the 3 upper floor children's bedrooms. The hallway expresses its spatial quality through a shift in materials. This has been achieved through the uses of vertical timber floor boards a different colour

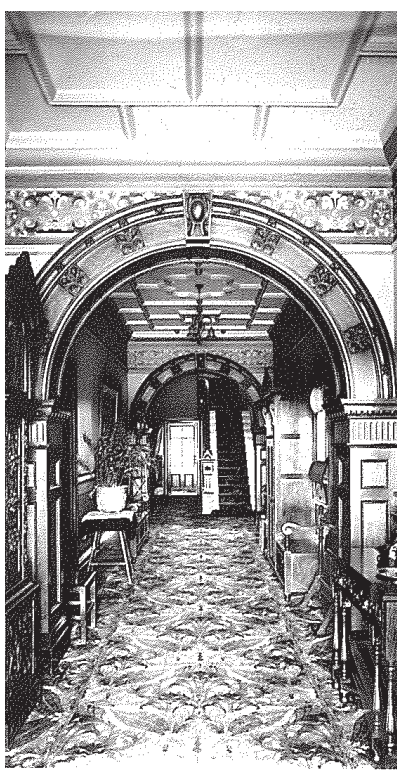

Fig 107: Image of nineteenth century hallway. This expresses the cluttered and ornamental nature of the room and the generosity of volume and space (Stewart, 1992: 53) to the floorboards used in the other living areas.

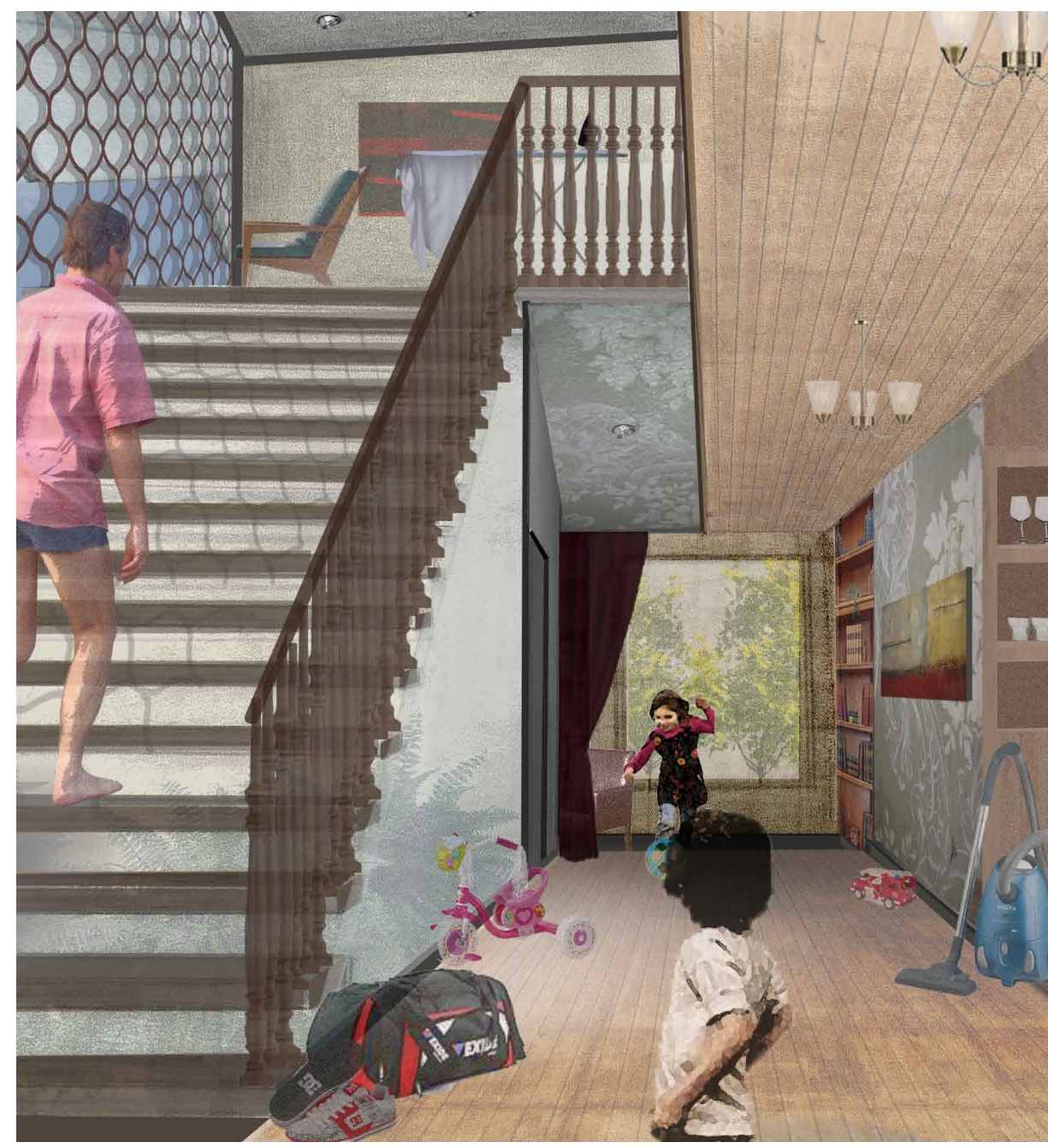

Fig 108: Contemporary hallway perspective expressing the lifestyle change and nature of a modern hallway. 


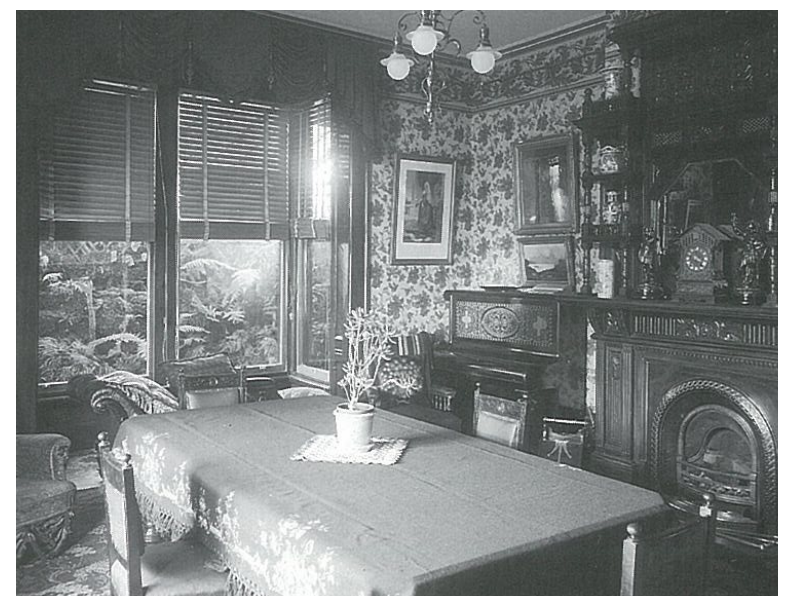

Fig 109: Traditional Dining Room, 1905 (Hanson, Salmond, \& Reynolds, 2010: 47)
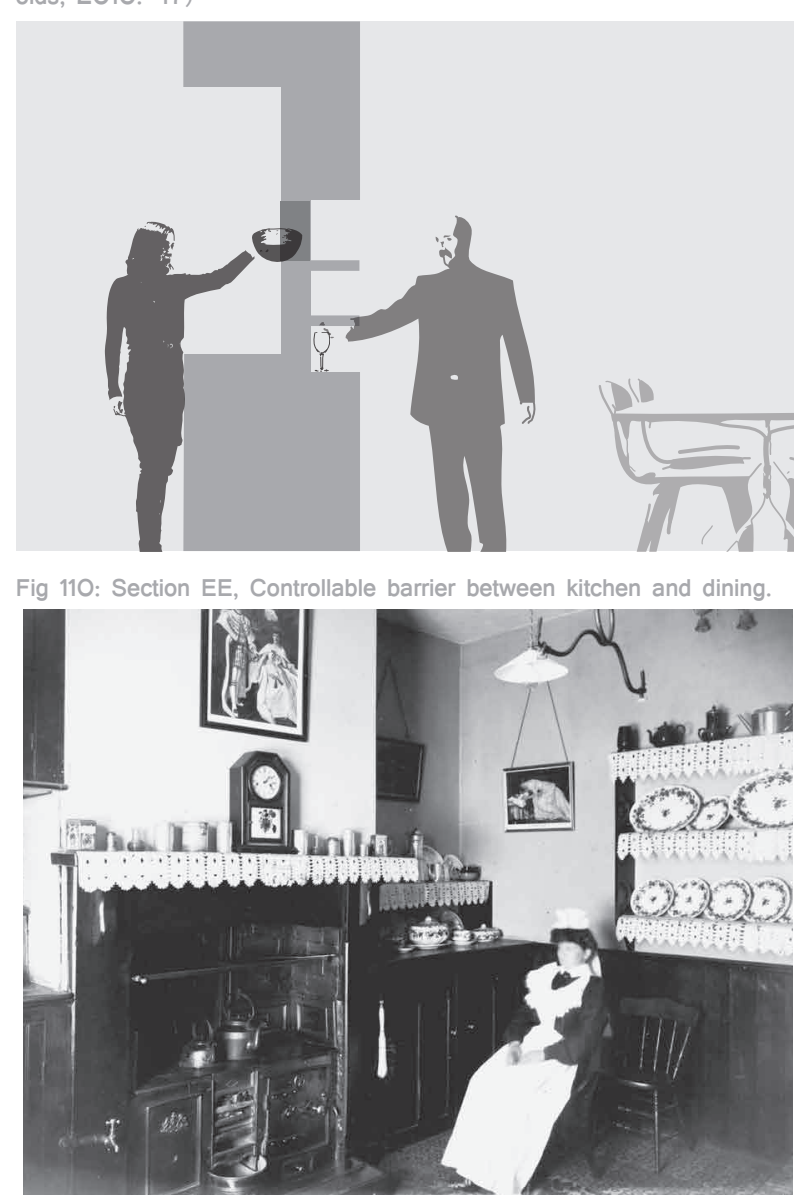

Fig 111: Traditional Kitchen, 1905 (Stewart, 1992: 67). 


\section{Kitchen dining}

The kitchen and dining room relationship aims to experiment with the notion of the traditional room separation vs a contemporary open plan. Upon entrance the dining space acts as one room, however the use of a double height and a shortened wall allows the kitchen to be placed behind it. Once in the kitchen you are open up to the entire back of the dwelling, allowing vision to the outdoor area and living room. The wall that divides the space has a built in control device to open up the spaces to each other. This uses a small screen that can be pulled back to allow communication between the spaces.

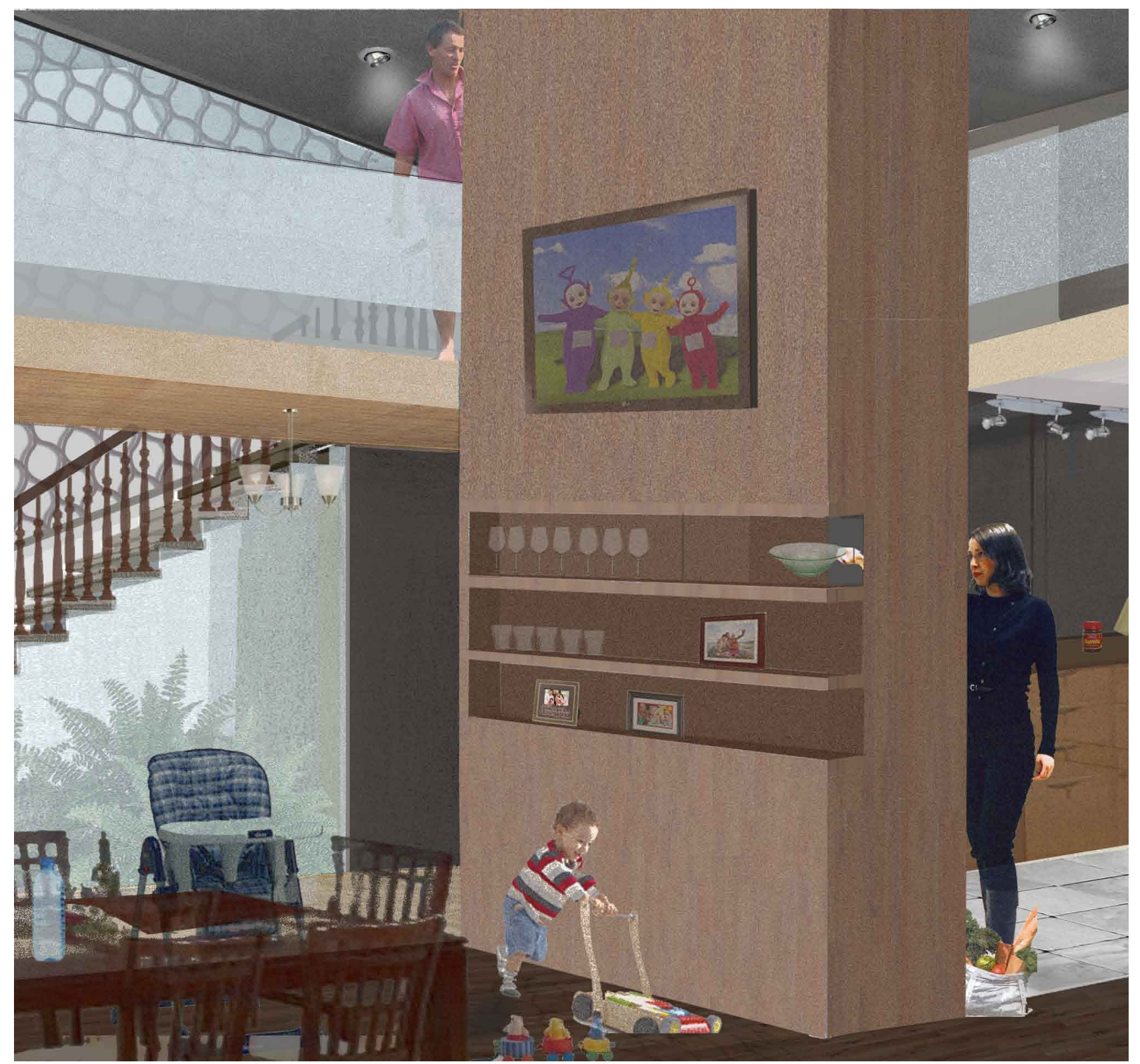

Fig 112: Contemporary kitchen and dining relationship expressing the communication between the two zones and the ability to be viewed from above. 
Section BB 1:100

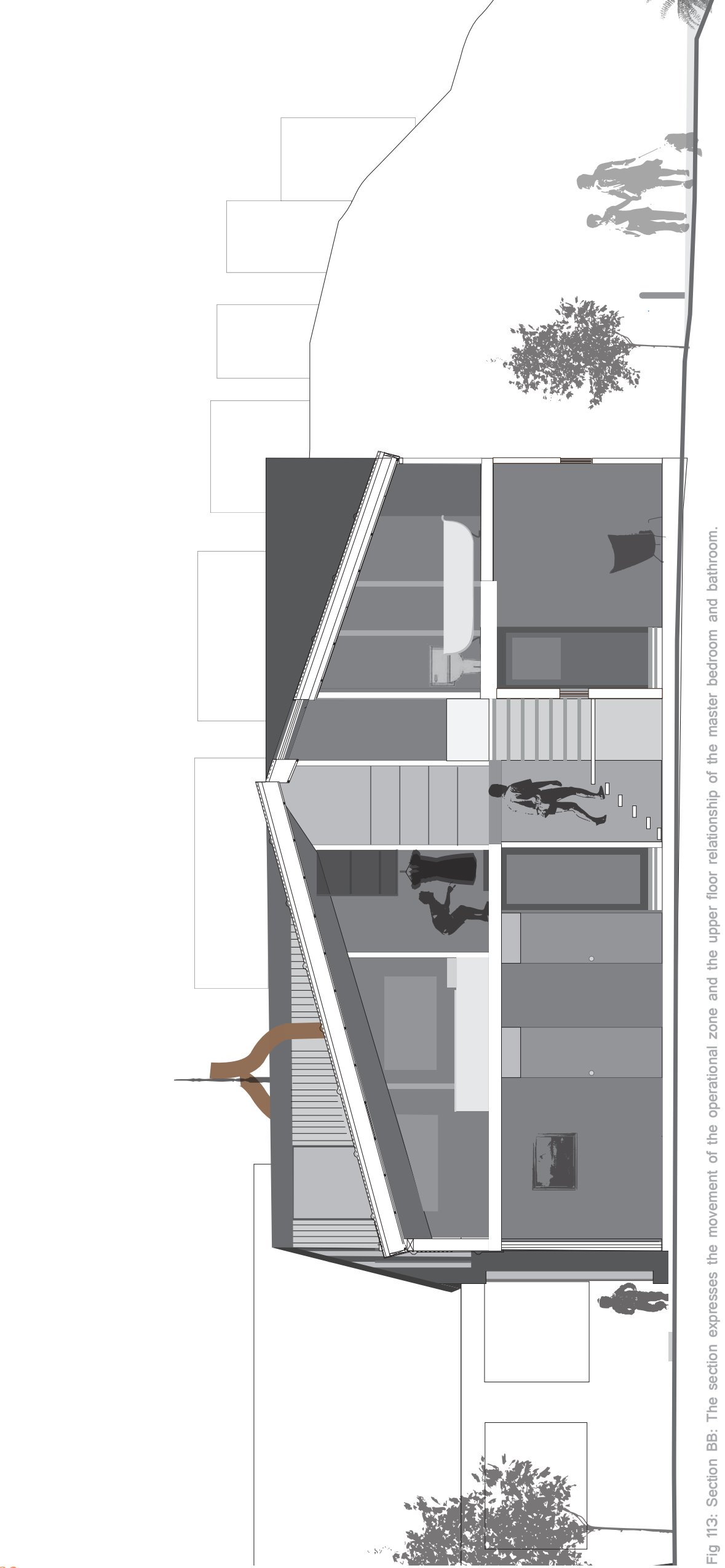




\section{Operational Zone}

The 'operational zone' operates the back of the dwelling. This provides a secondary entrance into the dwelling and a secondary stair-well. The stair well provides ease of access from the upper floor bedrooms and bathrooms to the laundry downstairs, with direct access to the outdoor area. The stair visually connects through to the retreat living zone through a window placed at eye level linking through the retreat zone to a view of the city. The garage connects with the operational zone allowing the family an option to go upstairs, to the office or through to the living space. The sunroom operates as private threshold, functioning as an internal verandah this creates a barrier between the office and outdoor living (see ground floor plan). This threshold allows the office zone to be opened up to the entire dwelling.

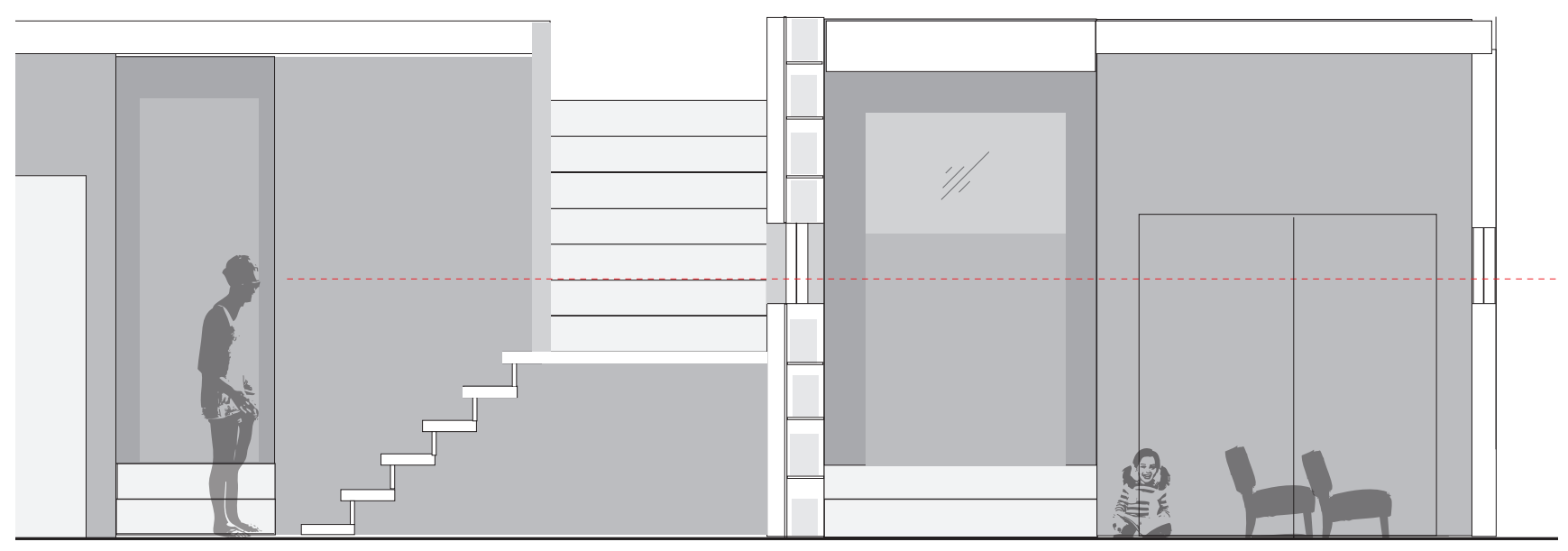

Fig 114: Section FF, The window to the city is embedded within the library wall of the retreat space, this allows a deep frame to be created that can only be experienced when passing through the upper stairs. The view back from the retreat space allows direct vision to the back garden. 
East Elevation 1:100
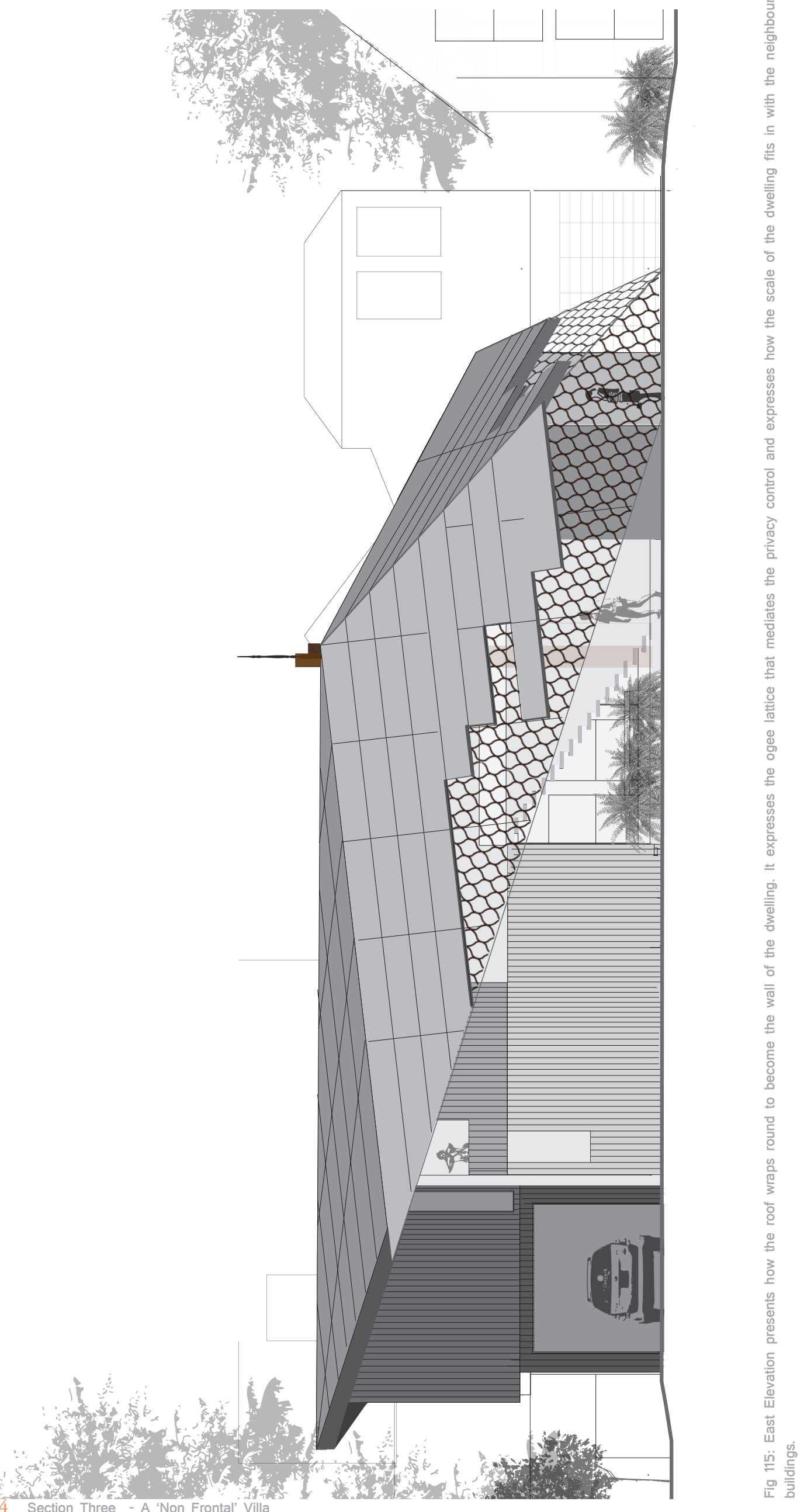


\section{Outdoor area}

As discovered through this research the facade has become a visual element both from the vertical plane of the street-scape to the horizontal plane of the aerial view. The design aims to express how the exterior view of the villa and its context in both vertical and horizontal planes can explore the traditional language in a contemporary way.

\section{Vertical Plane:}

A defining element of the traditional villa typology is the front verandah, it appeared in the research that the traditional verandah was no longer relevant in the twentyfirst century except for its ability to create a threshold between one zone and another. This relationship has been reinterpreted and is expressed in the design through various points in the design as seen earlier in the sun room functioning as an internal verandah and a threshold between the office and sunroom.

Another reinterpretation of the verandah is expressed through the relationship of the east facade through to the dining and outdoor zone. In this development planting has been placed underneath the main stair-well to act as a buffer between the public realm and the glass facade.

Privacy has further been controlled through the uses of a medium scale timber lattice, using the ogee as the ornamental pattern. The lattice appears to be tearing away from the roof structure above, as method of peeling back the facade to reveal the internal living sphere. It also wraps around to conceal the entrance space, while creating perforated vision though to the waiting zone.

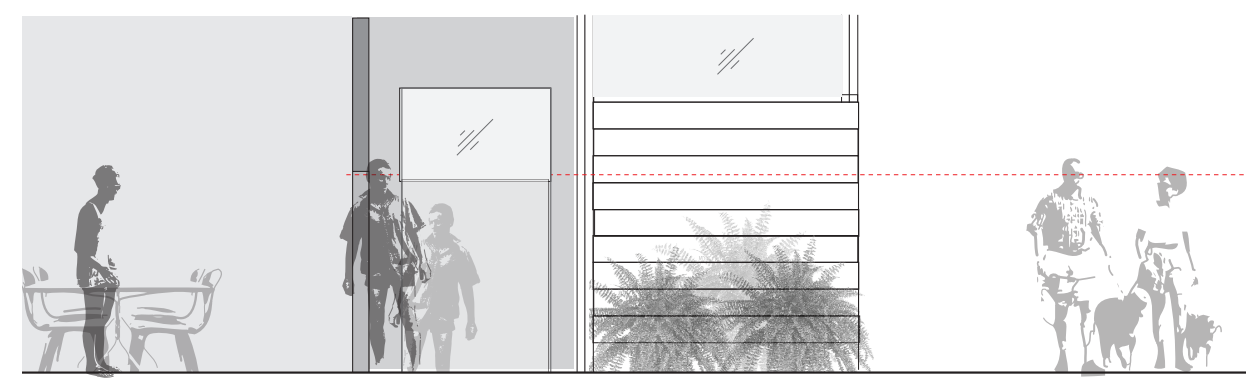

Fig 116: Section GG: The relationship between the dining/hallway/main stair case and the public realm.

The placement of the windows within the house has been introduced as functional windows for specific purpose within the rooms. The windows vary in shape and size depending on the function they are providing to the internal occupation space. 
Horizontal Plane

The horizontal plane goes beyond the roof to embody the immediate external context; the garden, driveway and outdoor area. The horizontal facade needed to take into consideration the elevated views from above and the surrounding buildings.

The garden plays two roles in this design. The north west corner wraps the front of the dwelling around to the back, allowing this space to be used for multiple options and linking to the outdoor decking area. The outdoor area expands down to site level and uses vegetation to provide a separation between the front and back garden. The back garden whist in line with the front is placed on the south west edge allowing the sun to still be gained and a suggested zone for a vegetable garden.

There is one main fire place in the dwelling that functions for 2 zones, the main living room and the outdoor area. The fire place becomes an element of ornamentation in the dwelling but further carters for the function of the 2 main communal zones. The design of the fireplace embodies a symbolic reference to traditional finial often placed on the front facade at the apex of the villa roof. In this design it acts as a reference point of the dwelling from both the street view and aerial view.

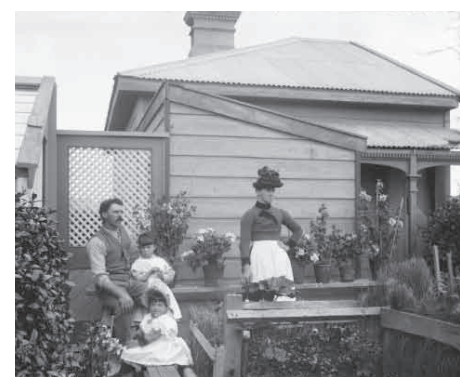

Fig: 117: Family out the back of a domestic garden 1889-1910. Image expresses the functional aspect of the back garden over the well maintained front garden [Photograph: Henry Charles Clark Wright]

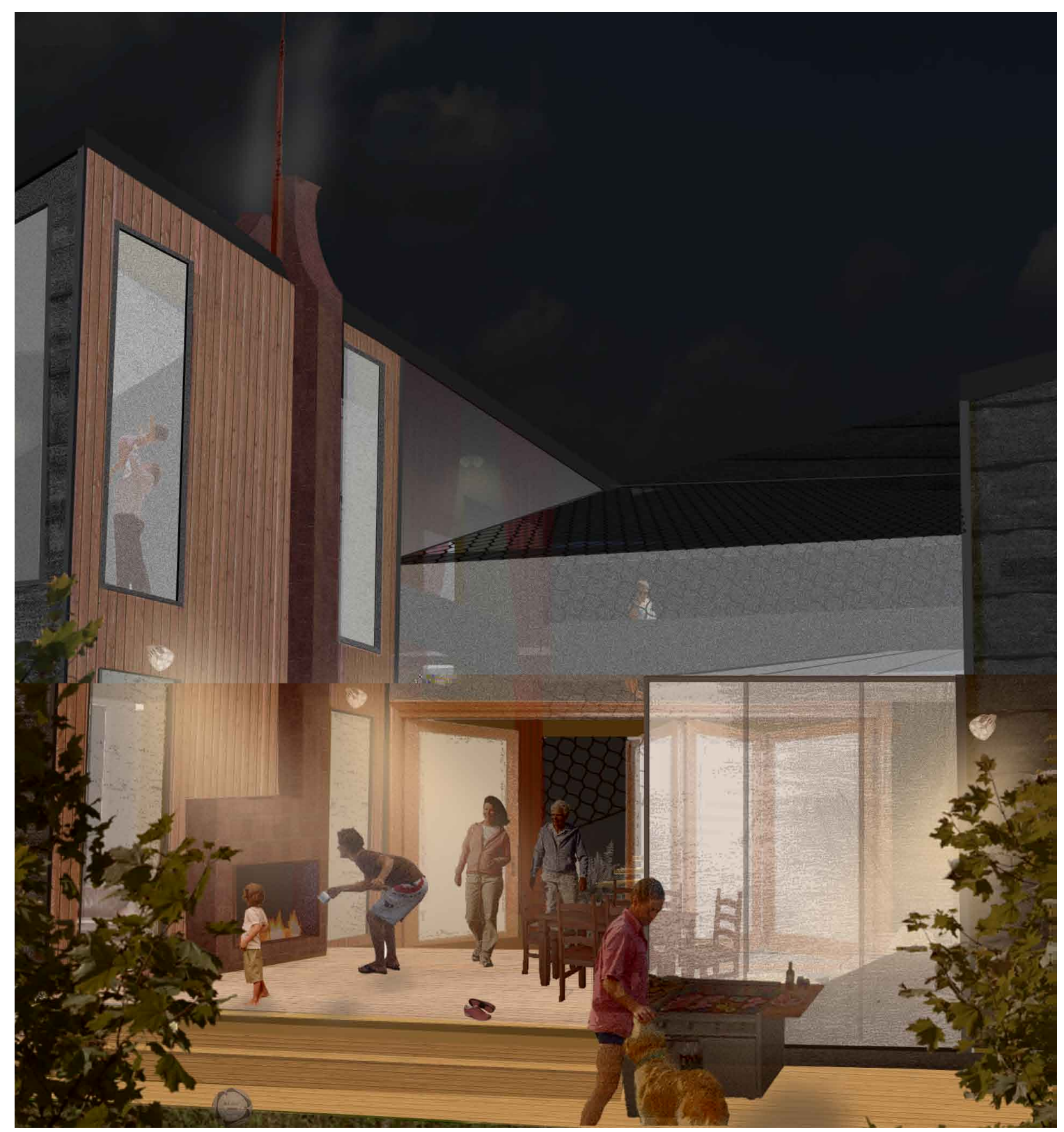

Fig 118: Outdoor Perspective view looking back into the dwelling and showing the fireplace, its finial reference and how it functions for the outdoor space.

96 Section Three - A 'Non Frontal' Villa 
Roof Studies - The Horizontal View

To conclude the design phase research further experimented with how the language of the garden, roof and outdoor area could begin to be read as one element from above whilst function as different occupational zones from within. An experiment was done to suggest 4 possible conceptual options of how the roof form could be treated to cater for the elevated aerial views. It became apparent in the design that the form that worked well from the aerial was the use of circles or ovals as it complements the angles and solidity of the roof. Its contrast to other roof forms becomes a symbol from above that could potentially evoke attention. As a concept it expresses that design and architectural change now need to cater from the aerial view.

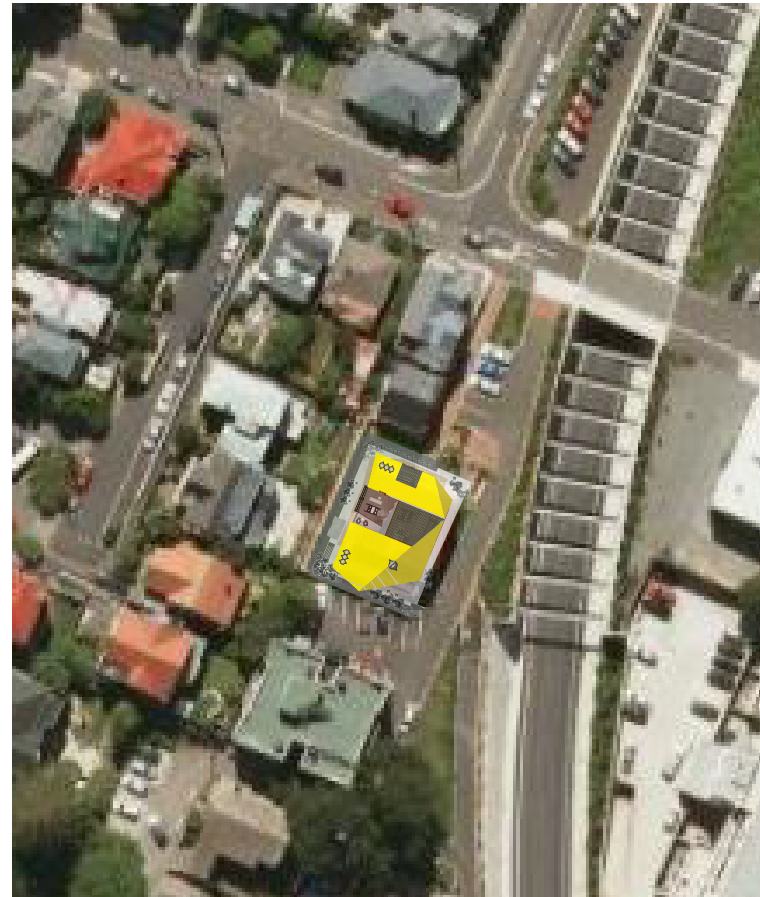

Colour used for a roof element creates a unique element in a residential environment. It will draw attention to the roof from above.

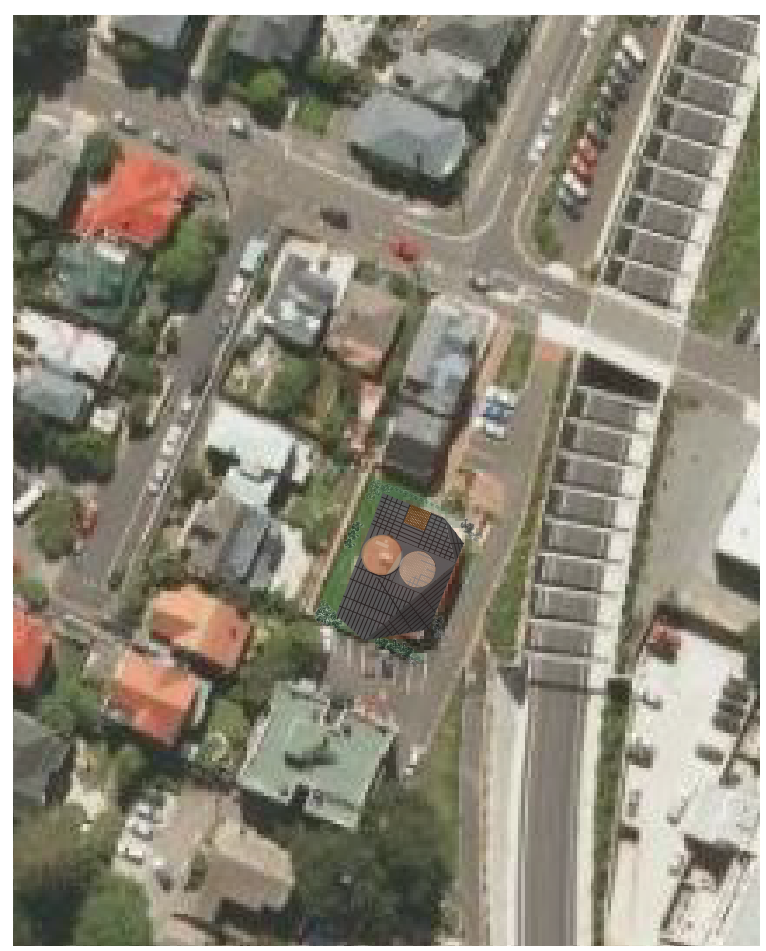

Circles contrast the sharpness of the roof and neighbouring roofs. The organic shape could draw attention from the aerial view as it is uncommon and contrasts the sharpness of the surrounding roofs.

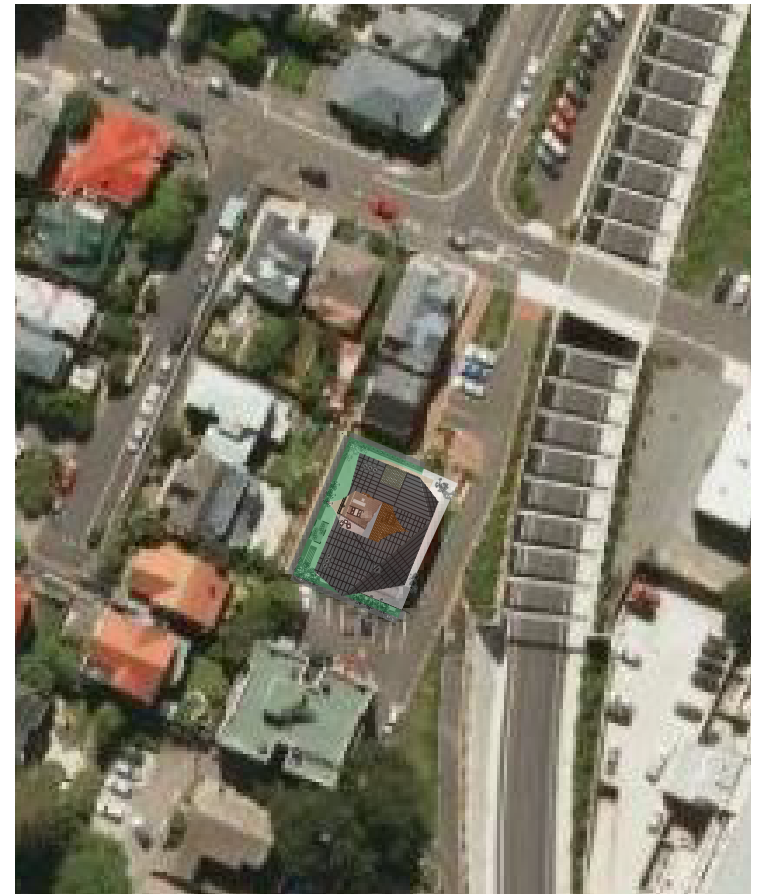

This option explores the Ogee pattern at a Macro scale allowing the shape to be evident from above, whilst implemented within the spatial planning of the home.

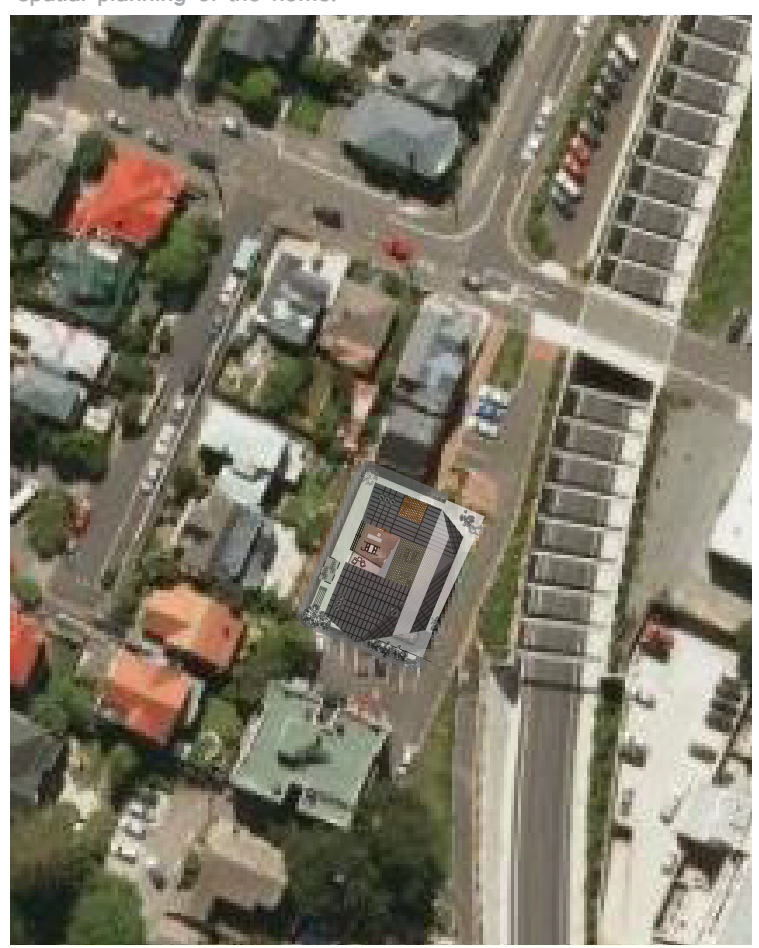

This option explores bringing the important elements from within the dwelling to the exterior envelope. This experiment makes the hallway visually evident from above. 


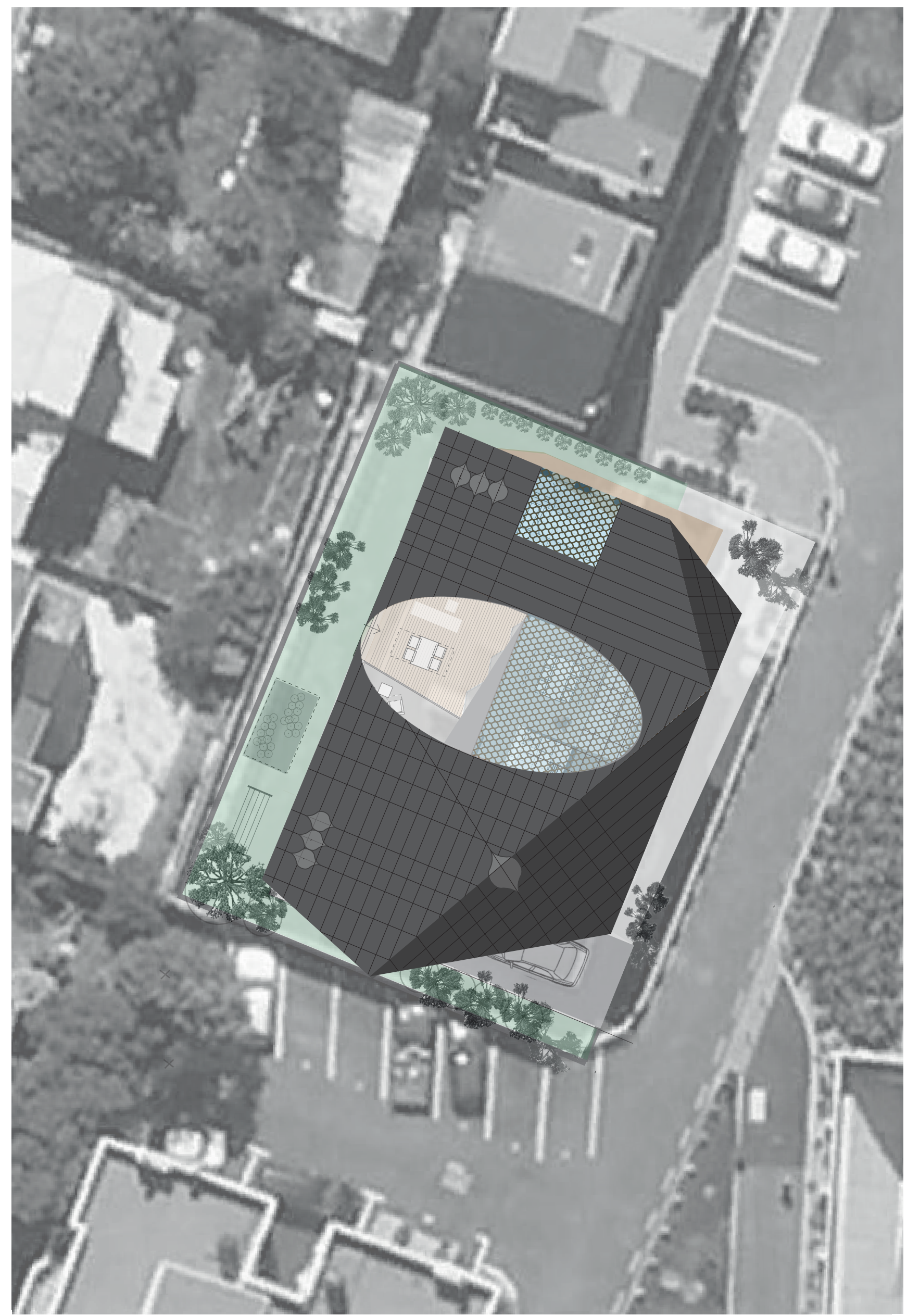

Fig 120: Aerial view with developed roof view presenting the organic oval used in the view from above. This is to contrast the solidity of the roof and provide an element that could evoke attention. 


\section{Conclusion}

This research began with an observation of the much loved New Zealand villa in contemporary society. Villa's are increasingly becoming referred to through the aesthetics of their facades and disproportionately valued for their streetscape presence.

A review of the traditional New Zealand villa from its origins to its place in society today revealed a number of themes. It became apparent that in order for the villa to hold a connection to history, changes to the interior and exterior envelope need to be implemented that value not only the aesthetic but the social history of the traditional villa. Architectural change needs to assess the traditional design of the villa through a contemporary lens and apply the concepts assessed to the building in its entirety - at different scales, planes, interior and exterior. A complete understanding will allow the cultural integrity of the villa to continue to develop as its contextual environment changes.

The first theme, determined in Chapter 4, was the continual development of the internal plan of the villa. The interior has forever been adapted and remodelled to fit with societal changes and occupational demands, while the exterior has remained dormant as a way of preserving the past. Present day facadism, referred to in Section One, only discussed the vertical nature of the method; the aesthetic of the front facade creating an idealised image of a time that has since passed. The front facade, while deceptive, is not the element hiding the modern changes. It became apparent that the roof is acting as a horizontal element of the facade. The roof is the element that conceals from above the modern changes made to the plan. A view from above incorrectly suggests that the entire dwelling is still in its original state within a community of villa's, recognised by the repetition of well kept gable roof forms. While at the beginning of this thesis the concern was based on the vertical plane of the streetscape facade the research has uncovered that the entire external envelope appears to have stopped developing as society continues to change. Consideration now needs to be given to technological advancements that have placed greater emphasis on the aerial view.

The second theme questioned how the villa would appear if both the plan and roof had simultaneously developed with societal change and time. The principles derived in Chapter 5 for the roof and Chapter 6 for the plan creates a base for which a conceptual model of the villa can be implemented. The principles successfully achieved a contemporary connection to the past through a spatial and occupational language. This is evident in the proportion, movement, spatial relationships and control of private and public zones within the contemporary design. As the Victorian tradition was the generator, the developed design retains Victorian concepts of space and interaction, but re-interprets these in a contemporary architectural language. Research has uncovered that the two cannot, and will not, maintain the traditional villa aesthetic. 
While the scope of the research did not focus on the aesthetics, it has become evident in the design outcome that aesthetics are a defining feature that links a dwelling to its past. The design stage presented in this research has yet to review Victorian aesthetics through a contemporary lens, therefore, the outcome does not visually resemble the traditional villa. As seen within the spatial principles presented in this thesis, there is possibility for the traditional aesthetics to be reinterpreted through a similar methodology. Such a process would allow architectural changes to retain Victoriana aesthetics in a contemporary light. This thesis argues that there is more to heritage dwellings than mainlining and replicating its traditional exterior aesthetics. A focus on the facade alone continues to result in a loss of a building's cultural integrity. The villa was not designed as an aesthetic object, it was designed to cater for a growing society and nineteenth century lifestyles. As society develops and becomes further concerned with retaining a connection to New Zealand's past, replicated aesthetics become all the villa is valued for. This design outcome does not suggest that all villa's in society today should evolve to this contemporary level, rather it aims to prove that there is more to the New Zealand villa than the aesthetic of the front facade. The research denotes that in today's contemporary environment the villa is a 'non frontal' dwelling: the aesthetic conditions of the three-dimensional exterior envelope need to be considered. The New Zealand villa can develop with time without losing its nineteenth century Victorian Society origins. This thesis contends the importance in understanding a problem from its origins to its present situation in order to determine what needs to be considered and implemented to allow a dwelling to adapt accordingly within the twenty-first century.

In practice, this thesis presented and established a methodology for reinterpreting any built structure into a new configuration. Understanding the villa further than its aesthetic and ornamental detail will allow its traditional typology and function to be reinterpreted into a contemporary context. A complete understanding, as presented through the spatial and occupational assessment completed in this thesis, will allow the cultural integrity of the villa to continue to develop within changing environments. This thesis hopes that by considering the villa as more than a streetscape aesthetic, its architecture can remain an icon, not only of the past but as a symbol of contemporary lifestyle.
7 The degree at which aesthetics have been considered has utilised the ogee pattern, one of many Victoriana villa aesthetics to test how aesthetics could influence and control how the villa spatially works for the occupants. 


\section{Bibliography}

Referenced Sources

Boldrick, S. (2007, August 7). Reviewing the Aerial View. Retrieved October 27, 2011, from Cambridge Journals: http://journals.cambridge.org/action/displayFullte xt type $=1 \&$ fid $=1293976 \&$ zid $=$ ARQ \&volumeId $=11$ \&issueId $=01 \&$ aid $=1293972$

Brooker, G., \& Stone, S. (2004). Re-readings: Interior Architecture and the Design Principals of Remodelling Existing Buildings. London: RIBA Enterprises.

Bryson, B. (2010). At Home. New York: Random House.

Cieraad, I. (1999). At Home: An Anthropology of Domestic Space. New York: Syracuse University.

Cook, M. (2011, July 4). The New Zealand Villa. (H. Wright, Interviewer)

Dalley, B., \& Labrum, B. (2000). Fragments - New Zealand's Social and Cultural History. New Zealand: Auckland University Press.

Evening Post. (1940, November 14). Clashing Styles and New Zealand Buildings. Evening Post, p. 7.

Hanson, J., Salmond, J., \& Reynolds, P. (2010). Villa from Heritage to Contemporary. New Zealand: Random House.

Heyden, H., \& Baydar, G. (2005). Negotiating Domesticity - Spatial Productions of Gender in Modern Architecture. New York: Routledge.

Jenkins, D. L. (1953). New Dreamland - Writing New Zealand's Architecture. Australia: Griffin Press.

Jenkins, D. L. (2011, July 11). The New Zealand Villa. (H. Wright, Interviewer)

Lawson, G. (2011, June 30). The New Zealand Villa. (H. Wright, Interviewer)

Loos, A. (1987). Spoken into the Void: Collected Essays by Adolf Loos 1897 - 1900. New York: MIT Press.

Macgregor, M. (1976). Etiquette and Elbowgrease - Housekeeping in Victorian New Zealand. New Zealand : A.H. \& A. W. Reed LTD.

Machado, R. (1976). Old Buildings as Palimpsests. Progressive Architecture, 46 49. 
Maciuika, J. V. (2000). Adolf Loos and the Aphorisitc Style: Rhetorical Practice in the Early Twentieth- Century Design Criticism. Design Issues, 75-86.

Marshall, D. (2011, June 29). The New Zealand Villa. (H. Wright, Interviewer)

Petersen, A. (2001). New Zealanders at home: A cultural history of domestic interiors 1814-1914. New Zealand: University of Otago Press.

Richards, J. (1994). Facadism. London: Routledge .

Ruskin, J. (1890). The Seven Lamps of Architecture. London: George Allen \& Unwin.

Salmond, J. (1986). Old New Zealand Houses 1800 - 1940s. Auckland: Reed Methuen Publishers LTD.

Scott, F. (2008). On Altering Architecture. London; New York: Routedge.

Stewart, D. (1992). The New Zealand Villa Past and Present. New Zealand: Penguin Books.

Toomath, W. (1996). Built in New Zealand - The houses we live in. New Zealand: Harper Collins Publishers.

. (2009). Aeiou. Retrieved August 20, 2011, from Vienna - Ringstrasse Boulevard and Parliament: http://www.aeiou.at/aeiou.photo.data.image.fw32/ fw17379h.jpg

Viollet-le-Duc, E., \& Hearn, M. (1990). The Architectural Theory of Viollet-le-Duc. Massachusetts: MIT Press.

Wagner, C. (n.d.). Re-thinking the Vernacular Approach to Domestic Architecture in New Zealand. Retrieved March 8, 2011, from http://203.77.194.71:83/isvs-4-1/ paper-dump/full-papers/9.pdf

Walker, M. (2011, July 7). The New Zealand Villa. (H. Wright, Interviewer)

Wellington City Council. (2006). Thorndon Character Area and Design Guides. Wellington City : Wellington City Council.

Wellington City Council. (2009). District Plan. Wellington: Wellington City Council.

Wellington City Council. (2010). Wellington Heritage Policy. Wellington: Wellington City Council. 
Wheeler, M. A. (1992). The Lamp of Memory. Manchester: Manchester University Press.

Wright, G. (1980). Moralism and the Model Home. Chicago: The University of Chicago Press.

\section{Unreferenced Sources}

Aotearoa Independent Media Centre. (2001, October 11). Retrieved September 13, 2010, from Wellington Inner City Bypass and the Environmental Court: http:// indymedia.org.nz/article/64352/wellington-inner-city-bypass and environmentcourt

Bastea, E. (2004). Memory and Architecture. Albuquerque: University of Mexico Press.

Beaudry, J. (2002). Jeremy Beaudry - Projects, Research and Text. Retrieved July 20, 2010, from Making Meaning out of the Memory of Architecture: http://meaning. boxwith.com/projects/making-meaning-memory

Benjamin, A. (1992). Architecture - Space - Painting. London: Academy Editions.

Bonny, S. A. (1988). New Zealand's Houses Today. Auckland: Weldon New Zealand.

Brickwell, C. (2003). Iconographies of 'the house' and the political imagination in the 1940s. New Zealand Journal of Design History, 291-306.

Brooker, G. (2006). Infected Interiors, Remodelling Contaminated Buildings. Retrieved August 4, 2010, from IDEA - Interior Design / Interior Architecture Educators Association.: http://www.idea-edu.com/Journal/2006/Infected-Interiors-Remodeling-Contaminated-Buildings

Brooks, M. (1987). John Ruskin and Victorian Architecture. London: Rutgers University Press.

Bruno, S. R. (2010). By researching history, owners uncover tales of their homes' early years. Retrieved July 9, 2010, from Nola: http://www.nola.com/homegarden/index. ssf/2010/06/by_researching_history_owners.html

Carolyn, J., \& Morrow, D. (2008). Urban Village. Auckland, New Zealand: Random House, New Zealand.

Clark, D. (1995). Authenticity: A plea for the sham buildings. Wellington: Victoria University of Wellington.

Cochran, C. (1984). Restoring a New Zealand House. Wellington, New Zealand: New Zealand Historic Places Trust. 
Cooke, M. (1972). The age of houses illustrated. Christchurch: Lincoln College.

Davis, C., \& Lineham, P. (1991). The future of the past: themes in New Zealand history. New Zealand: Massey University.

Elknik, A. (2011). Renovate 1940-1960s. Wellington : Printlink.

Evening Post. (1934, December 21). Architecture Today. Evening Post, p. 21.

Ferrara, A. (1993). Modernity and Authenticity - A study in the social and ethical thoughts of Jean Jacques Rousseau. New York: State University of New York Press.

Frascara, J. (2002). Design and the Social Sciences: Making Connections. London: Taylor and Francis.

Furey, L. (2010, September 15). Tonk's Road. (H. Wright, Interviewer)

Gilmore, J., \& Pine, J. (2007). Authenticity - What Consumers Really Want. Boston: Harvard Business School Press.

Griffiths, G. (1982). How old is our house? A guide to the New Zealand home owner. Dunedin: Otago Heritage Book.

Gumbley, W. (2010, September 15). Tonk's Road. (H. Wright, Interviewer)

Gumbley, W., \& Louise, F. (2005). Bypass Muster. Heritage New Zealand, 14-17.

Hay, F. (n.d.). Center for the Recycling and Reuse of Buildings. Retrieved August 4, 2011, from http://www.recyclingandreuseofbuildings.com/index.htm

Heywood, F. (2005). Adaptation: Altering the house to restore the home. Retrieved April 6, 2011, from Informaworl: http://www.informaworld.com/smpp/content $-\mathrm{d}$ $\mathrm{b}=\mathrm{all} \sim$ content $=\mathrm{a} 713994785$

Hollis, E. (2009). The Secret Life of Buildings: from the ruins of the Pantheon to the Vegas Strip in thirteen stories. New York: Metropolitan Books.

Huyssen, A. (2003). Present Pasts - Urban Palimpsest and the Politics of Memory. California: Stanford University Press.

Kennedy, R. W. (1953). The House and the Art of its Design. United States of America: Reinhold Publishing Corporation.

King, M. (2003). A Penguin History of New Zealand. New Zealand: Penguin Books. 
Kriegar, M. H. (2000). Whats Wrong with Plastic Trees. United States of America: Praegar Publishers.

Lane, B. M. (2007). Housing and Dwelling - Perspective on Modern Domestic Architecture. Oxon: Taylor and Francis.

Leach, N. (2006). Camouflage. Cambridge: MIT Press.

Leach, N. (1996). Rethinking Architecture. New York: Routledge.

Leach, N. (2006). The Anaesthetics of Architecture. Cambridge: MIT Press.

Macarthur, J. (2007). The picturesque: architecture, disgust and other irregularities. London; New York: Routledge.

Main, W. (2011). Wellington through a Victorian Lens. New Zealand: Street Roberts Publishers.

McCoy, E. (1977). Case Study Houses 1945 - 1962. Los Angeles: Hennessay and Ingalls Inc.

Munoz Vinas, S. (2005). Contemporary Theory of Conservation. Oxford: Butterworth-Heinemann.

New Zealand Transport Agency. (2010). Heritage Properties to Vitalise Tonks Grove. Retrieved September 2010, 2010, from http://www.nzta.govt.nz/about/me$\mathrm{dia} /$ releases/663/news/html

Pevsner, N. (1969). Ruskin and Viollet-le-Duc: English and Frenchness in the appreciation of Gothic Architecture. London: Thames and Hudson.

Phillips, D. (1997). Exhibiting Authenticity. Manchester: Manchester University Press.

Plecnik, J. (1983). 1872 - 1957: Architecture and the City. Oxford : Oxford Polytechnic.

Pool, D. (2007). The New Zealand Family from 1840: A Demographic History. New Zealand: Auckland University Press.

Port, M. C. (2004). Authenticity. Amsterdam: LIT Verlag Munster.

Post, T. D. (2008, June 7). Ghost town in the heart of Wellington. Retrieved September 1, 2010, from http://www.stuff.co.nz/national/477304

Potter, A. (2010). The Authenticity Hoax. United States of America: Harper Collins. 
Reed, C. (1996). Not at home: the suppression of domesticity in modern art and architecture. New York: Thames and Hudson.

Ruskin, J. (1960). Stones of Venice. London: Collins-Type Press .

Salmond, J. (2011, July 6). The New Zealand Villa. (H. Wright, Interviewer)

Scarpa, C. (1999). Architect: Intervening with History. New York: Monacelli Press .

Scarpa, C. (1988). Carlo Scarpa Selected Drawings. GA Document, 1-143.

Scarpa, C. (1986). Carlo Scarpa: Theory, Design, projects/ Maria Antonietta Crippa. Cambridge: MIT Press.

Scarpa, C. (2007). Layers. Stuttgart: Edition Axel Menges.

Sinclair, K. (2000). A History of New Zealand. New Zealand: Penguin Books.

Stacpoole, J. (1976). Colonial Architecture. Wellington: Reed.

Statistics New Zealand. (2006, March 7). Quick Stats About Housing. Retrieved July 19, 2011, from Statistics New Zealand: http://www.stats.govt.nz/ Census/2006CensusHomePage/QuickStats/quickstats-about-a-subject/housing. aspx

Thrilling, L. (1972). Sincerity and Authenticity. Boston: Harvard University Press.

Tonks, G. (2007). Tonks and the Bypass 1847 - 2007160 years. Wellington: Wellington City Council.

Tonks, G. (2007). Tonks of Early Wellington: Historical events of a Pioneering Family. Wellington: Wellington City Council .

Vesely, D. (2004). Architecture in the Age of Representation. Cambridge: MIT Press.

Walker, C. (2005). Exquisite Apart: 100 Years of Architecture in New Zealand. New Zealand: Balasoglou Books.

Wellington City Council. (2011). Approach to Heritage Management in Residential Areas of Thorndon. Wellington: Wellington City Council.

Wellington City Council. (2011, May 18). Thorndon Design Guide Workshop.

Woodcock, A., \& Davis, M. (1978). Catastrophe Theory - A revolutionary way of understanding how things change. Canada: Clarke, Irvin and Company Limited. 


\section{List of Figures}

Were figures have not been referenced in-text denotes authors own image, diagram or model.

Title Page

Fig. 1: Row of Victorian Villa facades. [Photograph: Patrick Reynolds] Hanson, J., Salmond, J., \& Reynolds, P] (2010). Villa from Heritage to Contemporary. New Zealand: Random House. Pp 45.

\section{Introduction}

Fig. 2: Vienna Ringstrasse Vienna - Ringstrasse Boulevard and Parliament. [Unknown Photographer] (2009).

Retrieved August 20, 2011, from Vienna - Ringstrasse boulevard and Parliament: http://www.aeiou.at/aeiou.photo.data.image.fw32/fw17379h.jpg

Section One: A Deceptive Facade

Chapter 1.

Fig 3: Tinakori Road Thorndon, Replicated Facades. [Author's own image] (2011)

Fig 4: Joy Street, Barnstaple, North Devon. A rebuilt facade stands in front of a new retail development [Photograph: Jonathan Richards]

Richards, J. (1994). Facadism. London: Routledge. Pp 10.

Fig 5: Tinakori Road, Thorndon. Victorian villa facades retain the traditional aesthetic. [Author's own image] (2011)

Fig 6: Tinakori Road, Thorndon, Victorian typology remains replicated through the facades. [Author's own image] (2011)

Section Two: A Contemporary Lens

Chapter 3.

Fig 7: Traditional Victorian Villa, Ohinerau Street, Remuera. [Photograph: William Toomath]

Toomath, W. (1996). Built in New Zealand - The houses we live in. New Zealand : Harper Collins Publishers. Pp 148.

Fig 8. An unidentified family outside a Victorian colonial house. [Photograph: James McAllister]

Retrieved April 11, 2011, from http://find.natlib.govt.nz/primo_library/libweb/ action/display.do?ct=display \&doc=nlnz_tapuhi505464\&indx=9\&vl(D311850

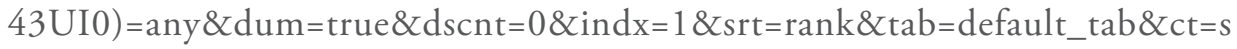
earch $\&$ frbg $=\& v i d=T F \& v l(1$ UI0 $)=$ contain $\& \& \mathrm{fn}=$ search $\& \mathrm{~d} \operatorname{stmp}=13019722312$ $53 \& v l($ freeText 0$)=$ victorian $\&$ mode $=\operatorname{Basic} \& v l(35124698$ UI1 $)=$ all_items $\& s c p$. scps $=$ scope $\% 3 \mathrm{~A}$ (Timeframes) 
Fig 9: Matiere, Christchurch, 1910. Return Bay Villa, presenting the prominence of the verandah. [Photograph: S Head Collection, Alexandra Turnbull Library]

Hanson, J., Salmond, J., \& Reynolds, P] (2010). Villa from Heritage to Contemporary. New Zealand: Random House. Pp 24.

Fig 10: Traditional Villa Elevations. [Author's own diagram] (2011)

Fig 11: Traditional Movement Patterns. [Author's own diagram] (2011)

Fig 12: Hierarchy of public to private. [Author's own diagram] (2011)

Fig 13: Typical Victorian Kitchen 1905. [Photograph: Steffano Webb]

Stewart, D. (1992). The New Zealand Villa Past and Present. New Zealand: Penguin Books. Pp 67.

Fig 14: Victorian Parlour 1890. [Photograph: Steffano Webb]

Toomath, W. (1996). Built in New Zealand - The houses we live in. New Zealand : Harper Collins Publishers. Pp 128.

Fig 15: Axonometric Diagram. [Author's own diagram] (2011)

Fig 16: Drawing of a nineteenth century brick fire place. [Drawing: Jeremy Salmond]

Salmond, J. (1986). Old New Zealand Houses 1800 - 1940s. Auckland: Reed Methuen Publishers LTD. Pp 123.

Fig 17: Typical Victorian Dining Room. [Photograph: Steffano Webb] Hanson, J., Salmond, J., \& Reynolds, P] (2010). Villa from Heritage to Contemporary. New Zealand: Random House. Pp 47.

Fig 18: Nineteenth century front door. [Photograph: William Toomath] Toomath, W. (1996). Built in New Zealand - The houses we live in. New Zealand: Harper Collins Publishers. Pp 129.

Fig 19: Hallway diagram. [Author's own diagram] (2011)

Fig 20: Typical decorated hallway. [Photograph: Steffano Webb] Stewart, D. (1992). The New Zealand Villa Past and Present. New Zealand: Penguin Books. Pp 53.

Fig 21: Verandah detail and ornamentation [Photograph: Norman Zammit] Stewart, D. (1992). The New Zealand Villa Past and Present. New Zealand: Penguin Books. Pp 39.

Fig 22: Traditional verandah diagram. [Author's own diagram] (2011) 
Fig 23: Traditional window relationship. [Author's own diagram] (2011)

Fig 24: Bay window configuration. [Author's own diagram] (2011)

Fig 25: Devonport 1903 [Photograph: Auckland War Memorial Museum] Hanson, J., Salmond, J., \& Reynolds, P] (2010). Villa from Heritage to Contemporary. New Zealand: Random House.Pp. 36.

Fig 26: Traditional villa orientation. [Author's own diagram] (2011)

Fig 27: Traditional front garden appearance. [Photograph: W. E. Harkness] Stewart, D. (1992). The New Zealand Villa Past and Present. New Zealand: Penguin Books. Pp. 44.

Fig 28: Neglected villa. [Photograph: Patrick Reynolds]

Hanson, J., Salmond, J., \& Reynolds, P] (2010). Villa from Heritage to Contemporary. New Zealand: Random House. Pp 104.

Chapter 4.

Fig 29: Renovated contemporary kitchen. [Photograph: Patrick Reynolds] Hanson, J., Salmond, J., \& Reynolds, P] (2010). Villa from Heritage to Contemporary. New Zealand: Random House. Pp. 271.

Fig 30: Internal villa renovation. [Photograph: Patrick Reynolds] Hanson, J., Salmond, J., \& Reynolds, P] (2010). Villa from Heritage to Contemporary. New Zealand: Random House. Pp. 268.

Fig 31: Internal hallway, villa renovation. [Photograph: Patrick Reynolds] Hanson, J., Salmond, J., \& Reynolds, P (2010). Villa from Heritage to Contemporary. New Zealand: Random House. Pp 328.

Fig 32: Internal living villa renovation. [Photograph: Patrick Reynolds] Hanson, J., Salmond, J., \& Reynolds, P] (2010). Villa from Heritage to Contemporary. New Zealand: Random House. Pp 318.

Fig 33: Internal villa renovation. [Photograph: Patrick Reynolds] Hanson, J., Salmond, J., \& Reynolds, P] (2010). Villa from Heritage to Contemporary. New Zealand: Random House. Pp 306.

Fig 34: Kitchen, villa renovation. [Photograph: Patrick Reynolds] Hanson, J., Salmond, J., \& Reynolds, P] (2010). Villa from Heritage to Contemporary. New Zealand: Random House. Pp 326.

Fig 35: Internal living, villa renovation. [Photograph: Patrick Reynolds] Hanson, J., Salmond, J., \& Reynolds, P] (2010). Villa from Heritage to Contemporary. New Zealand: Random House. Pp 200. 
Chapter 5.

Fig 36: Reinterpreted Diagrams. [Author's own diagram] (2011)

Salmond, J. (1986). Old New Zealand Houses 1800 - 1940s. Auckland: Reed Methuen Publishers LTD. Pp 173.

Fig 37: Traditional Roof: Shape and Form. [Author's own diagram] (2011)

Fig 38: Traditional Roof: Streetscape. [Author's own diagram] (2011)

Fig 39: Traditional Roof: Symmetry. [Author's own diagram] (2011)

Fig 40: Traditional Roof: Construction. [Author’s own diagram] (2011)

Fig 41: Traditional Roof: Chimney. [Photograph: Patrick Reynolds]

Hanson, J., Salmond, J., \& Reynolds, P] (2010). Villa from Heritage to Contemporary. New Zealand: Random House. Pp 112.

Fig 42: Contemporary Issues: Views. [Author's own diagram] (2011)

Fig 43: Contemporary Issues: Light. [Author's own diagram] (2011)

Fig 44: Contemporary Issues: Occupation. [Author's own diagram] (2011)

Fig 45: Contemporary Issues: Spans. [Author's own diagram] (2011)

Fig 46: Abstract Cardboard models for roof exploration. [Author's own model series] (2011)

Fig 47: Contemporary Roof Principles: Horizontality. [Author's own diagram] (2011)

Fig 48: Contemporary Roof Principles: Verticality. [Author's own diagram] (2011)

Fig 49: Contemporary Roof Principles: Pitch. [Author's own diagram] (2011)

Fig 50: Contemporary Roof Principles: Threshold. [Author's own diagram] (2011)

Fig 51: Contemporary Roof Principles: Ridge. [Author's own diagram] (2011)

Chapter 6.

Fig 52: Contemporary Planning Principles: Proportion. [Author's own diagram] (2011) 
Fig 53: Contemporary Planning Principles: Movement. [Author's own diagram] (2011)

Fig 54: Contemporary Planning Principles: Public and Private. [Author's own diagram] (2011)

Fig 55: Contemporary Planning Principles: Horizontal Form. [Author's own diagram] (2011)

Fig 56: Contemporary Planning Principles: Vertical form. [Author's own diagram] (2011)

Fig 57: Contemporary Planning Principles: Room Roles. [Author's own diagram] (2011)

Fig 58: Contemporary Planning Principles: Floor Displacement. [Author's own diagram] (2011)

Fig 59: Contemporary Planning Principles: Threshold. [Author's own diagram] (2011)

Fig 60: Applying Principles: Kitchen. [Author's own diagram] (2011)

Fig 61: Applying Principles: Living Room. [Author’s own diagram] (2011)

Fig 62: Applying Principles: Bathroom. [Author's own diagram] (2011)

Fig 63: Applying Principles: Bedroom. [Author's own diagram] (2011)

Fig 64: Applying Principles: Dining Room. [Author's own diagram] (2011)

Fig 65: Applying Principles: Verandah. [Author's own diagram] (2011)

Fig 66: Applying Principles: Hallway. [Author's own diagram] (2011)

Fig 67: Applying Principles: Bay Window. [Author’s own diagram] (2011)

Fig 68: Applying Principles: Fire Place. [Author's own diagram] (2011)

Fig 69: Applying Principles: Garden. [Author's own diagram] (2011)

Section Three: A 'Non Frontal' Villa

Chapter 7.

Fig 70: Arthur Street, Wellington. [Author's own photo] (2011) 
Fig 71: No. 270 Tonk's Road, Neglected Villa. [Photograph: Gary Tonk's]

Tonks, G. (2007). Tonks and the Bypass 1847 - 2007160 years. Wellington : Wellington City Council.

Fig 72: No. 270 Reconstructed and Relocated. [Photograph: Gary Tonks]

Tonks, G. (2007). Tonks and the Bypass 1847 - 2007160 years. Wellington : Wellington City Council.

Fig 73: Aerial View, 268 Cuba Street. [Google Earth] (2011)

Fig 74: Existing restored villa. [Author's own photo] (2011)

Fig 75: Aerial View, Oak Avenue Site. [Google Earth] (2011)

Fig 76: Existing restored villa. [Author's own photo] (2011)

Fig 77: Aerial View, 12 Arthur Street. [Google Earth] (2011)

Fig 78: Existing restored villa. [Author's own photo] (2011)

Fig 79: Site One: Room placement diagram. [Author's own diagram] (2011)

Fig 80: Site One: Conceptual Plan 1:200. [Author's own diagram] (2011)

Fig 81: Site One: Conceptual Section 1:200. [Author's own diagram] (2011)

Fig 82: Site One: Conceptual cardboard models 1:200. [Author's own models] (2011)

Fig 83: Site Two: Room placement diagram. [Author's own diagram] (2011)

Fig 84: Site Two: Conceptual Plan 1:200. [Author's own diagram] (2011)

Fig 85: Site Two: Conceptual Section 1:200. [Author's own diagram] (2011)

Fig 86: Site Two: Conceptual cardboard models 1:200. [Author's own models] (2011)

Fig 87: Site Three: Room placement diagram. [Author's own diagram] (2011)

Fig 88: Site Three: Conceptual Plan 1:200. [Author's own diagram] (2011)

Fig 89: Site Three: Conceptual Section 1:200. [Author's own diagram] (2011)

Fig 90: Site Three: Conceptual cardboard models 1:200. [Author's own models] (2011) 
Fig 91: Wellington Central City. [Google Earth] (2011)

Fig 92: Oak Avenue site studies [Google Earth and Author's own diagrams] (2011)

Fig 93: Conceptual cardboard models 1:100. [Author's own model] (2011)

Fig 94: Conceptual cardboard model series 1:100. [Author's own models] (2011)

Fig 95: Conceptual developed cardboard model series 1:100. [Author's own models] (2011)

Fig 96: Material Exploration. [Author's own photo] (2011)

Fig 97: 1:50 Model. [Author's own photo] (2011)

Fig 98: Conceptual Abstract Models 1:50. [Author's own photos] (2011)

Fig 99: Contemporary Room Placement. [Author’s own diagrams] (2011)

Chapter 8.

Fig 100: Ground Floor Plan 1:100. [Author's own image] (2011)

Fig 101: Upper Floor Plan 1:100. [Author's own image] (2011)

Fig 102: Section CC: Entrance. [Author's own image] (2011)

Fig 103: Contemporary Parlour Diagram. [Author's own image] (2011)

Fig 104: North Elevation 1:100. [Author's own image] (2011)

Fig 105: Section DD: Bay Window. [Author's own image] (2011)

Fig 106: Section AA 1:100. [Author's own image] (2011)

Fig 107: Traditional hallway. [Photograph: Steffano Webb]

Stewart, D. (1992). The New Zealand Villa Past and Present. New Zealand: Penguin Books. Pp. 53.

Fig 108: Contemporary Hallway Perspective. [Author’s own image] (2011)

Fig 109: Traditional Dining Room. [Photograph: Steffano Webb]

Hanson, J., Salmond, J., \& Reynolds, P] (2010). Villa from Heritage to Contemporary. New Zealand: Random House. Pp. 47. 
Fig 110: Section EE: Threshold between kitchen and dining room. [Author's own image] (2011)

Fig 111: Traditional Kitchen. [Photograph: Steffano Webb]

Stewart, D. (1992). The New Zealand Villa Past and Present. New Zealand: Penguin Books. Pp 67.

Fig 112: Contemporary Kitchen and Dining Relationship. [Author's own image] (2011)

Fig 113: Section BB 1:100. [Author's own image] (2011)

Fig 114: Section FF: Secondary stair to public relationship. [Author's own image] (2011)

Fig 115: East Elevation 1:100. [Author's own image] (2011)

Fig 116: Section GG: Relationship between the dining, hallway and main stair. [Author's own image] (2011)

Fig 117: Family out the back of a domestic garden 1889-1910. [Photograph: Henry Charles Clark Wright]

http://find.natlib.govt.nz/primo_library/libweb/action/display.do?dum=true\&scp. scps=scope $\% 3 \mathrm{~A}$ (Timeframes) \&vid=TF \&fn=search \&dstmp $=1322784772451$ $\& c t=$ display $\&$ ind $x=12 \& \mathrm{tab}=$ default $\_$tab $\& \mathrm{frbg}=\& \mathrm{vl}(\mathrm{D} 31185043 \mathrm{UI} 0)=$ any $\&$ $\mathrm{vl}($ freeText 0$)=$ family $\% 20 \mathrm{in} \% 20$ garden $\&$ mode $=$ Basic $\& \mathrm{dscn} \mathrm{t}=0 \&$ fromLogin $=\mathrm{t}$ rue \&srt $=\operatorname{rank} \& v l(1 \mathrm{UI0})=$ contains $\& v l(35124698$ UI1 $)=$ all_items $\&$ doc $=$ nlnz tapuhi1247754\&fromLogin=true

Fig 118: Outdoor Perspective. [Author's own image] (2011)

Fig 119: Roof exploration studies. [Google Earth and Author's own diagrams] (2011)

Fig 120: Aerial view with developed roof view. [Author's own image] (2011) 
Appendix 


\section{Appendix 1.}

Interviews were conduction with five New Zealand architects in order to attain a general understanding of how architects see the villa in contemporary society. Ethics approval has been obtained by Victoria University to conduct these interviews.

Each architect was asked three questions:

1. What are the positive attributes of the traditional villa in contemporary society?

2. What are the Negative attributes of the traditional villa in contemporary society?

3. Do you think we should Retain and Restore the remaining villas.

Below are the summarised findings from the interviews:

\section{Daniel Marshall}

\section{Positive}

- Spatial quality, the volume of the proportion of the internal space.

- The decorative elements within.

- Romance of the word villa and it's kind of connotation with the Italianate precedent and the kind of translation from stone to timber.

- The solidity.

\section{Negative}

- Built Bad.

- Cold.

- Site orientation shocking.

- No connection with the exterior.

\section{Retain and Restore}

- Building cost becomes a reality.

Gary Lawson

\section{Positive}

- Connection and link to an important part of our settler history.

- Their important role in establishing our population in Auckland, Wellington and Christchurch.

- Make nice streetscapes when they are in clusters.

- Picturesque and beautiful buildings.

- High ceiling.

- Generous spatially.

- Playful on the detail and offer something to a streetscape.

Verandah. 
- Cold.

- Rot.

- Sink on piles.

- Require maintenance

- Awkward to live in as a cellular unit.

\section{Retain and Restore}

Case by case if you have got a street of 6 or 7 villas and the third one in is in the balance. Then in most cases I think you should retain and restore to keep within the street. In most but not all, restoration and preservation should be seriously considered but in others not at all

Douglas Lloyd Jenkins

\section{Positive}

- Simple plans.

- Flexible manufacture makes them endlessly recognisable.

- Interior Decoration - Contemporary architecture avoids decoration however decorating out interiors is a basic human need. The villa can take any decorative scheme you throw at it.

- They have the right proportions.

- Plan caters for individual privacy.

- Natural adaptability to include modern technology.

Negative

- Siting - some that face the street don't always get the sun - this isn't always bad.

- Cold.

- Back end usually needs rebuilding as when necessary (lean too zone).

\section{Retain or Restore}

It should be one of respect, it doesn't automatically require 'authenticity' - It does however require careful thought and consideration. It is not necessary to restrict what gets done to villas.

\section{Marshall Cook}

Positive

- No positive attributes of the villa typology - there were.

- Positive would have been the hierarchal family management.

- Capable of sustaining a huge load of occupants as family grew.

Negative

- Cold.

- Uncomfortable.

- Badly insulated.

- Huge absorbers of energy.

- Unattractive buildings.

- Simplicity of construction. 
Retain or Restore

Disregard everything.

Malcolm Walker

Positive

- Simple.

- Address the street.

- Simplicity.

- Community about them.

Negative

- Cold.

- Badly sited.

- Living areas miserable and not communal.

Retain or Restore

I think they should be acknowledged and be careful with them but I don't think they should be hallowed. 


\section{Appendix 2.}

For the purpose of the developed design stage, the contemporary family has been generalised. The parameters have been distinguished from data taken from the Wellington region 2006 Stats New Zealand

\section{Census Statistics:}

The most popular statistics from the Quick Stats show that the typical housing unit included:

- Separate house on land

- 3 bedroom average

- Total of 6 rooms average

- The average number of residents was between 2 and 4 . For the purpose of this research I am going to assume there are 4 residents, 2 adults, 3 children

- One-family households make up $66.9 \%$ of all households in Wellington Region. For New Zealand as a whole, one-family households make up 69.1 percent of all households

- Couples with children make up 42.4 percent of all families in Wellington Region, while couples without children make up 40.0 percent of all families.

- In the Wellington region it is more likely to have 1 or 2 motor vehicles. 11.3 percent of households in Wellington Region have access to three or more motor vehicles, compared with 15.9 percent of all households in New Zealand.

From these statistics I further created a general brief to use as guide when designing and determining what spaces would need to be placed within the contemporary villa. (Statistics New Zealand, 2006)

\section{Client Brief}

Who

5 Residents, 2 adults, 3 children

Room requirements

-4 bedrooms

- 2 toilets/ bathroom + ensuite (once accessible for guests)

- Kitchen, Living and dining area - linked to the outdoor

- Outdoor cooking area

- Private outdoor area - space requirement for children, pets and entertaining guests.

- Multifunctional spaces with flexibility to change and be utilised for future activities.

- Work from home office, private and accessible to the house.

- Laundry

- Alternative living space for children and /or TV room

- Ability to accommodate 1 family car and possible visiting cars and room for expansion.

- Sufficient outdoor space for Vegetable Garden and Washing Line 